\title{
Pesticides in Streams of the United States-Initial Results from the National Water-Quality Assessment Program
}

NATIONAL WATER-QUALITY ASSESSMENT PROGRAM

Water-Resources Investigations Report 98-4222

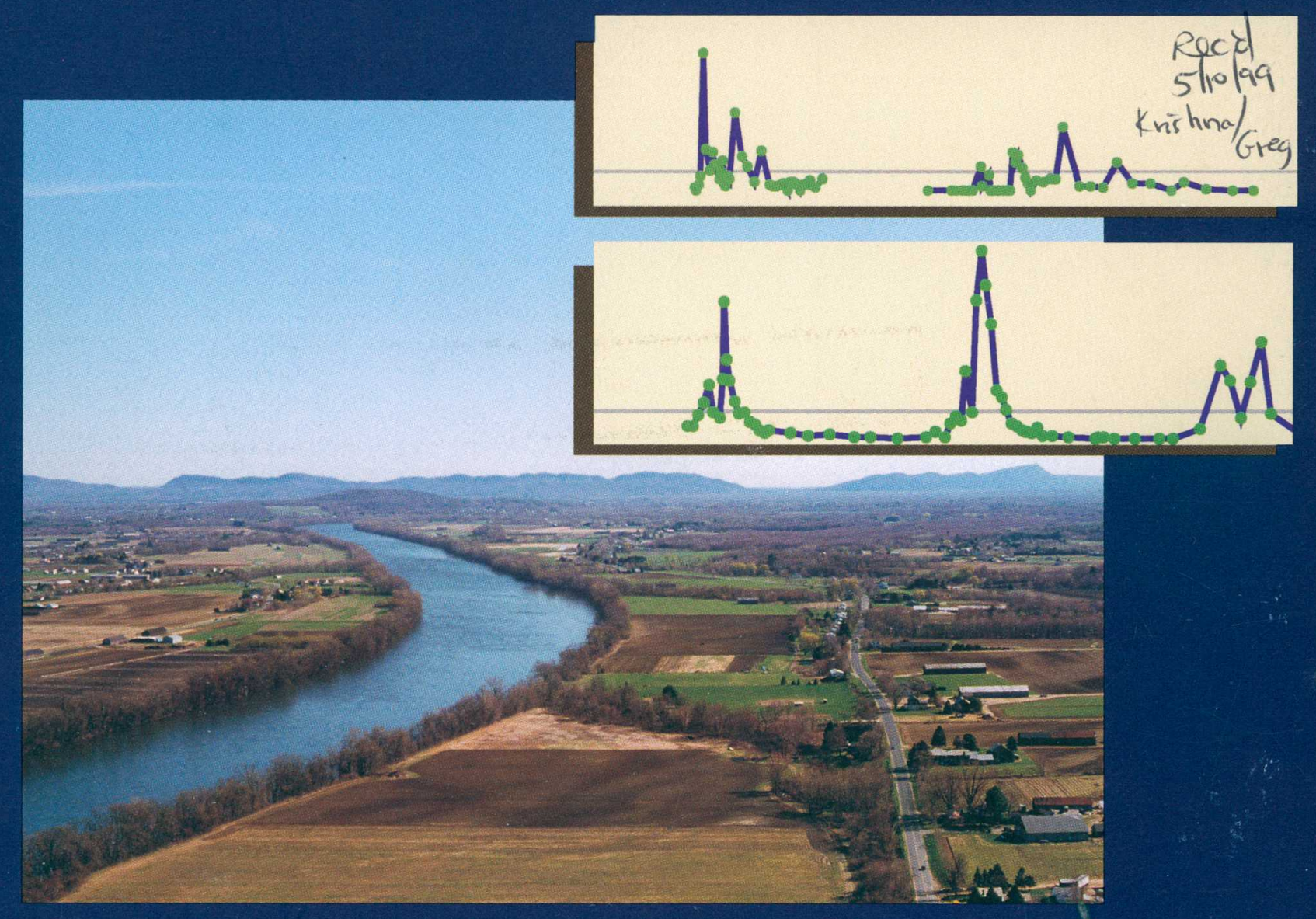

U.S. Department of the Interior U.S. Geological Survey

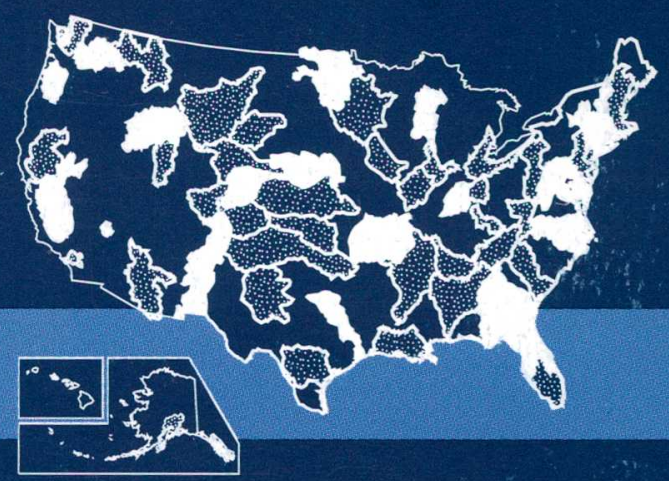


Cover photograph-The Connecticut River near Sunderland, Massachusetts. (Photograph by Peter A. Steeves) 


\section{Pesticides in Streams of the United States-Initial Results from the National Water-Quality Assessment Program}

By Steven J . Larson, Robert J . Gilliom, and Paul D. Capel

U.S. GEOLOGICAL SURVEY

Water-Resources Investigations Report 98-4222

$n$
6
8
8 


\title{
U.S. DEPARTM ENT OF THE INTERIOR BRUCE BABBITT, Secretary
}

\author{
U.S. GEOLOGICAL SURVEY
}

Charles G. Groat, Director

The use of firm, trade, and brand names in this report is for identification purposes only and does not constitute endorsement by the U.S. Geological Survey

For additional information write to:

District Chief

U.S. Geological Survey

Placer Hall

6000 J Street

Sacramento, California 95819-6129
Copies of this report can be purchased from:

U.S. Geological Survey

Branch of Information Services

Box 25286

Denver, CO 80225-0286 


\section{FOREWORD}

The mission of the U.S. Geological Survey (USGS) is to assess the quantity and quality of the earth resources of the Nation and to provide information that will assist resource managers and policymakers at Federal, State, and local levels in making sound decisions. Assessment of water-quality conditions and trends is an important part of this overall mission.

One of the greatest challenges faced by waterresources scientists is acquiring reliable information that will guide the use and protection of the Nation's water resources. That challenge is being addressed by Federal, State, interstate, and local water-resource agencies and by many academic institutions. These organizations are collecting water-quality data for a host of purposes that include: compliance with permits and water-supply standards; development of remediation plans for specific contamination problems; operational decisions on industrial, wastewater, or watersupply facilities; and research on factors that affect water quality. An additional need for water-quality information is to provide a basis on which regionaland national-level policy decisions can be based. Wise decisions must be based on sound information. As a society we need to know whether certain types of water-quality problems are isolated or ubiquitous, whether there are significant differences in conditions among regions, whether the conditions are changing over time, and why these conditions change from place to place and over time. The information can be used to help determine the efficacy of existing waterquality policies and to help analysts determine the need for and likely consequences of new policies.

To address these needs, the U.S. Congress appropriated funds in 1986 for the USGS to begin a pilot program in seven project areas to develop and refine the National Water-Quality Assessment (NAWQA) Program. In 1991, the USGS began full implementation of the program. The NAWQA Program builds upon an existing base of water-quality studies of the USGS, as well as those of other Federal, State, and local agencies. The objectives of the NAWQA Program are to:

- Describe current water-quality conditions for a large part of the Nation's freshwater streams, rivers, and aquifers.

- Describe how water quality is changing over time.
- Improve understanding of the primary natural and human factors that affect water-quality conditions.

This information will help support the development and evaluation of management, regulatory, and monitoring decisions by other Federal, State, and local agencies to protect, use, and enhance water resources.

The goals of the NAWQA Program are being achieved through ongoing and proposed investigations of 60 of the Nation's most important river basins and aquifer systems, which are referred to as study units. These study units are distributed throughout the Nation and cover a diversity of hydrogeologic settings. More than two-thirds of the Nation's freshwater use occurs within the 59 study units and more than twothirds of the people served by public water-supply systems live within their boundaries.

National synthesis of data analysis, based on aggregation of comparable information obtained from the study units, is a major component of the program. This effort focuses on selected water-quality topics using nationally consistent information. Comparative studies will explain differences and similarities in observed water-quality conditions among study areas and will identify changes and trends and their causes. The first topics addressed by the national synthesis are pesticides, nutrients, volatile organic compounds, and aquatic biology. Discussions on these and other waterquality topics will be published in periodic summaries of the quality of the Nation's ground and surface water as the information becomes available.

This report is an element of the comprehensive body of information developed as part of the NAWQA Program. The program depends heavily on the advice, cooperation, and information from many Federal, State, interstate, Tribal, and local agencies and the public. The assistance and suggestions of all are greatly appreciated.

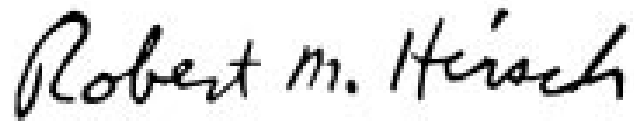

Robert M. Hirsch Chief Hydrologist 


\section{CONTENTS}

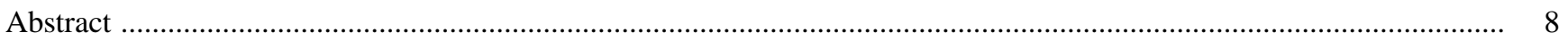

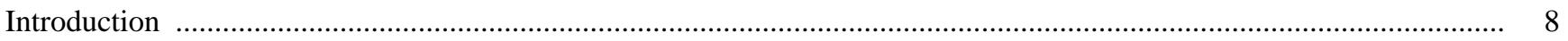

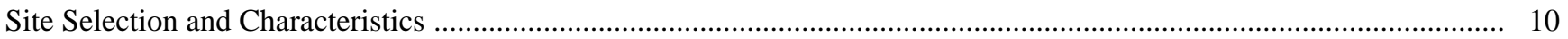

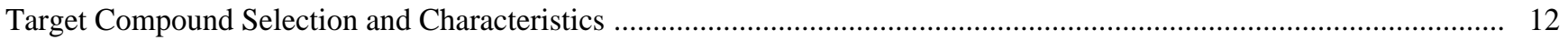

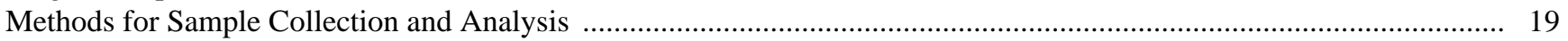

Methods for Data Analysis ...................................................................................................................... 21

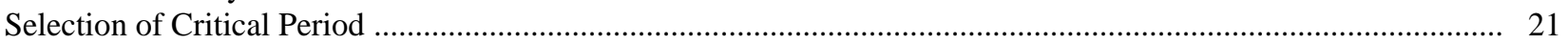

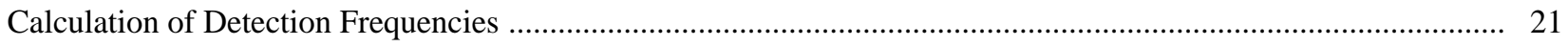

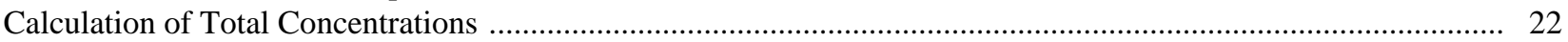

Calculation of Monthly and Annual Median Concentrations .............................................................................. 22

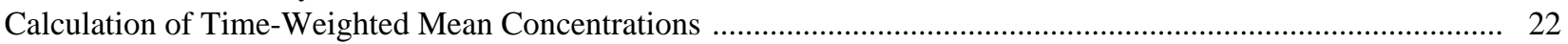

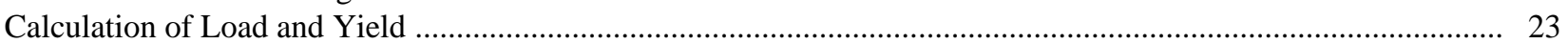

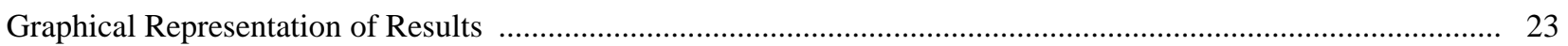

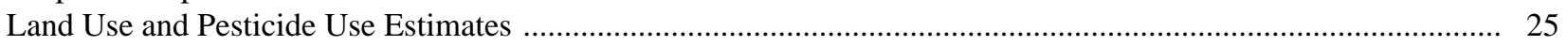

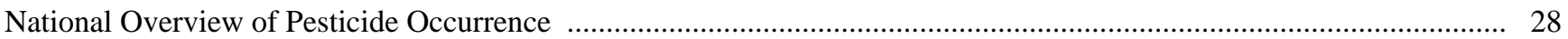

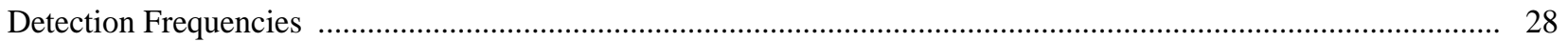

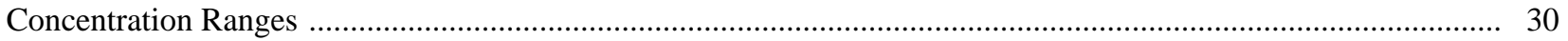

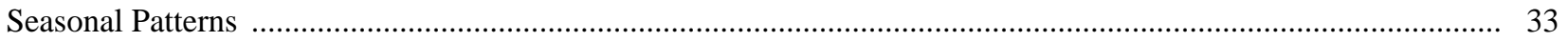

Effects of Land Use on Occurrence of Pesticides in Streams ............................................................................... 34

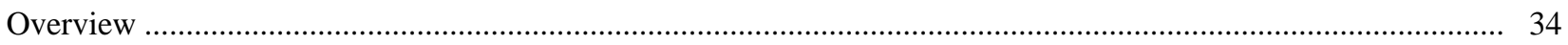

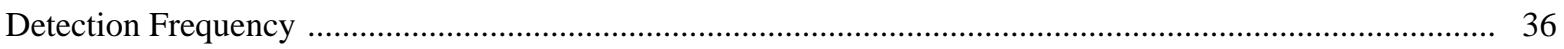

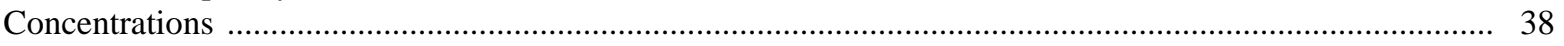

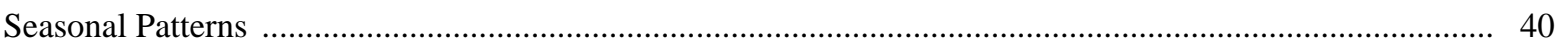

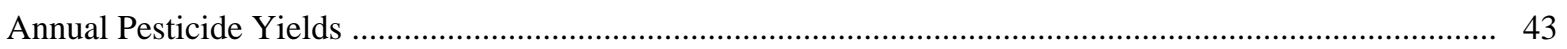

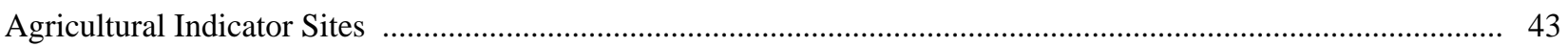

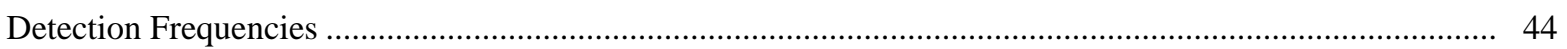

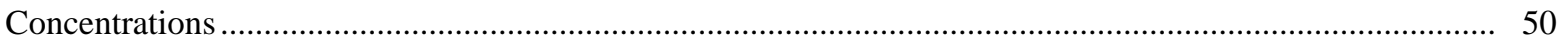

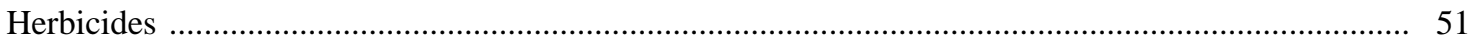

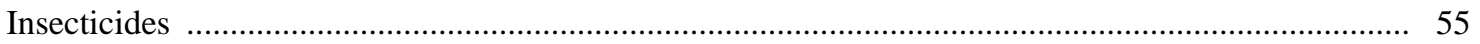

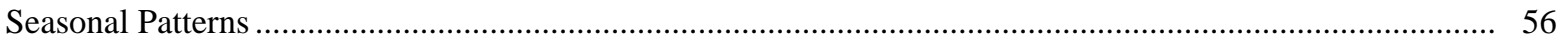

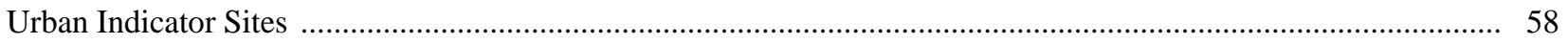

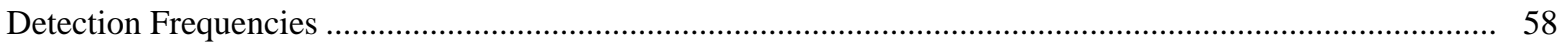

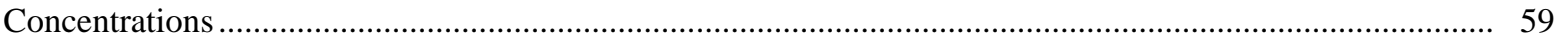

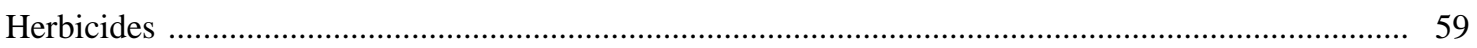

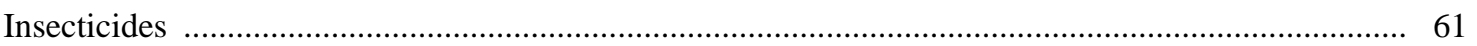

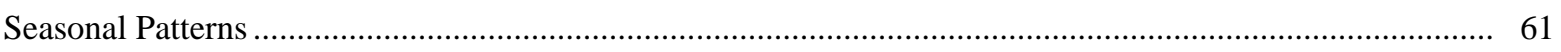

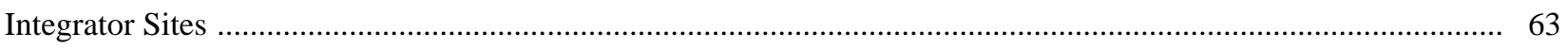

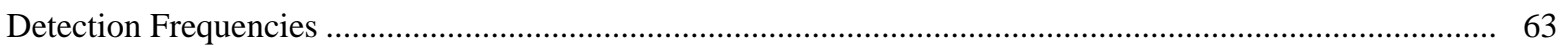

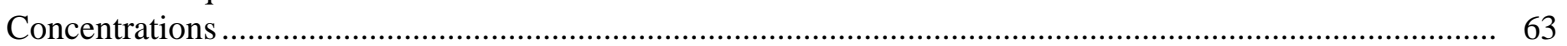

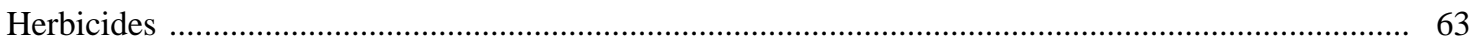

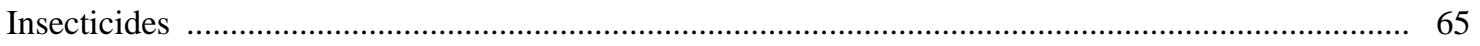

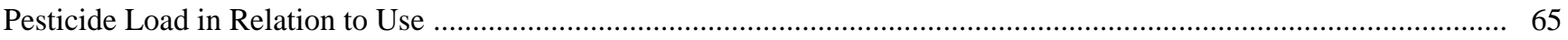

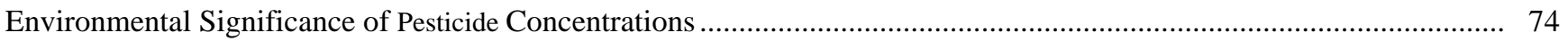

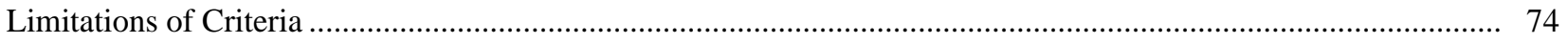

Comparison of Concentrations with Human-Health Criteria Values ................................................................... 76

Comparison of Concentrations with Aquatic-Life Criteria Values ....................................................................... 78

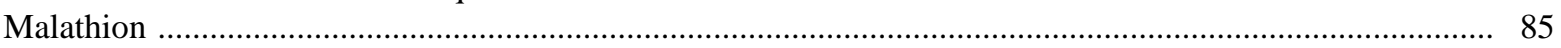

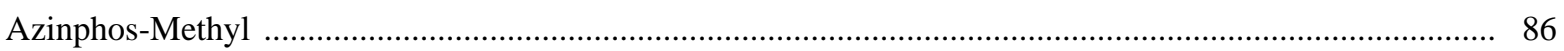




\section{FIGURES}

1. Map showing National Water-Quality Assessment study units

2. Map showing locations of stream sampling sites

3-41. Graphs showing:

3. Distribution of land use in agricultural indicator basins, urban indicator basins, and integrator basins .......... 15

4. Sampling frequency at the 58 sampling sites ........................................................................................

5. Hypothetical plots as examples of boxplots and concentration distribution plots ........................................ 24

6. Annual mean detection frequencies of all 46 target compounds at 50 sites during a 1 -year period ............... 28

7. Distribution of annual mean detection frequencies of all target herbicides and insecticides ........................ 29

8. Distribution of monthly median concentrations of total herbicides and insecticides at 50 sites during a 1-year period.

9. Distributions of monthly median concentrations of the seven most frequently detected herbicides and the five most frequently detected insecticides at 50 sites during a 1 -year period.

10. Distribution of the number of different compounds detected in each sample collected from the 58 sites each month during 1993-95

\section{0}

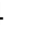
9

1. Distribution of total pesticide concentrations in all samples collected from the 58 sites each month during 1993-95

12. Distribution of the number of compounds detected at each site for each of the three types of sites

13. Distribution of the mean number of compounds detected in each sample for each of the three types of sites

14. Annual mean detection frequencies for all 46 target compounds for each of the three types of sites during a 1-year period.....

15. Distributions of annual mean detection frequencies of the most commonly detected compounds for each of the three types of sites.

6. Concentration distribution plots of monthly median total herbicide and insecticide concentrations for each of the three types of sites during a 1-year period.

17. Distribution of the mean number of compounds detected in each sample at any concentration for a 5-month critical period and for the rest of the year for each of the three types of sites.

18. Distribution of median total pesticide concentrations for each month for each of the three types of sites.......

19. Annual yields of total herbicides and insecticides for each of the three types of sites .

20. Intensity of annual agricultural use of herbicides and insecticides in 37 agricultural basins...........................

21. Annual mean detection frequency in relation to agricultural use for herbicides and insecticides at 32 agricultural sites

22. Monthly median concentrations of total herbicides and the six herbicides detected most frequently at the 37 agricultural indicator sites during a 1-year period

23. Monthly median concentrations of total insecticides and the four insecticides detected most frequently at the 37 agricultural indicator sites during a 1-year period

24. Examples of temporal concentration patterns at eight agricultural indicator sites

25. Distribution of annual mean detection frequencies of compounds consistently detected more frequently at urban indicator sites than at most agricultural indicator sites.....

26. Monthly median concentrations of selected compounds at 11 urban indicator sites during a 1 -year period...

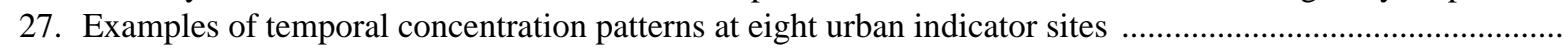

28. Monthly median concentrations of selected compounds at 10 integrator sites during a 1 -year period ............ 
29. Annual load of herbicides and insecticides in streams in relation to agricultural use in the drainage basin of a particular stream.

30. Annual load of total herbicides and insecticides in streams in relation to agricultural use in the drainage basin of a particular stream

31. Annual load of specific compounds in streams in relation to agricultural use in the drainage basin of a particular stream

32. Comparison of estimated loads of total herbicides and insecticides for 25 sites with sufficient data for load estimates for 2 different years

33. Estimated annual mean concentrations and time-weighted mean concentrations for selected compounds for all 58 sites for a 5-month critical period.

34. Concentrations of malathion in Las Vegas Wash, Nevada .................................................................

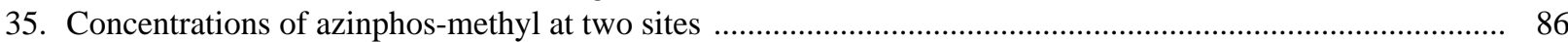

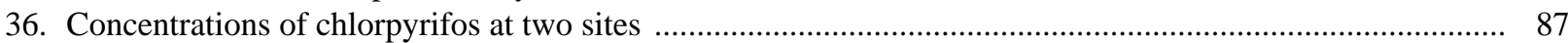

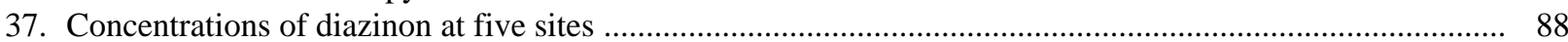

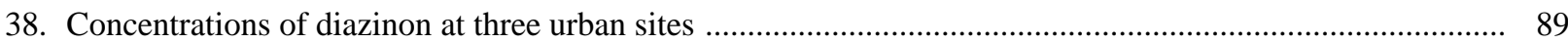

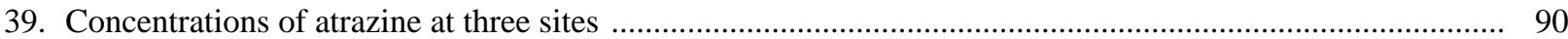

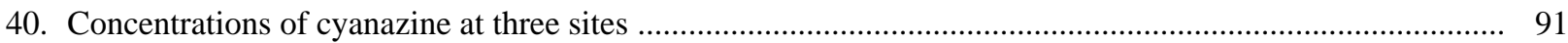

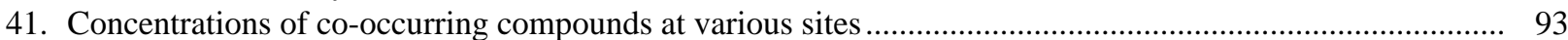

\section{TABLES}

1. Characteristics of sampling sites

2. Target compounds and their national agricultural use, analytical recovery, method detection limit, and primary uses

3. Coverage of pesticide use by the target compounds for agricultural indicator basins and integrator basins

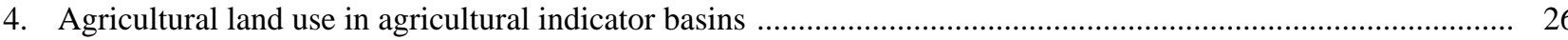

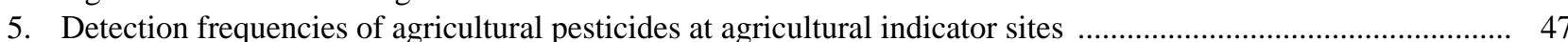

6. Agricultural use of selected pesticides per square kilometer of drainage basin ............................................. 54

7. Load of total herbicides and insecticides and selected individual pesticides in streams as a percentage of agricultural use in the basin

8. Human-health and aquatic-life criteria established for target compounds and the number of sites where the

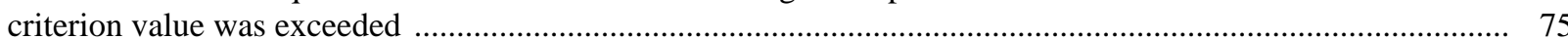

9. Estimated mean concentrations of selected compounds for a one-year period .............................................. 79

10. Compounds with concentrations greater than the aquatic-life criterion in at least one sample, by type of site..... 82

11. Estimated number of days per year that selected compounds exceeded an aquatic-life criterion value, by type of site.

\section{CONVERSION FACTORS, W ATER QUALITY UNITS, AND ABBREVIATIONS AND ACRONYMS}

\section{Conversion Factors}

\begin{tabular}{rll}
\hline Multiply & By & To obtain \\
\hline kilogram $(\mathrm{kg})$ & 2.205 & pound, avoirdupous \\
kilogram per square kilometer $\left(\mathrm{kg} / \mathrm{km}^{2}\right)$ & 0.00893 & pound per acre \\
kilogram per square kilometer per year $\left(\mathrm{kg} / \mathrm{km}^{2} / \mathrm{yr}\right)$ & 0.00893 & pound per acre per year \\
kilometer $(\mathrm{km})$ & 0.6214 & mile \\
liter $(\mathrm{L})$ & 33.82 & ounce, fluid \\
square kilometer $\left(\mathrm{km}^{2}\right)$ & 0.3861 & square mile \\
\hline
\end{tabular}

Temperature is given in degrees Celsius $\left({ }^{\circ} \mathrm{C}\right)$, which can be converted to degrees Fahrenheit $\left({ }^{\circ} \mathrm{F}\right)$ by the following equation:

$$
{ }^{\circ} \mathrm{F}=1.8\left({ }^{\circ} \mathrm{C}\right)+32 .
$$




\section{Water Quality Units}

Concentrations of constituents in water samples are given in either milligrams per liter $(\mathrm{mg} / \mathrm{L})$ or micrograms per liter $(\mu \mathrm{g} / \mathrm{L})$. Milligrams per liter is equivalent to "parts per million" and micrograms per liter is equivalent to "parts per billion."

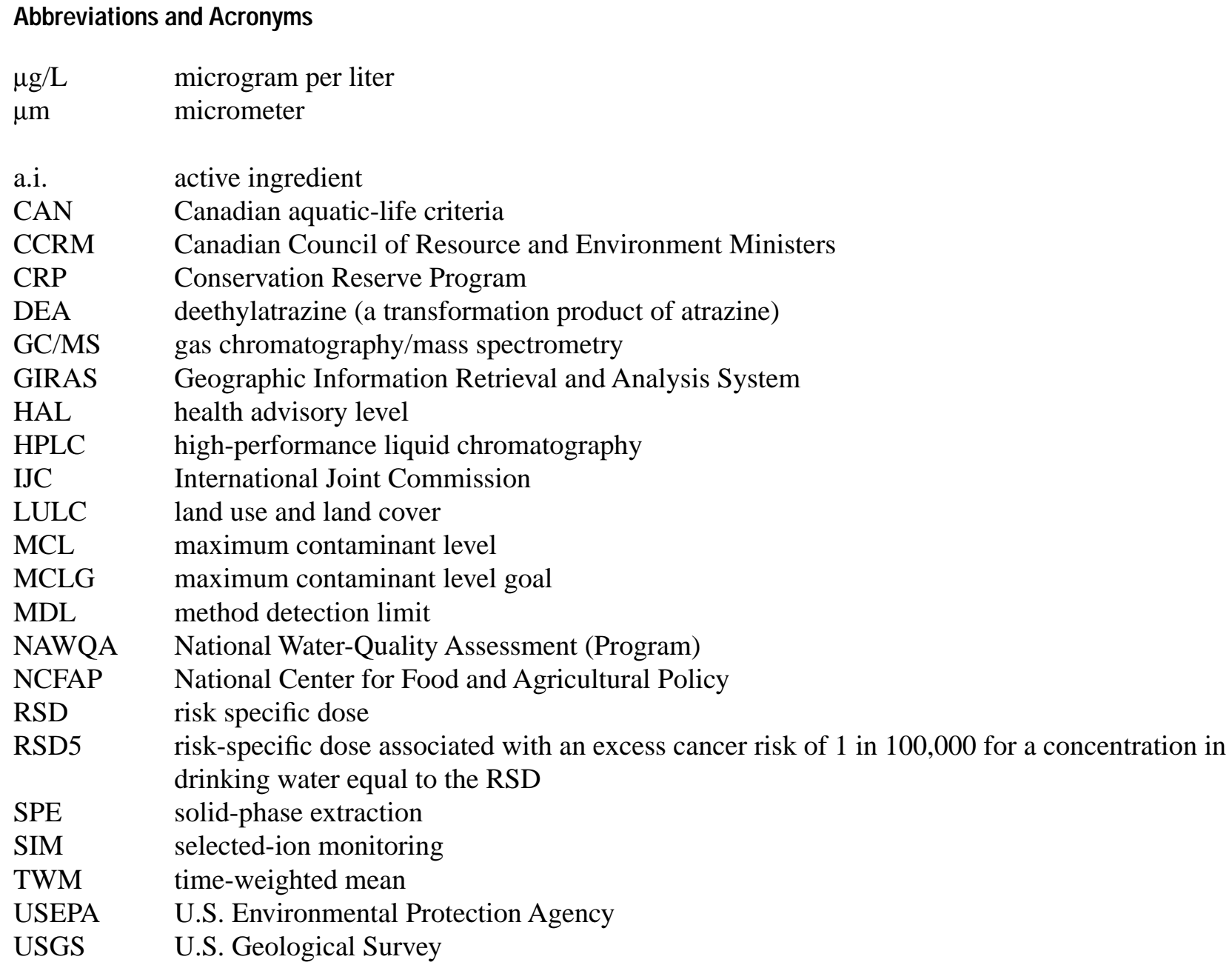




\title{
Pesticides in Streams of the United States - Initial Results from the National Water-Quality Assessment Program
}

\author{
BySteven J . Larson, Robert J . Gilliom, and Paul D. Capel
}

\section{ABSTRACT}

Water samples from 58 rivers and streams across the United States were analyzed for pesticides as part of the National Water-Quality Assessment Program of the U.S. Geological Survey. The sampling sites represent 37 diverse agricultural basins, 11 urban basins, and 10 basins with mixed land use. Forty-six pesticides and pesticide degradation products were analyzed in approximately 2,200 samples collected from 1992 to 1995 . The target compounds account for approximately 70 percent of national agricultural use in terms of the mass of pesticides applied annually.

All the target compounds were detected in one or more samples. Herbicides generally were detected more frequently and at higher concentrations than insecticides. Nationally, 11 herbicides, 1 herbicide degradation product, and 3 insecticides were detected in more than 10 percent of samples. The number of target compounds detected at each site ranged from 7 to 37 . The herbicides atrazine, metolachlor, prometon, and simazine were detected most frequently; among the insecticides, carbaryl, chlorpyrifos, and diazinon were detected the most frequently. Distinct differences in pesticide occurrence were observed in streams draining the various agricultural settings. Relatively high levels of several herbicides occurred as seasonal pulses in corn-growing areas. Several insecticides were frequently detected in areas where the dominant crops consist of orchards and vegetables. The number of pesticides detected and their concentrations were lower in wheat-growing areas than in most other agricultural areas. In most urban areas, the herbicides prometon and simazine and the insecticides carbaryl, chlorpyrifos, diazinon, and malathion were commonly detected. Concentrations of pesticides rarely exceeded standards and criteria established for drinking water, but some pesticides commonly exceeded criteria established for the protection of aquatic life.

\section{INTRODUCTION}

The National Water-Quality Assessment (NAWQA) Program of the U.S. Geological Survey (USGS) is designed to assess the status of and trends in the quality of the nation's surface- and ground-water resources and to link the status and trends with an understanding of the natural and human factors that affect the quality of water (Hirsch and others, 1988; Leahy and others, 1990; Gilliom and others, 1995). The study design balances the unique assessment requirements of individual hydrologic systems with a nationally consistent design structure that incorporates a multiscale, interdisciplinary approach. The building blocks of the national assessment are investigations in major hydrologic basins of the nation, referred to as study units (fig. 1). The goal for the first phase of investigation in each study unit is to characterize, in a nationally consistent manner, the broad-scale geographic and seasonal distributions of water-quality conditions in relation to major contaminant sources and background conditions.

The NAWQA study units include about 40 percent of the land area of the conterminous United States, encompass 60 to 70 percent of national water use, and include diverse hydrologic systems that differ widely in the natural and human factors that affect water quality. The study units are divided into three groups that are studied on a rotational schedule of 3year periods of intensive data collection. About one- 


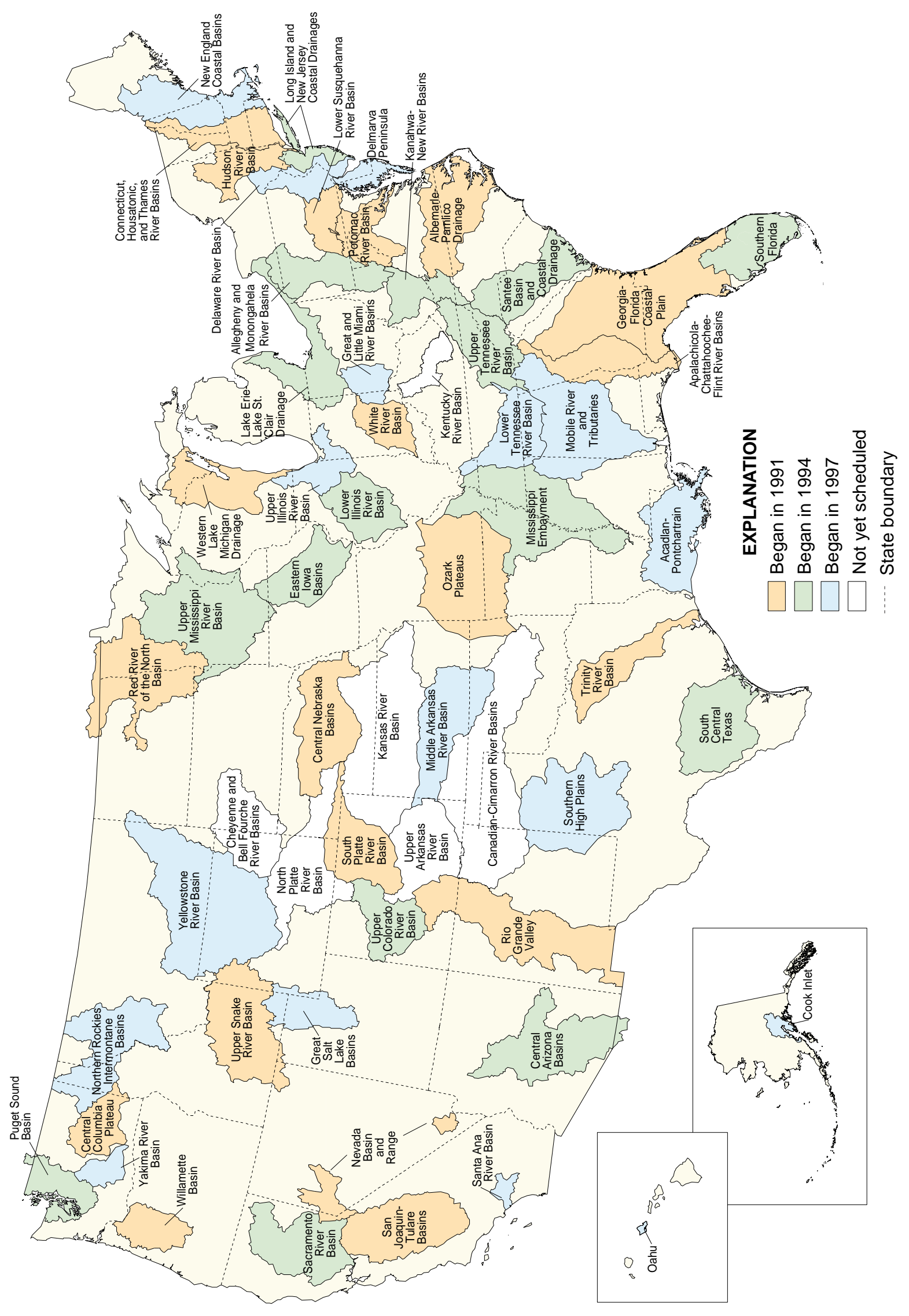

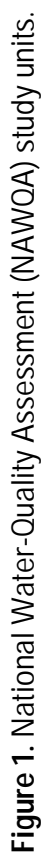


third of the study units are in the intensive datacollection phase at any given time, and the 9-year cycle is repeated perennially. The first complete cycle of intensive data collection in the study units began during 1992-93 and is scheduled to be completed in 2002.

The national assessment goals of NAWQA will be accomplished primarily in two ways. First, NAWQA will accumulate data from consistent and comparable perennial water-quality assessments for the most significant hydrologic systems of the nation; this will be stand alone as a major contribution to our knowledge of regional and national water-quality conditions. Second, NAWQA's National Synthesis Project will build on and expand the findings of individual study units by combining and interpreting the results from multiple study units and from historical information from the USGS and other agencies and researchers. National Synthesis analyses will produce regional and national assessments for priority water-quality issues.

The goal of Pesticide National Synthesis is to assess the extent and the nature of pesticide contamination of the nation's surface and ground water. The aggregated data from all study units will be analyzed to provide a national overview of the occurrence, distribution, and significance of pesticides in surface and ground water across a broad range of geographic, climatic, and land-use conditions.

This report is a national overview of the occurrence and distribution of pesticides in rivers and streams (hereafter referred to only as streams) in 19 of the 20 NAWQA study units that were intensively studied during 1991-95 (data from the Rio Grande study unit were not yet available). The assessment is based on analysis of 46 pesticide compounds in approximately 2,200 water samples from 58 streams sampled during 1992-95. All the data used for this report are available on the World Wide Web (U.S. Geological Survey, 1999). Specific objectives of this analysis are to

- Determine the identity and concentrations of pesticides detected in streams.

- Evaluate seasonal patterns of pesticide occurrence in streams.

- Compare pesticide occurrence in streams draining basins with differing land uses, including comparisons among basins with various agricultural crops and between agricultural and urban basins.

- Compare the transport of pesticides to streams among basins of differing land uses.

- Compare observed concentrations with standards and criteria established for the protection of the health of humans and aquatic biota.

Results from NAWQA investigations of pesticides in bed sediments of rivers and streams and in tissues of aquatic organisms currently are being analyzed; the initial results from NAWQA investigations of ground water are summarized in Kolpin and others (1998). Results from NAWQA pesticide studies during the past several decades have been summarized by Majewski and Capel (1995) for pesticides in the atmosphere, Barbash and Resek (1996) for ground water, and Larson and others (1997) for surface waters.

\section{SITE SELECTION AND CHARACTERISTICS}

Water samples were collected for pesticide analysis at 58 stream sites throughout the conterminous United States (fig. 2). These sites are a subset of the NAWQA surface-water monitoring sites. Eight to 12 stream sites were selected for regular monitoring of streamflow and general water chemistry for each of the study units shown in figure 2 . One to 5 of these stream sites were chosen for more intensive sampling and pesticide analysis.

Two general types of sites were selected for intensive sampling-indicator and integrator sites. Indicator sites were chosen to represent water-quality conditions of streams in relatively homogeneous basins associated with specific environmental settings (land use and natural characteristics) that were targeted for study. Water quality at the indicator sites is influenced primarily by the targeted environmental setting, and in most cases, the targeted setting accounts for more than 50 percent of the drainage area. In contrast, integrator sites were chosen to represent water-quality conditions of streams with relatively large basins that are influenced by complex combinations of land-use settings, point sources, and natural influences typical of the region. Integrator sites generally are downstream from indicator sites and are located at key nodes in the drainage network. Results from the integrator sites provide a general check on the persistence of water- 


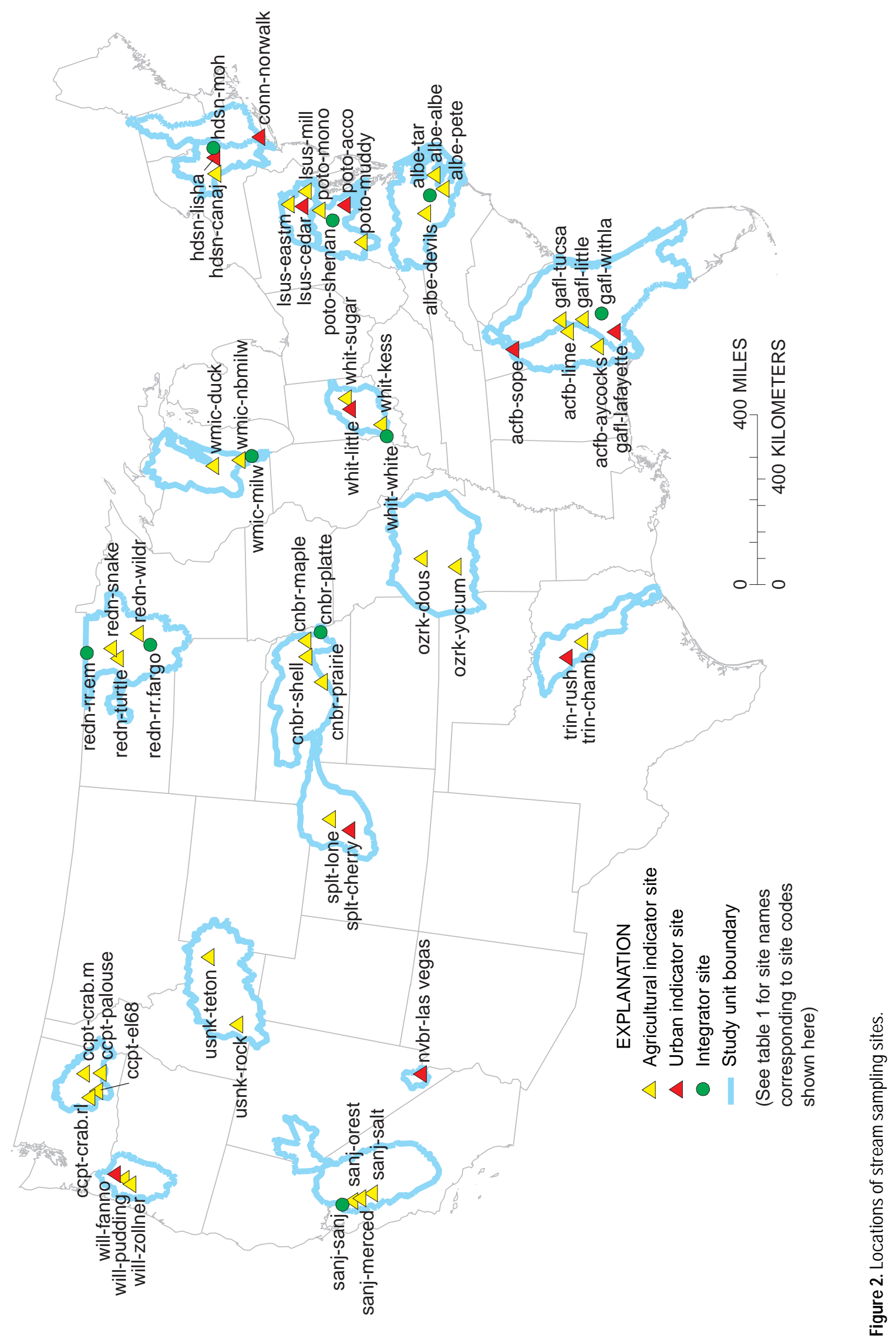

11 Pesticides in Streams of the United States- Initial Results from the National Water-Quality Assessment Program 
quality influences evident at the indicator sites; the results also can be used for water-budget and contaminant transport assessments. For a detailed description of the criteria and procedures used for site selection, see Gilliom and others (1995).

The 58 sites covered in this report consist of 37 agricultural indicator sites, 11 urban indicator sites, and 10 integrator sites. Sampling site locations are shown in figure 2 and site characteristics are summarized in table 1 and figure 3. In most of the agricultural basins, cropland and orchard-vineyard land account for more than 40 percent of the basin area and urban land accounts for less than 5 percent. The Merced River in the San Joaquin studyfied as cropland or orchard-vineyard land. Agricultural activity in the farmed area of this basin is very intense, however, with a variety of orchards, vineyards, and row crops; much of the streamflow during the growing season is from agricultural return flows.

Agricultural indicator sites and integrator sites are classified according to the major crops grown within the drainage basins (table 1). About threefourths of the agricultural indicator basins have major crops of corn, soybeans, alfalfa, and wheat and other grains, or some combination of these crops. This is consistent with the national distribution of row crops, with these four crops accounting for about 85 percent of the total rowcrop area in the United States (Gilliom and Thelin, 1997). Other crops, such as peanuts, cotton, vegetables, field and grass seed, and sorghum, are represented by fewer agricultural sites. Thus, aggregated results from the agricultural sites are influenced most by pesticide use associated with the four major crops.

Water-quality conditions at urban indicator sites are affected primarily by urban, suburban, commercial, and industrial sources. Urban land uses account for more than 50 percent of the basin area at all but one of the urban indicator sites. The one exception is the Las Vegas Wash site, where more than 90 percent of the drainage basin consists of rangeland. For most of the year, water in the Las Vegas Wash consists almost entirely of effluent from a sewage treatment plant and of runoff from the urban area; the primary influences on water quality in the Las Vegas Wash, therefore, are from urban sources.

Whenever possible, the order of the sites in table 1 is retained in the figures and the tables throughout this report to aid in cross-referencing site information between tables and figures. Sites are identified in some figures and tables by a site code which consists of the study unit abbreviation and a part of the site name. For example, in the White River Basin study unit, the site on Sugar Creek is designated as "whit-sugar." The code for each site is shown in figure 2 and listed in table 1.

\section{TARGET COMPOUND SELECTION AND CHARACTERISTICS}

This report includes results of the analysis of water samples for 46 compounds-25 herbicides, 17 insecticides, 2 herbicide transformation products, and 2 insecticide transformation products. The target compounds are listed in table 2, with estimates of their national agricultural use and their primary uses.

Compounds were selected for analysis on the basis of national agricultural and nonagricultural use, potential environmental significance, and chemical properties that allow analysis by gas chromatography/mass spectrometry (GC/MS).

The pesticides included in this report account for approximately 72 and 66 percent of national use of herbicides and insecticides, respectively, in terms of the mass used annually in agricultural applications during 1990-93 (Gianessi and Anderson, 1996). These pesticide-use totals do not include the use of inorganic pesticides, such as sulfur and copper, or biological pesticides or the use of oil as an insecticide. The target compounds include 15 of the top 25 herbicides and 15 of the top 25 insecticides used in agriculture in the United States during this period. No fungicides are included among the target compounds. Fungicides constituted approximately 6.5 percent of total agricultural use of pesticides in the United States during 1990-93 in terms of the mass applied annually (Gianessi and Anderson, 1996).

Pesticide use in nonagricultural applications in the United States is not well documented, but data are available that provide information on the relative amounts of different pesticides used on lawns and gardens during 1989-90 (Whitmore and others, 1992). In general, the pesticides discussed in this current report account for a lower proportion of 


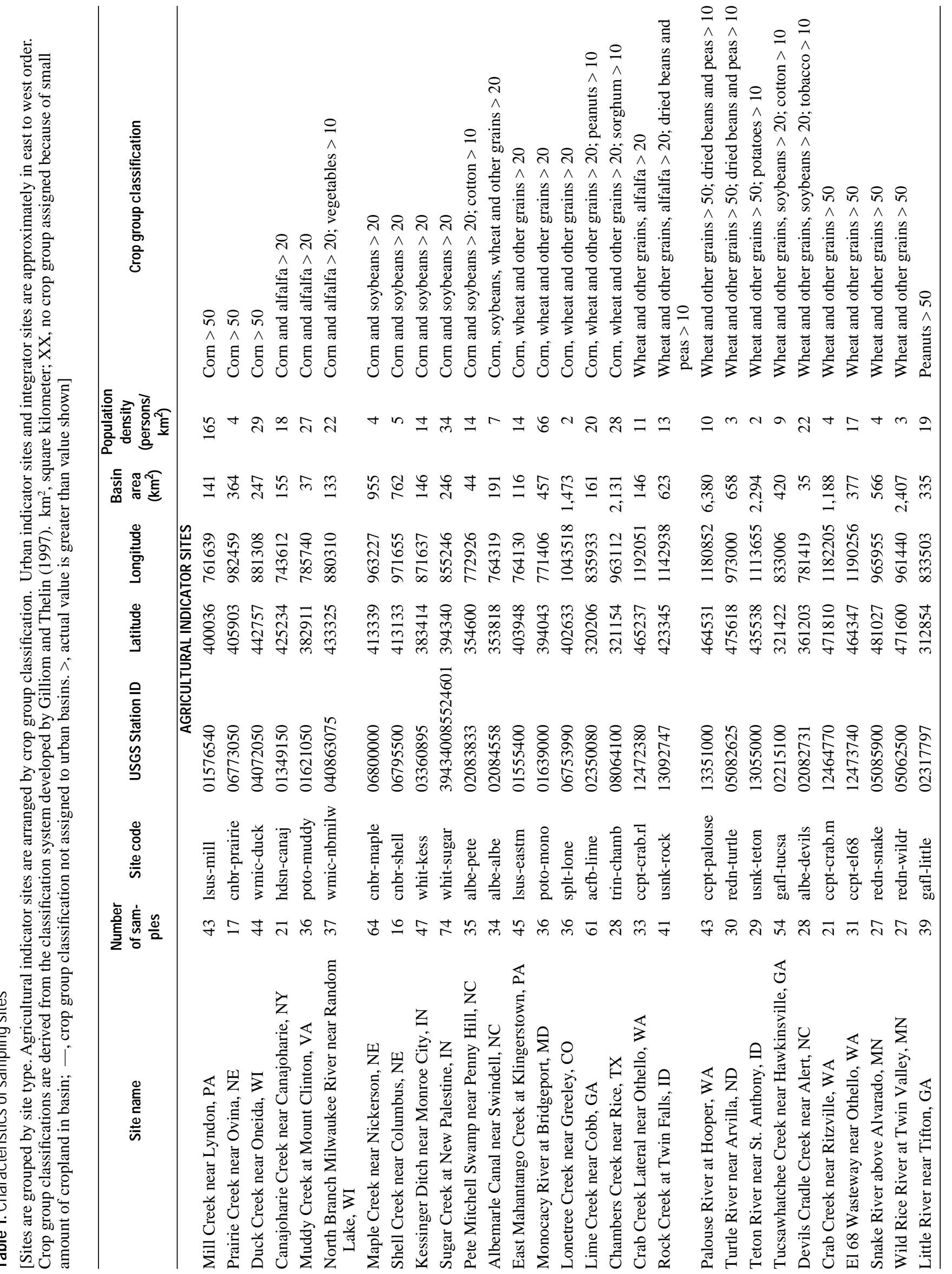




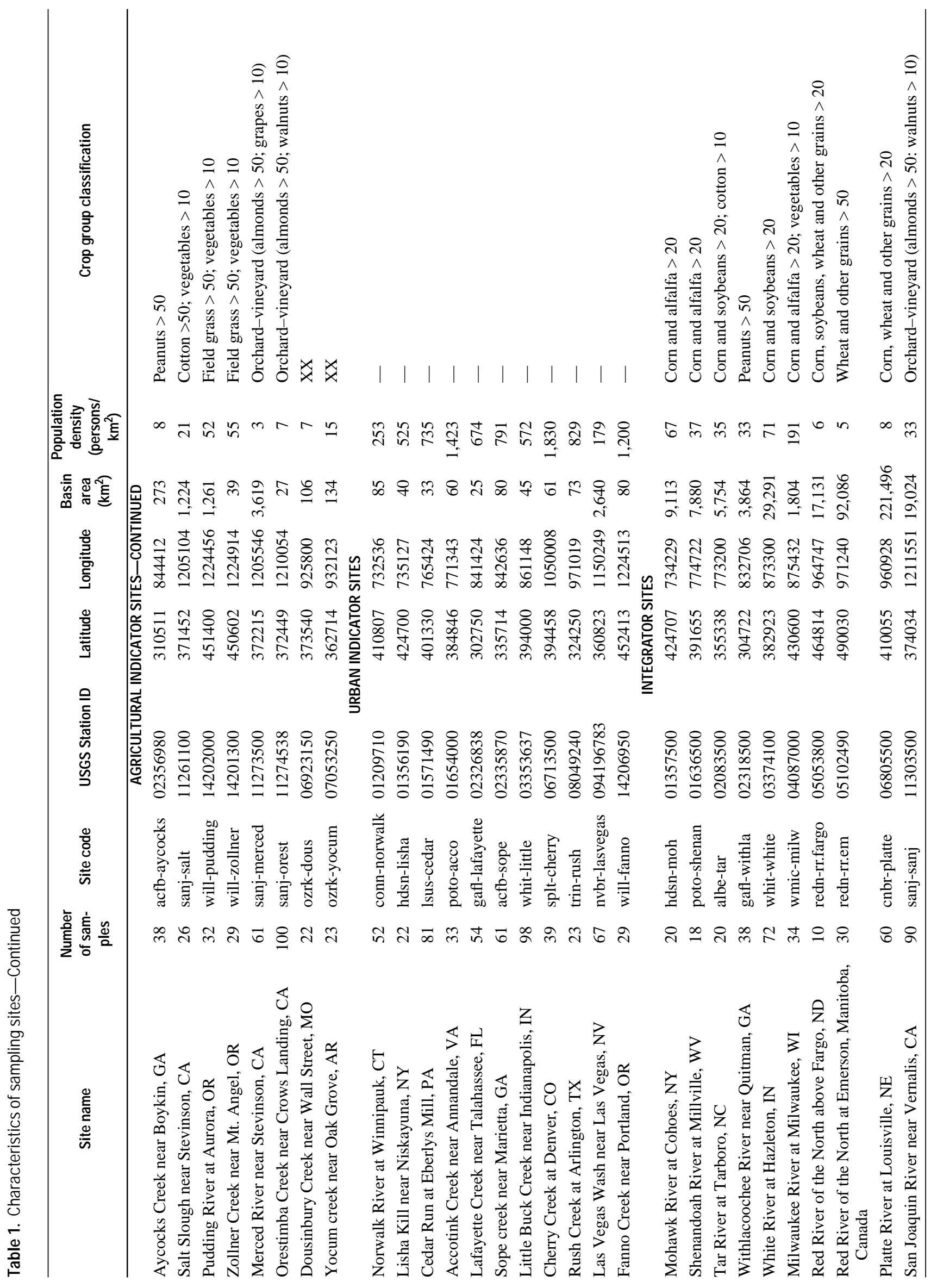



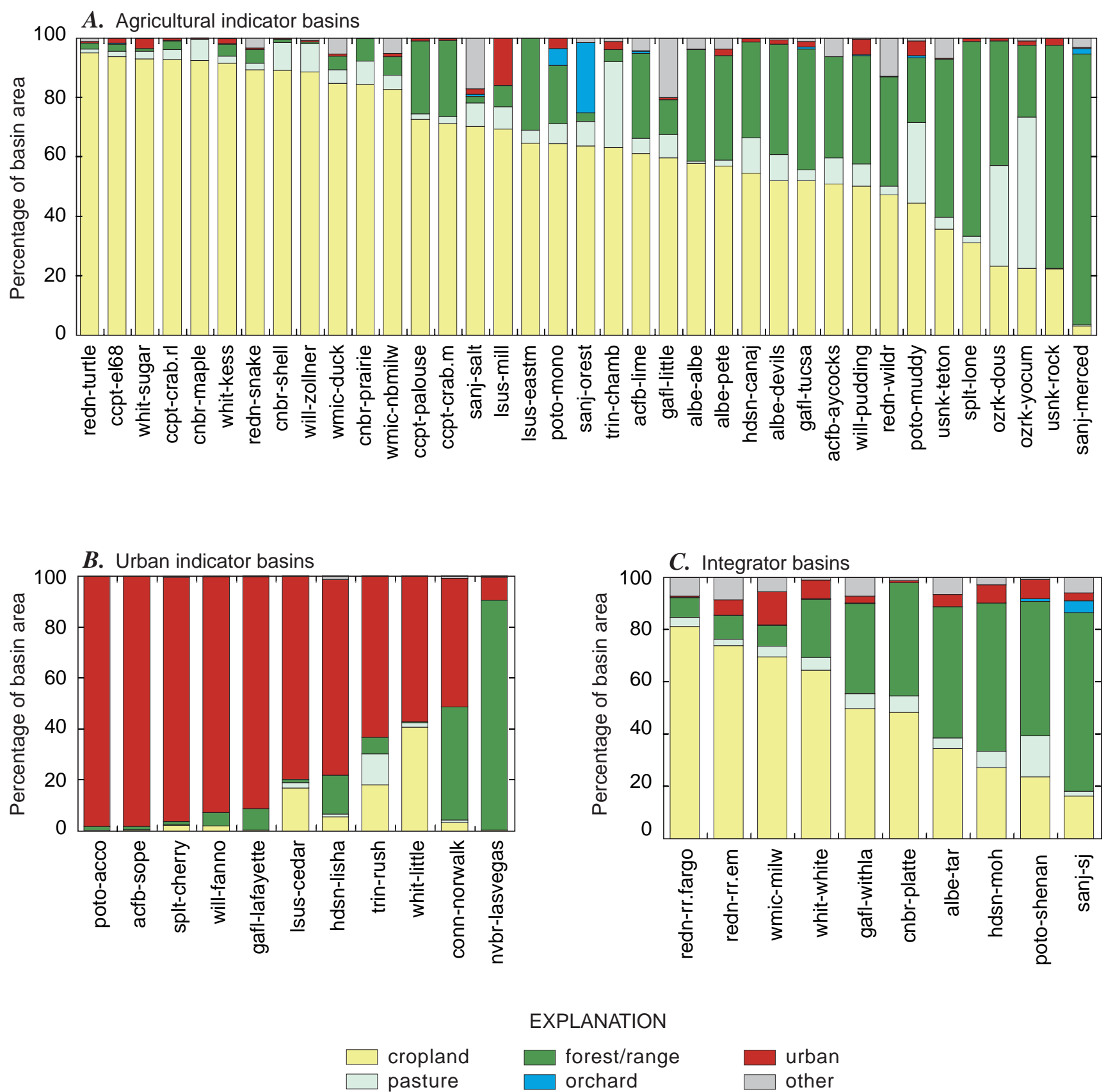

Figure 3. Distribution of land use in $(\boldsymbol{A})$ agricultural indicator basins, $(\boldsymbol{B})$ urban indicator basins, and $(\boldsymbol{C})$ integrator basins. Data are derived from U.S. Geological Survey (1990) and U.S. Department of Commerce (1995). Urban land-use data are derived from U.S. Geological Survey (1990), with revisions that are based on the 1990 population census (Hitt, 1994). Site codes are defined in table 1.

nonagricultural use than agricultural use with 6 of the top 20 insecticides, 6 of the top 20 herbicides, and none of the top 12 fungicides used on lawns and gardens included in the target compounds. The relatively low coverage of pesticide use in nonagricultural settings should be kept in mind in the discussions of results from urban indicator sites. Several other pesticides with high nonagricultural use were measured at these sites using a different analytical method (highperformance liquid chromatography, or HPLC); the results will be analyzed when the data are available.

For most of the agricultural indicator and integrator sites, the target pesticides account for a major portion of agricultural herbicide and insecticide 
Table 2. Target compounds and their national agricultural use, rank, analytical recovery, method detection limit, and primary uses.

[Agricultural use data from Giannessi and Anderson, 1996. Analytical recovery and method detection limit from Zaugg and others, 1995. Information on primary uses from Gianessi and Anderson (1996), and Meister (1996). d-H, herbicide degradation product; H, herbicide; I, insecticide; d-I, insecticide degradation product; $\mathrm{lb}$ a.i., pound active ingredient; $\mu \mathrm{g} / \mathrm{L}$, microgram per liter; - , no United States agricultural use reported]

\begin{tabular}{|c|c|c|c|c|c|c|}
\hline Compound & Type & $\begin{array}{c}\text { National } \\
\text { agricul- } \\
\text { tural use, } \\
\text { 1990-1993 } \\
\text { (million } \\
\text { Ib a.i.) }\end{array}$ & $\begin{array}{l}\text { Rank in } \\
\text { top } 200 \\
\text { agricul- } \\
\text { tural } \\
\text { pesti } \\
\text { cides }\end{array}$ & $\begin{array}{l}\text { Percent } \\
\text { analytical } \\
\text { recovery }\end{array}$ & $\begin{array}{c}\text { Method } \\
\text { detection } \\
\text { limit } \\
(\mu \mathrm{g} / \mathrm{L})\end{array}$ & Primary uses \\
\hline 2,6-Diethylaniline & $\mathrm{d}-\mathrm{H}$ & - & - & 47 & 0.003 & Degradation product of alachlor \\
\hline Alachlor & $\mathrm{H}$ & 26 & 7 & 113 & 0.002 & Corn, soybeans, sorghum, peanuts \\
\hline Atrazine & $\mathrm{H}$ & 62 & 1 & 98 & 0.001 & Corn, sorghum, sugarcane, pasture \\
\hline Benfluralin & $\mathrm{H}$ & 0.41 & 105 & 51 & 0.002 & Peanuts, alfalfa, lettuce, turf \\
\hline Butylate & $\mathrm{H}$ & 7.7 & 19 & 84 & 0.002 & Corn, sweet corn \\
\hline Carbaryl & I & 3.8 & 32 & 24 & 0.003 & Corn, sorghum, soybeans, pecans, lawns, turf, ornamentals \\
\hline Carbofuran & I & 4.9 & 24 & 31 & 0.003 & Corn, alfalfa, sorghum, soybeans \\
\hline Chlorpyrifos & I & 15 & 12 & 116 & 0.004 & Corn, alfalfa, cotton, structural pest control \\
\hline Cyanazine & $\mathrm{H}$ & 29 & 3 & 71 & 0.004 & Corn, cotton, sorghum, sweet corn \\
\hline Dieldrin & I & - & - & 90 & 0.001 & Fruits, potatoes, tomatoes, structural pest control (banned in U.S.) \\
\hline Disulfoton & I & 1.6 & 60 & 82 & 0.017 & Corn, wheat, potatoes, cotton \\
\hline EPTC $^{2}$ & $\mathrm{H}$ & 14 & 13 & 84 & 0.002 & Corn, alfalfa, dry beans, potatoes \\
\hline Ethalfluralin & $\mathrm{H}$ & 2.4 & 47 & 102 & 0.004 & Soybeans, dry beans sunflowers, peanuts \\
\hline Ethoprop & I & 1.2 & 67 & 84 & 0.003 & Potatoes, corn, tobacco, sugarcane, turf \\
\hline Fonofos & I & 2.7 & 45 & 80 & 0.003 & Corn, peanuts, potatoes, sweet corn, garden \\
\hline$\alpha-\mathrm{HCH}^{3}$ & d-I & - & - & 95 & 0.002 & Degradation product of lindane, component of technical grade $\mathrm{HCH}$ \\
\hline Lindane & I & 0.06 & 161 & 100 & 0.004 & Pecans, cucumbers, squash, sweet corn \\
\hline Linuron & $\mathrm{H}$ & 1.9 & 54 & 22 & 0.002 & Soybeans, carrots, cotton, potatoes, roadsides, fence rows \\
\hline Malathion & I & 3 & 40 & 71 & 0.005 & Cotton, alfalfa, sorghum, rice, fruits, ornamentals \\
\hline Methyl parathion & I & 8.6 & 16 & 46 & 0.006 & Cotton, sunflowers, corn, soybeans \\
\hline Permethrin, cis & I & 1.2 & 72 & 50 & 0.005 & Corn, alfalfa, soybeans, wheat, lawns, gardens, structural pest control \\
\hline Phorate & I & 3.7 & 34 & 76 & 0.002 & Corn, potatoes, wheat, sugarcane \\
\hline Prometon & $\mathrm{H}$ & - & - & 45 & 0.018 & General vegetation control, roads, railways, fencelines \\
\hline Pronamide & $\mathrm{H}$ & 0.2 & 127 & 71 & 0.003 & Alfalfa, lettuce, seed crops, artichokes, turf, woody ornamentals \\
\hline Propachlor & $\mathrm{H}$ & 3.9 & 31 & 100 & 0.007 & Sorghum, corn, green peas, squash \\
\hline Propanil & $\mathrm{H}$ & 7.2 & 20 & 73 & 0.004 & Rice \\
\hline Propargite & I & 3.1 & 39 & 64 & 0.013 & Corn, cotton, grapes, almonds \\
\hline Simazine & $\mathrm{H}$ & 4.8 & 26 & 94 & 0.005 & Corn, citrus, alfalfa, grapes, turf, fairways, lawns, aquatic control \\
\hline Tebuthiuron & $\mathrm{H}$ & - & - & 106 & 0.01 & Pasture, rights-of-way, industrial sites \\
\hline Terbacil & $\mathrm{H}$ & 0.51 & 93 & 39 & 0.007 & Alfalfa, mint, sugarcane, apples \\
\hline Terbufos & I & 7.2 & 21 & 139 & 0.013 & Corn, sugar beets, sorghum, sweet corn \\
\hline Thiobencarb & $\mathrm{H}$ & 1.4 & 64 & 91 & 0.002 & Rice \\
\hline Triallate & $\mathrm{H}$ & 2 & 53 & 91 & 0.001 & Wheat, barley, dry peas, flax \\
\hline Trifluralin & $\mathrm{H}$ & 19 & 10 & 59 & 0.002 & Soybeans, cotton, wheat, sunflowers \\
\hline
\end{tabular}

${ }^{1}$ dimethyl 2,3,5,6-tetrachloro-1,4-benzenedicarboxylate.

${ }^{2} \mathrm{~S}$-ethyl dipropylthiocarbamate.

${ }^{3} \alpha$-hexachlorocyclohexane. 
Table 3. Coverage of pesticide uuse by the target compounds for agricultural indicator basins and ingegrator basins

[>, actual value is greater thatn value shown]

\begin{tabular}{|c|c|c|c|c|}
\hline \multirow[b]{2}{*}{ Site code } & \multicolumn{3}{|c|}{$\begin{array}{l}\text { Coverage of pesticide use in drainage basin by } \\
\text { target compounds }\end{array}$} & \multirow[b]{2}{*}{ Crop group classification } \\
\hline & $\begin{array}{l}\text { Percentage of } \\
\text { total herbicide } \\
\text { use in basin }\end{array}$ & $\begin{array}{l}\text { Percentage } \\
\text { of total } \\
\text { insecticide } \\
\text { use in basin }\end{array}$ & $\begin{array}{l}\text { Percentage of total } \\
\text { pesticide use in basin } \\
\text { (herbicides, insecti- } \\
\text { cides, soil fungicides, } \\
\text { fumigants, other) }\end{array}$ & \\
\hline \multicolumn{5}{|c|}{ AGRICULTURAL INDICATOR BASINS } \\
\hline lsus-mill & 92 & 72 & 75 & Corn $>50$ \\
\hline cnbr-prairie & 93 & 95 & 93 & Corn $>50$ \\
\hline wmic-duck & 83 & 92 & 80 & Corn $>50$ \\
\hline hdsn-canaj & 81 & 96 & 83 & Corn and alfalfa $>20$ \\
\hline poto-muddy & 80 & 83 & 67 & Corn and alfalfa $>20$ \\
\hline wmic-nbmilw & 86 & 90 & 83 & Corn and alfalfa $>20$; vegetables $>10$ \\
\hline cnbr-maple & 89 & 95 & 90 & Corn and soybeans $>20$ \\
\hline cnbr-shell & 91 & 95 & 91 & Corn and soybeans $>20$ \\
\hline whit-kess & 83 & 85 & 77 & Corn and soybeans $>20$ \\
\hline whit-sugar & 83 & 92 & 82 & Corn and soybeans $>20$ \\
\hline albe-pete & 52 & 53 & 21 & Corn and soybeans $>20$; cotton $>10$ \\
\hline albe-albe & 61 & 76 & 49 & Corn, soybeans, wheat and other grains $>20$ \\
\hline 1sus-eastm & 90 & 66 & 72 & Corn, wheat and other grains $>20$ \\
\hline poto-mono & 81 & 51 & 35 & Corn, wheat and other grains $>20$ \\
\hline splt-lone & 80 & 90 & 63 & Corn, wheat and other grains $>20$ \\
\hline acfb-lime & 55 & 55 & 32 & Corn, wheat and other grains $>20$; peanuts $>10$ \\
\hline trin-chamb & 65 & 69 & 65 & Corn, wheat and other grains $>20 ;$ sorghum $>10$ \\
\hline ccpt-crab.rl & 56 & 72 & 8 & Wheat and other grains, alfalfa $>20$ \\
\hline usnk-rock & 76 & 60 & 13 & Wheat and other grains,alfalfa $>20$; dried beans-peas $>10$ \\
\hline ccpt-palouse & 34 & 62 & 26 & Wheat and other grains $>50$; dried beans-peas $>10$ \\
\hline redn-turtle & 52 & 82 & 31 & Wheat and other grains $>50$; dried beans-peas $>10$ \\
\hline usnk-teton & 67 & 95 & 6 & Wheat and other grains $>50$; potatoes $>10$ \\
\hline gafl-tucsa & 40 & 38 & 23 & Wheat and other grains, soybeans $>20$; cotton $>10$ \\
\hline albe-devils & 66 & 47 & 10 & Wheat and other grains, soybeans $>20$; tobacco $>10$ \\
\hline ccpt-crab.m & 14 & 84 & 17 & Wheat and other grains $>50$ \\
\hline ccpt-el68 & 29 & 72 & 5 & Wheat and other grains $>50$ \\
\hline redn-snake & 31 & 88 & 23 & Wheat and other grains $>50$ \\
\hline redn-wildr & 41 & 93 & 41 & Wheat and other grains $>50$ \\
\hline gafl-little & 50 & 50 & 22 & Peanuts $>50$ \\
\hline acfb-aycocks & 61 & 62 & 35 & Peanuts $>50$ \\
\hline sanj-salt & 45 & 67 & 25 & Cotton $>50 ;$ vegetables $>10$ \\
\hline will-pudding & 37 & 86 & 25 & Grass seed $>50 ;$ vegetables $>10$ \\
\hline will-zollner & 37 & 86 & 25 & Grass seed $>50 ;$ vegetables $>10$ \\
\hline sanj-merced & 39 & 71 & 27 & Orchard-vineyard (almonds > 50; grapes > 10) \\
\hline sanj-orest & 41 & 80 & 27 & Orchard-vineyard (almonds > 50; walnuts > 10) \\
\hline ozrk-dous & 64 & 100 & 74 & (Cropland <10) \\
\hline ozrk-yocum & 1 & 96 & 33 & (Cropland <10) \\
\hline
\end{tabular}


Table 3. Coverage of pesticide use by the target compounds for agricultural indic ator basins and integrator basins- Continued

\begin{tabular}{|c|c|c|c|c|}
\hline \multirow[b]{2}{*}{ Site code } & \multicolumn{3}{|c|}{$\begin{array}{l}\text { Coverage of pesticide use in drainage basin by } \\
\text { target compounds }\end{array}$} & \multirow[b]{2}{*}{ Crop group classification } \\
\hline & $\begin{array}{l}\text { Percentage of } \\
\text { total herbicide } \\
\text { use in basin }\end{array}$ & $\begin{array}{l}\text { Percentage } \\
\text { of total } \\
\text { insecticide } \\
\text { use in basin }\end{array}$ & $\begin{array}{l}\text { Percentage of total } \\
\text { pesticide use in basin } \\
\text { (herbicides, insecti- } \\
\text { cides, soil fungicides, } \\
\text { fumigants, other) }\end{array}$ & \\
\hline \multicolumn{5}{|c|}{ INTEGRATOR BASINS } \\
\hline cnbr-platte & 91 & 96 & 91 & Corn, wheat and other grains $>20$ \\
\hline whit-white & 84 & 90 & 83 & Corn and soybeans $>20$ \\
\hline wmic-milw & 84 & 92 & 80 & Corn and alfalfa $>20$; vegetables $>10$ \\
\hline hdsn-moh & 81 & 94 & 79 & Corn and alfalfa $>20$ \\
\hline poto-shenan & 76 & 75 & 53 & Corn and alfalfa $>20$ \\
\hline albe-tar & 51 & 53 & 15 & Corn and soybeans $>20 ;$ cotton $>10$ \\
\hline gafl-withla & 51 & 49 & 25 & Peanuts $>50$ \\
\hline redn-rr.fargo & 65 & 92 & 60 & Corn, soybeans, wheat and other grains $>20$ \\
\hline redn-rr.em & 51 & 88 & 40 & Wheat and other grains $>50$ \\
\hline sanj-sanj & 43 & 75 & 27 & Orchard-vineyard (almonds $>50$; walnuts $>10$ ) \\
\hline
\end{tabular}

use within the drainage basin (table 3). For example, for nearly all agricultural basins in which corn is the major crop, the target pesticides account for more than 80 percent of the total amount of herbicides and insecticides applied. The target pesticides accounted for a smaller part of the total pesticide use in some basins, particularly in wheat-growing areas and in the two agricultural basins in the Willamette River Basin in Oregon. Pesticides with high use in wheat growing areas and in the Williamette River Basin include the herbicides 2,4-D, bentazon, diuron, and MPCA, the insecticides aldicarb and acephate, and the fungicide chlorothalonil (Giannessi and Anderson, 1996), none of which are included in the target compounds in this report. The target pesticides account for a lower percentage of total pesticide use in most basins when compared with the total amount of all pesticides applied only for agricultural use, including herbicides, insecticides, fungicides, and soil fumigants (table 3). However, several of the pesticides not targeted in this study, particularly the commonly used soil fumigants methyl bromide, 1,3-D, and metam sodium, have physical and chemical properties or application techniques that result in a low potential for transport to streams (Goss and Wauchope, 1990; Draper and Wakeham, 1993). In addition, the volatility of the soil fumigants would be expected to result in relatively fast removal from streams (Gentile and others, 1989, 1992; del Rosario and others, 1994; Rathbun, 1998). Thus, although a considerable amount of pesticide use is not accounted for by the compounds discussed in this report, most of the major agricultural herbicides and insecticides and many of the compounds most likely to be found in streams are included.

In addition, several pesticide transformation products are included in the target compounds in the report. Deethylatrazine (DEA), a transformation product of the herbicide atrazine, frequently has been detected in streams draining areas in which atrazine is used (Larson and others, 1997). A transformation product of the herbicide alachlor, 2,6-

diethylacetanilide, also is included in the target compounds. Hexachlorocyclohexane $(\alpha-\mathrm{HCH})$ is a transformation product of the insecticide lindane $(\gamma-\mathrm{HCH})$ and a component of technical grade $\mathrm{HCH}$, an insecticide that is no longer used in the United States. A transformation product of the insecticide DDT, $p, p^{\prime}-$ DDE, is another target compound included in this report. This compound is the transformation product of DDT which is most commonly detected in bed sediments of streams and in tissues of aquatic organisms. 


\section{METHODS FOR SAMPLE COLLECTION AND ANALYSIS}

Water samples were collected at 58 sites in accordance with the NAWQA national sampling strategy (Gilliom and others, 1995). Samples were collected for 1 to 3 years at each site using a combination of fixed-interval and extreme-flow sampling. For the fixed-interval sampling, 4 to 8 samples generally were collected each month during critical periods of high pesticide use and runoff and 1 to 2 samples were collected each month during other periods. Additional samples were collected during periods of extreme high and low flows. Samples were collected more frequently for some sites where shortterm fluctuations were a concern. The sampling frequencies for the 58 sites included in this report are shown in figure 4 . The total number of samples collected at each site from 1992 through May of 1995 is shown in table 1 . The focus of this report is primarily on results from samples collected during 1993, 1994, and the first few months of 1995.

All samples were depth- and width-integrated using standard USGS methods (Shelton, 1994). All equipment used for collecting and processing water samples was constructed of Teflon, glass, aluminum, or stainless steel and was cleaned and rinsed with residuegrade methanol. All samples were filtered using precombusted glass-fiber filters with a nominal $0.7-\mu \mathrm{m}$ pore diameter to remove suspended particulate matter. Complete collection and processing methods are described by Shelton (1994).

The target compounds were extracted from water samples using C-18 solid-phase extraction (SPE) columns and identified and quantified using capillarycolumn GC/MS. Complete details of the analytical procedure are given in Zaugg and others (1995) and will be described only briefly here.

One-liter, filtered water samples were drawn through C-18 SPE columns under vacuum. The target compounds sorb to the $\mathrm{C}-18$ phase, effectively removing them from the water. The SPE columns were then dried using a gentle stream of carbon dioxide to remove residual water. The target compounds were removed from the SPE columns by elution with hexane:isopropanol (9:1). The volume of the eluate was reduced using a gentle stream of nitrogen. The sample extract was then injected onto a capillarycolumn gas chromatograph for separation of the target compounds. Pesticides and pesticide metabolites were identified and quantified using a mass selective detector operating in the selected-ion monitoring (SIM) mode.

Method detection limits (MDLs) were determined using standard U.S. Environmental Protection Agency (USEPA) procedures (U.S. Environmental Protection Agency, 1994; Zaugg and others, 1995; U.S. Geological Survey, 1998). MDLs for the 46 target compounds ranged from $0.001 \mu \mathrm{g} / \mathrm{L}$ to $0.018 \mu \mathrm{g} / \mathrm{L}$ (table 2). Target compounds were quantified at concentrations less than the reported MDL if compound identification criteria were met (Zaugg and others, 1995). Reported concentrations lower than the MDL were used in some of the calculations of summary statistics in this report.

Analytical recoveries for the target compounds are shown in table 2 . The values of the analytical recoveries are based on analysis of laboratory-spiked reagent-grade water using pesticide concentrations ranging from 0.01 to $0.3 \mu \mathrm{g} / \mathrm{L}$ (Zaugg and others, 1995; U.S. Geological Survey, 1998). Recoveries ranged from 13 to 156 percent, with recoveries for 80 percent of the compounds between 39 and 113 percent. This analytical method was developed to enable detection of very low concentrations of a maximum number of compounds; analysis conditions, however, were not optimal for all of the target compounds. Performance of this method was relatively poor or inconsistent for six compounds-azinphos-methyl, carbaryl, carbofuran, DEA, linuron, and terbacil. The analytical recovery for these compounds was low, and all reported concentrations are regarded as estimates. When these six compounds are excluded, recoveries ranged from 42 to 156 percent, with recoveries for 80 percent of the compounds between 50 and 113 percent.

Concentrations were not corrected for analytical recovery in the analyses for this report; therefore, it is important to keep in mind the differences in recovery among the target compounds when evaluating results. 


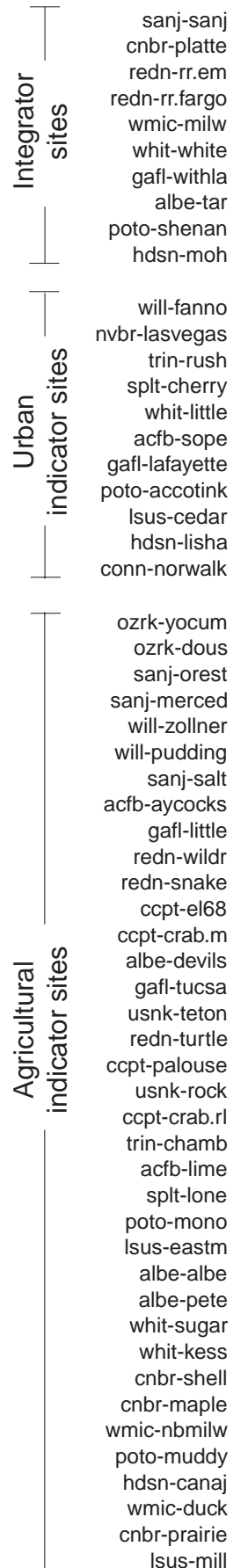

Isus-mill

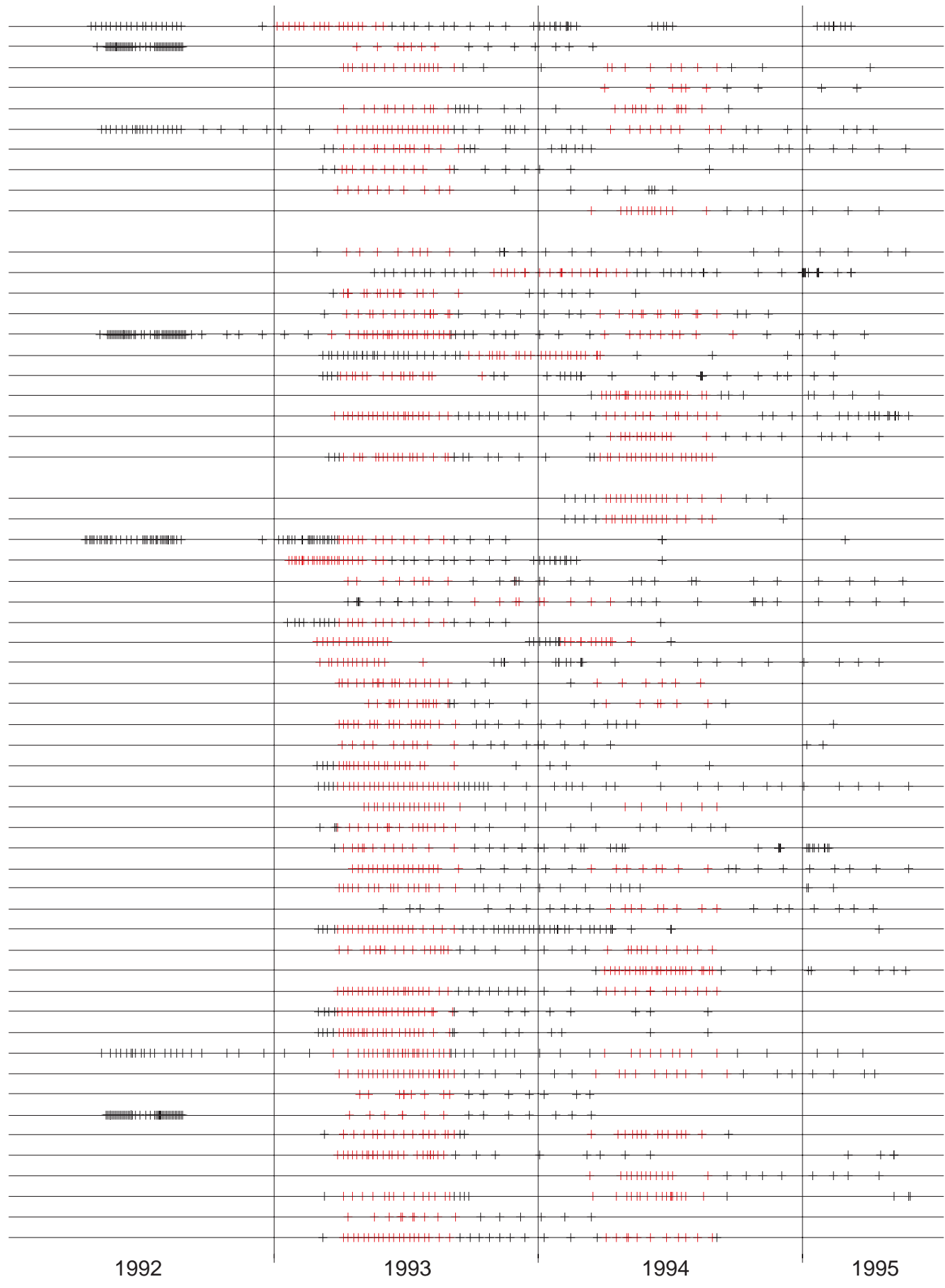

Date of sample collection

Figure 4. Sampling frequency at the 58 sampling sites. Each " + " symbol indicates the date of sample collection. Red symbols show samples collected during a 5-month critical period when pesticide concentrations were highest and sampling frequency was relatively high. Site codes are defined in table 1 . Sampling site locations are show $n$ in figure 2. 


\section{METHODS FOR DATA ANALYSIS}

Analysis of data on pesticides in streams presents many unique problems stemming from the characteristics of trace-level organic contaminants, strong seasonal variations in concentrations, variable data-collection strategies, and other factors. Although there are many possible ways to address these problems in data analysis, only the methods used for this report are described below.

\section{Selection of Critical Period}

The sampling frequency varied considerably among the 58 sites (fig. 4), and thus some comparisons between sites would not be appropriate if data from an entire year were used. For example, a comparison of mean concentrations for 1994 for Duck Creek (wmicduck) and for Cherry Creek (splt-cherry) would be biased because the samples were collected only from April through October at Duck Creek but throughout the year at Cherry Creek. For this reason, some of the comparisons made in this report are based on data from samples collected during a designated critical period.

A 5-month critical period was selected for each site during which pesticide concentrations were highest and sampling was relatively frequent. Samples collected during the critical period are shown in red in figure 4 . The choice of a critical period for each site was based on the temporal distribution of the total (summed) pesticide concentrations measured during the 1- to 3-year sampling period and on the sampling frequency at the site. When sufficient samples were collected at a site during 2 different years, a critical period was chosen for each year. Comparisons that are based on concentrations measured during the critical periods are influenced less by differences in sampling frequency and timing of pesticide application than are comparisons that are based on an entire year of data. For most sites, the chosen critical period was from April through August. For some sites in the South, the Northwest, and California, the critical period began in autumn or winter.

\section{Calculation of Detection Frequencies}

In general, more samples were collected during periods when elevated concentrations of pesticides were expected and stream discharge was high. At most sites, this occurs during May, June, and July. For the calculation of summary statistics, such as detection frequencies and mean or median concentrations, this targeted sampling must be accounted for or the results will be biased.

Annual mean detection frequencies for each compound at each site were derived by first calculating the detection frequency for each month. The mean of the 12 monthly detection frequencies was then used as an estimate of the detection frequency for a 1-year period. The 1-year period with the most intense sampling at each site was used, which for most sites was from spring 1993 to spring 1994. For months when no samples were collected at a site, the mean of the detection frequencies for the 2 adjacent months was used. Detection frequencies calculated in this way are estimates of the detection frequencies that would be obtained if samples were collected at even intervals throughout the year. At eight sites, samples had not been collected for several months of the 1-year period and thus unbiased detection frequencies were not calculated for these sites.

Differences in the detectability of the target compounds also must be accounted for if detection frequencies of the compounds are to be compared. For example, a comparison between the detection frequencies for atrazine, with an MDL of $0.001 \mu \mathrm{g} / \mathrm{L}$, and tebuthiuron, with an MDL of $0.01 \mu \mathrm{g} / \mathrm{L}$, would not necessarily reflect the true difference in occurrence of these compounds. Any difference could be due to the tenfold difference in analytical sensitivity. Although detections less than the MDLs were reported, the MDL values give an indication of the relative detectability of the target compounds. To account for these differences, a minimum concentration, or common reporting level of $0.01 \mu \mathrm{g} / \mathrm{L}$, was used for comparisons of the detection frequencies of the 46 compounds. Thus, detection frequencies that are based on the common reporting level represent the proportion of samples in which the concentration of a specific compound equaled or exceeded $0.01 \mu \mathrm{g} / \mathrm{L}$ rather than the proportion of samples in which the compound was detected. Four compounds-disulfoton, prometon, propargite, and terbufos-have MDLs higher than $0.01 \mu \mathrm{g} / \mathrm{L}$, but the reporting of detections less than the MDL moderate this potential bias. Propargite and terbufos have MDLs of $0.013 \mu \mathrm{g} / \mathrm{L}$, which is only slightly higher than the common reporting level of $0.01 \mu \mathrm{g} / \mathrm{L}$. Disulfoton, which has an MDL of $0.017 \mu \mathrm{g} / \mathrm{L}$, was detected in only 
6 samples, all of which had concentrations less than $0.01 \mu \mathrm{g} / \mathrm{L}$. Prometon which has an MDL of 0.018 $\mu \mathrm{g} / \mathrm{L}$, was detected in 1,179 samples (U.S. Geological Survey, 1999). However, one-third of the reported concentrations of prometon were less than the MDL; the most commonly reported concentration was 0.01 $\mu \mathrm{g} / \mathrm{L}$. Thus, the detection frequencies reported for the compounds with MDL's greater than $0.01 \mu \mathrm{g} / \mathrm{L}$ are reasonably accurate and comparable with detection frequencies for the other compounds.

\section{Calculation of Total Concentrations}

A total concentration of pesticide compounds was used for many of the analyses done for this report rather than the concentrations of each individual compound. Using the total pesticide concentration allowed basic comparisons to be made among basins with different crop types or land uses and where different pesticides may be used. The total concentration of herbicides, insecticides, or all pesticides in a sample was determined by summing the concentrations of individual compounds. Thus, the total herbicide concentration is defined as the sum of the concentrations of all 27 herbicide and herbicide transformation products included in the target compounds. Similarly, the total insecticide concentration is defined as the sum of the concentrations of all 19 insecticides and insecticide transformation products, and the total pesticide concentration is defined as the sum of the concentrations of all 46 target compounds. Individual compounds that were reported as not detected were assigned concentrations of zero for these sums.

\section{Calculation of Monthly and Annual Median Concentrations}

Uneven sampling frequency (fig. 4) affects the calculation of median concentrations of pesticides. Median concentrations calculated using all samples would be biased high because at most sites more samples were collected during periods of elevated pesticide concentrations. To minimize this bias, monthly median concentrations were calculated for each compound at each site. For months in which no samples were collected at a site, the mean of the median concentrations for the 2 adjacent months was used. For months when only one sample was collected, the concentration in that sample was used as the monthly median concentration. Concentrations that were reported as not detected were given a value of zero. In some cases, this resulted in a monthly median value less than the MDL for a particular compound. Monthly median concentrations also were determined for total herbicides and insecticides and for total pesticides.

For a few of the comparisons made in this report, an annual median concentration was used. Median concentrations for a 1-year period were calculated as the median of the 12 monthly median concentrations. This procedure gives equal weight to samples collected during each month so that the annual median concentration is not biased by the variable sampling frequency used during the year. In addition, using the median of the monthly values, rather than the mean, minimizes the influence of extreme values in the distribution of monthly median values. This method therefore, is a somewhat conservative way of calculating an annual median concentration. Samples were not collected at eight sites during several months of the 1-year period; annual median concentrations, therefore, were not calculated for these sites.

\section{Calculation of Time-Weighted Mean Concentrations}

Similar to median concentrations of a compound, the mean concentration calculated for a specified time interval can be affected by uneven sampling frequency. To minimize this bias, timeweighted mean concentrations were determined in which the concentration reported for a sample is assigned to a time interval that is based on the number of days between that sample and the adjacent samples. The time interval associated with each sample extends halfway to the date of the preceding sample and halfway to the date of the succeeding sample. For example, if samples were collected on May 1, 8 , and 19 , the concentrations reported for the May 8 sample would be assigned to all days from May 5 through May 13. The sum of concentrations assigned to all days during a specified time interval is then divided by the total number of days in the interval to obtain a timeweighted mean concentration. Because of the relatively low sampling frequency during some months at most sites, time-weighted mean concentrations were 
calculated only for the 5-month critical period when samples were collected frequently. By using concentrations for the critical period only, potential errors resulting from concentrations in a sample being assigned to long periods of time are avoided.

The time-weighted mean concentration of a compound can be strongly influenced by a single sample with a high concentration. For example, the highest calculated 5-month time-weighted mean concentration-9.6 $\mu \mathrm{g} / \mathrm{L}$ for cyanazine in Kessinger Ditch in Indiana (whit-kess) — is strongly influenced by one sample collected in May 1993, which contained $160 \mu \mathrm{g} / \mathrm{L}$ of cyanazine. If this sample was not used in the calculation, the time-weighted mean concentration for cyanazine would be $2.1 \mu \mathrm{g} / \mathrm{L}$ for the 5 -month period. However, because each sample is weighted according to the amount of time the sample represents and because sampling usually was more frequent when pesticide concentrations were highest, the timeweighted mean is not as sensitive to extreme values as a simple mean would be, for which all samples would be weighted equally. The time-weighted mean is a useful measure of concentration for assessing sustained exposure of ecosystems and water users to pesticides.

\section{Calculation of Load and Yield}

The load of a compound is the mass of that compound transported in a stream during a specified period. The load can be estimated as the product of the concentration of the compound and the discharge volume of the stream measured at the same location. Daily discharge values were available for each day during the sampling period for nearly all sampling sites. Daily concentration values for the target compounds were obtained by linear interpolation between measured values. The load estimates for most compounds probably are biased low because concentrations that were reported as not detected were given a value of zero in the load calculations and because concentrations were not adjusted for analytical recoveries (table 2). In addition, load estimates for small streams generally are less precise than load estimates for larger streams. This is because of the higher variability in the concentrations of pesticides in most small streams and the generally low probability of sampling at the time of peak pesticide concentrations. In most cases, peak concentrations in small streams probably were not sampled and thus the loads calculated at these sites are biased low. Pesticide loads were calculated for 1-year periods at sites with sufficient sampling and for 5-month critical periods at all sites. Load estimates also were calculated for total pesticides, total herbicides, and total insecticides by summing the concentrations of individual compounds prior to multiplication by the discharge values.

The yield of a target compound is defined as the load of that compound at the sampling site, divided by the area of the drainage basin. For the yield calculations in the report, we assumed that the pesticides entering the streams as a result of use on nonagricultural or nonurban land did not significantly affect the stream load. Yields at agricultural indicator sites were calculated by using the area of agricultural land (excluding pasture) in the drainage basin. Yields at urban indicator sites were calculated by using the area of urban land in the drainage basin. Yields at integrator sites were calculated by using the sum of the areas of agricultural land (excluding pasture) and urban land in the drainage basin. Thus, the yields are estimates of the amount of a pesticide transported in a stream per unit area of agricultural or urban land, or both, in the basin. Estimates of yield are subject to the same uncertainties as are estimates of load.

\section{Graphical Representation of Results}

Boxplots are used in many of the figures in this report to represent the distribution of data for different sites or different target compounds (fig. 5A). In all boxplots in this report, the box part of the figure encompasses data points between the 25th and 75th percentiles of the data, which represents the middle 50 percent of the data. The median of the data (the 50th percentile) is shown as a horizontal line through the box. Vertical lines (whiskers) extend from the box down to the 10th percentile and up to the 90th percentile so that the box and whiskers together represent the middle 80 percent of the data. In some of the boxplots, points below the 10th percentile and above the 90th percentile (extreme values) are indicated by circles. Extreme values are not shown in the figures if the main point is best expressed by showing how the bulk of the data are distributed; but for cases where the extreme values do show an important aspect of the data, the extreme values are included in the plot. Boxplots are useful for visually displaying the form of the distribution of data. For example, in the 

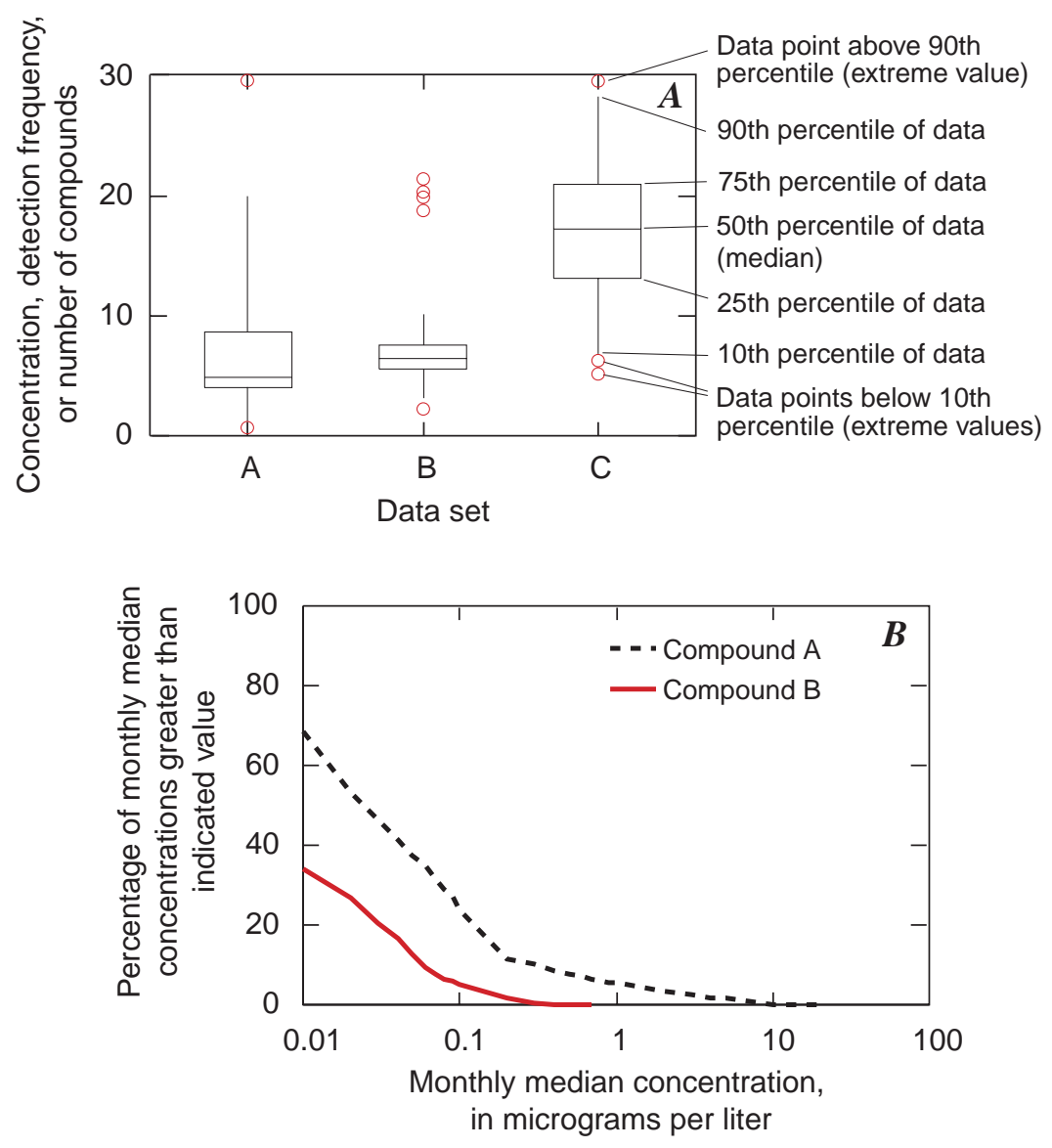

Figure 5. Hypothetical plots as examples of $(\boldsymbol{A})$ boxplots and $(\boldsymbol{B})$ concentration distribution plots. In figure $5 B$, the values on the $y$-axis show the percentage of monthly median concentrations greater than the value indicated on the $x$-axis. For example, 68 percent of monthly median concentrations of compound $A$ were greater than 0.01 micrograms per liter, and 6 percent of monthly median concentrations were greater than 1 microgram per liter.

hypothetical boxplots shown in figure $5 A$, it can be seen that the data represented by plot A are skewed toward the high end, with more than 50 percent of the data less than about 5 and the remainder of the data extending to 30. Plot B represents data in which most observations are tightly distributed between 3 and 10, except for a few much higher values. Plot $\mathrm{C}$ represents data that are uniformly distributed across a relatively wide range.

Concentration distribution plots also are used in this report to represent the distribution of concentrations within a data set (fig. 5B). In this type of plot, a line is used to represent the percentage of values in the data exceeding particular concentrations. The examples in figure $5 B$ illustrate how to interpret the frequency distribution plots. For a given concentration on the $x$-axis, the percentage of monthly median concentrations exceeding that concentration can be read from the $y$-axis. For example, the line representing compound A shows that 68 percent of the monthly median concentrations of compound A exceeded 0.01 $\mu \mathrm{g} / \mathrm{L}$ and 6 percent exceeded $1 \mu \mathrm{g} / \mathrm{L}$. For compound B, concentrations generally were lower, with only about 33 percent of monthly median concentrations exceeding $0.01 \mu \mathrm{g} / \mathrm{L}$ and none exceeding $1 \mu \mathrm{g} / \mathrm{L}$. The information shown in the concentration distribution plots is similar to that shown in the boxplots, except that the entire distribution is shown rather than selected percentiles. The frequency distribution plots are useful for comparing measured concentrations in samples with a concentration of particular interest, such as a water-quality criterion value. 


\section{Land-Use and Pesticide-Use Estimates}

The distribution of land use within the 58 drainage basins included in this study is shown in figure 3. The land-use percentages were derived from U.S. Geological Survey Land Use and Land Cover (LULC) data (U.S. Geological Survey, 1990) stored in the Geographic Information Retrieval and Analysis System, or GIRAS (Mitchell and others, 1977), and from the 1992 Census of Agriculture (U.S. Department of Commerce, 1995). Land-use classes are based on the Anderson Level I classification system (Anderson and others, 1976), except for the class for agricultural land where the Level II classification "cropland and pasture" has been divided into "cropland" and "pasture" on the basis of the proportion of cropland to pasture reported in the 1992 Census of Agriculture. The LULC data are based on aerial photographs from the mid-1970s. These photographs were used to delineate polygons of land use mainly on 1:250,000-scale maps. Both the age of the LULC data and the relatively low resolution are potential sources of error in the land-use estimates used in this report, especially for the small basins. The LULC data, however, are the highest resolution, nationally consistent classification of land use and land cover currently available for the United States. The LULC data for urban areas have been updated by incorporating 1990 U.S. Census Bureau population data (Hitt, 1994). The combination of two data sources (LULC and Census of Agriculture), which differ in both time and resolution, is another source of potential error in the estimates of general land use and in the estimates of crop acreages and pesticide use described below.

Estimates of the amount of land in each basin planted in specific crops (table 4) also were derived from 1992 Census of Agriculture and LULC data. County-level estimates of the harvested acreage of specific crops were available from the Census of Agriculture. Using the LULC data, the amount of cropland and pasture, as defined by the Anderson Level II classification (Anderson and others, 1976), was determined for the land in each county wholly or partly included in a drainage basin. The total county acreage for a specific crop was multiplied by the ratio of cropland and pasture in the part of the county included in the drainage basin to the total cropland and pasture in the county. This provided an estimate of the acreage of a specific crop in the part of the county included in the drainage basin. The values for each county wholly or partly included in the basin were then summed to obtain an estimate of the total amount of land in the drainage basin planted in each crop. The use of the LULC data improved the estimates for crop acreage compared with the use of only the Census of Agriculture county data. The assumption was made that the part of a county included in a drainage basin is representative of the county as a whole in terms of the mix of crops grown. Deviations from this assumption result in an overestimation or underestimation of the acreage for specific crops. The estimates are probably more accurate for large basins than for the small basins because the large basins generally contain larger portions of counties or whole counties.

The estimates of the amount of land planted in specific crops are based on harvested acreage; thus not all the land identified as cropland in figure 3 is accounted for in the crop acreage estimates. Fallow land, land planted in cover crops or soil improvement crops, land on which crops failed, and land that is part of the Conservation Reserve Program (CRP) are examples of croplands that are not included in the estimates of crop acreage in the basins. Because nearly all agricultural pesticide use occurs on land where crops are harvested, the estimates of crop acreage provide a useful basis for comparison among the basins in this report.

Estimates of pesticide use in the drainage basins were derived from data compiled by the National Center for Food and Agricultural Policy (NCFAP) (Gianessi and Anderson, 1996) and from estimates of crop acreage described above. For each state, NCFAP estimated the percentage of acres treated with specific pesticides for 87 agricultural crops. NCFAP combined these values with estimates of the mass of each pesticide applied per acre for each of the crops to obtain an average use coefficient, by state, for each pesticide/ crop combination. NCFAP applied these state-based use coefficients to county-level estimates of crop acreages from the 1992 Census of Agriculture to obtain estimates of the amounts of specific pesticides used within each county in the conterminous United States. To obtain estimates for the drainage basins discussed in this report, the amount of cropland and pasture in each whole or partial county included in a drainage basin was multiplied by the appropriate county-level use estimate for each pesticide. The values for each county were then summed. 


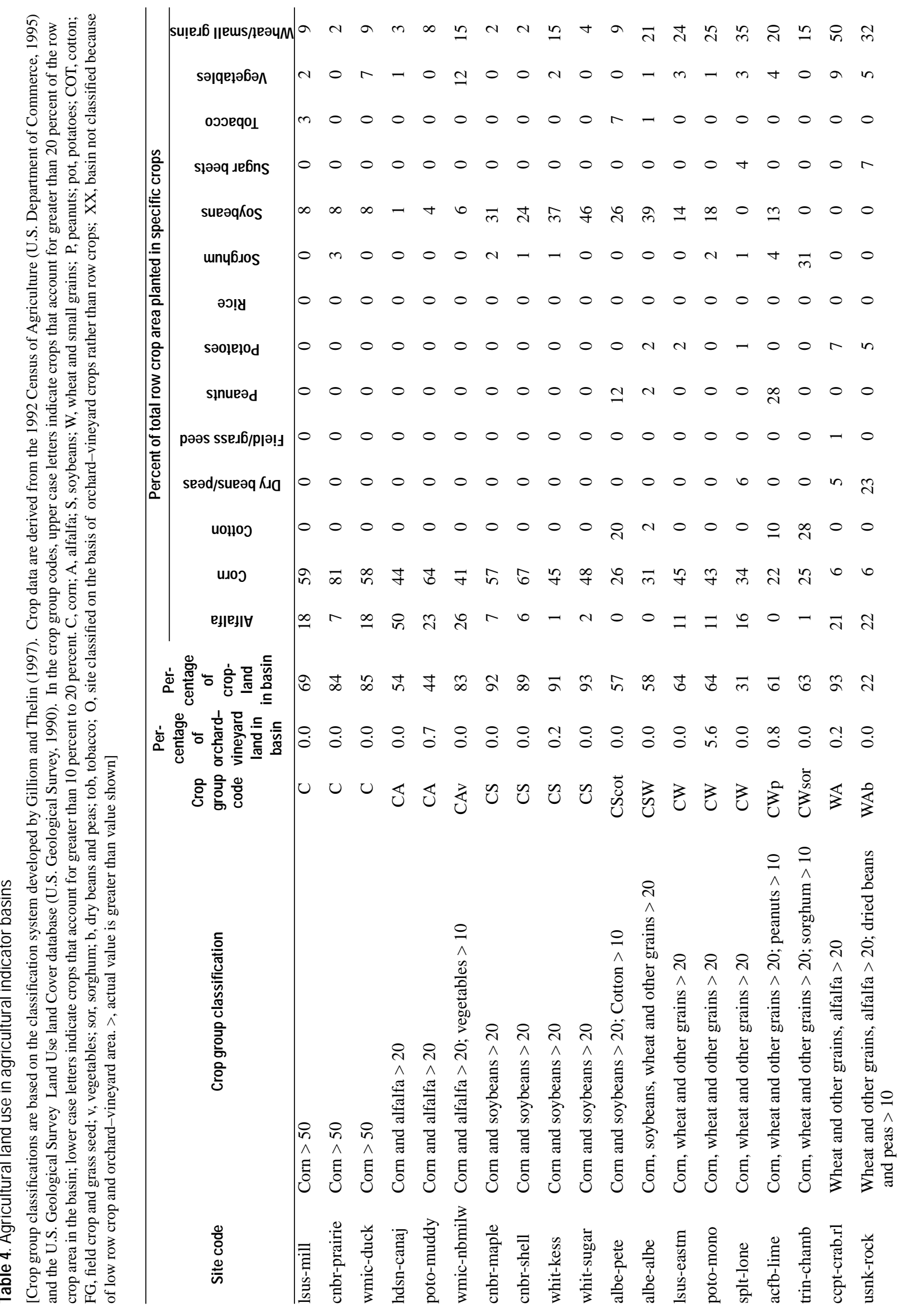




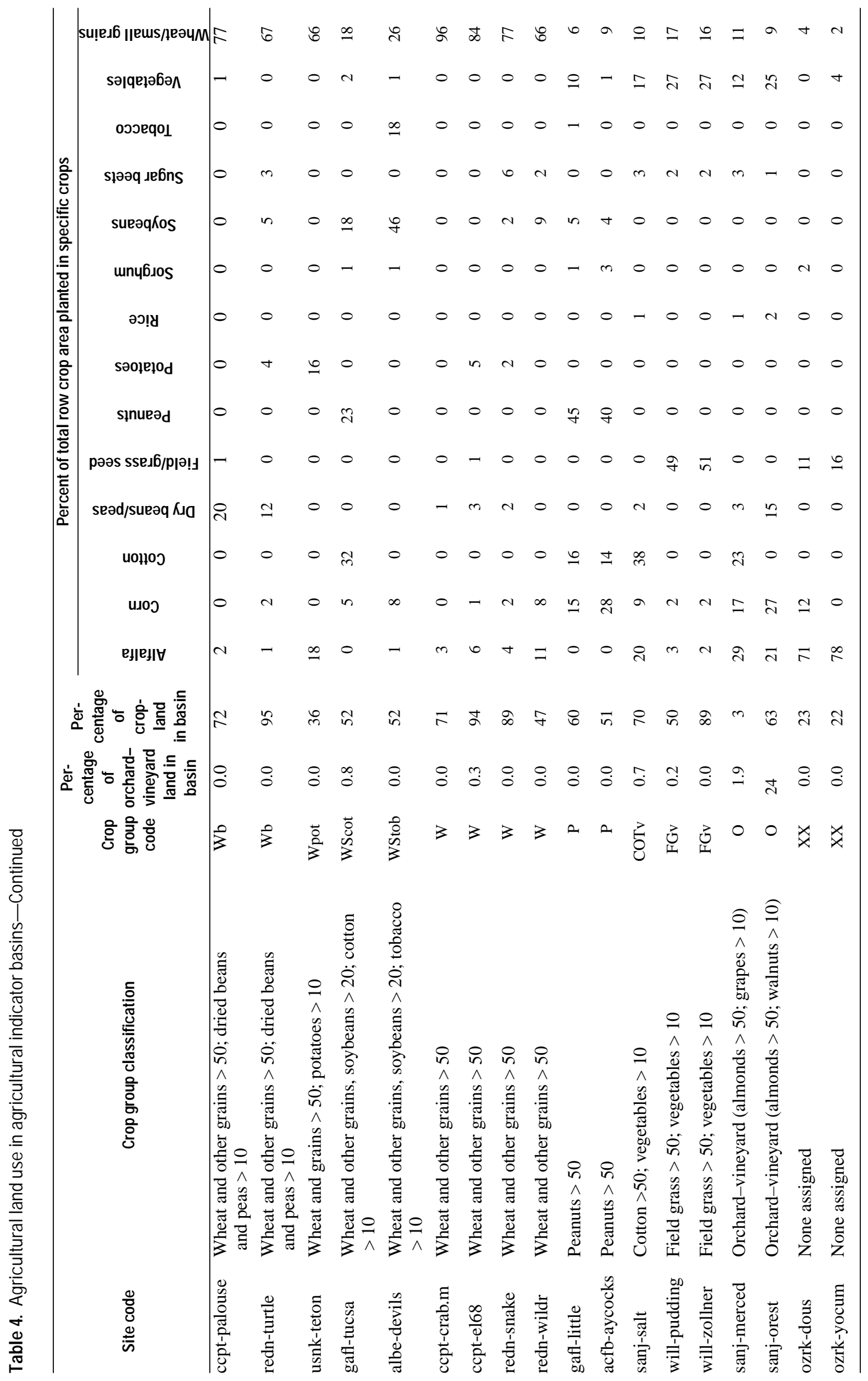

27 Pesticides in Streams of the United States- Initial Results from the National W ater-Quality Assessment Program 
The pesticide-use coefficients used by NCFAP were based on data obtained from a variety of sources during 1990-93 and 1995. These data can reasonably be applied to 1994 as well and thus the pesticide-use estimates derived from the NCFAP data are applicable to the entire sampling period discussed in this report, but with some limitations.

Several potential sources of error in the pesticide-use estimates should be noted. First, the estimates are for pesticide use on agricultural cropland only. Pesticide applications to lawns, gardens, nursery stock, forests, water bodies, rights-of-way, federally owned grazing and pasture land, and other noncropland areas are not included. Seed treatments and postharvest applications of pesticides also are not included.

Second, the use coefficients developed by NCFAP are based on statewide estimates of application and treatment rates, and therefore, local variability in cropping and management practices may not be reflected in the use coefficients. Third, the crop acreages are based on 1992 Census of Agriculture data and thus may not represent acreages during the actual sampling period. Fourth, some crop acreage may not have been included in the Census of Agriculture data because of Census nondisclosure rules. Finally, there may have been changes in the pesticides used and in crop acreage or application and treatment rates in some basins during the 3-year sampling period.

\section{NATIONAL OVERVIEW OF PESTICIDE OCCURRENCE}

A broad overview of national findings provides the context for a more detailed analysis of pesticides in streams in relation to land use, pesticide use, and environmental significance. The national overview addresses which pesticides were detected in streams, how often they were detected, their concentrations, and the seasonal patterns in pesticide occurrence.

\section{Detection Frequencies}

The annual mean detection frequencies for all the target compounds at 50 of the 58 sampling sites are shown in figure 6 . The 50 sites include 33 agricultural indicator sites, 10 urban indicator sites, and 7 integrator sites. For the other eight sites, sampling was not sufficient during some periods of the year for calculation of a comparable annual mean detection frequency. Each bar in figure 6 represents an estimate

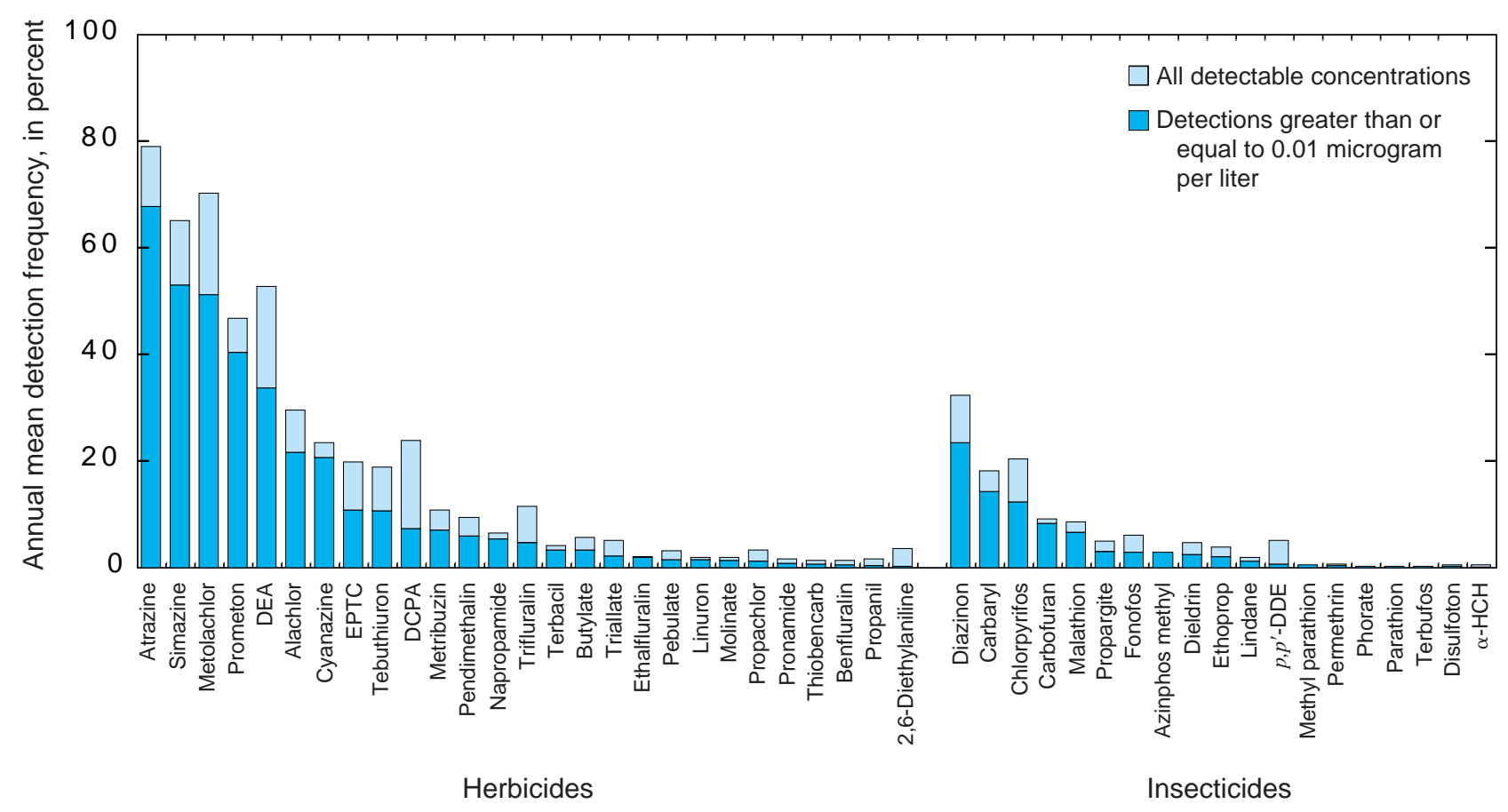

Figure 6. Annual mean detection frequencies of all 46 target compounds at 50 sites during a 1-year period. Detection frequencies at each site were determined as the mean of 12 monthly detection frequencies. For each compound, the detection frequencies at all 50 sites were averaged. 
of the mean of monthly detection frequencies for a 1year period for each of the 50 sites. This is a relatively unbiased estimate of detection frequency for a year because each period of the year is equally represented regardless of the number of samples analyzed during that period. The range of detection frequencies for each pesticide among the 50 sites is shown in figure 7 .

All the target compounds were detected in at least one sample from at least 1 of the 58 streams. Herbicides generally were detected more frequently than insecticides (fig. 6). Among the most commonly detected herbicides were atrazine, metolachlor, alachlor, and cyanazine. These compounds are used extensively in agriculture primarily in the Midwest. The herbicides simazine and prometon also were detected frequently in most basins. Simazine is used in both agricultural and nonagricultural settings throughout the United States. Prometon is used almost entirely in nonagricultural settings (Capel and others, 1999). The insecticides detected most frequently include diazinon, carbaryl, chlorpyrifos, carbofuran, and malathion. With the exception of carbofuran, which is used primarily in agriculture, these compounds are used extensively in both agricultural and nonagricultural settings.

Several pesticides that are used extensively for agriculture on a nationwide basis (see table 2) were detected infrequently at nearly all sites (fig. 7). These pesticides include the herbicides pendimethalin, linuron, propachlor, and propanil and the insecticides

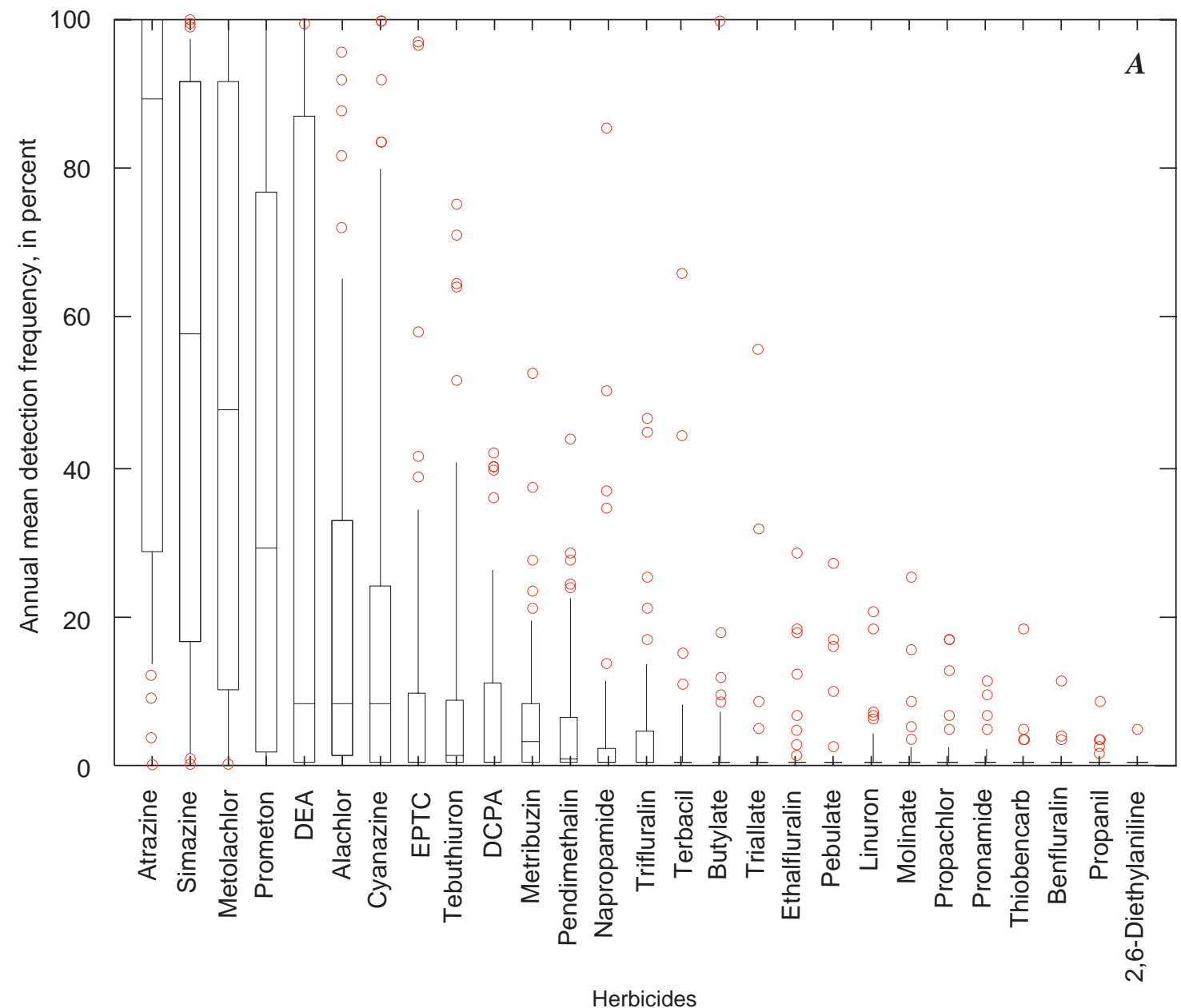

Figure 7. Distribution of annual mean detection frequencies of all target $(\boldsymbol{A})$ herbicides and $(\boldsymbol{B})$ insecticides. Each boxplot represents the distribution of detection frequencies for a specific compound among 50 sampling sites for a 1-year period. A common reporting level of 0.01 microgram per liter was used for calculation of detection frequencies for all compounds. See figure $5 A$ for an explanation of boxplots. 
disulfoton, terbufos, and methyl parathion. Of these compounds, linuron, propachlor, and propanil had low use in all basins in this study. In addition, the physical and chemical properties of most of these compounds and the methods used to apply these compounds for agricultural applications result in a low potential for removal from agricultural fields in runoff (Goss and Wauchope, 1990).

A wide range in detection frequency among sites is evident for many of the pesticides (fig. 7). Detection frequencies for several of the most commonly detected compounds, including atrazine, simazine, metolachlor, prometon, DEA, cyanazine, and diazinon, ranged from zero percent at some sites to 100 percent at others. Some compounds, such as napropamide, terbacil, butylate, and ethoprop, were detected frequently at a few sites but rarely or not at all at other sites. Much of this variability can be attributed to differences in the amounts of these pesticides used in the different basins.

\section{Concentration Ranges}

Distributions of total herbicide and insecticide concentrations at 50 sites are shown in figure 8 .

Monthly median concentrations are used in this plot to minimize the effects of the uneven sampling frequency described earlier. Each line in figure 8 represents values for 600 monthly median concentrations - one value for each month for each of the 50 sites. The plots in figure 8 show the overall distribution of concentrations

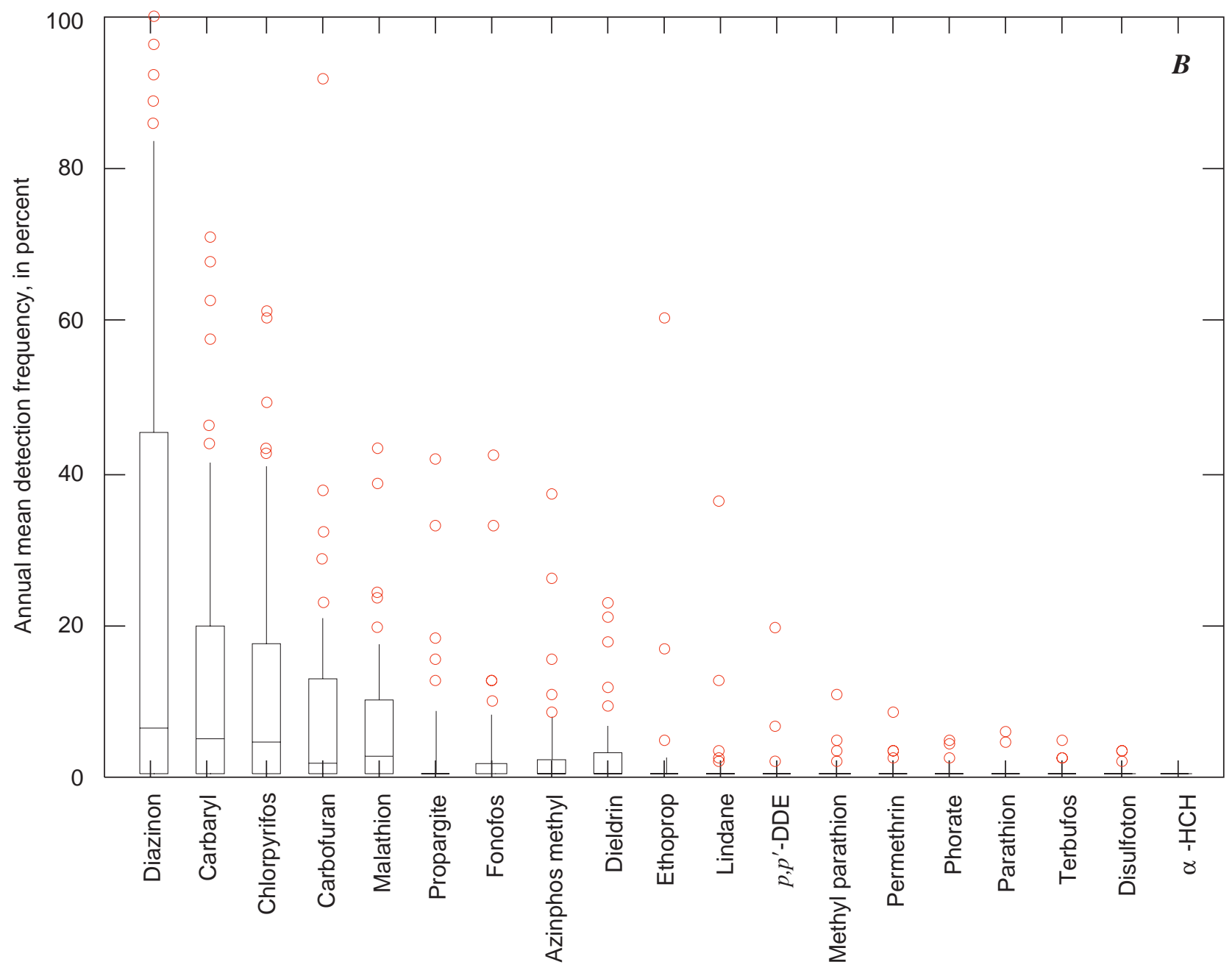

Insecticides

Figure 7.- Continued. 


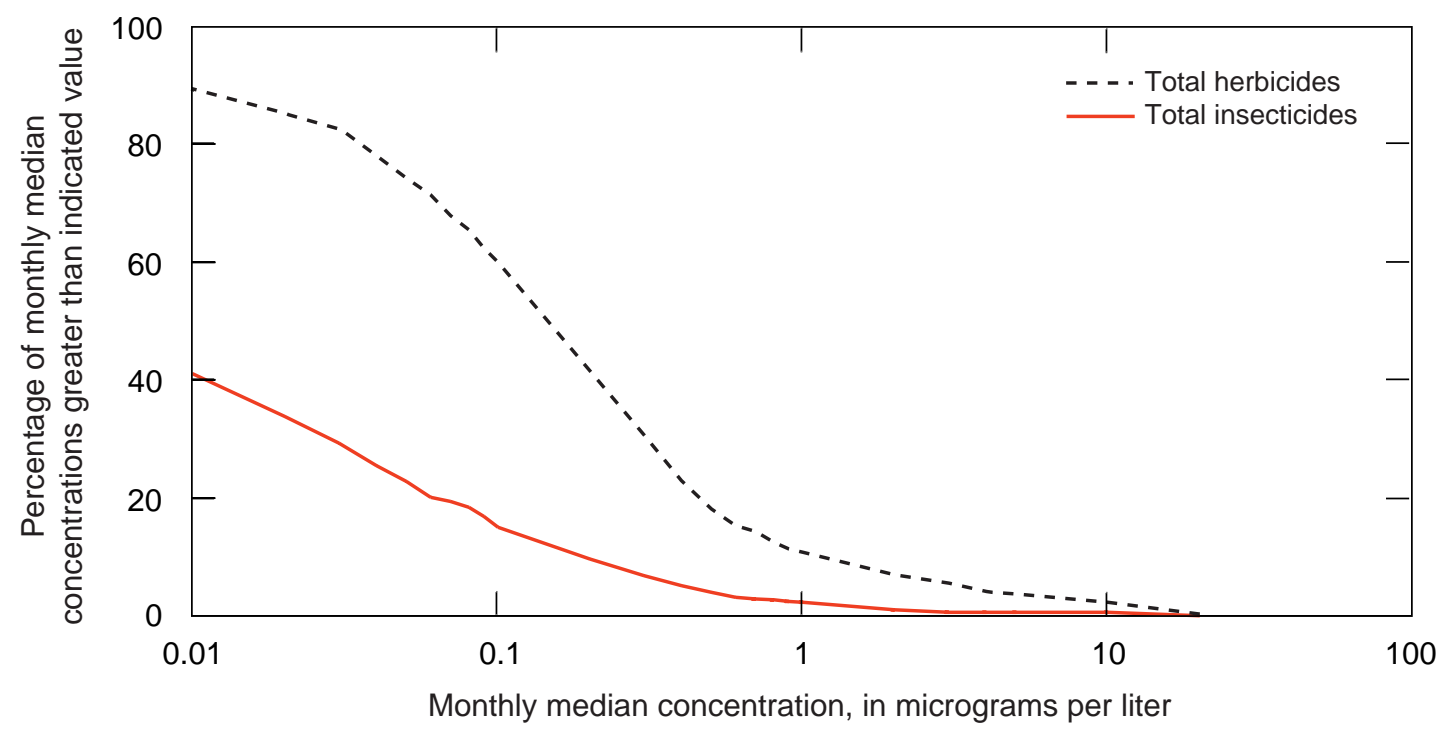

Figure 8. Distribution of monthly median concentrations of total herbicides and insecticides at 50 sites during a 1year period. (See figure $5 B$ and associated text for an explanation of concentration distribution plots.)

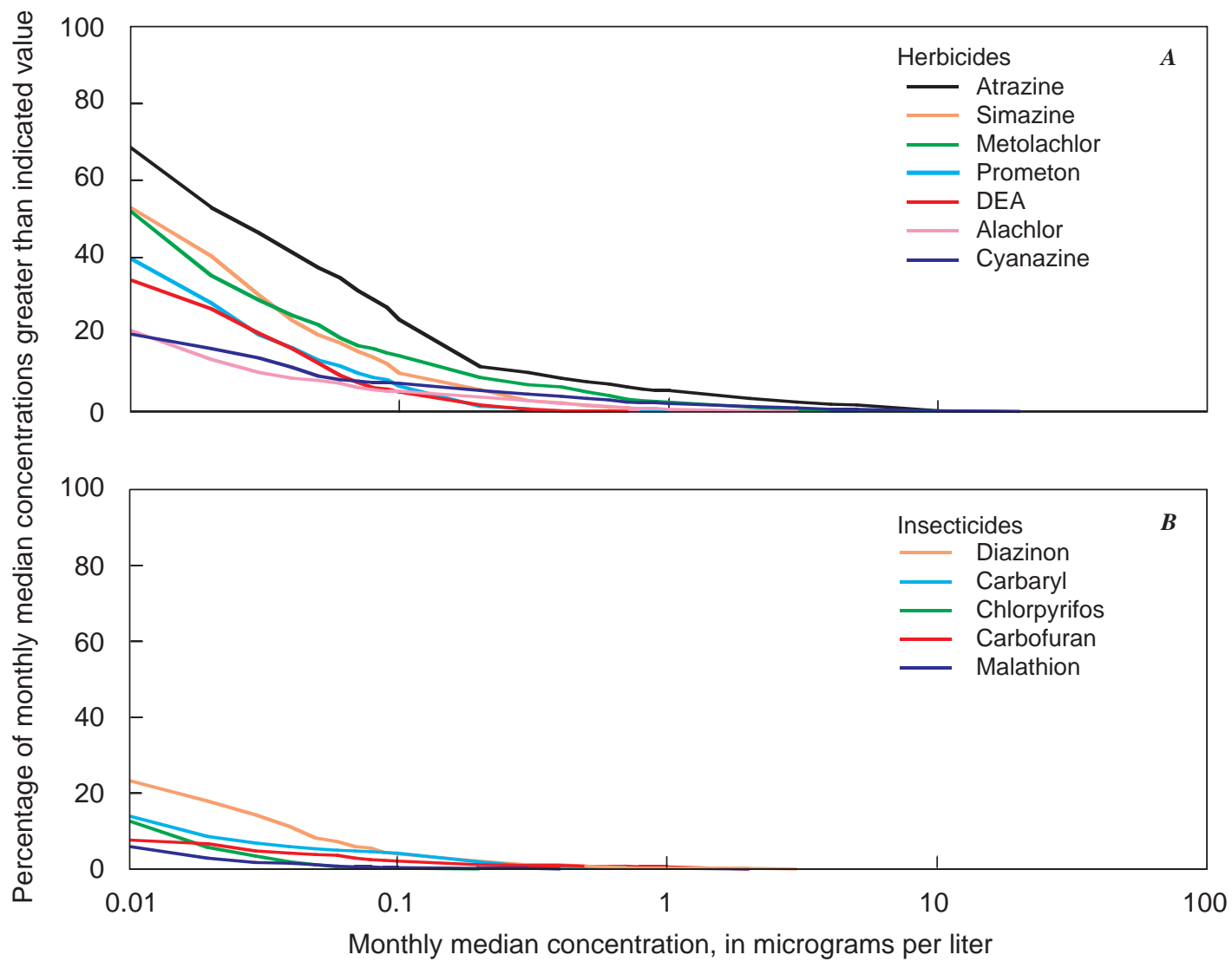

Figure 9. Distributions of monthly median concentrations of $(\boldsymbol{A})$ the seven most frequently detected herbicides and $(B)$ the five most frequently detected insecticides at 50 sites during a 1-year period. (See figure $5 B$ and associated text for an explanation of concentration distribution plots.) 
measured at all three types of sites, although the distributions are most strongly influenced by concentrations at the agricultural indicator sites (33 of the 50 sites).

Herbicides generally were detected at higher concentrations than insecticides. Approximately 90 percent of monthly median herbicide concentrations were greater than $0.01 \mu \mathrm{g} / \mathrm{L}$ compared with about 40 percent for insecticide concentrations. Monthly median concentrations were greater than $1 \mu \mathrm{g} / \mathrm{L}$ about 10 percent of the time for herbicides compared with about 2 percent of the time for insecticides. To help put the concentration levels shown in figure 8 into perspective, aquatic-life criteria values range from 1 to $10 \mu \mathrm{g} / \mathrm{L}$ for most herbicides and from 0.01 to $0.1 \mu \mathrm{g} / \mathrm{L}$ for most insecticides (Canadian Council of Resource and Environment Ministers, 1991; Nowell and Resek, 1994). Because equal weight was given to the samples collected during each month, figure 8 indicates that detectable levels of herbicides were present in samples for most of the year at nearly all sites.

In general, the pesticides detected most frequently (fig. 6) also had the highest concentrations. Monthly median concentrations of the most frequently detected herbicides and insecticides at the 50 sites are shown in figure 9. Again, each of the lines in these plots represents 600 values -12 monthly median concentrations from each site. For the seven most frequently detected herbicides, less than 25 percent of monthly median concentrations were greater than 0.1 $\mu \mathrm{g} / \mathrm{L}$ and less than 6 percent were greater than $1 \mu \mathrm{g} / \mathrm{L}$ (fig. 9A). Atrazine was detected more frequently than any of the other herbicides over the entire concentration range. For the five most frequently detected insecticides, less than 5 percent of monthly median concentrations were greater than $0.1 \mu \mathrm{g} / \mathrm{L}$ and less than 0.1 percent were greater than $1 \mu \mathrm{g} / \mathrm{L}$ (fig. $9 B$ ). For most of the compounds shown in figure 9, the distribution of concentrations is highly skewed, with

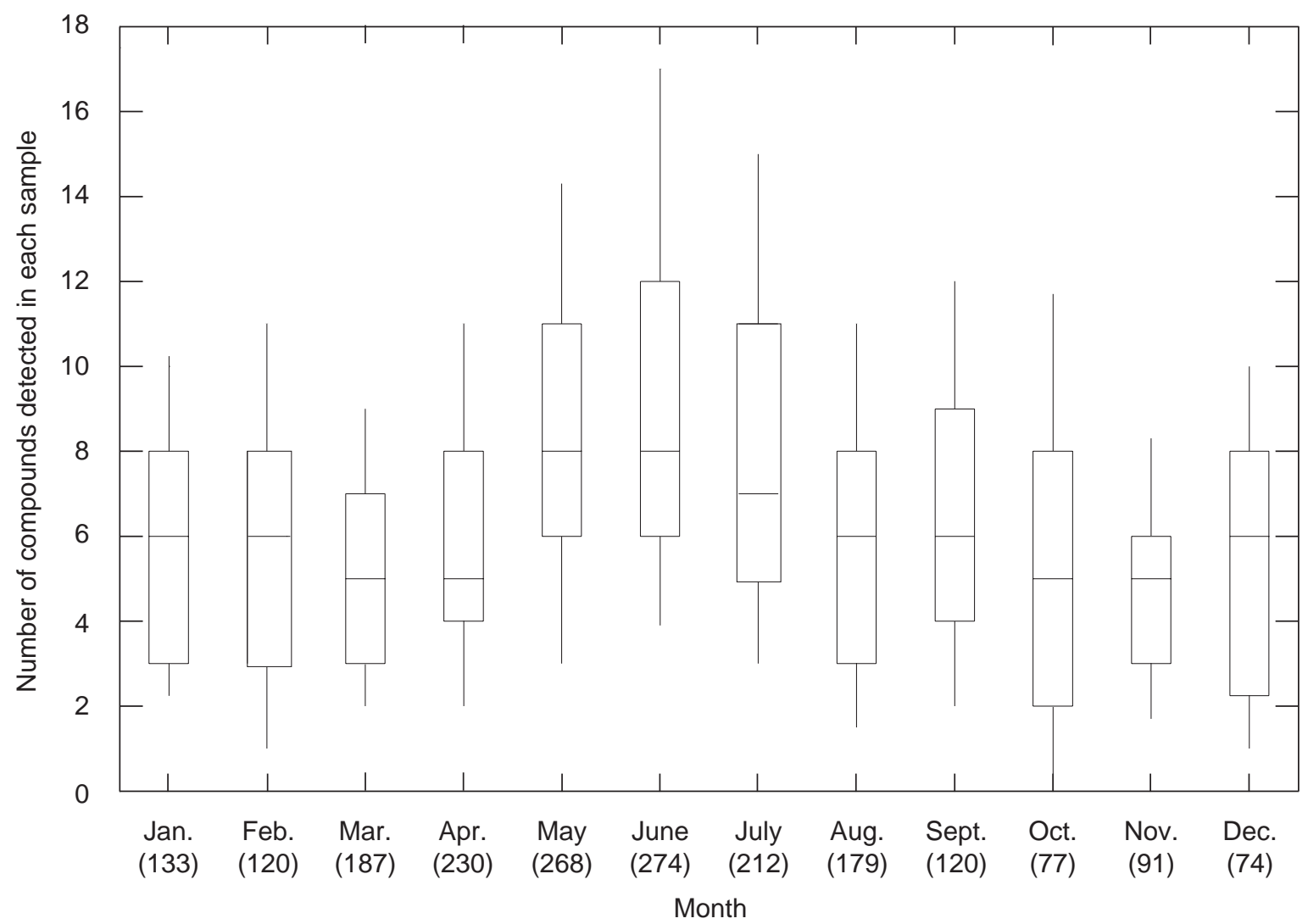

Figure 10. Distribution of the number of different compounds detected in each sample collected from the 58 sites each month during 1993-95. All reported detections were counted (a common reporting level was not used). The total number of samples that were collected during each month is shown in parentheses. (See figure $5 A$ and associated text for an explanation of boxplots.) 
low concentrations occurring most of the year and elevated concentrations occurring only as seasonal pulses.

\section{Seasonal Patterns}

Seasonal patterns in pesticide occurrence were evident at nearly all sites. More compounds were detected during May, June, and July than during the rest of the year at most sites (fig. 10). Two to 8 of the target compounds were detected in most of the samples collected during August through April. During May, June, and July, however, most of the samples contained 5 to 12 target compounds, and approximately 25 percent of the samples collected during these 3 months contained more than 11 of the target compounds. Most of the increase in the number of compounds detected in each sample during these 3 months was due to an increase in the number of herbicides detected. In many of the agricultural indicator basins and integrator basins, herbicides are applied during May and early June, and some fraction of the amount applied is transported to surface water in runoff resulting from spring rains or irrigation. This phenomenon is called the "spring flush"; it has been described in several studies, particularly in studies of the Midwest (Thurman and others, 1991; Goolsby and Battaglin, 1993; Schottler and others, 1994).

A similar seasonal pattern also was evident in pesticide concentrations at most sites. Figure 11 shows the distribution of total pesticide concentrations in samples collected at the 58 sites each month of 1993 , 1994, and 1995. Each of the boxplots in figure 11 represents 74 to 274 samples, depending on the month. A higher proportion of samples collected during May, June, and July, and to a lesser extent during August, had elevated total pesticide concentrations compared with

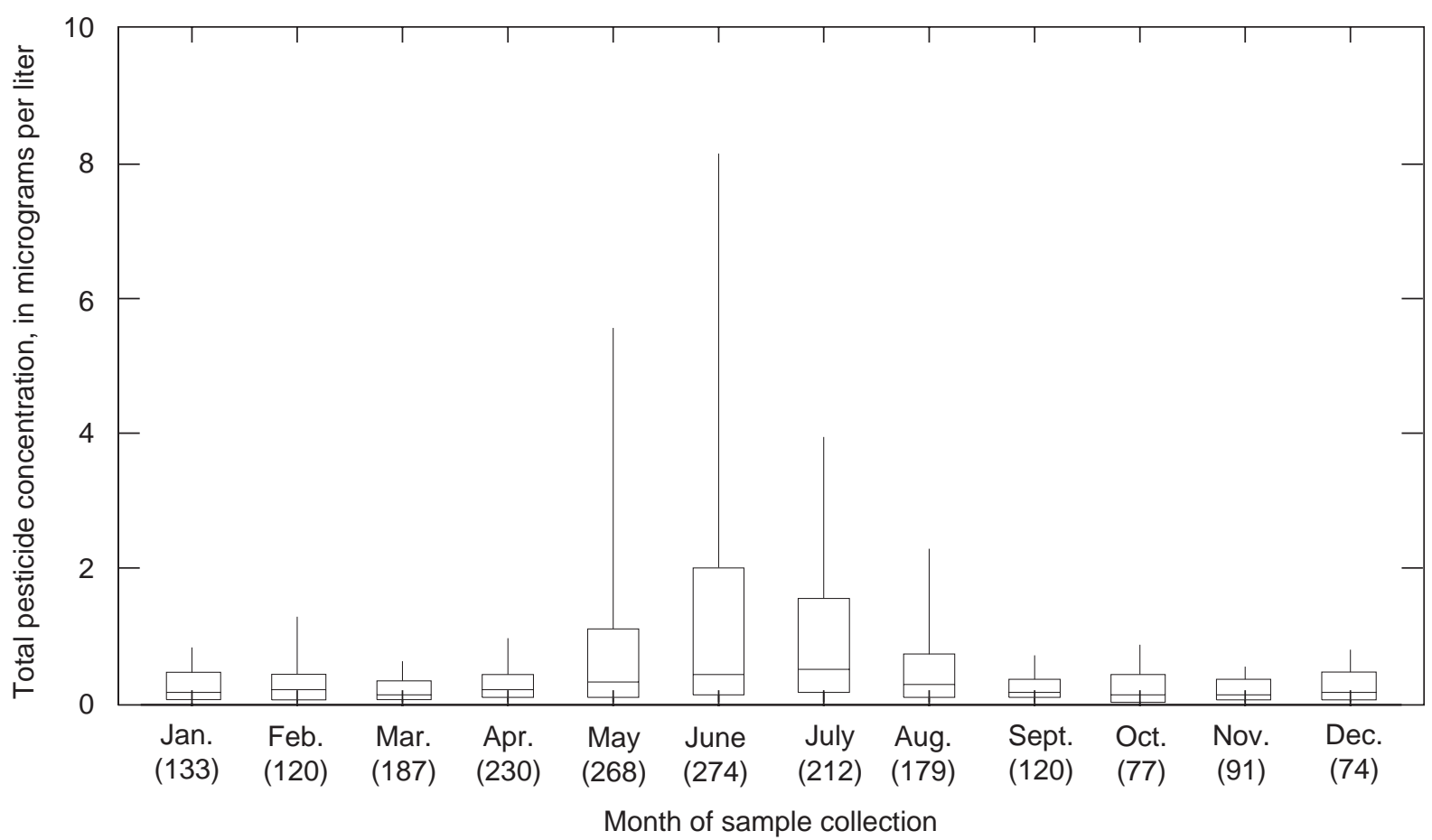

Figure 11. Distribution of total pesticide concentrations in all samples collected from the 58 sites each month during 1993-95. The total number of samples that were collected during each month is show $n$ in parentheses. (See figure $5 A$ and associated text for an explanation of boxplots.) 
the samples collected during the rest of the year.

During these 4 months, total pesticide concentrations were near or greater than $1 \mu \mathrm{g} / \mathrm{L}$ in approximately 25 percent of samples. During May and June, total pesticide concentrations were greater than $5 \mu \mathrm{g} / \mathrm{L}$ in more than 10 percent of samples. During the remainder of the year, total pesticide concentrations were less than $1 \mu \mathrm{g} / \mathrm{L}$ in more than 90 percent of samples.

The use of aggregated data from the 58 sites (fig. 11) conceals some differences in seasonal patterns among the sites. At some sites, the highest pesticide concentrations were measured during autumn or winter. At many of the urban indicator sites, the seasonal pattern was less obvious, with elevated pesticide concentrations occurring for a longer period. These different seasonal patterns are obscured in figure 11 because of the large number of sites that exhibit the spring flush phenomenon. Seasonal patterns observed at the different types of sites will be discussed in more detail in the next section.

\section{EFFECTS OF LAND USE ON OCCURRENCE OF PESTICIDES IN STREAMS}

The use of most pesticides is directly related to land use. The largest amounts of pesticides are used on agricultural land, with different combinations of chemicals used on different crops and in different climates. The total amount of pesticides applied in urban areas is less than the total amount applied in agricultural areas, but urban pesticide use is often more intensive than agricultural use in terms of the amount applied per unit area. Little or no pesticides are applied to undeveloped land. Thus, understanding the relation between land use and pesticide use is key to evaluating the causes of pesticide occurrence in streams.

\section{Ovenview}

A mixture of the target compounds was present in most samples from the three types of sites. The number of different compounds detected at most of the

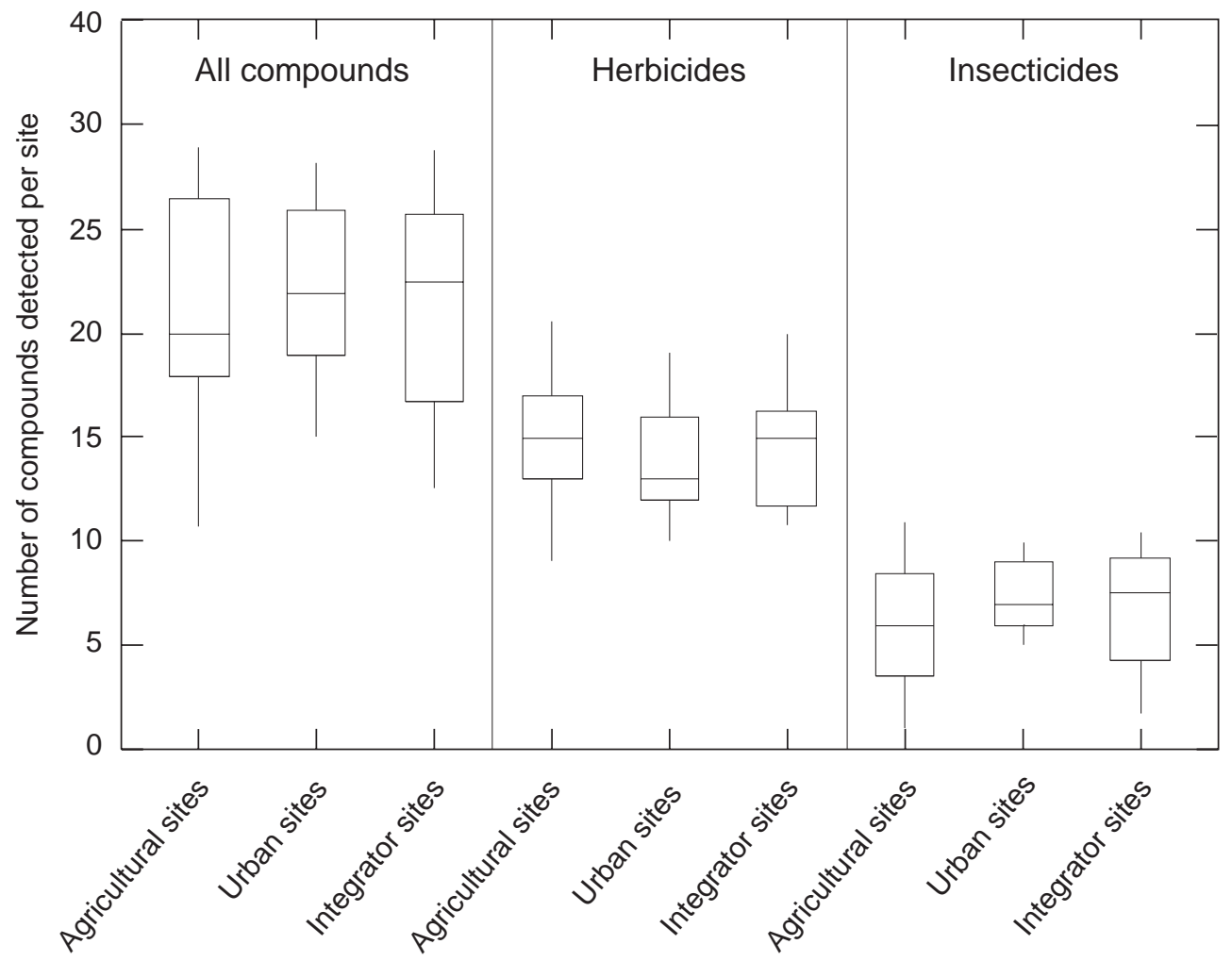

Figure 12. Distribution of the number of compounds detected at each site for each of the three types of sites. Detections at any concentration are included for all samples collected at all 58 sites during 1993-95. (See figure $5 A$ and associated text for an explanation of boxplots.) 
agricultural and urban indicator sites and at most of the integrator sites was similar (fig. 12). Between 17 and 26 of the target compounds were detected at most of the sites, including 13 to 17 herbicides and 3 to 8 insecticides. A number of different compounds were detected at all sites, but the number varied considerably among the sites of a particular type. Variability was greatest among the agricultural sites, with the number of detected compounds ranging from 7 to 37 (U.S. Geological Survey, 1999). This wide range is to be expected because of the variety of different crops represented by the agricultural sites. In addition, pesticides not included in the target compounds are used extensively in some of the agricultural basins (table 3). At some of these sites, the number of compounds detected in the streams may have been relatively low because the pesticides that had the highest use in the drainage basin were not targeted in this study. The number of detected compounds at the 11 urban sites ranged from 11 to 29 , which was smaller than the range for the agricultural sites, and the number of detected compounds at the 10 integrator sites ranged from 10 to 33 (U.S. Geological Survey, 1999).

Because of the seasonal nature of both pesticide use and the occurrence of pesticides in streams, the number of compounds detected in individual samples from a site usually was much lower than the total number of compounds detected at that site. The average number of different compounds detected in each sample from each site is shown in figure 13. The values shown in figure 13 were adjusted to account for differences in the number of samples collected at each site and for the uneven sampling frequency at most sites. Thus, these values are estimates of the average number of compounds that would be detected in samples collected at even intervals throughout the year. At most of the agricultural sites, an average of 3 to 8 of the target compounds were detected in each sample, including 3 to 7 herbicides and 0 to 1 insecticide. At most urban sites, an average of 5 to 8 compounds were detected in each sample, including 3 to 6 herbicides and 1 to 2 insecticides. At most integrator sites, an average of 5 to 8 compounds were detected in each

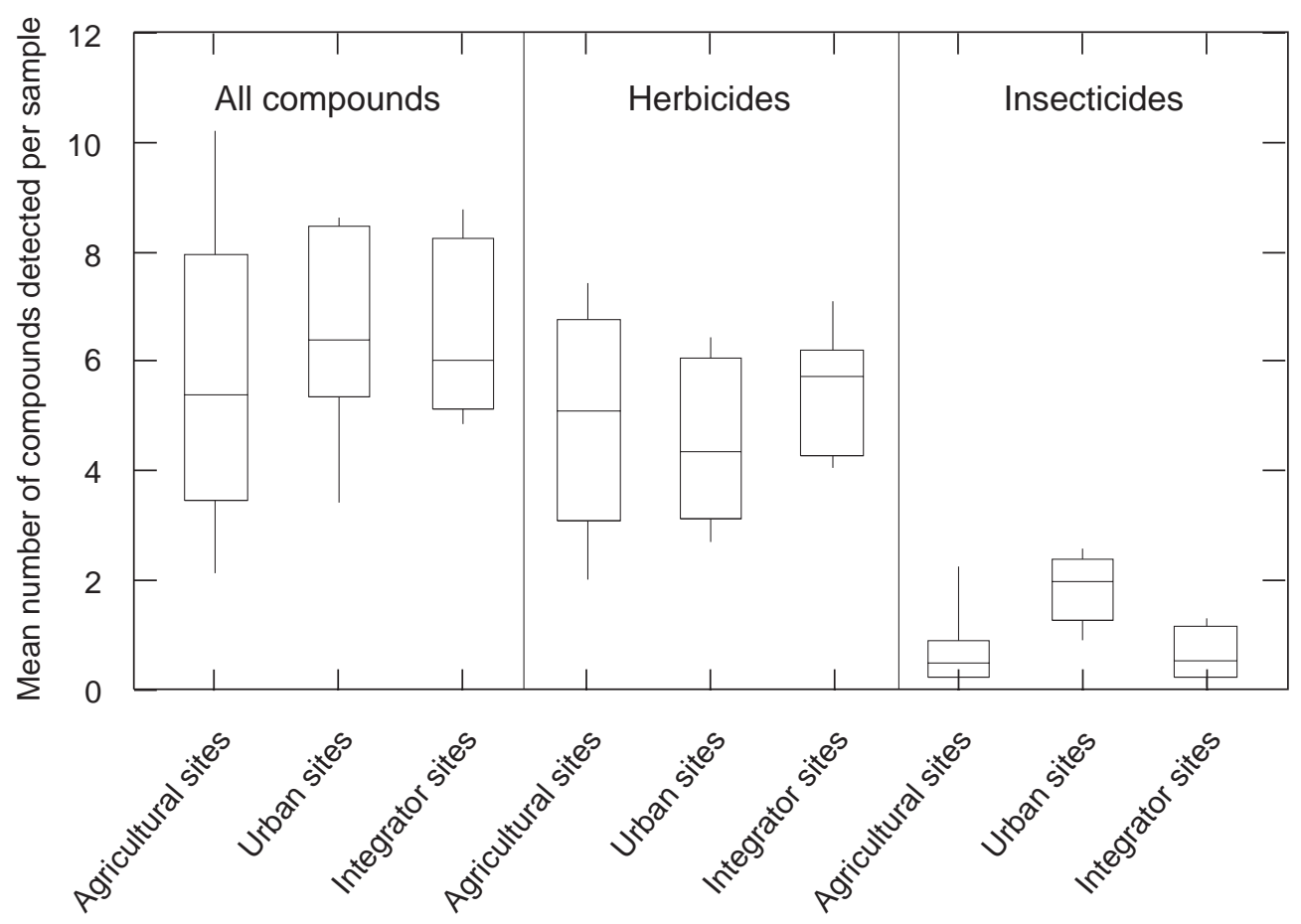

Figure 13. Distribution of the mean number of compounds detected in each sample for each of the three types of sites. Detections at any concentration are included for all samples collected at all 58 sites during 1993- 95. For each site, the mean number of compounds detected in each sample was determined for each month, and the mean of these monthly values was used as the value for that site. (See figure $5 A$ and associated text for an explanation of boxplots.) 
sample, including 4 to 6 herbicides and 0 to 1 insecticide. Similar to the number of compounds detected at each site, the variability in the number of compounds detected in each sample was greatest at the agricultural sites. The average number of compounds detected in each sample from the agricultural sites ranged from less than 1 to more than 13 compared with an average of 3 to 9 compounds at the urban sites and 4 to 10 compounds at the integrator sites (U.S.

Geological Survey, 1999).

\section{Detection Frequency}

Overall detection frequencies of all target compounds are shown for each of the three types of sites in figure 14. The range of detection frequencies for the most commonly detected herbicides and insecticides among sites in each group is shown in figure 15 . As in figure 6 , the detection frequencies in both figures 14 and 15 are unbiased with respect to sampling frequency and are based on a common reporting level of $0.01 \mu \mathrm{g} / \mathrm{L}$.

In general, the same compounds were detected at all three types of sites, but at different frequencies. The agricultural and the integrator sites were very similar in terms of which pesticides were detected (fig. $14 A, C)$, but the detection frequencies at the integrator sites were slightly higher. This was expected because the integrator basins generally are larger and have a wider variety of crops and other land uses than most of the agricultural basins and because high-use pesticides are applied in nearly all of the integrator basins. Use of some of the high-use compounds was low (or zero) in some agricultural basins, which were chosen to represent specific crops or groups of crops.

Many compounds, including some with relatively high national agricultural use, such as trifluralin, butylate, molinate, phorate, and terbufos, had low detection frequencies at all three types of sites. In terms of the aggregated data for each type of site (fig. 14), annual average detection frequencies were less than 5 percent at all three types of sites for 13 herbicides and 14 insecticides. Most of the compounds with low average detection frequencies, however, were detected frequently at one or a few sites (fig. 7).

Several compounds, including the herbicides prometon, simazine, and tebuthiuron and the insecticides carbaryl, chlorpyrifos, diazinon, and malathion, were detected most frequently at urban sites. Atrazine and metolachlor, herbicides used almost exclusively in agricultural applications throughout most of the United States, also were detected frequently at most urban sites. The frequent detections of these compounds are due, in part, to the presence of some agricultural land in most of the urban basins. These compounds also have been detected frequently in precipitation in the Midwest (Capel, 1991; Wotzka and others, 1994; Goolsby and others, 1997), which is another potential source of these compounds to urban basins.

The boxplots in figure 15 indicate that many of the detection frequencies shown in figure 14 for the combined sites are actually the mean of widely varying values among the sites within each type of site. For example, detection frequencies for atrazine, simazine, metolachlor, and DEA ranged from near zero at some agricultural sites to 100 percent at other sites (fig. 15). For the agricultural and the integrator basins, much of this variability probably is due to large differences in the use of specific pesticides among the basins. The variability in detection frequencies for many of the compounds at the urban sites also may primarily be due to differences in use, but data on nonagricultural pesticide use are not available. Among urban sites, variability of detection frequencies for the compounds most characteristic of urban streams (simazine, prometon, diazinon, carbaryl, and chlorpyrifos) generally is lower than the variability for major herbicides at agricultural sites (fig. 15). This implies that use of these five compounds is relatively consistent among the 11 urban areas compared with the use of major herbicides which is much more variable in the 37 agricultural basins. The agricultural basins represent several agricultural crops and related pest-management situations.

A few compounds were frequently detected at nearly all the sites (fig. 15). Detection frequencies for atrazine were greater than 80 percent at more than onehalf of the agricultural and the urban indicator sites and at more than three-fourths of the integrator sites. Detection frequencies for metolachlor were greater than 50 percent at more than one-half of the agricultural and the integrator sites. Detection frequencies for simazine and prometon were greater than 90 percent at more than one-half of the urban sites and greater than 40 percent at more than one-half of the integrator sites. These high detection frequencies indicate that these compounds are present for much of the year at many of the sampling sites. 
A. Agricultural indicator sites $(\mathrm{n}=33)$

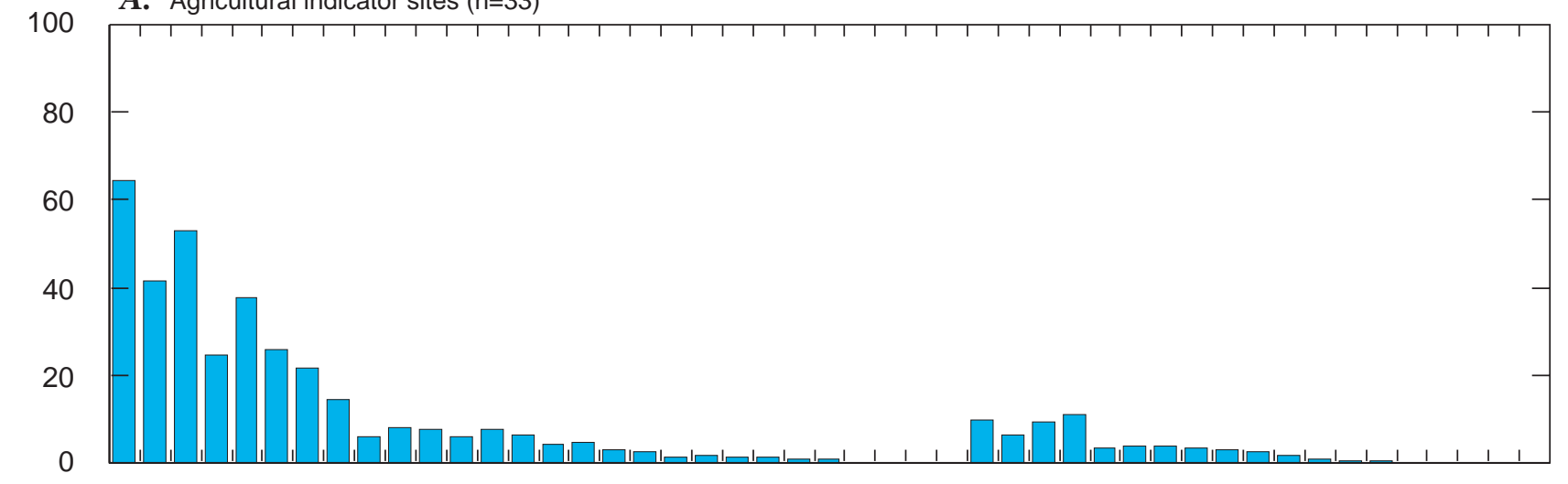

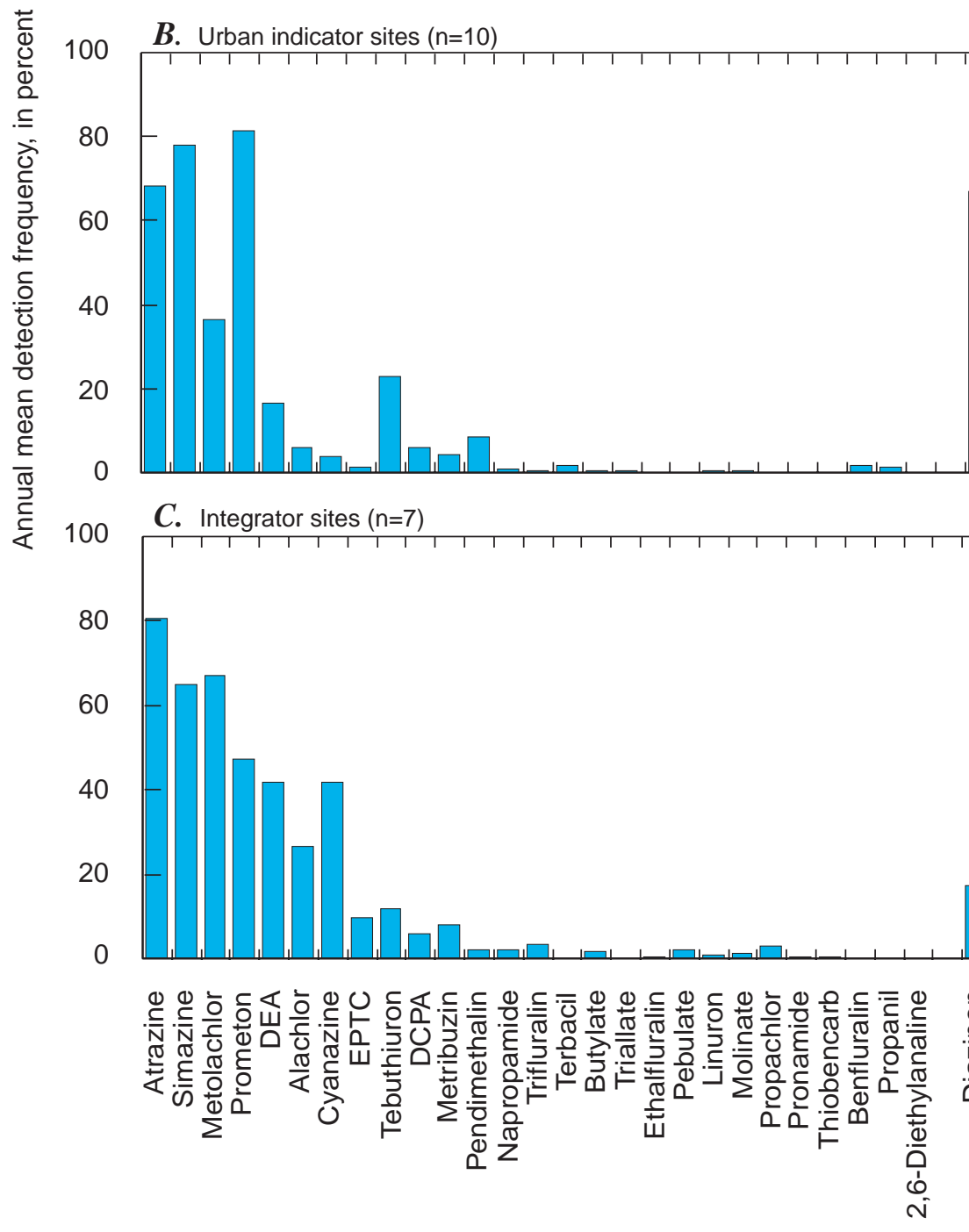

Herbicides

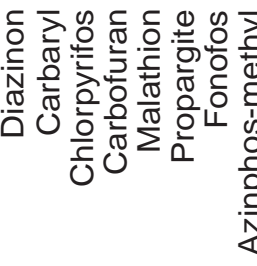

Insecticides

Figure 14. Annual mean detection frequencies for all 46 target compounds for each of the three types of sites during a 1-year period. Each bar represents the mean of the annual detection frequencies for a specific compound at all sites in the group during a 1-year period. Detection frequencies are based on a common reporting level of 0.01 microgram per liter for all compounds. 


\section{Concentrations}

The distributions of monthly median total herbicide and total insecticide concentrations are shown in figure 16 for the three types of sites for a 1year period. The distribution of total herbicide concentrations was similar for all three types of sites (fig. 16A). Approximately 60 percent of monthly median concentrations were greater than $0.1 \mu \mathrm{g} / \mathrm{L}$ and less than 12 percent were greater than $1 \mu \mathrm{g} / \mathrm{L}$. Monthly median concentrations greater than $5 \mu \mathrm{g} / \mathrm{L}$ occurred only at the agricultural indicator sites and the integrator sites, reflecting the relatively high concentrations resulting from the spring flush that occurs at many of these sites.

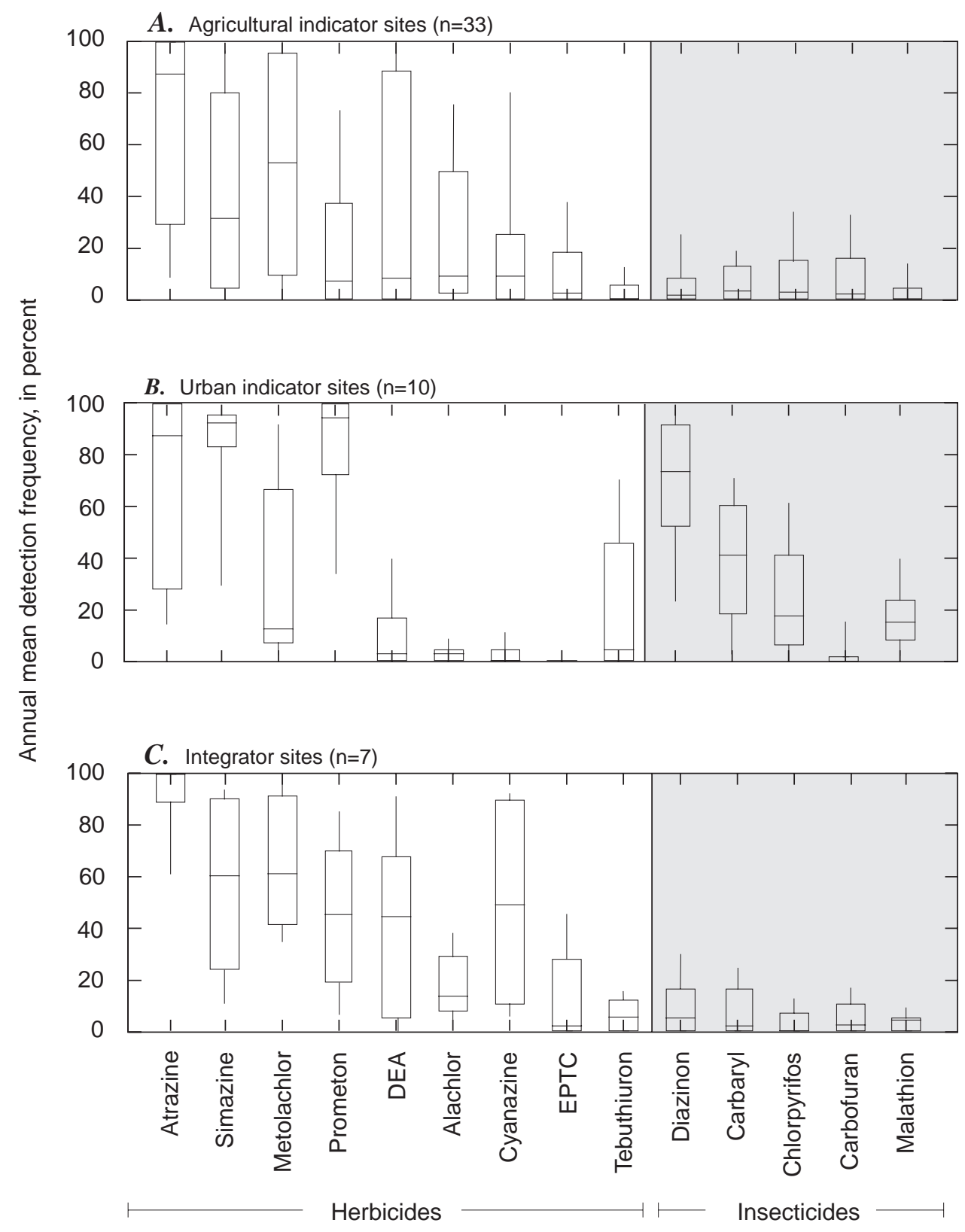

Figure 15. Distributions of annual mean detection frequencies of the most commonly detected compounds for each of the three types of sites. Each boxplot represents the distribution of detection frequencies for a specific compound among the sites in each group during a 1-year period. Detection frequencies are based on a common reporting level of 0.01 microgram per liter for all compounds. (See figure $5 A$ and associated text for an explanation of boxplots.) 
The distribution of total insecticide concentrations for the urban indicator sites was distinctly different from the distributions for the agricultural and the integrator sites (fig. 16B). At the urban sites, nearly 100 percent of monthly median concentrations were greater than $0.01 \mu \mathrm{g} / \mathrm{L}$, indicating that one or more insecticides were detected for most of the year at nearly all the urban sites. In contrast, only about 30 percent of monthly median insecticide concentrations were greater than $0.01 \mu \mathrm{g} / \mathrm{L}$ at the agricultural and the integrator sites. Higher insecticide concentrations also were much more common at urban sites than at agricultural or integrator sites. At the urban sites, approximately 80 percent of monthly median total insecticide concentrations were greater than 0.1 $\mu \mathrm{g} / \mathrm{L}$ and about 10 percent were greater than $1 \mu \mathrm{g} / \mathrm{L}$. At the agricultural and the integrator sites, only about 10 percent of monthly median concentrations were greater than $0.1 \mu \mathrm{g} / \mathrm{L}$, and virtually none were greater than 1 $\mu \mathrm{g} / \mathrm{L}$.

The concentration distribution plots in figure 16 show the general concentration patterns observed for the three types of sites. It is important to note that the median concentrations shown in these plots minimize the influence of extreme values in the distribution of actual concentrations. Maximum total herbicide

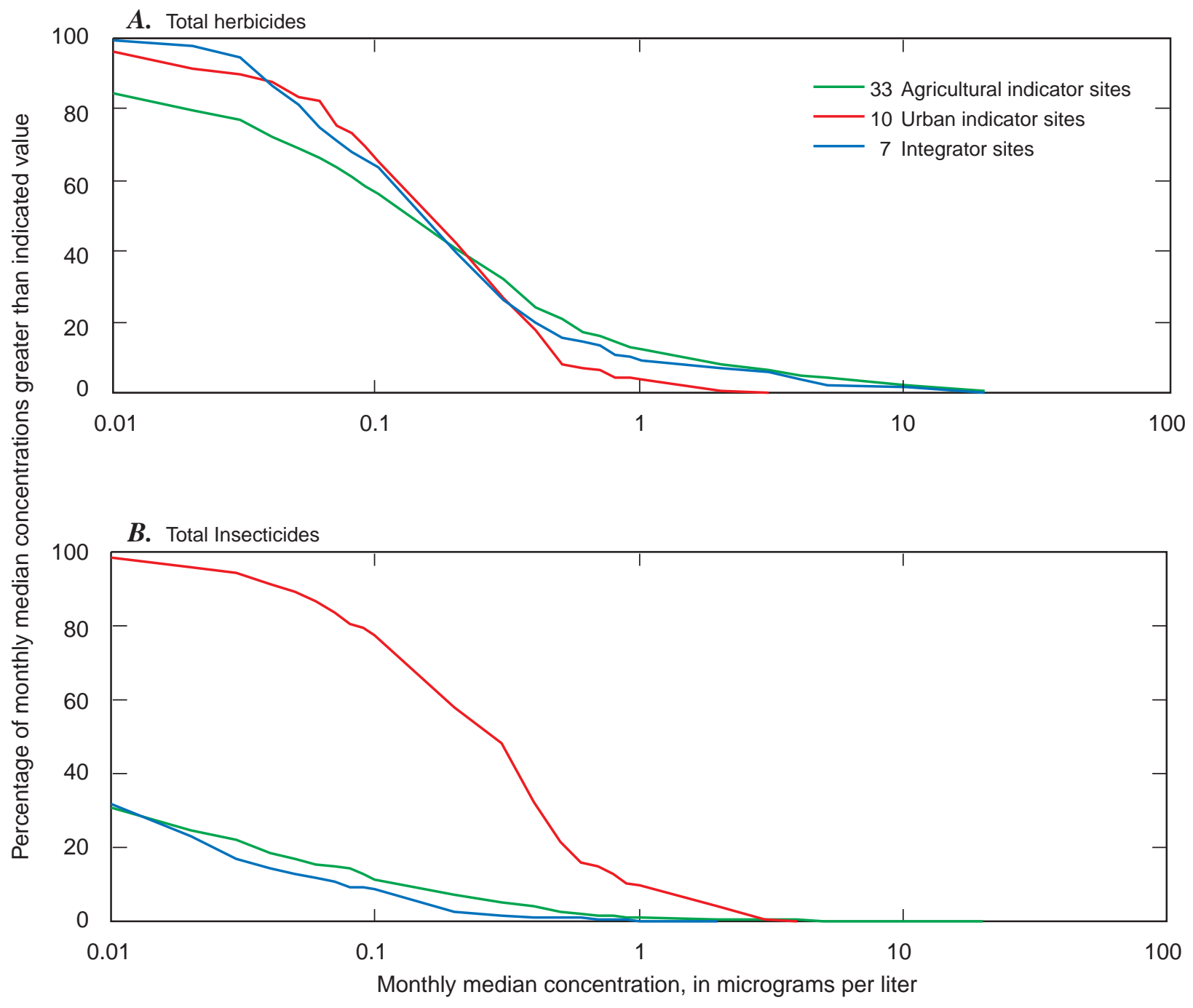

Figure 16. Concentration distribution plots of $(\boldsymbol{A})$ monthly median total herbicide and $(\boldsymbol{B})$ insecticide concentrations for each of the three types of sites during a 1-year period. (See figure $5 B$ and associated text for an explanation of concentration distribution plots.) 
concentrations at some agricultural sites were much higher than is indicated in figure $16 \mathrm{~A}$, with concentrations greater than $10 \mu \mathrm{g} / \mathrm{L}$ common in individual samples at some sites during May and June. In addition, the apparent similarity of herbicide concentrations at the three types of sites shown in figure 16 is somewhat misleading because of the use of monthly median concentrations. Peak concentrations of herbicides at urban sites and at most integrator sites generally were lower than at agricultural sites, but concentrations usually remained elevated for longer periods of time. The concentration distribution plots in figure 16 , which show monthly median concentrations and give equal weight to concentrations for each month, tend to smooth out the differences between the three types of sites. The variability in concentrations among agricultural, urban, and integrator sites is discussed in separate sections of this report.

\section{Seasonal Patterns}

Pesticides concentrations varied seasonally at nearly all the sampling sites, but temporal patterns were most apparent at the agricultural indicator sites and the integrator sites. A critical period was defined for each site (fig. 4) during which both the number of pesticides present and the pesticide concentrations were highest. The average number of compounds detected in individual samples during the critical period and during the rest of the year is shown in figure 17. At most agricultural sites, an average of 4 to 10 compounds were detected in each sample during the 5month critical period compared with 2 to 6 compounds detected in each sample during the rest of the year. At the integrator sites, the difference was slightly less evident, with 6 to 10 pesticides detected in each sample during the critical period compared with 3 to 7 during the rest of the year. At most urban sites, however, there was little difference in the number of compounds

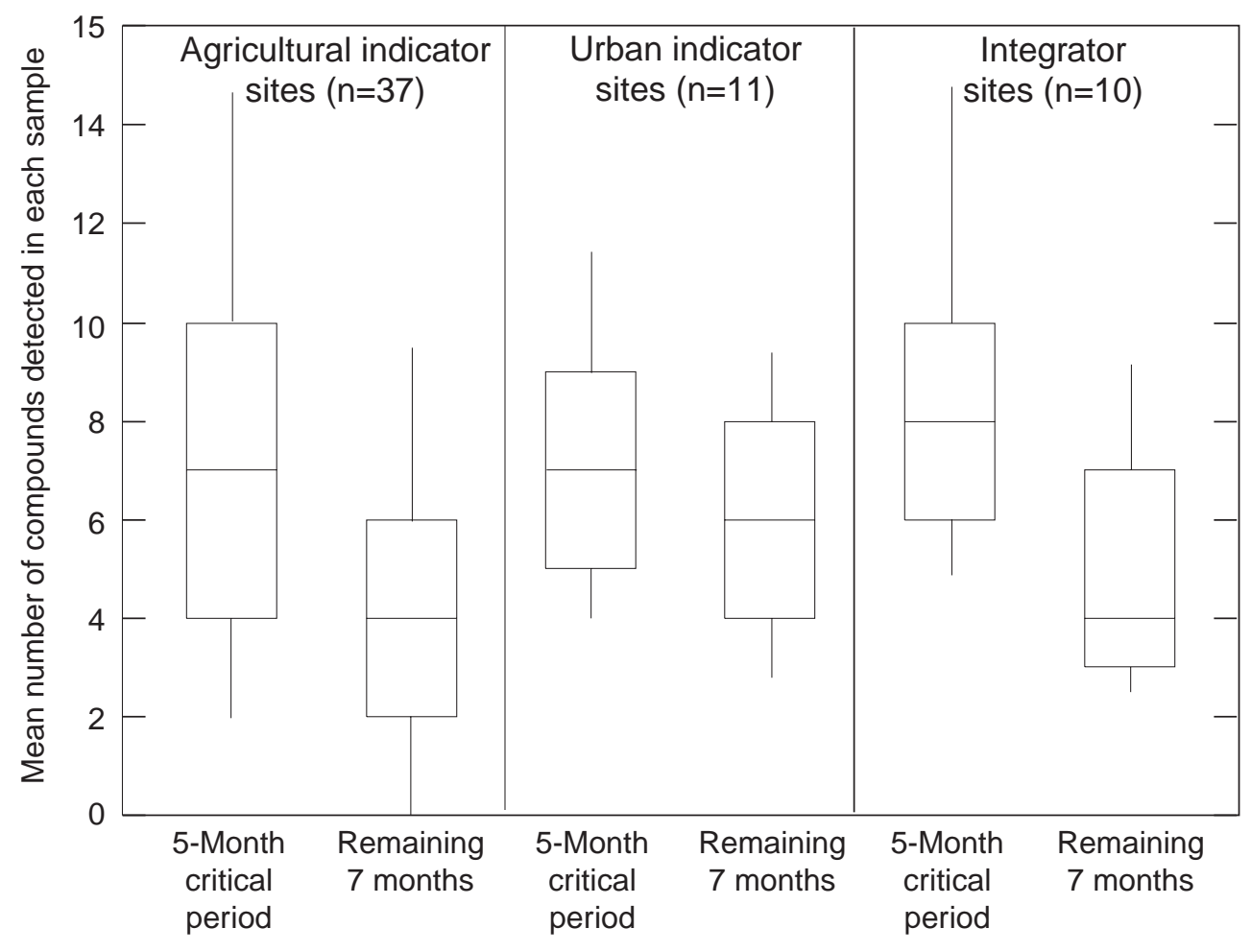

Figure 17. Distribution of the mean number of compounds detected at any concentration in each sample for a 5-month critical period and for the rest of the year for each of the three types of sites. (See figure $5 \mathrm{~A}$ and associated text for an explanation of boxplots.) 
detected in each sample during the critical period and during the rest of the year.

The difference in seasonal patterns among the three types of sites also is evident in terms of concentrations. In figure 18, total pesticide concentrations are plotted for each month for each of the three types of sites. At most agricultural and integrator sites (fig. 18A,C) there was a distinct seasonal peak in herbicide concentrations during May, June, and July, with monthly median concentrations

A. Agricultural indicator sites $(\mathrm{n}=32)$

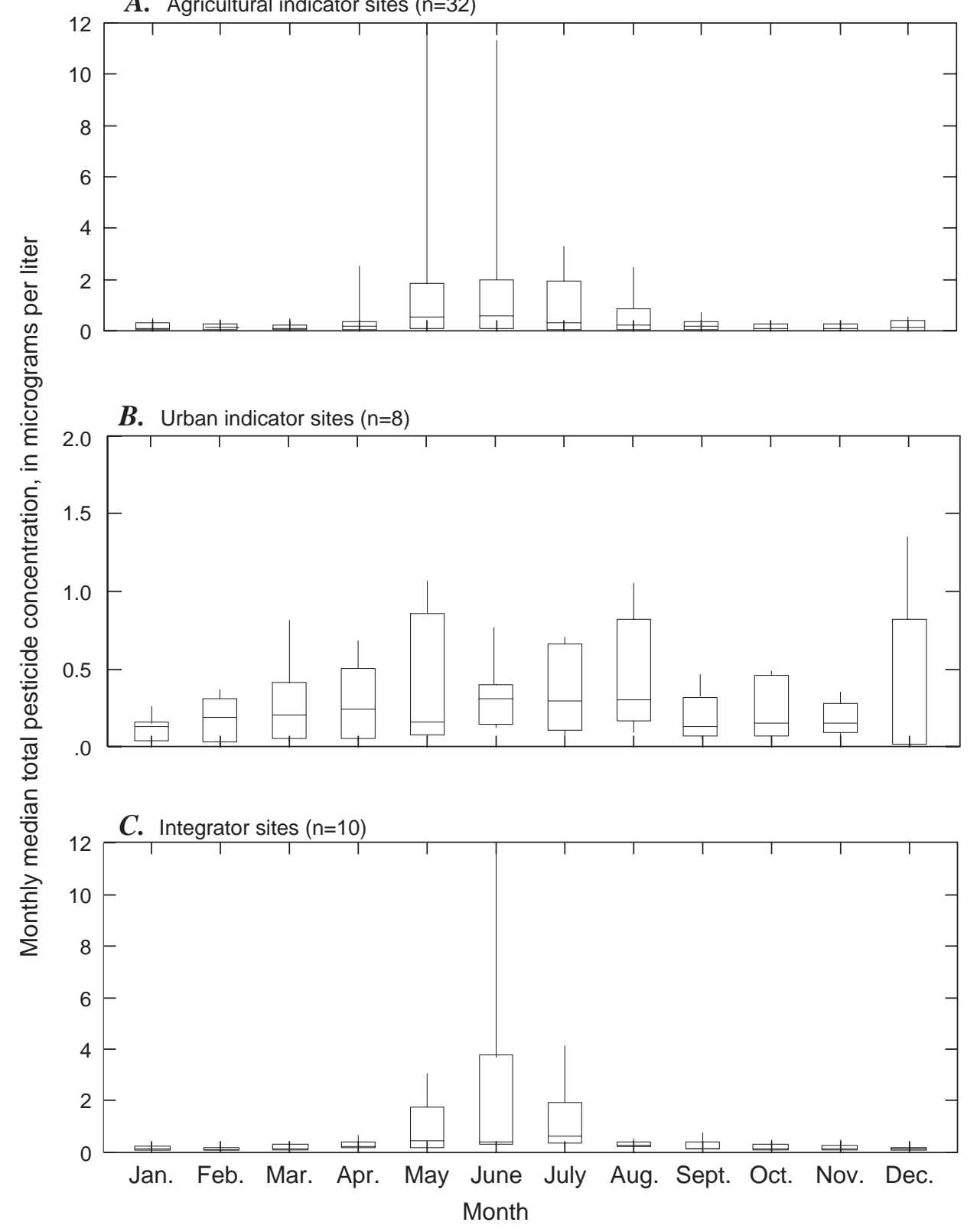

Figure 18. Distribution of median total pesticide concentrations for each month for each of the three types of sites. Each boxplot represents the distribution of monthly median concentrations for 1 month among the sites in each group for a 1-year period. Five agricultural indicator sites (acfb-aycocks, gafllittle, redn-wildr, w mic-duck, w mic-nbmilw ) had insuffic ient sampling during some months and therefore were not included in plot A. Three urban indicator sites (Isus-cedar, trin-rush. whit-little), which had substantial amounts of agricultural land in the drainage basin, were not included in plot $B$. (See figure $5 A$ and associated text for an explanation of boxplots.) 
greater than $10 \mu \mathrm{g} / \mathrm{L}$ at some sites. During autumn and winter, monthly median concentrations were less than $0.5 \mu \mathrm{g} / \mathrm{L}$ at nearly all sites. This pattern was much less obvious at most urban sites (fig. 18B). Although concentrations at some urban sites were elevated from May through August, monthly median concentrations at most sites remained less than $1 \mu \mathrm{g} / \mathrm{L}$ throughout the year. In general, total pesticide concentrations were less variable during the year at the urban sites than at the agricultural and the integrator sites. Three urban indicator sites that have significant portions of agricultural land in their drainage basins-Cedar Run in Pennsylvania (lsus-cedar), Rush Creek in Texas (trin-rush), and Little Buck Creek in Indiana (whitlittle) (see fig. 3); these sites were are not included in figure $18 B$ so that the concentrations shown are primarily the result of urban influences. This restriction is especially important for assessing seasonal patterns
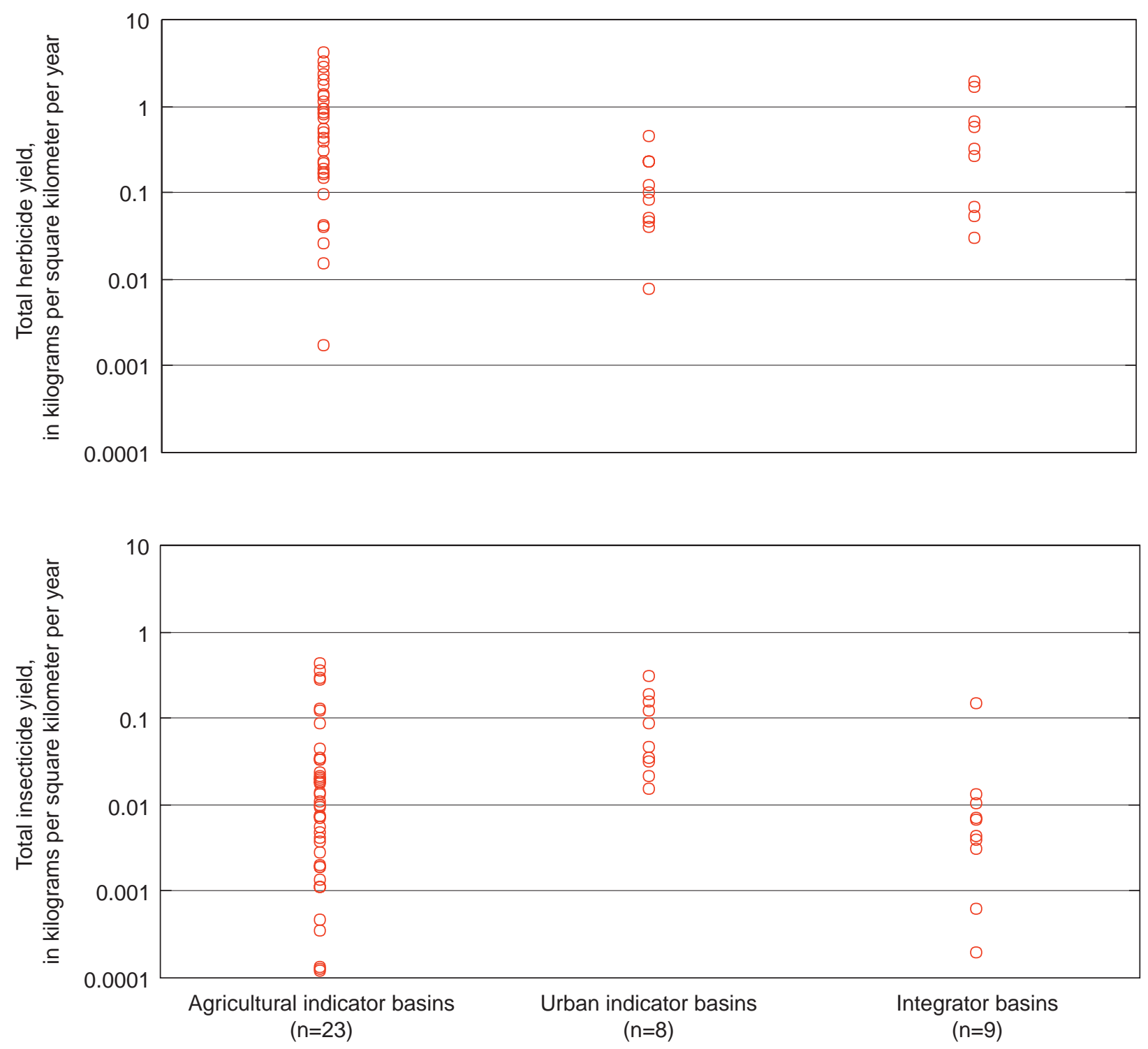

Figure 19. Annual yields of $(\boldsymbol{A})$ total herbic ides and $(\boldsymbol{B})$ insecticides for each of the three types of sites. Yields at agricultural sites were calculated by using the area of agricultural land (excluding pasture) in the drainage basin. Yields at urban sites were calculated by using the area of urban land in the drainage basin. Yields at integrator sites were calculated by using the sum of the areas of agricultural land (excluding pasture) and urban land in the drainage basin. Three urban sites with significant portions of agric ultural land in their drainage basins are not included in these plots. Some agricultural indicator sites and integrator sites also were not included in these plots if the target compounds accounted for less than 50 percent of the total agric ultural use of herbicides or insecticides in the drainage basin (see table 3). 
for urban basins because the concentrations during the spring flush from even a relatively small amount of agricultural land would tend to overwhelm concentrations resulting from urban influences.

\section{Annual Pesticide Yields}

The effects of land use on pesticide occurrence in streams also can be assessed by comparing the yields of pesticides in streams influenced by different land uses. Pesticide yield is defined as the mass of a pesticide (or a selected group of pesticides) transported in a stream for a specific period (load) per unit area of land. Comparisons that are based on yields minimize the influence of differences in stream discharge, which can affect both detection frequencies and concentrations.

Annual total herbicide and total insecticide yields at individual sampling sites are shown in figure 19. The yields varied widely, especially among the agricultural indicator sites. Yields at the agricultural sites ranged more than three orders of magnitude for both total herbicides and total insecticides. Total herbicide yields at most agricultural sites were between 0.01 and $4.1 \mathrm{~kg} / \mathrm{km}^{2} / \mathrm{yr}$, and total insecticide yields generally were about 10 times lower, ranging from about 0.0001 to $0.4 \mathrm{~kg} / \mathrm{km}^{2} / \mathrm{yr}$ (fig. 19). To a large extent, the variability among the agricultural sites can be attributed to differences in the pesticides used on the various crops grown in these basins. This variability is examined more closely in the next section. Variability in weather, soils, and topography among the agricultural sites may also be important factors (Leonard, 1990). In addition, load estimates (and therefore yield estimates) for streams with small drainage basins have greater uncertainty than load estimates for streams with larger basins, a consequence of the relatively short duration of elevated pesticide concentrations and the greater short-term variability in discharge in most of these small streams. The probability of sampling small streams during peak concentrations is lower than the probability of sampling peak concentrations in larger streams because elevated pesticide concentrations in larger streams usually are spread out over longer periods. The range in yields was somewhat smaller for the integrator sites, with values ranging from about 0.03 to $1.9 \mathrm{~kg} /$ $\mathrm{km}^{2} / \mathrm{yr}$ for total herbicides and 0.0002 to $0.15 \mathrm{~kg} / \mathrm{km}^{2}$ / $\mathrm{yr}$ for total insecticides (fig. 19). The integrator sites are considerably larger than most of the agricultural sites, and the estimates of yield for these sites are probably more accurate.

Total herbicide yields at the eight urban sites with little or no agricultural use were between 0.008 and $0.45 \mathrm{~kg} / \mathrm{km}^{2} / \mathrm{yr}$ (fig. 19). This range is at the lower end of the range observed for the agricultural sites. Total insecticide yields at urban sites ranged from 0.015 to $0.31 \mathrm{~kg} / \mathrm{km}^{2} / \mathrm{yr}$, which is at the upper end of the range for the agricultural sites, meaning that total insecticide yields were higher at many of the urban sites than at most of the agricultural sites. This is consistent with the detection frequency and concentration data discussed earlier, which indicated that insecticides are detected more frequently and at higher concentrations in streams draining urban areas than in streams draining many agricultural areas. These data show that, in terms of mass per unit area, the amount of insecticides transported to streams from urban basins exceeded the amount transported from most of the agricultural basins. Compared with agricultural and integrator sites, yields among urban sites were less variable, reflecting a general similarity in pesticide use among different urban areas.

\section{Agricultural Indicator Sites}

The agricultural indicator sites in the NAWQA Program were chosen to represent streams affected by selected agricultural settings; the agricultural sites are defined primarily by specific crops or groups of crops. Comparison of the pesticide levels measured in streams draining basins with different types of agricultural settings can provide information on the relative contribution of different types of agricultural activities to the occurrence of pesticides in streams. An important consideration in making this type of comparison, however, is how much of the pesticide use in a particular basin is accounted for by the target pesticides. Table 3 shows that coverage of total pesticide use by the target compounds varies widely among the agricultural basins. Because the coverage of pesticide use for certain crops, such as corn and soybeans, is more complete than coverage is for other crops, such as wheat or peanuts, certain comparisons are not appropriate. For example, comparisons of total pesticide yields from corn-growing areas and wheatgrowing areas would be biased because the coverage of pesticide use in the corn-growing areas is more extensive. On the other hand, comparisons of the loads 
of individual pesticides as a percentage of their use in the basin are not biased and therefore can provide useful information on the behavior of pesticides in different agricultural settings. In addition, comparisons of detection frequencies and concentrations of pesticides measured at sites representing different crop groups can be made as long as the differences in coverage of pesticide use are considered.

The agricultural sites have been classified according to the major crops grown within the drainage basin (table 4). The classifications for these basins are derived from a national-scale classification of agricultural land in the United States (Gilliom and Thelin, 1997), which uses percentage criteria to define combinations of 1 to 3 crops that account for 50 percent or more of harvested cropland within a county. Crop data used for the classification of the basins in this study are derived from the 1992 Census of Agriculture (U.S. Department of Commerce, 1995) and from the U.S. Geological Survey's Land Use and Land Cover database (U.S. Geological Survey, 1990), as described in the methods section. For most of the basins in this study, the classifications are based on the percentage of harvested cropland planted in specific row crops, such as corn, soybeans, alfalfa, cotton, and wheat and small grains. For two of the agricultural basins in the San Joaquin study unit—Orestimba Creek and the Merced River - orchards and vineyards account for a substantial portion of the agricultural land use in the basin; thus, the classification of these two basins is based on the amounts of specific orchard and vineyard crops grown. No classification was assigned to the two basins in the Ozark Plateaus study unit because the estimates of harvested cropland in these basins account for less than 10 percent of the total basin area and because there is no reported orchard or vineyard acreage. The classifications in Gilliom and Thelin (1997) were developed to account for major crop groups at a national scale. In some cases, the combinations of crops grown in the small agricultural basins included in this study do not fit exactly into any of the categories established in the national classification scheme (for example, Salt Slough in California). In such cases, the site was assigned the category that most closely matched the distribution of crops grown in the basin. In other cases, an important crop in a particular basin was not included in the assigned category (for example, cotton in the Chambers Creek Basin in Texas or peanuts in the Tucsawhatchee Creek Basin in Georgia). With these limitations in mind, the crop-group classifications provide a useful way of organizing the agricultural sites for comparisons of pesticide occurrence in various agricultural settings.

\section{Detection Frequencies}

Herbicides were detected much more frequently than insecticides at most of the agricultural indicator sites (fig. 14A). The most commonly detected herbicides include atrazine, metolachlor, alachlor, cyanazine, and EPTC — herbicides used heavily in corn and soybean growing areas. DEA, a transformation product of atrazine and the herbicides simazine and prometon, which have significant nonagricultural use, also were detected frequently at many of the agricultural sites. The remaining 19 herbicides and all the target insecticides were detected in less than 10 percent of samples at most of the agricultural sites.

Detection frequencies for some compounds varied widely among the agricultural sites (fig. 15). Much of this variability is caused by differences in the amounts of these compounds used in the various agriculture basins. This variability in use is illustrated in figure 20, which shows the amounts of specific compounds used for agriculture in these basins. In figure 20, pesticide use is normalized to basin area to account for differences in basin size. For some compounds, use varies widely. For example, atrazine use exceeded $25 \mathrm{~kg} / \mathrm{km}^{2}$ in 6 basins, but was less than $1 \mathrm{~kg} / \mathrm{km}^{2}$ in 14 basins. Use of metolachlor, alachlor, cyanazine, pendimethalin, and chlorpyrifos also varied widely. Use of terbacil, diazinon, azinphos-methyl, and propargite was relatively high in a few basins but low (or zero) in all others. A few compounds, including the herbicides prometon, tebuthiuron, thiobencarb, and propanil, and the insecticide lindane, had very low (or zero) reported agricultural use in all the agricultural basins.

In general, the relation between detection frequency at the agricultural sites and pesticide use in the basins was significant, but weak. Figure 21 shows the relation between annual detection frequencies and the amount used for agriculture in the basins for all target herbicides and insecticides with reported agricultural use. A general positive relation is evident for both herbicides and insecticides, as most compounds with higher use were detected more frequently in most basins. However, there is considerable variability. For example, detection 
frequencies for herbicides used at rates of 1 to $10 \mathrm{~kg} / \mathrm{km}^{2}$ ranged from 0 to 100 percent. Many compounds with relatively high use were detected infrequently or not at all. Linear regression of the data used in figure 21 shows that only about one-fourth of the variability in detection frequency is accounted for by differences in pesticide use $\left(r^{2}=0.30\right.$ for herbicides and 0.23 for insecticides). For some individual compounds, the correlation between use and detection frequency was somewhat higher, but only two

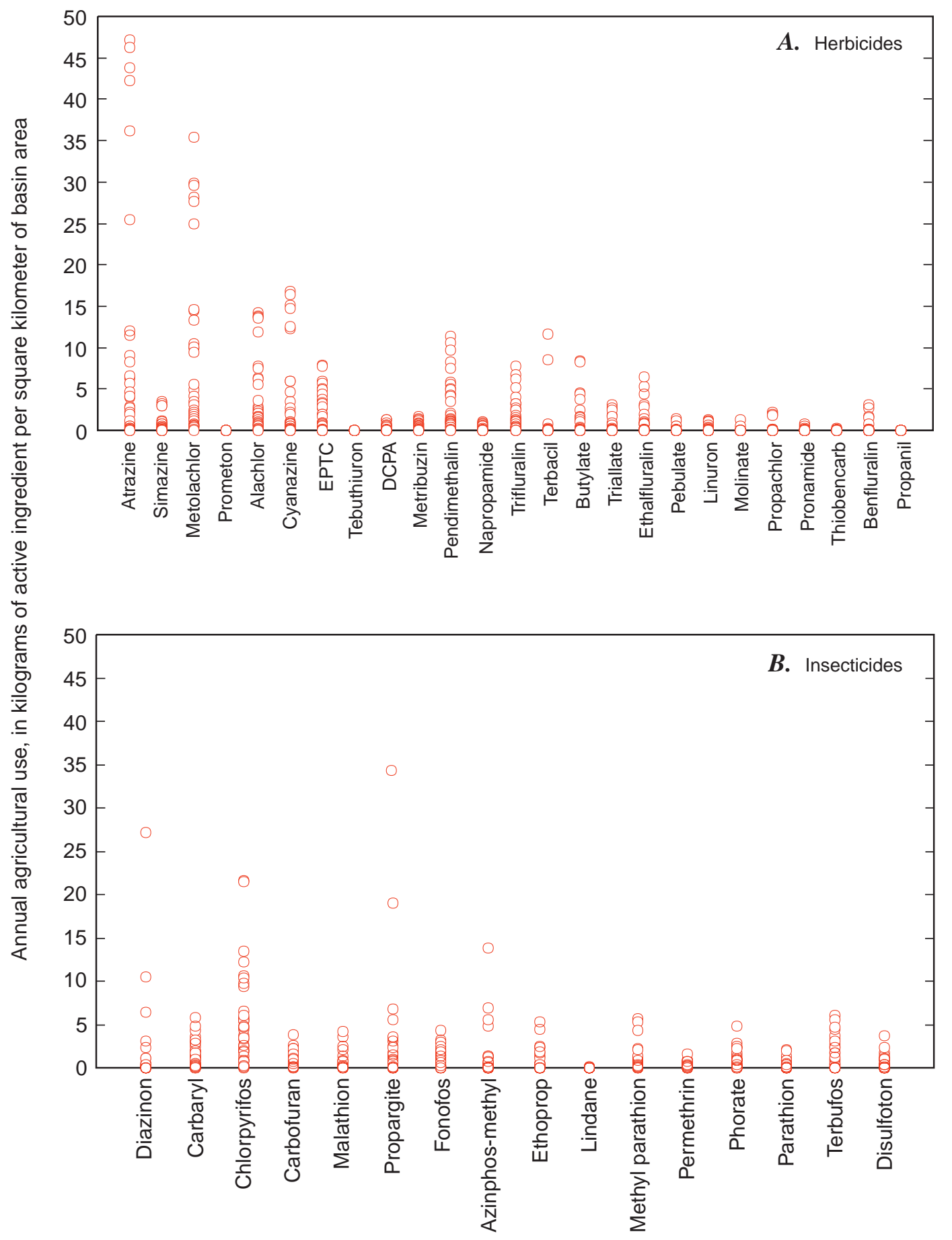

Figure 20. Intensity of annual agric ultural use of $(\boldsymbol{A})$ herbicides and $(\boldsymbol{B})$ insecticides in 37 agricultural basins. Each point represents use in one basin. Agricultural-use data are from Gianessi and Anderson (1996). 


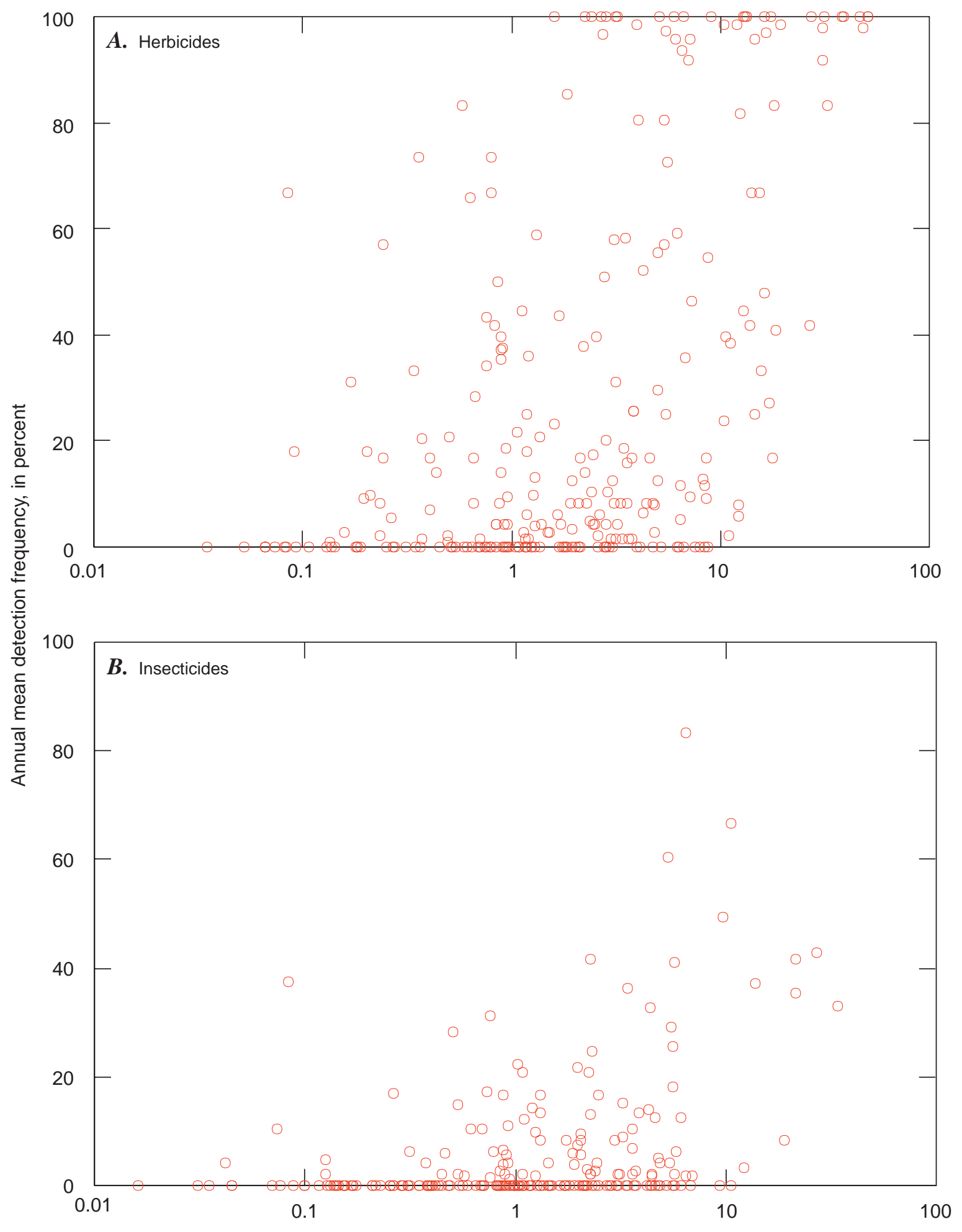

Annual agricultural use, in kilograms per square kilometer

Figure 21. Annual mean detection frequency in relation to agricultural use for $(\boldsymbol{A})$ herbicides and $(\boldsymbol{B})$ insecticides at 32 agricultural sites. Each value represents the annual mean detection frequency of a specific compound at one site. Detection frequencies are shown only for compounds with reported use of 100 or more kilograms active ingredient (a.i.) in a particular basin. A common reporting level of 0.01 mic rogram per liter was used for all compounds. Five agricultural sites were excluded because sampling was not sufficiently frequent throughout the year to calculate an unbiased annual detection frequency. Agricultural-use data are from Gianessi and Anderson (1996). 
Table 5. Detection frequencies of agric ultural pesticides at agric ultural indicator sites.

[ Detection frequencies greater than 50 percent are indicated by dark shading. Detection frequencies greater than 10 and less than or equal to 50 percent are indicated by lighter shading. Crop group codes are defined in table 4]

\begin{tabular}{|c|c|c|c|c|c|c|c|c|c|c|c|c|c|c|c|c|c|}
\hline \multirow[b]{2}{*}{ Site code } & \multirow[b]{2}{*}{$\begin{array}{l}\text { Crop } \\
\text { group } \\
\text { code }\end{array}$} & \multicolumn{16}{|c|}{ Herbicides } \\
\hline & & $\frac{8}{8}$ & $\frac{8}{4}$ & $\begin{array}{l}\frac{1}{0} \\
\frac{7}{8} \\
\frac{8}{8} \\
\frac{8}{3} \\
\Sigma\end{array}$ & $\begin{array}{l}\frac{1}{8} \\
\frac{7}{8} \\
\frac{10}{8}\end{array}$ & है & $\frac{u}{\sigma}$ & 8 & $\frac{5}{5}$ & 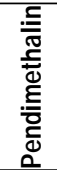 & $\begin{array}{l}\frac{0}{8} \\
\frac{8}{8} \\
\frac{8}{8} \\
\frac{6}{10}\end{array}$ & 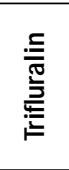 & $\frac{\overline{8}}{\overline{8}}$ & $\frac{8}{10}$ & $\frac{8}{\frac{8}{60}}$ & $\begin{array}{l}\frac{5}{6} \\
\frac{5}{5} \\
\frac{5}{10}\end{array}$ & $\frac{8}{\frac{80}{3}}$ \\
\hline lsus-mill & $\mathrm{C}$ & 100 & 100 & 100 & 12 & 12 & 0 & 0 & 2 & 6 & 2 & 0 & 10 & 0 & 0 & 0 & 0 \\
\hline cnbr-prairie & $\mathrm{C}$ & 100 & 33 & 83 & 42 & 17 & 8 & 0 & 4 & 4 & 0 & 0 & 0 & 0 & 0 & 0 & 0 \\
\hline wmic-duck & $\mathrm{C}$ & 100 & 66 & 100 & 37 & 98 & 23 & 0 & 7 & 4 & 0 & 0 & 0 & 0 & 0 & 0 & 0 \\
\hline hdsn-canaj & $\mathrm{CA}$ & 100 & 4 & 81 & 0 & 20 & 3 & 0 & 0 & 0 & 0 & 0 & 0 & 0 & 0 & 0 & 0 \\
\hline poto-muddy & $\mathrm{CA}$ & 100 & 88 & 36 & 8 & 9 & 0 & 0 & 2 & 0 & 0 & 0 & 0 & 0 & 0 & 0 & 0 \\
\hline wmic-nbmilw & $\mathrm{CAv}$ & 100 & 81 & 17 & 26 & 48 & 19 & 0 & 0 & 0 & 0 & 0 & 0 & 0 & 0 & 0 & 0 \\
\hline cnbr-maple & CS & 100 & 17 & 42 & 25 & 100 & 0 & 0 & 4 & 17 & 0 & 25 & 0 & 0 & 0 & 0 & 0 \\
\hline cnbr-shell & CS & 100 & 21 & 92 & 67 & 100 & 8 & 0 & 8 & 17 & 0 & 8 & 0 & 8 & 0 & 0 & 0 \\
\hline whit-kess & $\mathrm{CS}$ & 100 & 67 & 100 & 96 & 83 & 16 & 2 & 37 & 24 & 0 & 4 & 0 & 100 & 0 & 0 & 0 \\
\hline whit-sugar & CS & 98 & 34 & 98 & 67 & 27 & 1 & 0 & 9 & 2 & 0 & 4 & 0 & 9 & 0 & 0 & 0 \\
\hline albe-pete & CScot & 57 & 7 & 100 & 92 & 11 & 0 & 2 & 12 & 5 & 2 & 6 & 0 & 0 & 0 & 0 & 0 \\
\hline albe-albe & CSW & 55 & 2 & 48 & 82 & 0 & 0 & 0 & 0 & 2 & 2 & 0 & 2 & 0 & 0 & 0 & 0 \\
\hline lsus-eastm & $\mathrm{CW}$ & 98 & 59 & 98 & 52 & 51 & 0 & 21 & 3 & 13 & 6 & 0 & 3 & 0 & 0 & 0 & 2 \\
\hline poto-mono & $\mathrm{CW}$ & 99 & 99 & 97 & 26 & 38 & 0 & 0 & 6 & 1 & 0 & 0 & 0 & 0 & 0 & 0 & 0 \\
\hline splt-lone & $\mathrm{CW}$ & 100 & 24 & 100 & 58 & 73 & 97 & 36 & 3 & 28 & 5 & 17 & 0 & 17 & 0 & 18 & 0 \\
\hline acfb-lime & $\mathrm{CWp}$ & 40 & 25 & 13 & 2 & 10 & 0 & 0 & 2 & 0 & 0 & 0 & 0 & 0 & 0 & 2 & 0 \\
\hline trin-chamb & CWsor & 100 & 79 & 100 & 38 & 4 & 0 & 0 & 27 & 8 & 0 & 4 & 0 & 0 & 0 & 0 & 0 \\
\hline ccpt-crab.rl & WA & 100 & 35 & 5 & 8 & 8 & 33 & 40 & 8 & 14 & 6 & 3 & 44 & 0 & 0 & 12 & 0 \\
\hline usnk-rock & WAb & 31 & 0 & 2 & 3 & 0 & 17 & 0 & 0 & 0 & 2 & 0 & 0 & 0 & 0 & 4 & 0 \\
\hline ccpt-palouse & $\mathrm{Wb}$ & 83 & 67 & 0 & 0 & 0 & 3 & 0 & 14 & 0 & 0 & 0 & 0 & 0 & 56 & 4 & 0 \\
\hline redn-turtle & $\mathrm{Wb}$ & 20 & 0 & 4 & 4 & 8 & 19 & 0 & 0 & 0 & 0 & 0 & 0 & 0 & 4 & 0 & 0 \\
\hline usnk-teton & Wpot & 0 & 0 & 0 & 0 & 0 & 0 & 0 & 0 & 0 & 0 & 0 & 0 & 0 & 0 & 0 & 0 \\
\hline gafl-tucsa & WScot & 18 & 5 & 59 & 0 & 10 & 2 & 0 & 0 & 0 & 0 & 0 & 0 & 2 & 0 & 2 & 0 \\
\hline albe-devils & WStob & 28 & 57 & 58 & 3 & 0 & 0 & 2 & 3 & 0 & 36 & 0 & 0 & 0 & 0 & 0 & 0 \\
\hline ccpt-crab.m & $\mathrm{W}$ & 13 & 29 & 0 & 4 & 0 & 0 & 0 & 0 & 0 & 0 & 0 & 0 & 0 & 8 & 0 & 0 \\
\hline ccpt-el68 & W & 92 & 16 & 14 & 73 & 10 & 30 & 42 & 23 & 43 & 0 & 21 & 66 & 0 & 0 & 17 & 0 \\
\hline redn-snake & W & 33 & 2 & 19 & 0 & 17 & 13 & 0 & 2 & 0 & 0 & 0 & 0 & 0 & 31 & 0 & 0 \\
\hline redn-wildr & W & 47 & 0 & 2 & 2 & 17 & 4 & 0 & 2 & 0 & 0 & 11 & 0 & 0 & 24 & 3 & 0 \\
\hline gafl-little & $\mathrm{P}$ & 31 & 0 & 83 & 8 & 13 & 0 & 0 & 0 & 0 & 0 & 0 & 0 & 0 & 0 & 4 & 0 \\
\hline acfb-aycocks & $\mathrm{P}$ & 63 & 30 & 88 & 13 & 0 & 0 & 0 & 0 & 0 & 0 & 0 & 0 & 10 & 0 & 0 & 0 \\
\hline sanj-salt & COTv & 57 & 96 & 44 & 10 & 81 & 97 & 22 & 0 & 0 & 13 & 44 & 0 & 0 & 0 & 0 & 10 \\
\hline will-pudding & FGv & 100 & 85 & 96 & 8 & 0 & 17 & 40 & 17 & 0 & 50 & 0 & 0 & 0 & 0 & 0 & 0 \\
\hline will-zollner & FGv & 100 & 100 & 100 & 26 & 0 & 41 & 10 & 52 & 0 & 85 & 10 & 15 & 0 & 0 & 0 & 0 \\
\hline sanj-merced & $\mathrm{O}$ & 0 & 83 & 20 & 0 & 0 & 21 & 1 & 0 & 1 & 0 & 3 & 0 & 7 & 0 & 0 & 0 \\
\hline sanj-orest & $\mathrm{O}$ & 33 & 94 & 72 & 11 & 7 & 39 & 39 & 4 & 0 & 34 & 46 & 0 & 0 & 0 & 28 & 27 \\
\hline ozrk-dous & $\mathrm{XX}$ & 4 & 0 & 0 & 0 & 0 & 0 & 0 & 0 & 0 & 0 & 0 & 0 & 0 & 0 & 0 & 0 \\
\hline ozrk-yocum & $X X$ & 8 & 4 & 8 & 8 & 0 & 0 & 0 & 0 & 0 & 0 & 0 & 0 & 0 & 0 & 0 & 0 \\
\hline
\end{tabular}


Table 5. Detection frequencies of agricultural pesticides at agricultural indicator sites- Continued

\begin{tabular}{|c|c|c|c|c|c|c|c|c|c|c|c|c|c|c|c|c|c|}
\hline \multirow[b]{2}{*}{ Site code } & \multirow[b]{2}{*}{$\begin{array}{l}\text { Crop } \\
\text { group } \\
\text { code }\end{array}$} & \multicolumn{5}{|c|}{ Herbicides-Continued } & \multicolumn{11}{|c|}{ Insecticides } \\
\hline & & 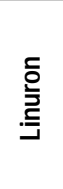 & $\frac{8}{8}$ & $\frac{\frac{8}{8}}{\frac{8}{8}}$ & $\begin{array}{l}\frac{8}{8} \\
\frac{8}{8}\end{array}$ & $\begin{array}{l}\frac{8}{8} \\
\frac{8}{8} \\
\frac{8}{8} \\
F\end{array}$ & 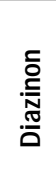 & $\frac{8}{8}$ & $\begin{array}{l}\frac{8}{2} \\
\frac{2}{2} \\
\frac{2}{0} \\
\delta\end{array}$ & है & 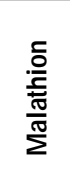 & $\frac{8}{8}$ & $\begin{array}{l}8 \\
\frac{8}{8} \\
8\end{array}$ & $\begin{array}{l}\text { है } \\
\frac{1}{8} \\
\frac{8}{8} \\
\frac{1}{8}\end{array}$ & $\begin{array}{l}\frac{8}{0} \\
\frac{8}{8} \\
\frac{1}{4}\end{array}$ & 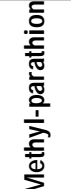 & 起 \\
\hline$\overline{\text { 1sus-mill }}$ & $\mathrm{C}$ & 0 & 0 & 0 & 0 & 0 & 7 & 7 & 4 & 0 & 2 & 0 & 0 & 0 & 0 & 0 & 0 \\
\hline cnbr-prairie & $\mathrm{C}$ & 0 & 0 & 6 & 0 & 0 & 0 & 11 & 6 & 21 & 0 & 0 & 9 & 0 & 0 & 0 & 0 \\
\hline wmic-duck & $\mathrm{C}$ & 0 & 0 & 0 & 0 & 0 & 1 & 0 & 1 & 3 & 0 & 0 & 4 & 0 & 0 & 0 & 0 \\
\hline hdsn-canaj & $\mathrm{CA}$ & 0 & 0 & 0 & 0 & 0 & 17 & 0 & 0 & 0 & 0 & 0 & 0 & 0 & 0 & 0 & 0 \\
\hline poto-muddy & CA & 0 & 0 & 0 & 0 & 0 & 8 & 3 & 0 & 0 & 2 & 0 & 0 & 0 & 0 & 0 & 0 \\
\hline wmic-nbmilw & CAv & 0 & 0 & 0 & 0 & 0 & 0 & 2 & 0 & 0 & 2 & 0 & 0 & 0 & 0 & 0 & 0 \\
\hline cnbr-maple & $\mathrm{CS}$ & 0 & 0 & 13 & 0 & 0 & 0 & 0 & 13 & 8 & 0 & 0 & 4 & 0 & 0 & 0 & 0 \\
\hline cnbr-shell & $\mathrm{CS}$ & 0 & 0 & 17 & 0 & 0 & 0 & 4 & 29 & 8 & 13 & 0 & 8 & 0 & 0 & 0 & 0 \\
\hline whit-kess & $\mathrm{CS}$ & 6 & 0 & 2 & 0 & 0 & 0 & 13 & 8 & 21 & 14 & 0 & 0 & 0 & 0 & 0 & 0 \\
\hline whit-sugar & CS & 4 & 0 & 0 & 0 & 0 & 13 & 4 & 4 & 1 & 1 & 0 & 0 & 0 & 0 & 0 & 0 \\
\hline albe-pete & CScot & 0 & 0 & 0 & 0 & 0 & 3 & 3 & 3 & 0 & 0 & 3 & 3 & 0 & 2 & 0 & 0 \\
\hline albe-albe & CSW & 0 & 0 & 0 & 2 & 0 & 0 & 14 & 2 & 13 & 4 & 0 & 2 & 2 & 2 & 0 & 0 \\
\hline 1sus-eastm & $\mathrm{CW}$ & 2 & 0 & 0 & 0 & 0 & 0 & 21 & 10 & 22 & 4 & 0 & 0 & 0 & 0 & 0 & 0 \\
\hline poto-mono & $\mathrm{CW}$ & 18 & 0 & 0 & 0 & 0 & 12 & 22 & 2 & 1 & 3 & 0 & 0 & 2 & 0 & 3 & 0 \\
\hline splt-lone & $\mathrm{CW}$ & 20 & 0 & 0 & 0 & 0 & 6 & 15 & 17 & 28 & 0 & 15 & 5 & 2 & 2 & 10 & 2 \\
\hline acfb-lime & $\mathrm{CWp}$ & 0 & 0 & 0 & 0 & 0 & 0 & 2 & 0 & 0 & 0 & 0 & 6 & 0 & 2 & 0 & 0 \\
\hline trin-chamb & CWsor & 0 & 0 & 0 & 0 & 0 & 8 & 0 & 0 & 0 & 0 & 0 & 0 & 4 & 0 & 0 & 0 \\
\hline ccpt-crab.rl & WA & 6 & 0 & 0 & 0 & 0 & 2 & 15 & 13 & 0 & 6 & 18 & 0 & 26 & 2 & 0 & 3 \\
\hline usnk-rock & WAb & 0 & 0 & 0 & 0 & 0 & 0 & 4 & 0 & 0 & 0 & 0 & 0 & 0 & 0 & 0 & 0 \\
\hline ccpt-palouse & $\mathrm{Wb}$ & 0 & 0 & 0 & 0 & 0 & 4 & 0 & 0 & 0 & 0 & 0 & 0 & 0 & 0 & 0 & 0 \\
\hline redn-turtle & $\mathrm{Wb}$ & 0 & 0 & 0 & 0 & 0 & 0 & 0 & 0 & 10 & 0 & 0 & 0 & 0 & 0 & 0 & 0 \\
\hline usnk-teton & Wpot & 0 & 0 & 0 & 0 & 0 & 0 & 0 & 0 & 0 & 2 & 0 & 0 & 0 & 0 & 0 & 0 \\
\hline gafl-tucsa & WScot & 0 & 0 & 0 & 0 & 0 & 3 & 2 & 0 & 0 & 0 & 2 & 0 & 0 & 0 & 0 & 0 \\
\hline albe-devils & WStob & 0 & 0 & 0 & 0 & 0 & 1 & 0 & 2 & 2 & 0 & 0 & 0 & 0 & 0 & 0 & 0 \\
\hline ccpt-crab.m & $\mathrm{W}$ & 0 & 0 & 0 & 0 & 0 & 0 & 4 & 0 & 0 & 0 & 0 & 0 & 4 & 0 & 0 & 0 \\
\hline ccpt-el68 & W & 0 & 0 & 0 & 0 & 0 & 6 & 0 & 17 & 31 & 7 & 42 & 3 & 10 & 0 & 0 & 0 \\
\hline redn-snake & W & 0 & 0 & 0 & 0 & 0 & 0 & 0 & 2 & 10 & 0 & 0 & 0 & 0 & 0 & 0 & 0 \\
\hline redn-wildr & W & 0 & 2 & 0 & 0 & 0 & 0 & 0 & 0 & 0 & 0 & 0 & 0 & 0 & 0 & 0 & 0 \\
\hline gafl-little & $\mathrm{P}$ & 0 & 0 & 0 & 0 & 0 & 0 & 1 & 2 & 1 & 4 & 0 & 0 & 0 & 1 & 0 & 0 \\
\hline acfb-aycocks & $\mathrm{P}$ & 0 & 0 & 0 & 0 & 0 & 0 & 5 & 0 & 0 & 0 & 0 & 0 & 0 & 0 & 0 & 0 \\
\hline sanj-salt & COTv & 2 & 25 & 0 & 9 & 18 & 67 & 14 & 35 & 13 & 10 & 8 & 0 & 0 & 0 & 0 & 0 \\
\hline will-pudding & FGv & 0 & 0 & 0 & 0 & 0 & 0 & 0 & 4 & 38 & 17 & 0 & 0 & 6 & 17 & 0 & 8 \\
\hline will-zollner & FGv & 0 & 0 & 0 & 6 & 0 & 83 & 41 & 49 & 92 & 19 & 0 & 33 & 6 & 60 & 0 & 0 \\
\hline sanj-merced & $\mathrm{O}$ & 0 & 3 & 0 & 0 & 0 & 25 & 6 & 36 & 17 & 0 & 7 & 0 & 8 & 0 & 0 & 0 \\
\hline sanj-orest & $\mathrm{O}$ & 0 & 15 & 0 & 11 & 3 & 43 & 5 & 42 & 9 & 0 & 33 & 42 & 37 & 0 & 0 & 0 \\
\hline ozrk-dous & $\mathrm{XX}$ & 0 & 2 & 0 & 0 & 0 & 0 & 0 & 0 & 2 & 0 & 0 & 0 & 0 & 0 & 0 & 0 \\
\hline ozrk-yocum & $\mathrm{XX}$ & 0 & 0 & 0 & 0 & 0 & 0 & 0 & 0 & 0 & 0 & 0 & 0 & 0 & 0 & 0 & 0 \\
\hline
\end{tabular}


compounds (azinphos-methyl and disulfoton) had values of $r^{2}$ higher than 0.5 . Clearly, factors other than the amount used, such as pesticide properties, weather, and agricultural practices (Leonard, 1990), can have a major influence on the occurrence of pesticides in streams. Perhaps most importantly, the weakness of correlations between pesticide occurrence and use may result largely from inaccuracies in the pesticide-use estimates for the agricultural basins for the year that samples were collected.

Detection frequencies for specific compounds at the agricultural sites are shown in table 5. The sites in this table are arranged by crop-group classification. Detection frequencies greater than 50 percent are indicated with dark shading and those greater than 10 percent but less than 50 percent are indicated with lighter shading. In general, when a wide variety of crops were grown in a basin, a wider variety of pesticides were detected in the streams. The presence of certain crops, such as vegetables, orchard and vineyard crops, and nursery stock, commonly was associated with detection of a higher number of compounds. The patterns evident in table 5 help illustrate the similarities and differences among sites within a given crop-group classification and among sites with different classifications.

In terms of compounds that were detected most frequently, a generally consistent pattern is evident for sites where corn is a major crop (table 5). The herbicides atrazine, metolachlor, alachlor, and cyanazine were detected frequently at nearly all of these sites. Simazine also was detected frequently even though it was not one of the major compounds used on corn in these basins (Gianessi and Anderson, 1996). Several other herbicides, including metribuzin, pendimethalin, and trifluralin, were detected frequently at corn and soybeans sites; these compounds commonly are applied to soybeans (Gianessi and Anderson, 1996). Most of the sites where corn is a major crop had fewer than three insecticides with detection frequencies greater than 10 percent. Carbaryl, chlorpyrifos, and carbofuran were the most commonly detected insecticides at these sites. The pattern for Lonetree Creek in Colorado (splt-lone) is an exception to the generally consistent pattern among the corn sites. At this site, several other compounds also were detected relatively often, including the herbicides EPTC, DCPA, butylate, ethalfluralin, and linuron and the insecticides propargite and methyl-parathion.
Agricultural land in this basin generally is irrigated, and stream discharge during much of the growing season is primarily due to irrigation return flows, which may contain elevated levels of pesticides (Kimbrough and Litke, 1996).

Among the sites where wheat (but not corn) is a major crop, fewer compounds had detection frequencies greater than 10 percent. At most of these sites, detection frequencies for all insecticides were less than 10 percent. Only a few sites had any herbicides with detection frequencies greater than 50 percent. Atrazine and simazine were detected relatively often at several of the wheat sites. The lower number of herbicides detected at these sites was due, in part, to poor coverage of herbicide use in these basins by the target compounds (table 3). Several major herbicides used on wheat, including 2, 4-D, bromoxynil, dicamba, diuron, and MCPA, are not included in the target compounds; however, most of the insecticides used on wheat, including chlorpyrifos, disulfoton, methyl parathion, permethrin, and phorate, are included in the target compounds. These compounds were detected infrequently or not at all at most of the wheat sites. Two sites in the Central Columbia Plateau study unit-Crab Creek Lateral (ccpt-crab.rl) and EL68 Wasteway (ccptel68) - are exceptions to the general pattern among the wheat sites (table 5). At both of these sites, a number of herbicides and insecticides had detection frequencies greater than 10 percent. The higher number of compounds detected at these two sites may be due to the presence of a relatively small amount of land with orchards (mainly apples) and greenhouse and nursery crops in these basins (table 4). The results for these two sites suggest that minor crops with relatively high pesticide use may have a strong influence on pesticide occurrence in streams.

Peanuts are the major crop in two basins-Little River (gafl-little) and Aycocks Creek (acfb-aycocks) in Georgia. Substantial portions of three other basins are also planted in peanuts-Pete Mitchell Swamp in North Carolina (albe-pete) and Lime Creek (acfb-lime) and Tucsawhatchee Creek (gafl-tucsa) in Georgia (table 4). No clear pattern in detection frequencies is evident in table 5 for sites in these basins. In general, few compounds had detection frequencies greater than 10 percent in the streams draining these basins. Several of the major pesticides used on peanuts, including the herbicides 2,4-DB, paraquat, bentazon, and acifluorfen and the insecticide aldicarb, are not included in the 
target compounds. Metolachlor, which is used extensively on peanuts and other crops grown in these basins (Gianessi and Anderson, 1996), was detected frequently at most of the sites in these basins. Several other compounds used on peanuts, including the herbicides pendimethalin, trifluralin, and ethalfluralin and the insecticides carbaryl, chlorpyrifos, and phorate, were detected infrequently or not at all in streams draining these basins.

Cotton accounts for more than 10 percent of harvested cropland in seven of the basins (table 4). Similar to sites with peanuts, no clear pattern is evident in the detection frequencies shown in table 5 for the sites with cotton. The target compounds cyanazine, pendimethalin, trifluralin, malathion, azinphos-methyl, methyl parathion, and parathion are used extensively on cotton; use of these compounds, however, varies considerably in these seven basins (Gianessi and Anderson, 1996). None of these compounds were detected consistently among the sites where cotton is a major crop. Several pesticides were detected frequently in Salt Slough (sanj-salt) and the Merced River (sanjmerced); a substantial amount of cotton is grown in these basins. Many other crops also are grown in these basins, including a variety of vegetables and several orchard and vineyard crops, making it difficult to determine the source of a particular pesticide detected in streams draining these basins. The detections of molinate and thiobencarb in these streams probably are the result of applications to rice, which is the only crop on which these compounds are used in the United States (Gianessi and Anderson, 1996).

In the two agricultural basins in the Willamette River valley in Oregon-Zollner Creek Basin and Pudding River Basin - the major crops are grass seed and a wide variety of vegetables. In addition, there are plant nurseries in both basins, and several orchard crops are grown in the Pudding River Basin (E\&S Environmental Chemistry, Inc., and Tetra Tech, Inc., 1995). A number of pesticides were frequently detected at the will-zollner and will-pudding sampling sites in these basins which reflects the diverse agricultural activities in these basins. The pattern of detections at these two sites is very similar, with many of the same compounds detected at both sites (table 5). This was not unexpected because the Zollner Creek Basin is within the larger Pudding River Basin. Detection frequencies for all agricultural pesticides are higher for Zollner Creek than for Pudding River, except for
DCPA, and several compounds were detected in Zollner Creek that were not detected in the Pudding River. This also was expected as the Zollner Creek Basin is much smaller and more intensively farmed than the Pudding River Basin as a whole. Fifteen different pesticides had detection frequencies greater than 10 percent in Zollner Creek (table 5). For several compounds, the detection frequencies for Zollner Creek and the Pudding River were higher than at the other 56 sites. These compounds include napropamide, an herbicide used primarily on various berry crops; ethoprop, an insecticide used primarily on green beans and sweet corn; and carbofuran, an insecticide used primarily on strawberries in this area (Gianessi and Anderson, 1996). Diazinon, which frequently was detected in Zollner Creek, but not in the Pudding River, is applied to a variety of crops in this area, including hops, vegetables, and nursery crops. Atrazine, detected in all samples at both sites, is used mainly on sweet corn in this area (Gianessi and Anderson, 1996).

Orchards and vineyards are the dominant uses of agricultural land in the Merced River and Orestimba Creek basins in California (table 5). A variety of vegetables and other row crops also are grown in both basins. Similar to the sites in the Willamette River valley, a number of pesticides were frequently detected in both basins. Simazine, which is used on several orchard crops and in nonagricultural applications in these basins, was the herbicide detected most frequently at both sites. Azinphos-methyl, chlorpyrifos, and diazinon also were detected relatively frequently at both sites, primarily as a result of application to orchard crops. Seventeen pesticides had detection frequencies greater than 10 percent in Orestimba Creek. Several pesticides, including alachlor, ethalfluralin, fonofos, metolachlor, pebulate, and propargite, were detected more frequently in Orestimba Creek than in the Merced River. These compounds are applied primarily to beans and other vegetables in the Orestimba Creek Basin (Panshin and others, 1998).

\section{Concentrations}

The concentrations of specific compounds varied considerably among the agricultural indicator sites, which is consistent with the widely varying agricultural use among the basins (fig. 20). Monthly median concentrations of the compounds detected most frequently at agricultural sites are shown in figure 22 
(herbicides) and figure 23 (insecticides). These figures show concentrations for a 1-year period for the 37 agricultural sites, so that there are (at most) 12 values for each site in each of the plots. The sites are arranged by crop-group classifications and are presented in the same order as the sites in tables 4 and 5. Monthly median concentrations less than the detection limit are shown as points on the $x$-axis. The median of the monthly values for each site, shown in red, represents the midpoint of the monthly values. The plots in figure 22 and 23 provide a relatively unbiased representation of the concentrations measured at each of the agricultural sites because each month is given equal weight. In addition, the use of medians, rather than means, minimizes the influence of extreme values in the distribution of concentrations. Corresponding plots for the urban indicator sites and the integrator sites are discussed in the sections on these types of sites that follow. Figures 22 and 23 are used in the next two sections to illustrate the concentration ranges of specific herbicides and insecticides measured at the agricultural sites.

\section{Herbicides}

Monthly median total herbicide concentrations at the 37 agricultural sites are shown in figure $22 \mathrm{~A}$. At the 17 sites in corn-growing areas, median concentrations generally ranged from 0.1 to $1 \mu \mathrm{g} / \mathrm{L}$ for most months. Monthly median concentrations exceeded $10 \mu \mathrm{g} / \mathrm{L}$ during seasonal peaks at several sites in the corn crop group. Concentrations were lower at two sites in the corn group-Albemarle Canal Basin in North Carolina (albe-albe) and Lime Creek Basin in Georgia (acfb-lime) - which is consistent with the generally lower detection frequencies for herbicides at these two sites (table 5). The percentage of cropland planted in corn was somewhat lower in Albemarle Canal and Lime Creek basins than in most of the other basins in the corn group (table 4), and the amounts of the target herbicides used in these two basins also was lower than in most of the other basins in corn-growing areas (table 6). At the 11 sites where wheat (but not corn) is a major crop, total herbicide concentrations generally were an order of magnitude lower than at sites in corn-growing areas, with monthly median concentrations of 0.01 to $0.1 \mu \mathrm{g} / \mathrm{L}$ during most months. At the two sites where peanuts are the major crop (gafllittle and acfb-aycocks), concentrations also were low, with monthly median total herbicide concentrations less than $0.1 \mu \mathrm{g} / \mathrm{L}$ for much of the year. Concentrations at the sites in the San Joaquin and Willamette River basins were similar to concentrations at most of the corn sites, with monthly median total herbicide concentrations between 0.1 to $1 \mu \mathrm{g} / \mathrm{L}$ for much of the year. Total herbicide concentrations at the two sites in the Ozark Plateau study units (ozrk-dous and ozrkyocum) were very low. Harvested cropland accounts for less than 10 percent of the basin area at these two sites (table 3), and use of the target herbicides is very low (table 6). The concentrations of the six herbicides detected most frequently at the agricultural sites are discussed below.

Monthly median concentrations of atrazine, metolachlor, and cyanazine generally ranged from 0.01 to $1 \mu \mathrm{g} / \mathrm{L}$ at most sites in corn-growing areas (fig. $22 B, C, D)$. Atrazine concentrations also were in this range in Zollner Creek (will-zollner) and the Pudding River (will-pudding), probably as a result of application to sweet corn. Concentrations of these three herbicides generally were lower at sites representing other crop groups, which is consistent with the much lower use of these compounds in these basins.

Concentrations of the atrazine transformation product DEA (fig. 22E) followed a spatial pattern quite similar to that of atrazine concentrations, but concentrations were substantially lower at most sites. DEA was detected throughout the year at most sites in corn-growing areas of the Midwest and West, with median concentrations between 0.01 and $0.1 \mu \mathrm{g} / \mathrm{L}$ for most months. Concentrations of DEA were very similar to atrazine concentrations at several of the sites in corn-growing areas of the East (lsus-mill, hdsncanaj, poto-muddy, albe-pete, and lsus-eastm). The relatively narrow range of monthly median concentrations at these sites also shows that DEA concentrations were fairly constant throughout the year. Similar to atrazine, concentrations of DEA were considerably lower at sites representing crop groups other than corn even though it was present for much of the year at several of these sites. It should be noted that the concentrations of DEA shown in figure 22 probably are biased low because of the low analytical recovery of this compound (table 2). On the basis of mean analytical recoveries of atrazine (98 percent) and DEA (16 percent), it is possible that the actual DEA concentrations may have been higher than atrazine concentrations during some months at several sites. 
A. Total herbicides

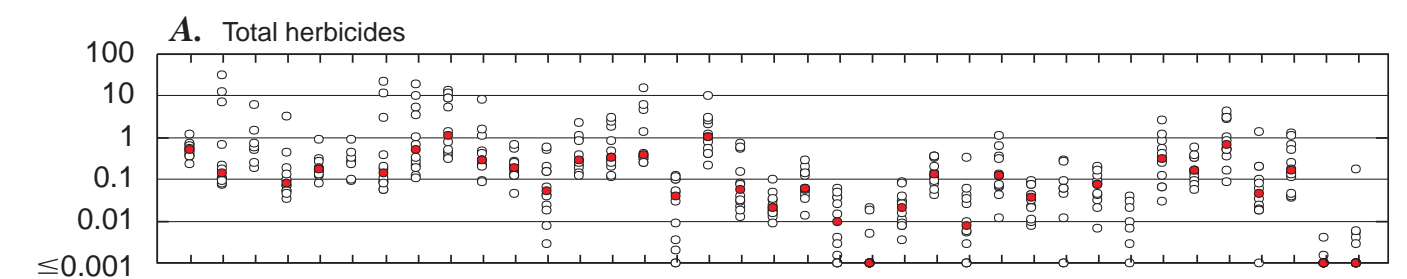

B. Atrazine
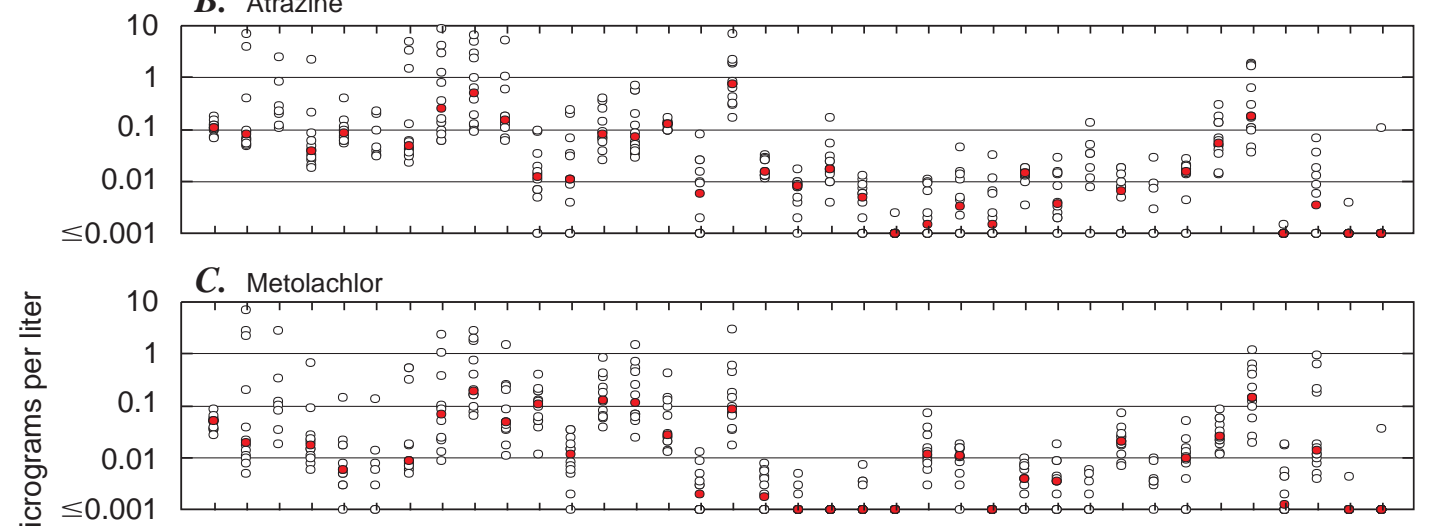

$\begin{array}{llll}\text { E } & & \text { D. Cyanazine }\end{array}$

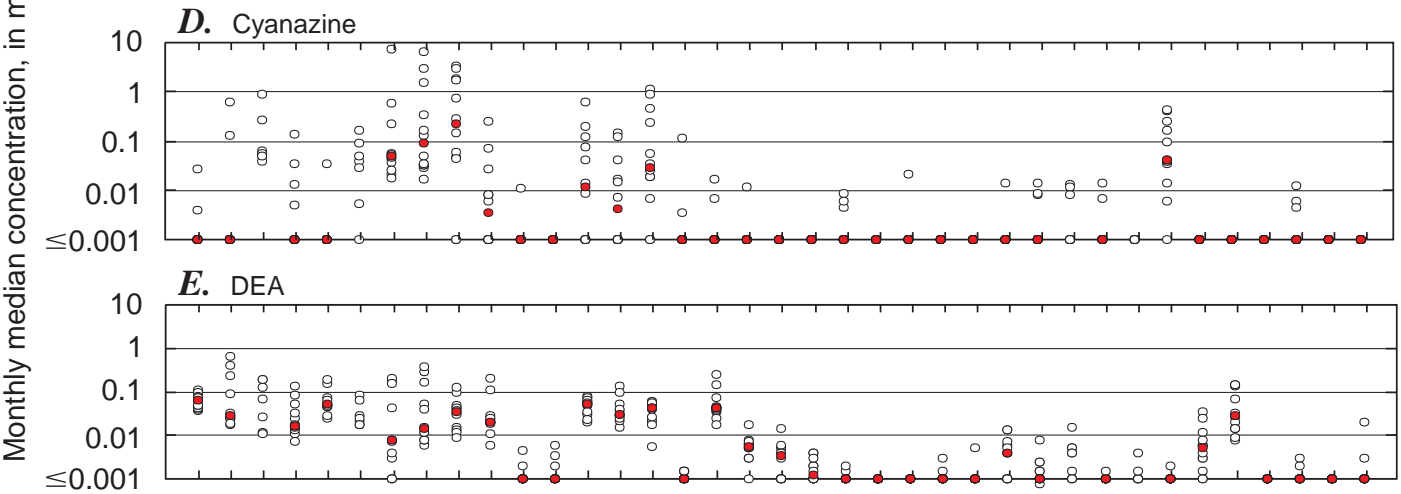

$\leq 0.001$

$\boldsymbol{F}$. Prometon

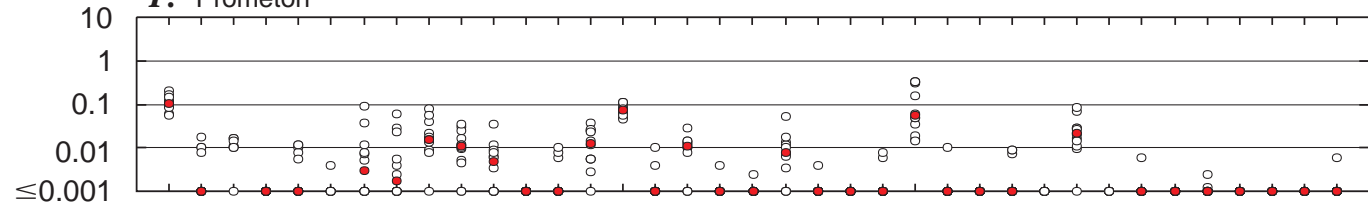

$$
\leq 0.001
$$

10

G. Simazine
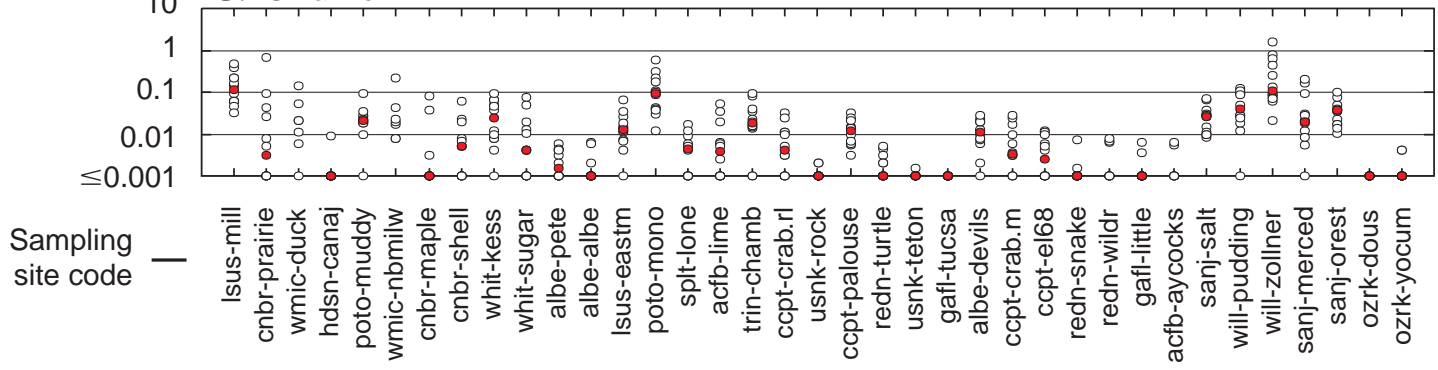

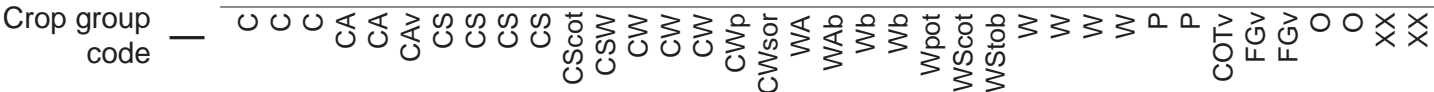

Figure 22. M onthly median concentrations of total herbicides and the six herbicides detected most frequently at the 37 agricultural indicator sites during a 1-year period. Each value represents the median concentration for 1 month. The annual median for each site is show $n$ in red. M onthly median concentrations less than the detection limit are show $n$ as points on the $x$-axis. For sites at which all 12 monthly values were below the detection limit, the annual median value is plotted on the $x$-axis. The sites are arranged by crop group classification and presented in the same order as in table 1 . Site codes are defined in table 1 and crop group codes are defined in table 4. 
A. Total insecticides

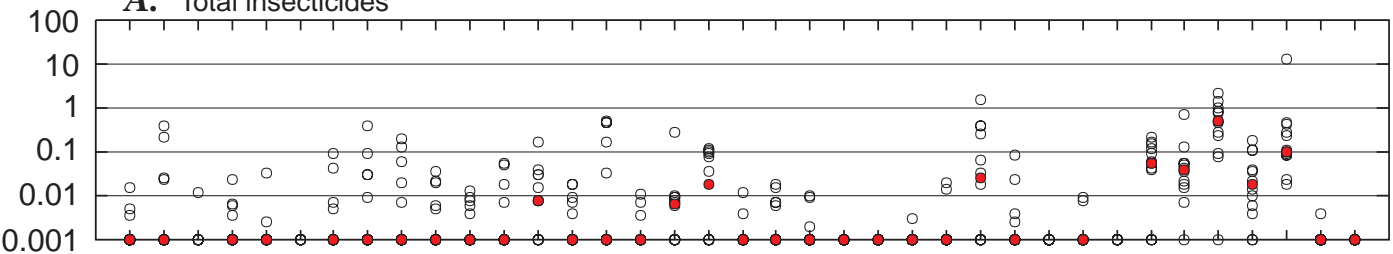

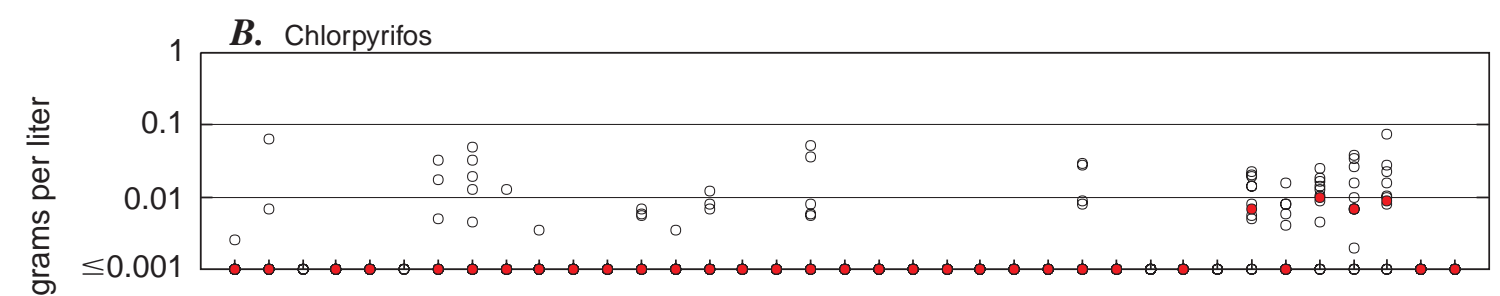

C. Diazinon
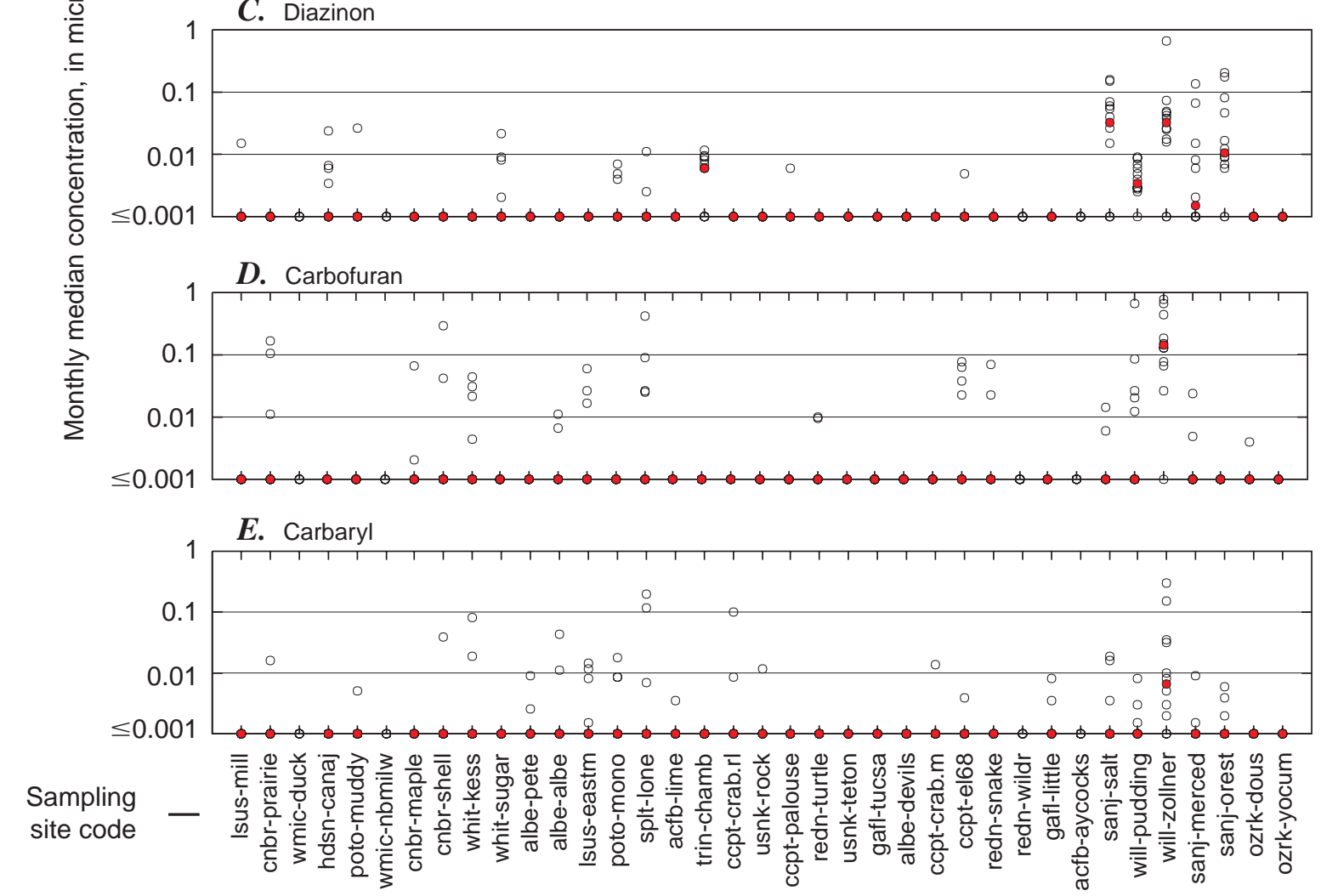

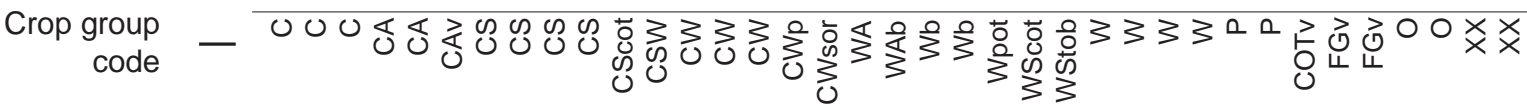

Figure 23. M onthly median concentrations of total insecticides and the four insecticides detected most frequently at the 37 agricultural indicator sites during a 1-year period. Each value represents the median concentration for 1 month. The annual median for each site is show $n$ in red. M onthly median concentrations less than the detection limit are show $n$ as points on the $x$ axis. For sites at which all 12 monthly values were less than the detection limit, the median value is plotted on the $x$-axis. The sites are arranged by crop group classification and presented in the same order as in table 1 . Site codes are defined in table 1 and crop group codes are defined in table 4. 
Table 6. Agricultural use of selected pesticides per square kilometer of drainage basin.

[Values represent estimates for 1990-95 (see discussion in text). Crop group codes are defined in table 4]

\begin{tabular}{|c|c|c|c|c|c|c|c|c|c|}
\hline \multirow{2}{*}{ Site code } & \multirow{2}{*}{$\begin{array}{l}\text { Crop } \\
\text { group } \\
\text { code }\end{array}$} & \multicolumn{8}{|c|}{ Agricultural use in basin (kilograms per square kilometer) } \\
\hline & & Atrazine & Metolachlor & Cyanazine & Simazine & Chlorpyrifos & Diazinon & Carbofuran & Carbaryl \\
\hline \multicolumn{10}{|c|}{ AGRICULTURAL BASINS } \\
\hline lsus-mill & $\mathrm{C}$ & 27 & 38 & 6.5 & 3.2 & 5.4 & 0.0 & 2.1 & 0.9 \\
\hline cnbr-prairie & $\mathrm{C}$ & 51 & 32 & 18 & 0.0 & 5.8 & 0.3 & 2.2 & 0.9 \\
\hline wmic-duck & $\mathrm{C}$ & 14 & 17 & 15 & 0.0 & 3.3 & 0.1 & 0.7 & 0.1 \\
\hline hdsn-canaj & $\mathrm{CA}$ & 6.0 & 4.0 & 2.9 & 0.5 & 3.7 & 0.0 & 0.6 & 0.0 \\
\hline poto-muddy & $\mathrm{CA}$ & 13 & 6.8 & 0.9 & 1.3 & 2.5 & 0.0 & 2.5 & 0.4 \\
\hline wmic-nbmilw & CAv & 11 & 14 & 13 & 0.0 & 2.6 & 0.0 & 0.5 & 0.2 \\
\hline cnbr-maple & $\mathrm{CS}$ & 39 & 27 & 13 & 0.0 & 4.6 & 0.2 & 1.8 & 1.7 \\
\hline cnbr-shell & $\mathrm{CS}$ & 46 & 31 & 16 & 0.0 & 5.5 & 0.3 & 2.1 & 1.4 \\
\hline whit-kess & $\mathrm{CS}$ & 51 & 32 & 18 & 0.8 & 2.0 & 0.0 & 1.1 & 1.3 \\
\hline whit-sugar & $\mathrm{CS}$ & 48 & 31 & 17 & 0.8 & 1.9 & 0.0 & 0.9 & 0.1 \\
\hline albe-pete & CScot & 5.4 & 17 & 1.3 & 0.7 & 12 & 0.5 & 2.3 & 1.9 \\
\hline albe-albe & CSW & 8.7 & 16 & 1.2 & 1.2 & 4.4 & 0.1 & 3.8 & 1.2 \\
\hline 1sus-eastm & $\mathrm{CW}$ & 12 & 19 & 2.8 & 1.3 & 2.0 & 0.1 & 1.0 & 0.5 \\
\hline poto-mono & $\mathrm{CW}$ & 10 & 17 & 2.2 & 4.0 & 6.5 & 1.1 & 0.8 & 2.0 \\
\hline splt-lone & $\mathrm{CW}$ & 2.7 & 1.6 & 0.8 & 0.0 & 0.9 & 0.1 & 0.5 & 0.0 \\
\hline acfb-lime & CWp & 11 & 8.2 & 2.4 & 0.4 & 11.0 & 0.1 & 2.0 & 3.6 \\
\hline trin-chamb & CWsor & 5.1 & 2.3 & 0.9 & 0.0 & 0.9 & 0.0 & 0.5 & 0.9 \\
\hline ccpt-crab.rl & WA & 2.4 & 2.4 & 0.3 & 0.9 & 6.1 & 1.1 & 1.6 & 3.2 \\
\hline usnk-rock & WAb & 0.2 & 0.4 & 0.7 & 0.1 & 0.3 & 0.1 & 0.6 & 0.1 \\
\hline ccpt-palouse & $\mathrm{Wb}$ & 0.0 & 0.5 & 0.0 & 0.1 & 0.1 & 0.0 & 0.0 & 0.1 \\
\hline redn-turtle & $\mathrm{Wb}$ & 0.1 & 1.4 & 0.2 & 0.0 & 1.3 & 0.0 & 1.3 & 0.4 \\
\hline usnk-teton & Wpot & 0.0 & 0.8 & 0.0 & 0.1 & 0.3 & 0.0 & 1.2 & 0.0 \\
\hline gafl-tucsa & WScot & 2.5 & 6.2 & 7.2 & 0.3 & 9.4 & 0.0 & 0.6 & 3.1 \\
\hline albe-devils & WStob & 0.8 & 3.1 & 0.1 & 0.1 & 5.7 & 0.5 & 0.8 & 1.3 \\
\hline ccpt-crab.m & W & 0.0 & 0.0 & 0.0 & 0.0 & 0.1 & 0.0 & 0.0 & 0.0 \\
\hline ccpt-el68 & $\mathrm{W}$ & 0.1 & 0.4 & 0.1 & 0.1 & 0.7 & 0.3 & 0.8 & 0.4 \\
\hline redn-snake & $\mathrm{W}$ & 0.3 & 0.9 & 0.2 & 0.0 & 0.9 & 0.0 & 0.7 & 0.2 \\
\hline redn-wildr & $\mathrm{W}$ & 0.7 & 1.2 & 0.5 & 0.0 & 0.3 & 0.0 & 0.1 & 0.0 \\
\hline gafl-little & $\mathrm{P}$ & 6.9 & 12 & 3.9 & 0.2 & 14 & 0.3 & 1.4 & 2.5 \\
\hline acfb-aycocks & $\mathrm{P}$ & 10 & 8.8 & 2.9 & 0.2 & 10 & 0.0 & 2.0 & 2.0 \\
\hline sanj-salt & COTv & 0.2 & 1.1 & 5.4 & 7.1 & 22 & 11 & 2.3 & 4.3 \\
\hline will-pudding & FGv & 3.2 & 6.1 & 0.0 & 1.8 & 4.9 & 3.1 & 0.1 & 2.9 \\
\hline will-zollner & $\mathrm{FGv}$ & 6.7 & 13.0 & 0.0 & 2.8 & 9.7 & 6.5 & 0.2 & 5.7 \\
\hline sanj-merced & $\mathrm{O}$ & 0.1 & 0.4 & 0.6 & 0.6 & 3.4 & 2.3 & 0.3 & 0.5 \\
\hline sanj-orest & $\mathrm{O}$ & 0.6 & 5.6 & 1.2 & 6.6 & 22 & 27 & 1.5 & 4.8 \\
\hline ozrk-dous & $\mathrm{XX}$ & 0.7 & 0.4 & 0.2 & 0.0 & 0.3 & 0.0 & 0.5 & 0.1 \\
\hline ozrk-yocum & $X X$ & 1.2 & 0.0 & 0.0 & 0.0 & 0.0 & 0.0 & 0.0 & 0.2 \\
\hline
\end{tabular}


Table 6. Agricultural use of selected pesticides per square kilometer of drainage basin - Continued

\begin{tabular}{|c|c|c|c|c|c|c|c|c|c|}
\hline \multirow{2}{*}{ Site code } & \multirow{2}{*}{$\begin{array}{l}\text { Crop } \\
\text { group } \\
\text { code }\end{array}$} & \multicolumn{8}{|c|}{ Agricultural use in basin (kilograms per square kilometer) } \\
\hline & & Atrazine & Metolachlor & Cyanazine & Simazine & Chlorpyrifos & Diazinon & Carbofuran & Carbaryl \\
\hline \multicolumn{10}{|c|}{ INTEGRATOR BASINS } \\
\hline cnbr-platte & $\mathrm{CW}$ & 8.0 & 5.2 & 2.7 & 0.0 & 1.1 & 0.0 & 0.5 & 0.3 \\
\hline whit-white & CS & 30 & 18 & 11 & 0.5 & 1.2 & 0.0 & 0.6 & 0.2 \\
\hline wmic-milw & $\mathrm{CAv}$ & 9 & 11 & 10 & 0.0 & 2.1 & 0.0 & 0.4 & 0.1 \\
\hline hdsn-moh & $\mathrm{CA}$ & 2.7 & 1.8 & 1.3 & 0.2 & 1.7 & 0.0 & 0.3 & 0.0 \\
\hline poto-shenan & $\mathrm{CA}$ & 4.3 & 2.5 & 0.3 & 0.6 & 1.1 & 0.0 & 0.8 & 0.3 \\
\hline albe-tar & CScot & 1.2 & 5.9 & 0.4 & 0.2 & 6.7 & 0.5 & 0.7 & 1.2 \\
\hline gafl-withla & $\mathrm{P}$ & 7.6 & 6.7 & 4.0 & 0.3 & 9.7 & 0.2 & 1.7 & 2.3 \\
\hline redn-rr.fargo & CSW & 2.2 & 4.6 & 2.3 & 0.0 & 1.1 & 0.0 & 0.2 & 0.3 \\
\hline redn-rr.em & W & 0.7 & 1.7 & 0.7 & 0.0 & 1.0 & 0.0 & 0.4 & 0.2 \\
\hline sanj-sanj & $\mathrm{O}$ & 0.1 & 0.8 & 0.9 & 1.4 & 5.6 & 4.4 & 0.5 & 1.0 \\
\hline
\end{tabular}

Among the agricultural sites, concentrations of the herbicide prometon (fig. $22 F$ ) were highest at three sites with few apparent similarities-Mill Creek in Pennsylvania (lsus-mill), in a corn-growing area with relatively high population density; Lonetree Creek in Colorado (splt-lone), with major crops of corn, wheat, and grains and very low population density; and Devils Cradle Creek in North Carolina (albe-devils), with major crops of wheat, soybeans, and tobacco and a medium population density (table 1). Prometon concentrations at these sites were between 0.01 and 0.3 $\mu \mathrm{g} / \mathrm{L}$ for much of the year (fig. $22 F$ ) The relatively narrow range of concentrations at these sites indicates that prometon concentrations were fairly uniform throughout the year. Detections of prometon were rare and concentrations very low at sites in the San Joaquin and Willamette basins and in most wheat-growing areas. Prometon is used almost exclusively in nonagricultural settings, such as transportation rightsof-way, and little quantitative information is available on the amounts used (Capel and others, 1999).

Monthly median concentrations of simazine (fig. $22 G$ ) generally ranged from 0.01 to $0.1 \mu \mathrm{g} / \mathrm{L}$, with highest concentrations at sites in the San Joaquin Basin in California (sanj-salt, sanj-merced, and sanj-orest) and the Willamette Basin in Oregon (will-pudding and will-zollner) and at two sites in corn-growing areas of the East (lsus-mill and poto-mono). This herbicide is used on a variety of agricultural crops, including orchard crops, and has substantial nonagricultural use as well. Several orchard crops are grown in the San Joaquin and Willamette basins. In addition, the two eastern sites with the highest simazine concentrations, Mill Creek in Pennsylvania (lsus-mill) and the Monocacy River in Maryland (poto-mono), and the two sites in the Willamette Basin (will-pudding and will-zollner) have the highest population densities of any of the agricultural sites (table 1). The simazine concentrations measured at these sites are likely the result of a combination of agricultural and nonagricultural use.

\section{Insecticides}

Monthly median total insecticide concentrations at the 37 agricultural sites are shown in figure $23 \mathrm{~A}$. Concentrations were less than $0.1 \mu \mathrm{g} / \mathrm{L}$ during most months at sites in corn-growing areas. Concentrations were lower at most sites in wheat-growing areas, except for the Crab Creek Lateral (ccpt-crab.rl) and El68 Wasteway (ccpt-el68) sites in Washington. Higher insecticide concentrations at these sites are consistent with the higher detection frequencies at these sites discussed earlier and may be due to the presence of orchard and nursery crops in these two basins.

Insecticide concentrations were very low at the two peanuts sites (gafl-little and acfb-aycocks) and at the sites in the Ozark Plateau (ozrk-dous and ozrk-yocum) study unit, with most or all monthly median concentrations less than the detection limit. Insecticide concentrations generally were much higher at the sites 
in the San Joaquin (sanj-merced, sanj-orest, and sanjsalt) and the Willamette River basins (will-pudding, and will-zollner). Monthly median total insecticide concentrations at these sites ranged from 0.01 to 1 $\mu \mathrm{g} / \mathrm{L}$ during most months (fig. $23 F$ ). These higher insecticide concentrations are consistent with the higher detection frequencies and the greater number of insecticides measured at these sites where a wide variety of crops are grown.

The insecticides most frequently detected at agricultural sites were chlorpyrifos, diazinon, carbofuran, and carbaryl. These insecticides were detected less frequently at agricultural sites than the most frequently detected herbicides, and concentrations generally were lower. Monthly median concentrations of these four insecticides are shown in figure $23 B-E$. Note that the maximum value on the concentration scale in these plots is $1 \mu \mathrm{g} / \mathrm{L}$ compared with $10 \mu \mathrm{g} / \mathrm{L}$ in the plots for individual herbicides. At most sites, monthly median concentrations of these compounds were less than the detection limit for much of the year. During the remainder of the year, monthly median concentrations were less than $0.1 \mu \mathrm{g} / \mathrm{L}$ at most sites. Concentrations of these four insecticides were substantially higher at the five agricultural sites in the San Joaquin (sanj-merced, sanj-orest, and sanj-salt) and Willamette (will-pudding and will-zollner) River basins (fig. 23). Monthly median concentrations of chlorpyrifos and diazinon were between 0.01 and 0.1 $\mu \mathrm{g} / \mathrm{L}$ for much of the year at several of these sites. Concentrations of all four of the most frequently detected insecticides were elevated for much of the year at the Zollner Creek site (will-zollner) in the Willamette River Basin (fig. 23). The Zollner Creek site had the highest carbofuran concentrations of any of the 58 sites discussed in this report.

\section{Seasonal Patterns}

Seasonal patterns in pesticide occurrence were apparent at most of the agricultural indicator sites. Both the number of pesticides detected (fig. 17) and their concentrations (fig. 18) were highest during a relatively well-defined period at most sites. The period of elevated concentrations extended from April or May through July at most of the agricultural sites. At some of the agricultural sites, elevated concentrations occurred during autumn or winter.

Seasonal concentration patterns for eight agricultural sites are shown in figure 24 . The plots in this figure illustrate the general temporal patterns of total herbicide and insecticide concentrations for a 1- to 2 -year period. The plots in figure $24(A-C)$ show concentrations measured at sites in corn-growing areas of the eastern, midwestern, and western United States. The temporal patterns of total herbicide concentrations in Mill Creek (fig. 24A), Kessinger Ditch (fig. 24B), and Lonetree Creek (fig. 24C) were similar, with elevated concentrations occurring primarily during the months of May and June and very low concentrations occurring during the remainder of the year. This pattern is typical of most sites representing corn-growing areas, where herbicides are applied shortly before or after planting in the spring. The duration and the levels of elevated herbicide concentrations at these three sites varied widely, however, depending on basin size, amount and intensity of rainfall or irrigation, and soil properties. The temporal pattern is not as well-defined for insecticide concentrations at the sites in figure 24 $(A-C)$, with spikes in concentration occurring periodically from spring through autumn.

Figures $24(D-F)$ show temporal patterns in pesticide concentrations observed at the three agricultural sites in the Central Valley of California. Seasonal patterns at these sites were different from those at sites in corn-growing areas and varied considerably among the three sites. Concentrations of herbicides and insecticides were elevated in samples collected in January and February from these three sites; the elevated concentrations were due to applications to orchards (primarily almonds and walnuts) during the dormant season. In Salt Slough and Orestimba Creek, concentrations of insecticides remained at detectable levels for much of the year. This is consistent with the variable periods of pesticide application to the wide variety of crops grown in the Salt Slough and Orestimba basins (Panshin and others, 1998). Seasonal patterns in these basins also are complicated by water-management policies for a system of canals, wasteways, and reservoirs and by regulation of irrigation return flows. The large insecticide peak in Orestimba Creek in August of 1993 is due to a high concentration $(26 \mu \mathrm{g} / \mathrm{L})$ of propargite in one of the samples (U.S. Geological Survey, 1999).

Figures $24(G, H)$ show the temporal patterns in concentrations for the two agricultural sites in the Willamette River Basin in Oregon. The concentration patterns are somewhat similar for these two sites, with detectable levels of herbicides and insecticides 
A. Isus-mill
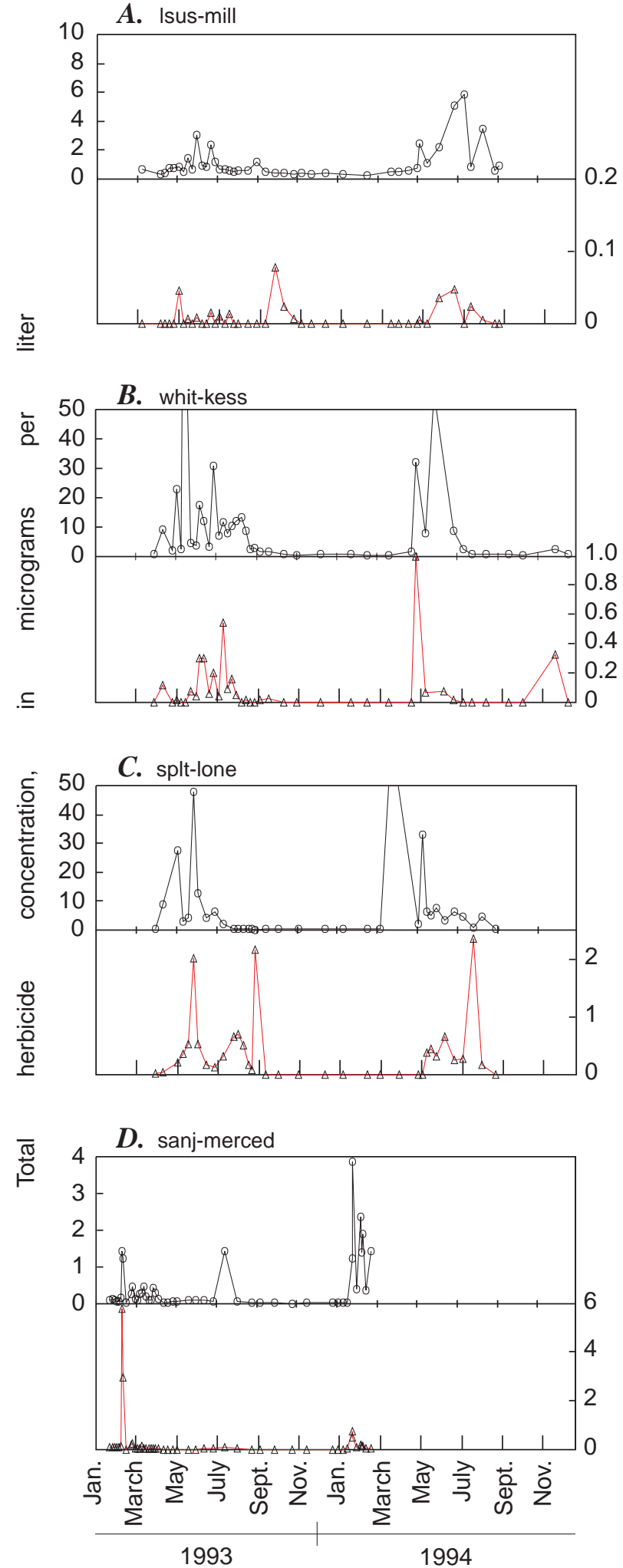

E. sanj-salt
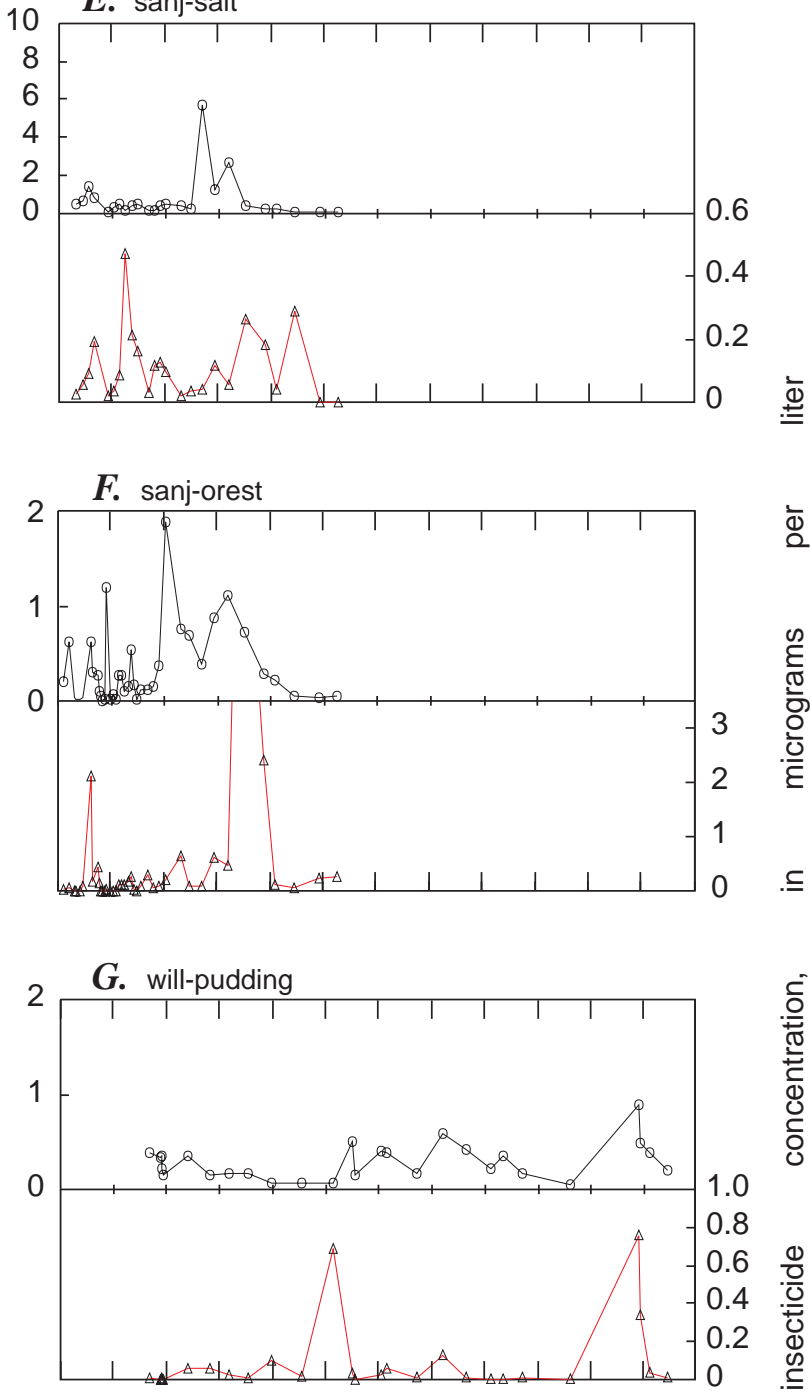

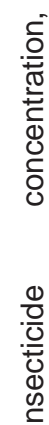

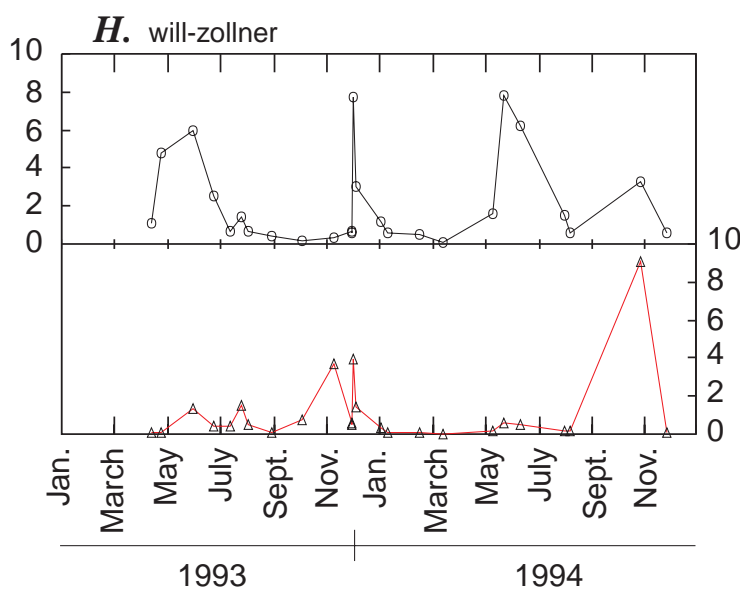

Figure 24. Examples of temporal concentration patterns at eight agricultural indicator sites. The upper plot for each site show s total herbicide concentrations, and the lower plot shows total insecticide concentrations. The concentration of total herbicides is show $n$ on the left axis, and the concentration of total insecticides is shown on the right axis. The same 2-year period is show $\mathrm{n}$ for each site. Samples with no detections of either herbicides or insecticides were assigned a concentration of zero. 
throughout much of the year and elevated concentrations in early summer and autumn.

Concentrations in Zollner Creek, however, generally were much higher than concentrations in the Pudding River. Similar to the San Joaquin River valley, a wide variety of crops is grown in Willamette River Basin and use of pesticides is high.

The plots of total herbicide and insecticide concentrations in figure 24 show some generally consistent patterns among these sites. Each site, however, had its own unique temporal concentration pattern, and therefore, it is difficult to generalize, even among sites representing similar crop groups. For example, the peaks in insecticide concentrations shown in figure $24(A-C)$ were caused by different insecticides at each site. In Mill Creek in Pennsylvania (lsus-mill), the main contributors to the peaks in total insecticide concentration were diazinon, carbaryl, and chlorpyrifos. These peaks could be the result of nonagricultural pesticide use. In Kessinger Ditch in Indiana (whit-kess), the peaks in total insecticide concentration primarily were due to carbofuran and carbaryl. In Lonetree Creek in Colorado (splt-lone), each peak in total insecticide concentration was due to a different insecticide or group of insecticides. The first peak, in late May of 1993, represents elevated concentrations of carbofuran, terbufos, phorate, and chlorpyrifos. The second peak, in late August of 1993, represents concentrations of carbaryl and diazinon. The third peak, in July of 1994, was almost entirely due to a high concentration of propargite. Thus, despite the generally consistent temporal patterns in pesticide concentrations for many of these sites (fig. 24), the timing and the magnitude of elevated concentrations of specific pesticides can be influenced by unique situations that can occur within individual drainage basins.

\section{Urban Indicator Sites}

\section{Detection Frequencies}

Several pesticides were detected much more frequently in streams draining urban basins than in streams draining agricultural basins (figs. 14 and 15). The herbicides simazine and prometon and the insecticides diazinon, carbaryl, chlorpyrifos, and malathion were detected much more frequently at most urban sites than at most agricultural sites. The annual mean detection frequencies of these compounds are compared in figure 25 for urban and agricultural sites.

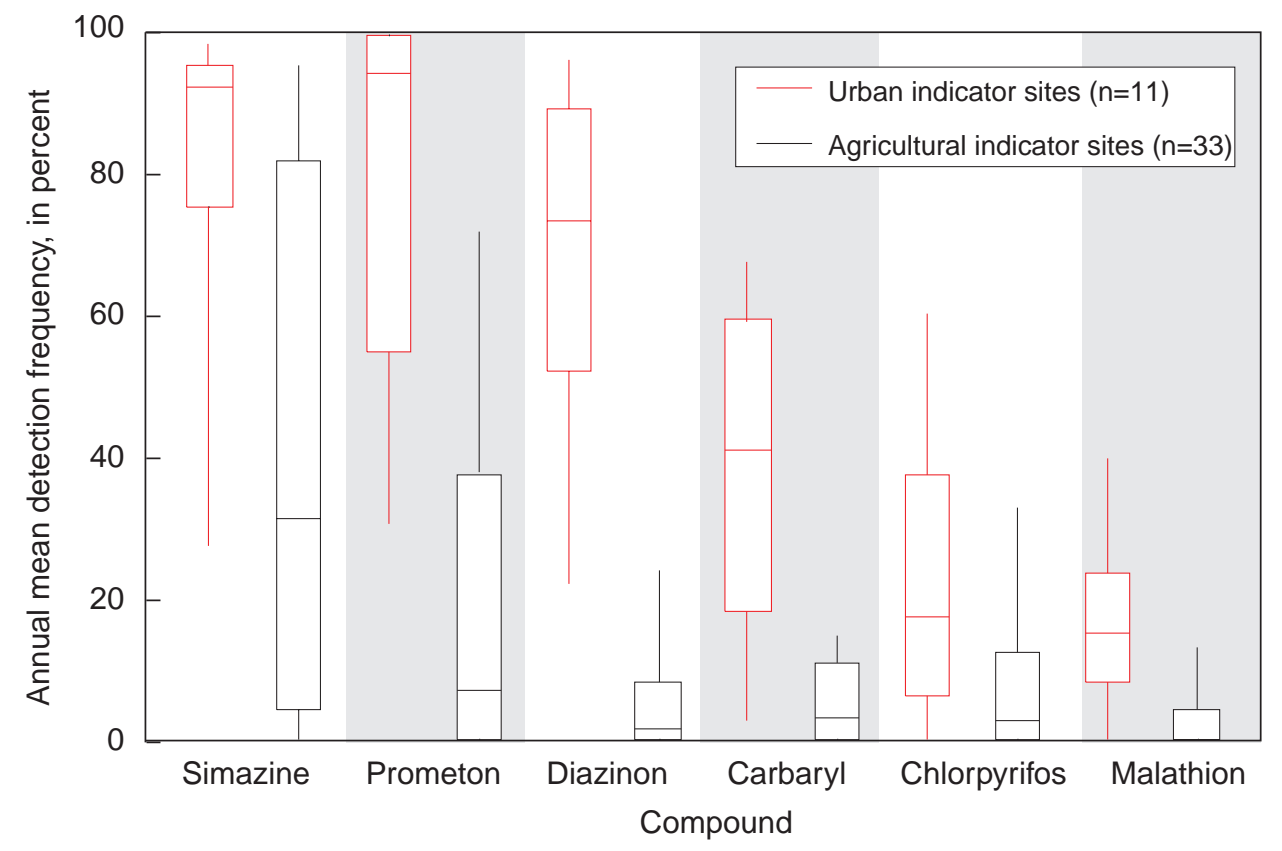

Figure 25. Distribution of annual mean detection frequencies of compounds consistently detected more frequently at urban indicator sites than at most agricultural indicator sites. Each box represents the distribution of detection frequencies for a specific compound among the sites in each group for a 1 -year period. A common reporting level of 0.01 microgram per liter was used for calculation of detection frequencies for all compounds. (See figure $5 \mathrm{~A}$ and associated text for an explanation of 
Together, these six compounds serve as a signature of urban influences in a basin because their concentrations were elevated at nearly all urban indicator sites for much of the year. The herbicide tebuthiuron also was detected more frequently at most urban sites than at most agricultural indicator or integrator sites (fig. 15). All seven of these pesticides have significant nonagricultural use (Meister, 1996; Larson and others, 1997), but data on the actual amounts of these pesticides used in urban areas are not currently available.

Pesticides that are used primarily for agriculture, such as atrazine and metolachlor, also were detected frequently at many of the urban indicator sites (fig. $14 B)$. The frequent detection of these pesticides probably is due to the presence of some cropland in most of the urban basins (fig. 3). Atrazine is registered for use on turf grass in several southeastern states; the actual amounts used are unknown. Atrazine was detected frequently in some urban basins with very little cropland; these basins are in parts of the country where atrazine is not registered for home use. For example, in Cherry Creek in Colorado (splt-cherry) and Fanno Creek in Oregon (will-fanno), each of which have about 2 percent cropland in their drainage basins, the detection frequencies of atrazine in 1993 were 88 and 100 percent, respectively (U.S. Geological Survey, 1999). Atrazine and several other commonly used agricultural herbicides have been detected frequently in precipitation and air samples in several regions of the United States (Capel, 1991; Wotzka and others, 1994; Goolsby and others, 1997). The atmospheric deposition of these compounds may partly explain their frequent detection in streams draining urban basins. The presence of agricultural pesticides in urban streams helps explain why the number of pesticides detected in streams draining urban and agricultural basins is similar in most cases (fig. 12). Most of the urban streams discussed in this report contain the urban signature compounds, as well as low-level concentrations of agricultural pesticides used in the region.

\section{Concentrations}

The distribution of total herbicide and insecticide concentrations measured at the urban indicator sites is shown in figure 16. The general characteristics of these distributions were discussed previously. The most obvious difference between concentrations at the urban indicator sites and concentrations at the agricultural indicator and the integrator sites is the higher incidence of elevated levels of insecticides at the urban sites. The distributions of total herbicide and insecticide concentrations at the urban sites are nearly identical if the aggregated data at the urban sites are used. This distribution is in sharp contrast to the distribution for the agricultural and the integrator sites where elevated herbicide concentrations were much more common than elevated insecticide concentrations. Nearly 100 percent of the monthly median concentrations of total herbicides and insecticides were greater than $0.01 \mu \mathrm{g} / \mathrm{L}$ at the urban sites (fig. 16), which indicates that both types of pesticides were at detectable levels in streams draining urban basins for much of the year.

The range of concentrations of individual pesticides detected at the 11 urban indicator sites is shown in figure 26 . These plots are analogous to those in figures 22 and 23 and show monthly median concentrations of the pesticides that were detected most frequently at the urban sites. The 3 herbicides and 4 insecticides shown in figure 26 were detected more frequently at urban sites than at agricultural or integrator sites. The plots in figure 26 are used in the next two sections to illustrate the concentration ranges of specific herbicides and insecticides detected at the urban sites.

\section{Herbicides}

Monthly median concentrations of simazine ranged from 0.01 to $1.0 \mu \mathrm{g} / \mathrm{L}$ at most urban indicator sites (fig. 26A). Concentrations at these sites were similar to, or higher than, concentrations of simazine at most of the agricultural indicator sites and integrator sites. Monthly median concentrations greater than 0.1 $\mu \mathrm{g} / \mathrm{L}$ were common at four sites-Accotink Creek in Virginia (poto-acco), Sope Creek in Georgia (acfbsope), Rush Creek in Texas (trin-rush), and Las Vegas Wash in Nevada (nvbr-lasvegas). Only one site-Accotink Creek (poto-acco)—had a monthly median concentration greater than $1 \mu \mathrm{g} / \mathrm{L}$. Simazine concentrations in individual samples from this site were greater than $1 \mu \mathrm{g} / \mathrm{L}$ for 4 consecutive months during 1994. There was no reported agricultural use of simazine in Accotink Creek Basin during the sampling period (Gianessi and Anderson, 1996) which suggests that these relatively high concentrations were the result of nonagricultural use. Two sites-Norwalk River in Connecticut (conn-norwalk) and Lisha Kill in New York (hdsn-lisha)—had much lower simazine 
A. simazine

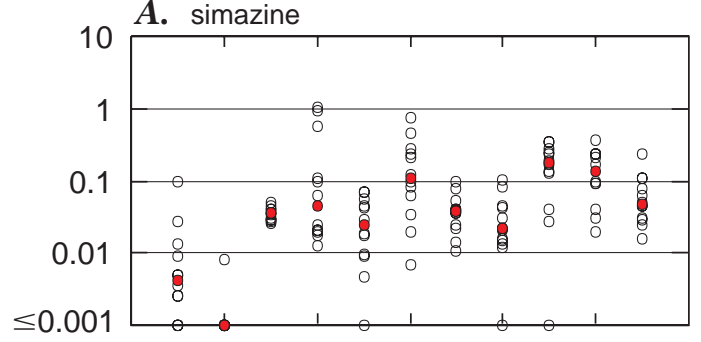

B. prometon

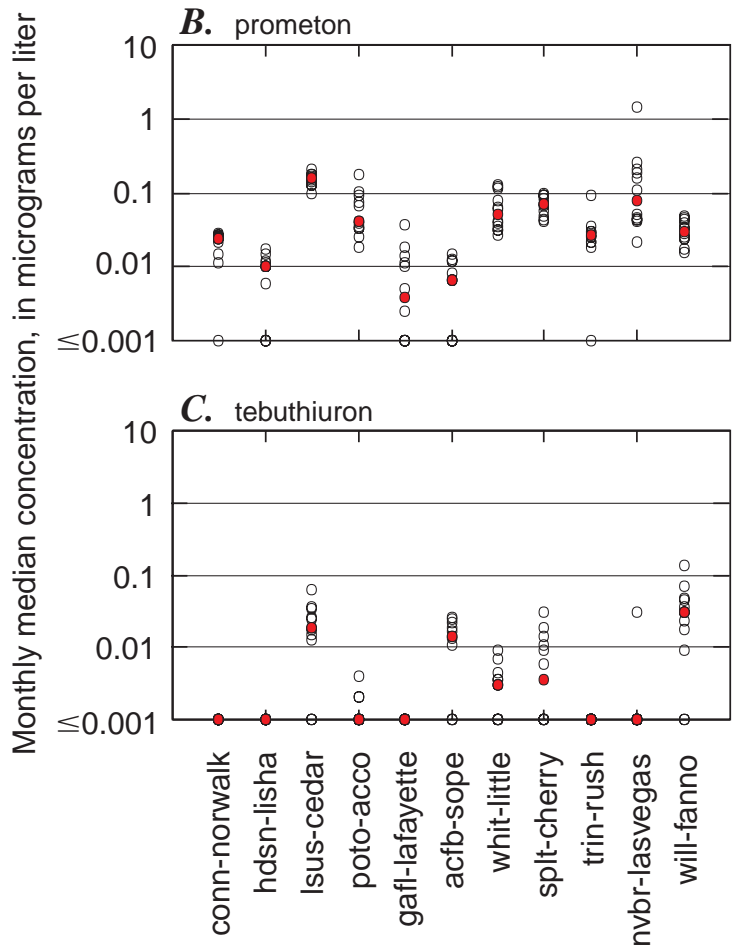

Sampling site code
Insecticides
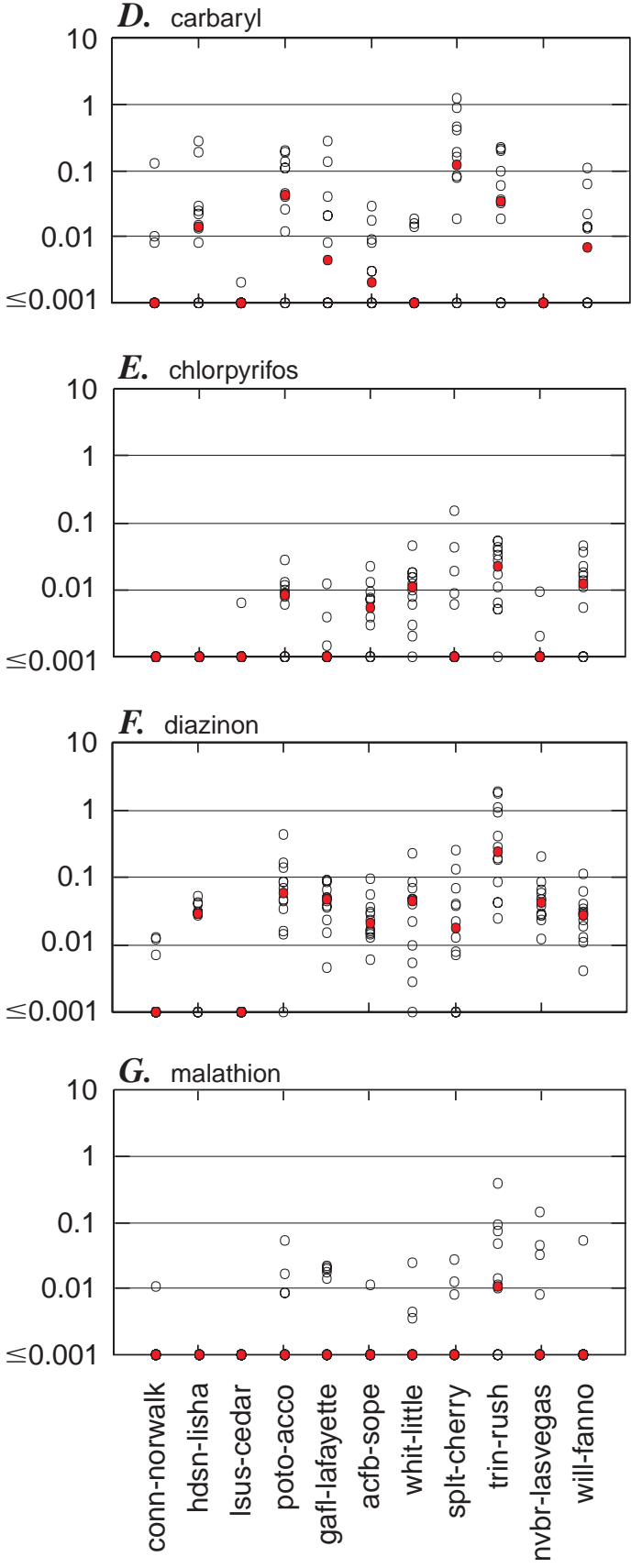

Sampling site code

Figure 26. M onthly median concentrations of selected compounds at 11 urban indic ator sites during a 1-year period. Each value represents the median concentration for 1 month. The annual median for each site is shown in red. M onthly median concentrations less than the detection limit are shown on the $x$-axis. For sites at which all 12 monthly values were less than the detection limit, the annual median value is plotted on the $x$-axis. The order of sites, from left to right, is approximately east to west and is in the same order as presented in table 1 . Site codes are defined in table 1. 
concentrations than the other urban sites for most of the year. At most of the urban sites, concentrations of simazine varied substantially throughout the year, as shown by the large range in the monthly median concentrations (fig. 26A). Monthly median concentrations were higher than the detection limit for the entire year at 6 of the 11 sites.

Monthly median concentrations of prometon (fig. 26B) ranged from 0.01 to $0.1 \mu \mathrm{g} / \mathrm{L}$ at most urban sites. This relatively narrow range indicates that prometon concentrations were relatively consistent for much of the year at most of the urban sites. Prometon concentrations at the urban sites were higher than concentrations at most of the agricultural and the integrator sites. Prometon is used almost exclusively in nonagricultural settings, although there is little quantitative information available on the amounts used.

Monthly median concentrations of tebuthiuron (fig. 26C) were between 0.01 and $0.1 \mu \mathrm{g} / \mathrm{L}$ at 3 of the urban sites (lsus-cedar, acfb-sope and will-fanno) throughout much of the year, but concentrations were considerably lower at the other 8 sites. Monthly median concentrations were less than the detection limit for the entire year at 4 sites. Tebuthiuron has virtually no reported agricultural use in the United States (Gianessi and Anderson, 1996), and little information is available on the quantities used in nonagricultural settings.

\section{Insecticides}

Carbaryl concentrations (fig. 26D) varied considerably among the urban indicator sites. At several sites, monthly median concentrations ranged from 0.01 to about $0.2 \mu \mathrm{g} / \mathrm{L}$ during most months. Carbaryl concentrations at these sites were higher than concentrations at nearly all the agricultural sites (fig. 23). The highest carbaryl concentrations were detected in Cherry Creek in Denver, Colorado (splt-cherry) where monthly median concentrations were greater than $0.1 \mu \mathrm{g} / \mathrm{L}$ for 6 of the 12 months. Concentrations were substantially lower at seven urban sites, with most monthly median concentrations less than $0.01 \mu \mathrm{g} / \mathrm{L}$.

Chlorpyrifos concentrations (fig. 26E) also varied among the urban sites. At five sites, most monthly median concentrations ranged from about 0.002 to $0.05 \mu \mathrm{g} / \mathrm{L}$. Chlorpyrifos concentrations at these sites were comparable with concentrations detected at agricultural sites in the San Joaquin and Willamette River basins but higher than concentrations detected at all other agricultural sites (fig. 23).
Concentrations of chlorpyrifos were lower at the other six urban sites, with monthly median concentrations less than the detection limit during most months. Monthly median concentrations were less than the detection limit for the entire year at two urban sites, Norwalk River (conn-norwalk) and Lisha Kill (hdsnlisha).

Diazinon concentrations (fig. 26F) ranged from 0.01 to $0.1 \mu \mathrm{g} / \mathrm{L}$ for much of the year at nine of the urban sites. The highest concentrations were detected in Rush Creek in Arlington, Texas (trin-rush), where monthly median concentrations were greater than 0.1 $\mu \mathrm{g} / \mathrm{L}$ for most of the year and greater than $1 \mu \mathrm{g} / \mathrm{L}$ during several months. Diazinon concentrations at most urban sites were comparable with concentrations at agricultural sites in the San Joaquin and Willamette River basins and higher than concentrations at all other agricultural sites (fig. 23). Concentrations were much lower at the other two urban sites-Norwalk River in Connecticut (conn-norwalk) and Cedar Run in Pennsylvania (lsus-cedar) - where concentrations were less than the detection limit during most months.

Although malathion was detected more frequently at the urban sites than at the agricultural or the integrator sites, concentrations were quite low for much of the year (fig. 26G). For months in which malathion was detected, monthly median concentrations generally were less than $0.1 \mu \mathrm{g} / \mathrm{L}$. Only at Rush Creek (trin-rush) were more than half of the monthly median concentrations of malathion greater than the detection limit.

\section{Seasonal Patterns}

Seasonal patterns in the occurrence of pesticides were less obvious for the urban indicator sites than for the agricultural indicator sites and the integrator sites. In terms of both the number of compounds detected in each sample (fig. 17) and the monthly median concentrations (fig. 18), there was little difference between the critical period and the rest of the year at most urban sites for both herbicides and insecticides.

The temporal patterns for pesticide concentrations at urban sites can be examined more closely by looking at results from individual sites (fig. 27). Although concentrations varied throughout the year at several urban sites, no clear seasonal pattern is evident among the eight sites shown in figure 27. At several sites, including Norwalk River (conn-norwalk), Lisha Kill (hdsn-lisha), Lafayette Creek (gafl- 

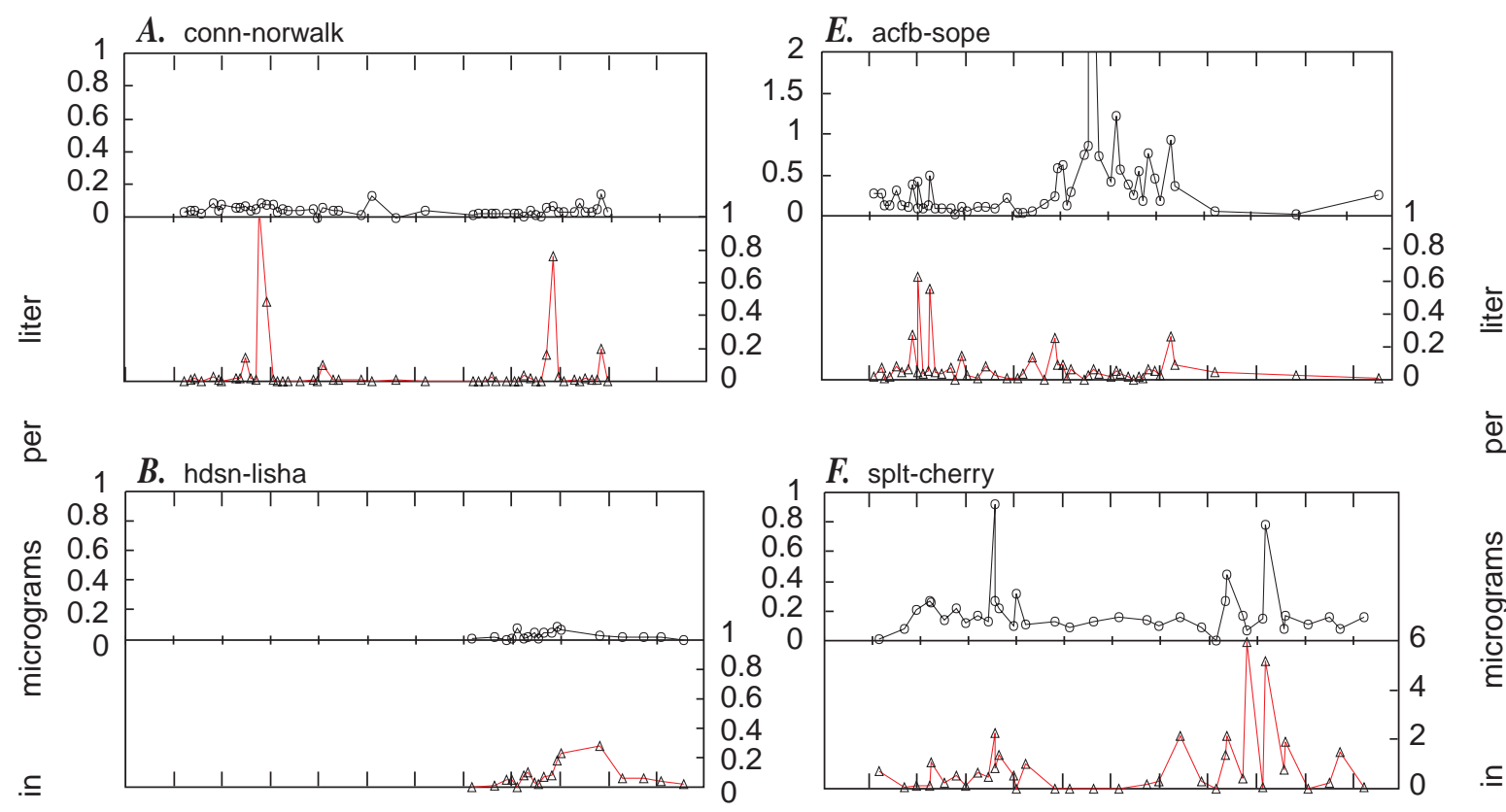

F. splt-cherry

$\grave{\bar{\varpi}}$
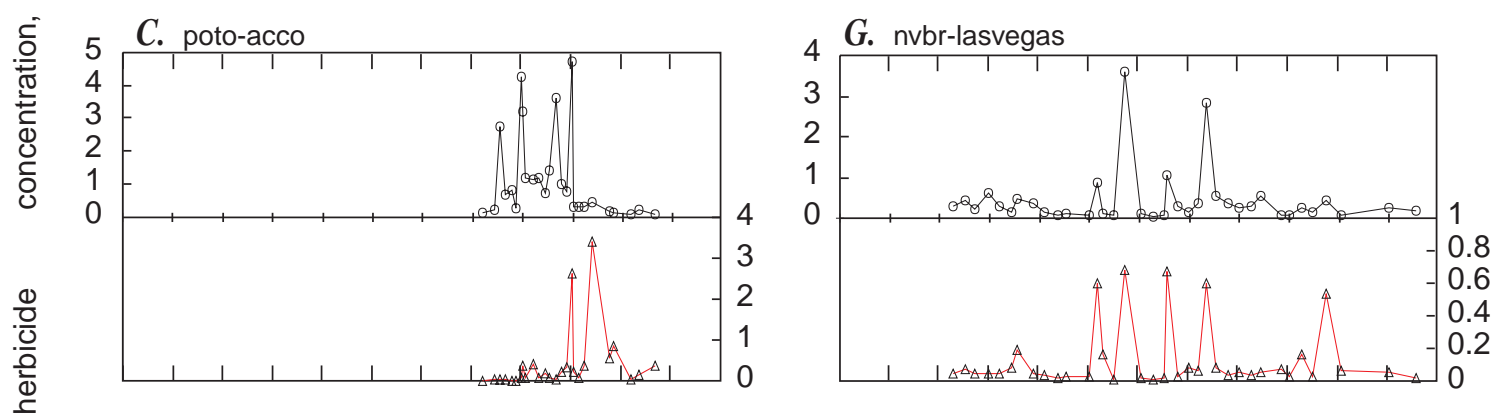

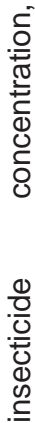
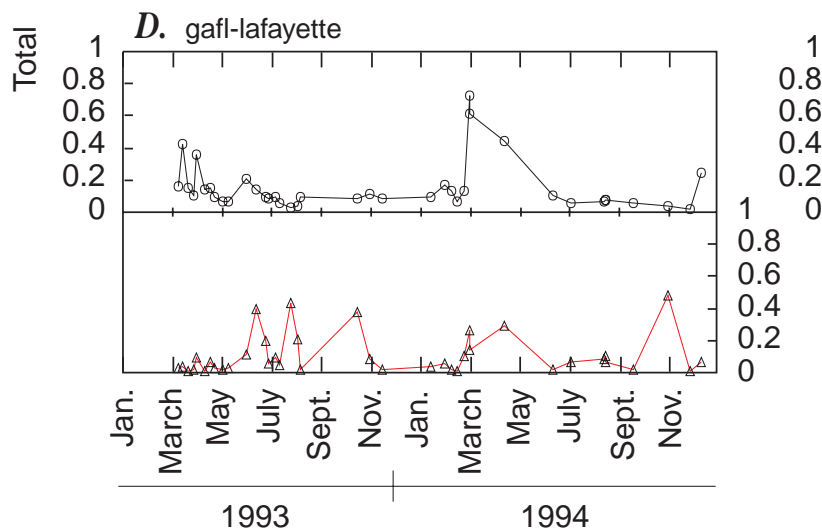

H. will-fanno

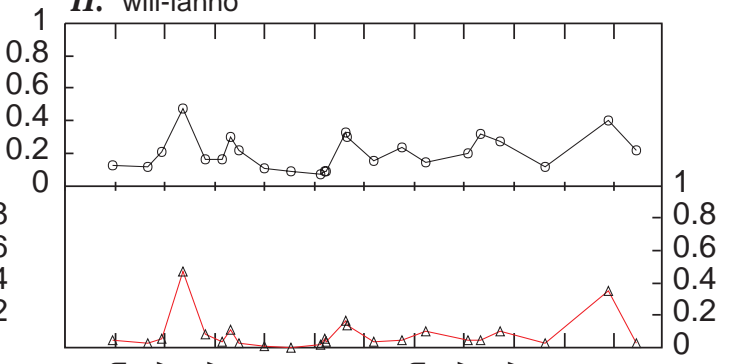

$\stackrel{\bar{\pi}}{\stackrel{0}{0}}$

Figure 27. Examples of temporal concentration patterns at eight urban indicator sites. The upper plot for each site shows total herbic ide concentrations, and the lower plot show s total insecticide concentrations. Total herbic ide concentrations are show $\mathrm{n}$ on the left axis and total insectic ide concentrations are show $n$ on the right axis. The same 2-year period is shown for each site. The three urban sites that have a signific ant portion of agricultural land in their drainage basins- Cedar Run in Pennsylvania (Isus-cedar), Little Buck Creek in Indiana (whit-little), and Rush Creek in Texas (trin-rush) - are not included in these plots so that the concentration patterns show $n$ are primarily the results of urban influences. 
lafayette), and Fanno Creek (will-fanno), total herbicide concentrations were relatively low in all samples. At other sites, including Sope Creek (acfbsope), Las Vegas Wash (nvbr-lasvegas), and Accotink Creek (poto-acco), herbicide concentrations were elevated for long periods at various times of the year. Elevated total herbicide concentrations at most of the urban sites were almost entirely due to concentrations of simazine, prometon, and atrazine. Insecticide concentration patterns also were variable at the urban sites. Distinct spikes in insecticide concentrations were observed at several sites, including Norwalk River (conn-norwalk), Sope Creek (acfb-sope), and Las Vegas Wash (nvbr-lasvegas). Insecticide concentrations were elevated for much of the year at other sites, including Cherry Creek (splt-cherry), Lafayette Creek (gafl-lafayette), and Accotink Creek (poto-acco). At most sites, elevated total insecticide concentrations were due to concentrations of diazinon, carbaryl, and malathion.

\section{Integrator Sites}

\section{Detection Frequencies}

At the integrator sites, the overall detection frequencies of several agricultural herbicides were similar to or somewhat higher than the detection frequencies at the agricultural indicator sites (figs. 14 and 15). This was true for all the most commonly detected agricultural herbicides, including atrazine, metolachlor, alachlor, and cyanazine and the atrazine transformation product DEA. These somewhat higher detection frequencies are not surprising because a wider variety of crops generally are grown in the integrator basins and because all the integrator basins likely received applications of these widely used herbicides. The agricultural indicator sites, on the other hand, represent specific crops or groups of crops, some of which received little or no application of these compounds. At the integrator sites, detection frequencies of pesticides with substantial nonagricultural use, including several insecticides and the herbicides prometon and simazine, generally were between the detection frequencies at the agricultural and the urban sites. Between 3 and 7 percent of the land within most integrator basins is urban land (fig. 3), and therefore, detection of compounds with substantial urban use is likely. In most of the urban basins, however, more than 60 percent of the land is urban land, resulting in a much stronger urban signal and higher detection frequencies for these pesticides.

\section{Concentrations}

Aggregated data from each group of sites indicate that total herbicide and insecticide concentrations measured at the integrator sites were very similar to concentrations measured at the agricultural indicator sites (fig. 16). The general characteristics of the distribution of concentrations for the integrator sites were discussed previously. Monthly median total herbicide concentrations between 0.01 and $0.1 \mu \mathrm{g} / \mathrm{L}$ were slightly more common at the integrator sites than at the agricultural indicator sites, but distributions at these two types of sites were nearly identical for concentrations greater than $0.1 \mu \mathrm{g} / \mathrm{L}$ (fig. $16 A)$. The more common occurrence of herbicides at moderate concentrations at the integrator sites is consistent with the general pattern of a longer period of elevated concentrations in streams with larger drainage basins (Richard and Baker, 1993; Larson and others, 1995). The distributions of total insecticide concentrations were very similar at the integrator sites and the agricultural indicator sites (fig. 16B).

The range of concentrations of individual pesticides measured at the 10 integrator sites are shown in figure 28. These plots are analogous to those in figures 22, 23, and 26 and show monthly median concentrations of pesticides detected frequently at the integrator sites. The plots in figure 28 are used in the next two sections to illustrate the range in concentrations of specific herbicides and insecticides measured at the integrator sites.

\section{Herbicides}

Monthly median concentrations of atrazine were less variable among the integrator sites (fig. 28A) than among the agricultural indicator sites (fig. 22B), with concentrations between 0.01 and $0.1 \mu \mathrm{g} / \mathrm{L}$ for most of the year at most sites. The two integrator sites with the highest atrazine concentrations- the White River in Indiana (whit-white) and the Platte River in Nebraska (cnbr-platte) — had relatively high atrazine use compared with the other integrator sites (table 6). A strong seasonal peak in atrazine concentrations at these two sites is evident in figure 28A, with monthly median concentrations greater than $1 \mu \mathrm{g} / \mathrm{L}$ for several months during the growing season. Atrazine concentrations were lowest in the San Joaquin River in California 


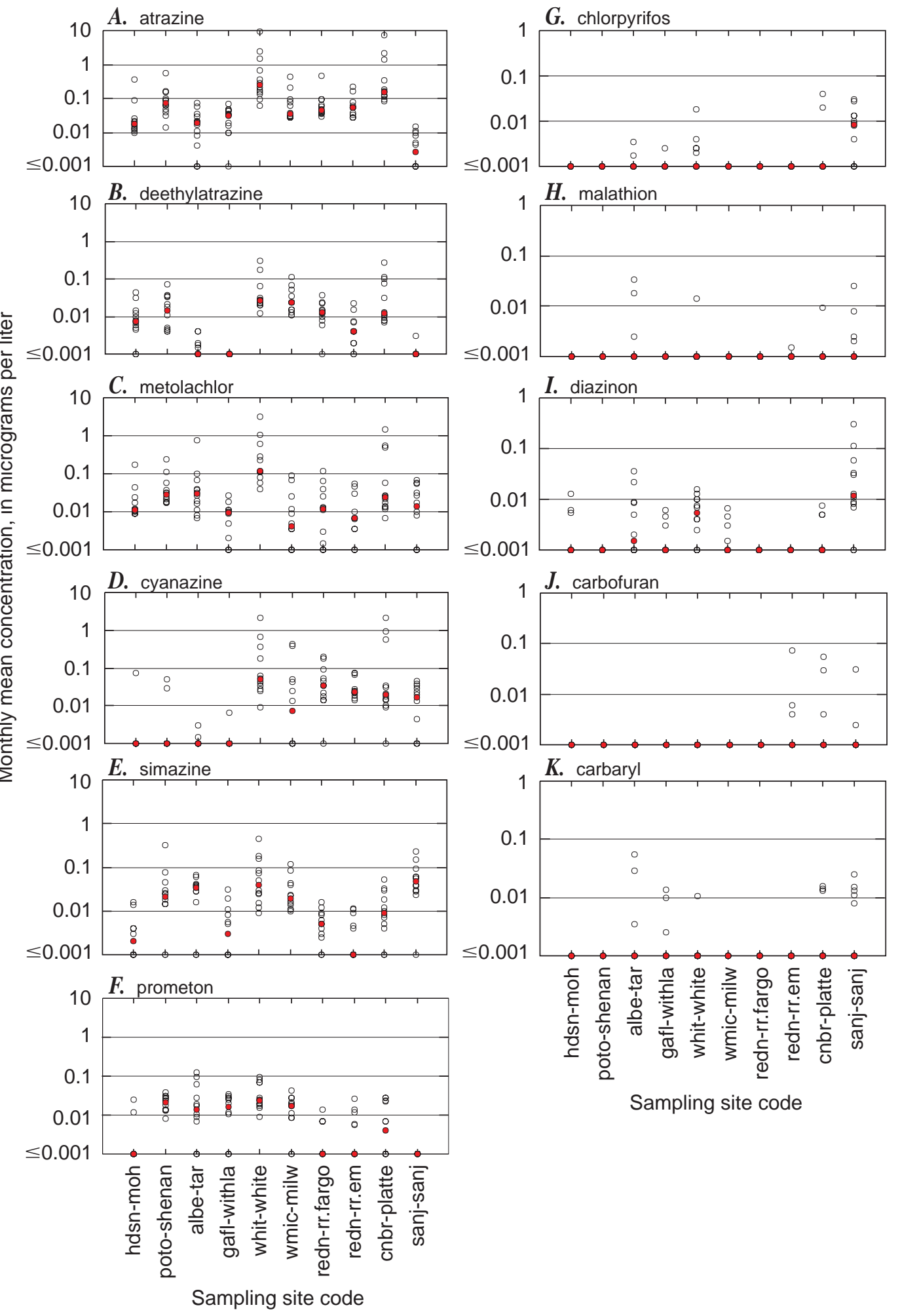

Figure 28. M onthly median concentrations of selected compounds at 10 integrator sites duirng a 1-year period. Each value represents the median concentration for 1 month. The annual median for each site is show $n$ in red. M edian concentrations less than the detection limit are shown on the $x$-axis. For the sites at which all 12 monthly medians were less than the detection limit, the annual median value is plotted on the $x$-axis. The order of sites, from left to right, is approximately east to west and is in the same order as presented in table 1 . Site codes are defined in table 1. 
(sanj-sanj) where atrazine use in the basin is relatively low. Monthly median concentrations were greater than $0.01 \mu \mathrm{g} / \mathrm{L}$ for the entire year at seven of the integrator sites (fig. 28A).

Concentrations of DEA (fig. 28B) generally followed the same spatial pattern at the integrator sites as concentrations of atrazine, but the monthly median concentrations were 5 to 10 times lower at most of the sites. Detectable levels of DEA were present for most of the year at seven of the integrator sites. The concentrations of DEA shown in figure 28 are probably biased low because of the low analytical recovery of DEA (table 2).

At most of the integrator sites, monthly median concentrations of metolachlor were similar to the monthly median concentrations of atrazine, ranging from 0.01 to $0.1 \mu \mathrm{g} / \mathrm{L}$ for much of the year (fig. 28C). Concentrations of metolachlor were more consistent among the integrator sites than were concentrations of atrazine, which is consistent with the more uniform use of metolachlor in these basins (table 6). The highest metolachlor concentrations were in the White River (whit-white). Use of metolachlor was the highest (per unit area) in the White River Basin than in any other of the integrator basins.

Concentrations of cyanazine were variable among the integrator sites (fig. 28D). Monthly median concentrations were less than the detection limit for most of the year at the four eastern sites where use of cyanazine was relatively low. Concentrations ranged from 0.01 to $0.1 \mu \mathrm{g} / \mathrm{L}$ for much of the year at the other six sites. The White River site (whit-white) had the highest cyanazine concentrations (fig. $28 \mathrm{D}$ ) and the highest reported use of cyanazine (table 6) compared with the other integrator sites. Concentrations of cyanazine at the other integrator sites did not correlate well with agricultural-use data, as concentrations were similar at sites with widely differing values for cyanazine use (table 6).

Concentrations of simazine (fig. 28E) also were variable among the integrator sites, with monthly median concentrations between 0.01 and $0.1 \mu \mathrm{g} / \mathrm{L}$ for much of the year at several sites but much lower at other sites. Simazine concentrations generally were highest in the San Joaquin River (sanj-sanj), which is the only integrator basin with substantial agricultural use of simazine (table 6). Simazine concentrations were low, but detectable, for much of the year at sites in areas with low population density - the Platte (cnbr- platte) and Red River basins (redn-rr.fargo and rednrr.em) (table 1). Concentrations also were low in the Mohawk River in New York (hdsn-moh), however, which drains an area of relatively high population density.

Prometon concentrations (fig. 28F) were between 0.01 and $0.1 \mu \mathrm{g} / \mathrm{L}$ for much of the year at five of the integrator sites but much lower at the other sites. Similar to simazine, concentrations were low at sites in the Platte and Red rivers (cnbr-platte, redn-rr.fargo, and redn-rr.em) where population density is low, but concentrations also were low in the Mohawk River (hdsn-moh) where population density is relatively high. Monthly median concentrations of prometon were less than the detection limit for the entire year in the San Joaquin River (sanj-sanj).

\section{Insecticides}

With the exception of diazinon, concentrations of insecticides generally were low at the integrator sites (figs. $28 \mathrm{G}-K$ ). Median concentrations of chlorpyrifos, malathion, carbofuran, and carbaryl were less than 0.01 $\mu \mathrm{g} / \mathrm{L}$ during most months at all 10 integrator sites. These concentrations are similar to those measured at most of the agricultural sites for these insecticides, with monthly median concentrations less than the detection limit for much of the year. Concentrations of chlorpyrifos, diazinon, and carbaryl were higher in the San Joaquin River (sanj-sanj). Monthly median concentrations of diazinon were greater than the detection limit for much of the year at three sites - the San Joaquin River (sanj-sanj) where diazinon has extensive agricultural use, the Tar River in North Carolina (albe-tar) where diazinon has moderate agricultural use and population density is relatively high, and the White River in Indiana (whit-white) where there is little reported agricultural use, but population density is high. Previous studies of diazinon occurrence in large midwestern rivers have reported a positive correlation between population density in a drainage basin and the amount of diazinon transported in the river (Larson and others, 1995).

\section{PESTICIDE LOAD IN RELATION TO USE}

The transport of pesticides in different types of streams was discussed previously in terms of yield, or load per unit area. A wide range in annual pesticide 
yields was observed, with estimates ranging more than three orders of magnitude for the agricultural sites (fig. 19). Much of this variability is caused by differences in the amounts of pesticides used in the agricultural basins. Comparisons of loads among the basins can be made more effectively by expressing the annual pesticide load as a percentage of the annual use in the drainage basin.

The general relation between pesticide load and pesticide use is shown in figure 29. These plots show the estimated annual stream load of each pesticide in relation to the amount of that pesticide used agriculturally in the basin. All target compounds with reported agricultural use of 100 kilograms $(\mathrm{kg})$ or more in a basin are included. For basins with low pesticide use, represented by points on the left side of the plots in figure 29, the percentages were highly variable, ranging more than three orders of magnitude. Many of these points represent small agricultural basins for which accurate load estimates are difficult to obtain, as discussed previously. Moreover, the pesticide-use estimates for small basins are probably much less

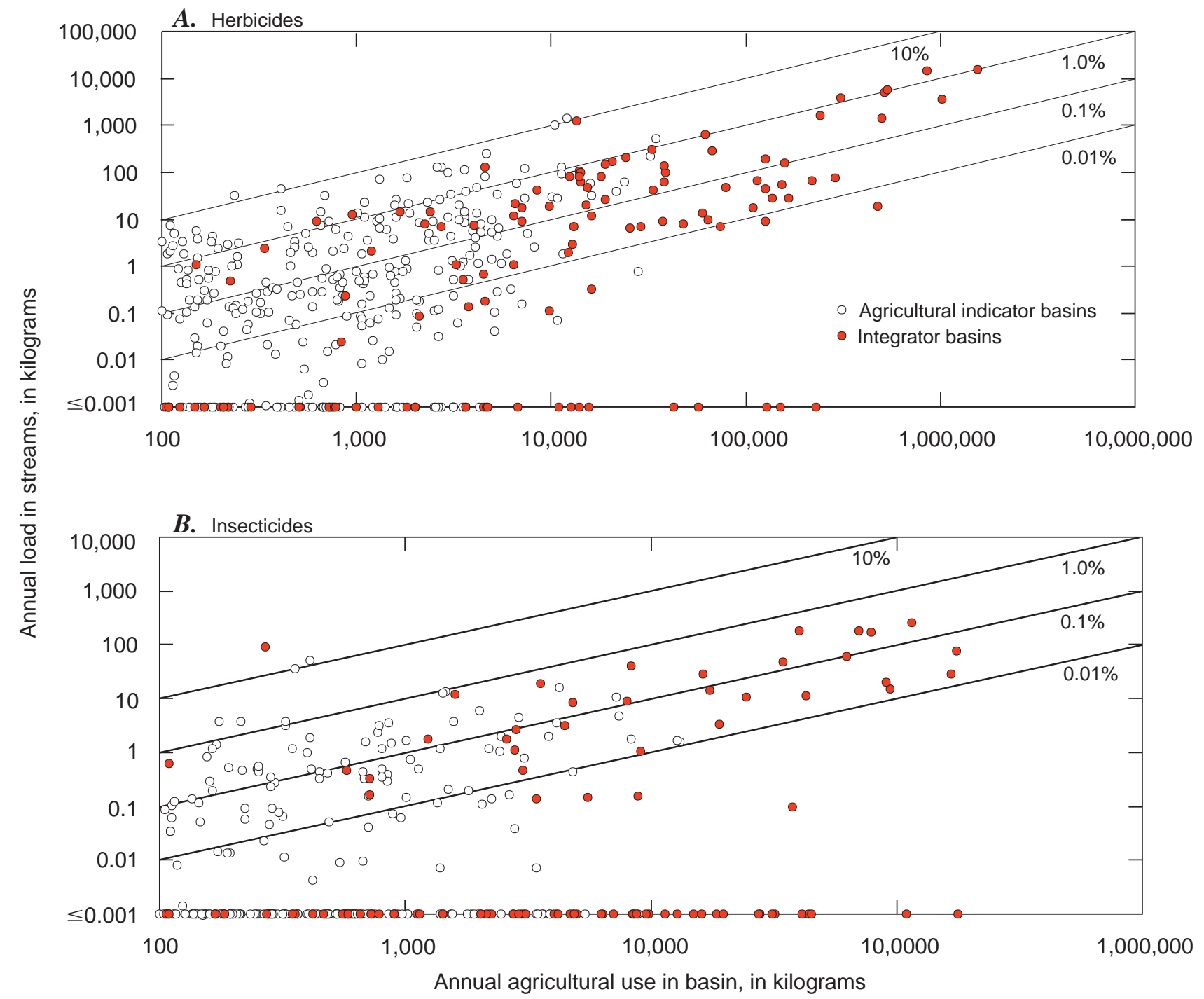

Figure 29. Annual load of $(\boldsymbol{A})$ herbicides and $(\boldsymbol{B})$ insecticides in streams in relation to agric ultural use in the drainage basin of a particular stream. Each value represents the load of a specific compound at one site. The diagonal lines represent theoretical percentages of the amount of pesticides used in the basin. For example, a point on the lowest diagonal line means that the estimated load of one pesticide at a specific sampling site was 0.01 percent of the amount of that pesticide applied agriculturally in the basin of that site. Agricultural-use data are from Gianessi and Anderson (1996) 
reliable than for larger basins. Points on the right side of the plots in figure 29, which show results from integrator sites and the larger agricultural sites, are probably a more accurate representation of the relation between pesticide use and pesticide load in streams.

The estimated load for many compounds, both herbicides and insecticides, was between 0.01 and 1.0 percent of the amount applied in the basin. The points along the bottom of the plots in figure 29 show that at some sites there was no measurable load (all nondetections were assumed to be zero) for a number of compounds despite relatively high use in the basin.
The large variability in the values for load as a percentage of use is to be expected for this diverse group of compounds which have considerable variability in physical properties and in application practices (Larson and others, 1995). In addition, the sites represent basins with a wide range of soil types, climate, and topography, all of which influence the runoff of pesticides to streams.

Figure 29 shows that insecticide loads generally represent a somewhat smaller percentage of use than herbicide loads. This is shown more clearly in figure 30 , in which the total load of the target herbicides and

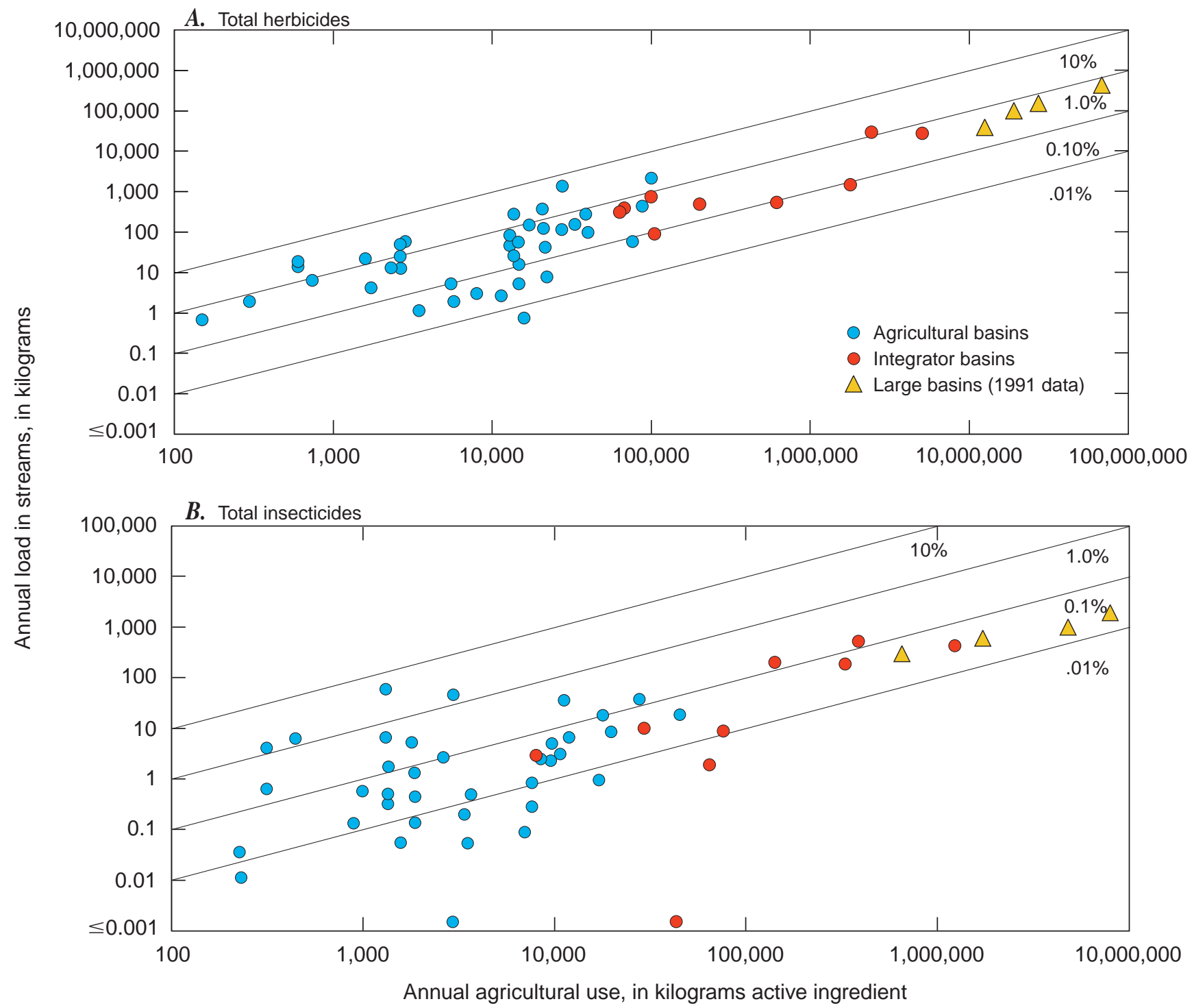

Figure 30. Annual load of $(\boldsymbol{A})$ total herbicides and $(\boldsymbol{B})$ insecticides in streams in relation to agricultural use in the drainage basin of a particular stream. Each value represents the annual load of total herbicides or total insecticides at one site. The diagonal lines represent theoretical percentages of the amount used in the basin. For example, a point on the low est diagonal line means that the estimated load at a particular sampling site was 0.01 percent of the amount applied agriculturally in the basin of that site. Agricultural-use data are from Gianessi and Anderson (1996). 
insecticides is plotted in relation to the total amount of the target herbicides and insecticides used

agriculturally in the basins. Data used for figure 30 are tabulated in table 7. Similar to figure 29, there is considerable scatter in the data in figure 30 for basins with low use. The total load of the target herbicides in basins with high herbicide use, however, generally represents between 0.1 and 1 percent of the total amount of the target herbicides used in the basins. The total load of the target insecticides is lower than the total herbicide load at most sites, representing 0.01 to 0.1 percent of the amount of the target insecticides used in the basins. The median values of the percentages calculated for each site are 0.52 for total herbicides and 0.04 for total insecticides (table 7). For comparison, data from several much larger basins are included in figure 30. These data show the relation between load and use in the Mississippi River Basin and several large subbasins from a 1991 study (Larson and others, 1995). The general agreement between the results from the 1991 study and the results from the NAWQA sites indicates that the relation between load and use is relatively constant over a wide range of spatial scales.

The percentages of pesticide use shown in figure 30 are based on the relation between the load of total (summed) herbicides and insecticides and their summed agricultural use and thus represent an average value for the target compounds. The percentage of pesticide use for a specific site is most influenced by those pesticides with the greatest use in the basin of that site. For example, the load of total herbicides in the Platte and White rivers was about 1 percent of the total amount of the target herbicides applied in their drainage basins. The Platte and White River basins are primarily in corn-growing areas, and the herbicides atrazine, metolachlor, and cyanazine accounted for 70 to 75 percent of total herbicides use. In contrast, the load of total herbicides in the Red River and Fargo (redn-rr.fargo) and at the Emerson (redn-rr.em) was about 0.1 percent of the total amount of the target herbicides applied in the basins of these sites. The main crops grown in both of the Red River basins are wheat and other grains and relatively small amounts of corn. The primary herbicides (of the target compounds included in this report) used in the basins of the Red River sites are trifluralin and EPTC. Atrazine, metolachlor, and cyanazine account for less than 25 percent of total herbicide use in the basins of the two Red River sites. As shown below, the loads of EPTC and trifluralin in streams consistently represent a smaller percentage of the amount of pesticides used in the basin than the loads of atrazine, metolachlor, and cyanazine; thus it is important to consider which specific pesticides are used when comparing loads of total herbicides or insecticides among basins.

The relation between load in streams and agricultural use in the basins of the streams is shown in figure 31 for several pesticides. Data used for figure 31 are tabulated in table 7. Loads of the herbicides atrazine, metolachlor, and cyanazine (fig. 31A-C) represent about 1 percent of the amounts of these compounds used in the drainage basins. Percentages of trifluralin and EPTC (fig. 31D,E) are lower than the percentages for atrazine, metolachlor, and cyanazine by 1 to 2 orders of magnitude, with loads representing about 0.01 to 0.1 percent of the amounts of trifluralin and EPTC used in the drainage basins. This large difference can partly be attributed to differences in the physical properties of these herbicides and their methods of agricultural application. Trifluralin and EPTC are considerably more volatile than atrazine, metolachlor, and cyanazine and generally are incorporated into the soil as they are applied, reducing the potential for transport in surface runoff. Atrazine, cyanazine, and metolachlor are commonly applied to the soil surface before crops have emerged from the soil, increasing the likelihood of transport in surface runoff. In addition, trifluralin has a strong tendency to become attached to soil particles, further reducing its potential for transport in surface runoff. Data from the 1991 study of the Mississippi River and several of its large tributaries (Larson and others, 1995) are included in figure $31 \mathrm{~A}-\mathrm{E}$. Values of loads as a percentage of use for the large rivers sampled in the 1991 study are consistent with the data from the integrator sites and from most of the agricultural indicator sites sampled during the current study. The general agreement between the results from the 1991 study and the results from the current study indicate that the relation between load in the streams and agricultural use in the basins is relatively constant for these herbicides among basins with widely varying use of these compounds.

Stream load was also compared to basin use for two of the most commonly detected insecticides, carbaryl (fig. $31 F$ ) and carbofuran (fig. $31 G$ ).

Variability was higher for these insecticides than for the herbicides, but the load at sites with high use of carbaryl and carbofuran in the drainage basins was relatively consistent at about 0.1 percent of the amount used in the basins. Determination of an accurate 


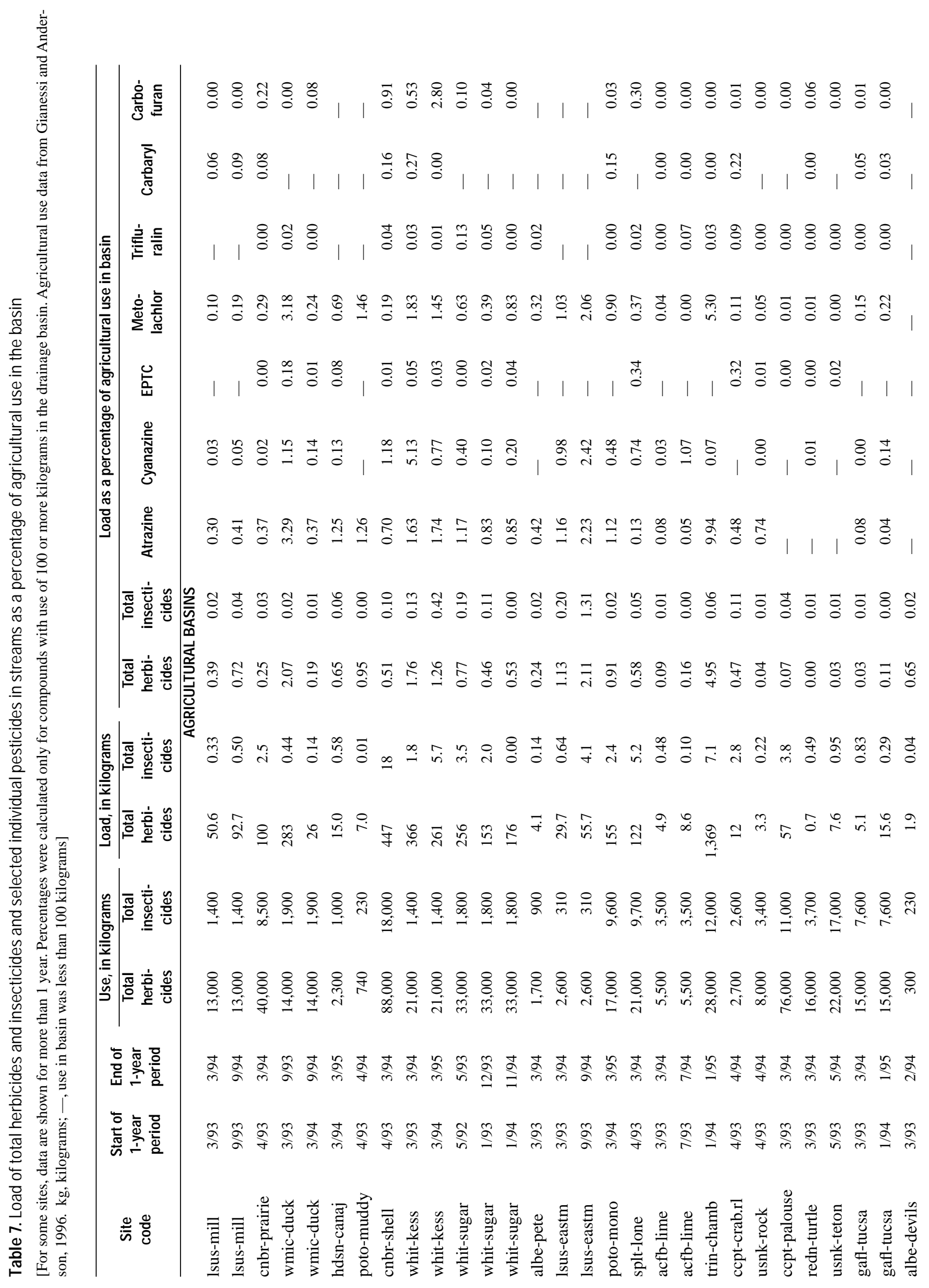




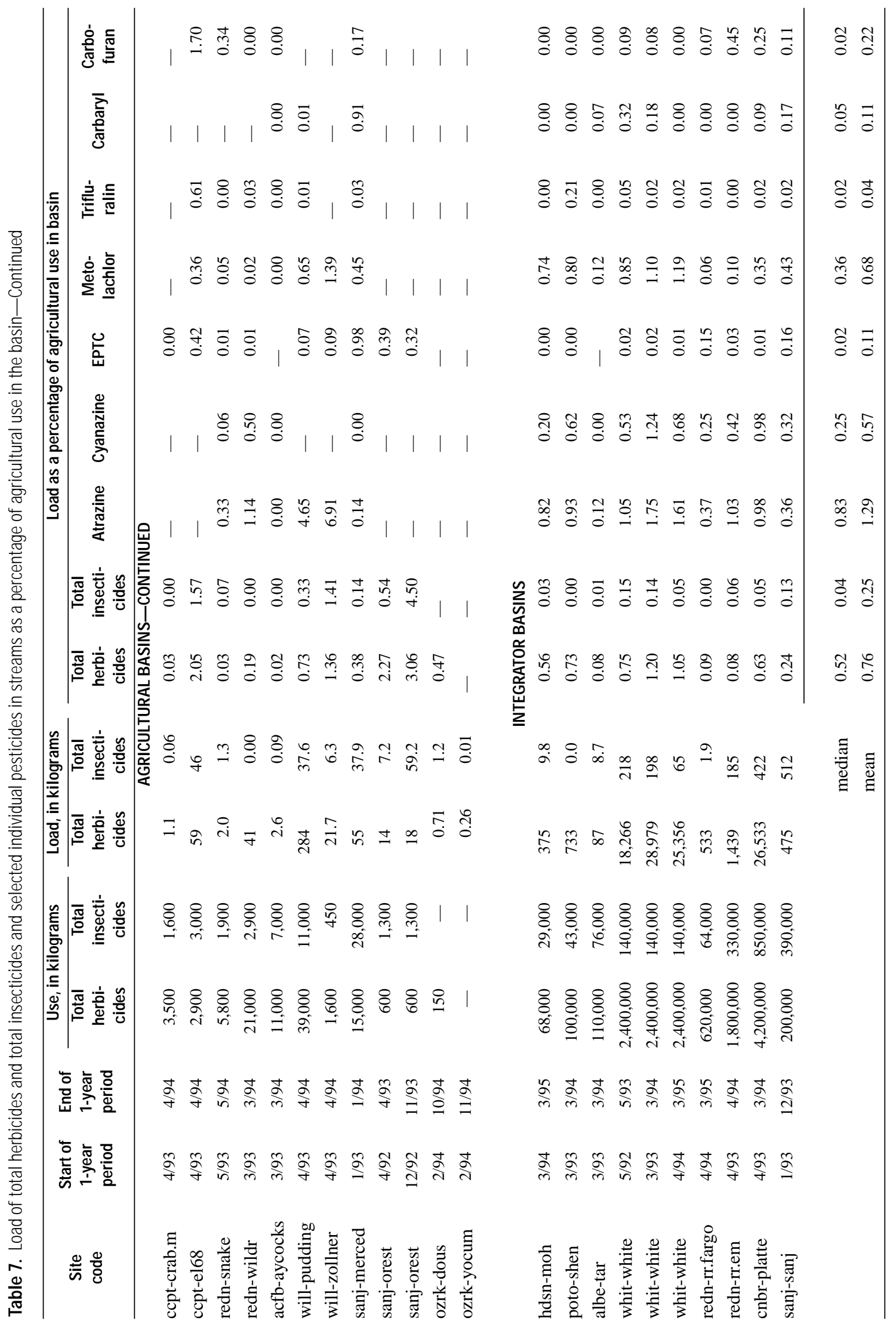

Pesticide Load in Relation to Use $\quad 70$ 

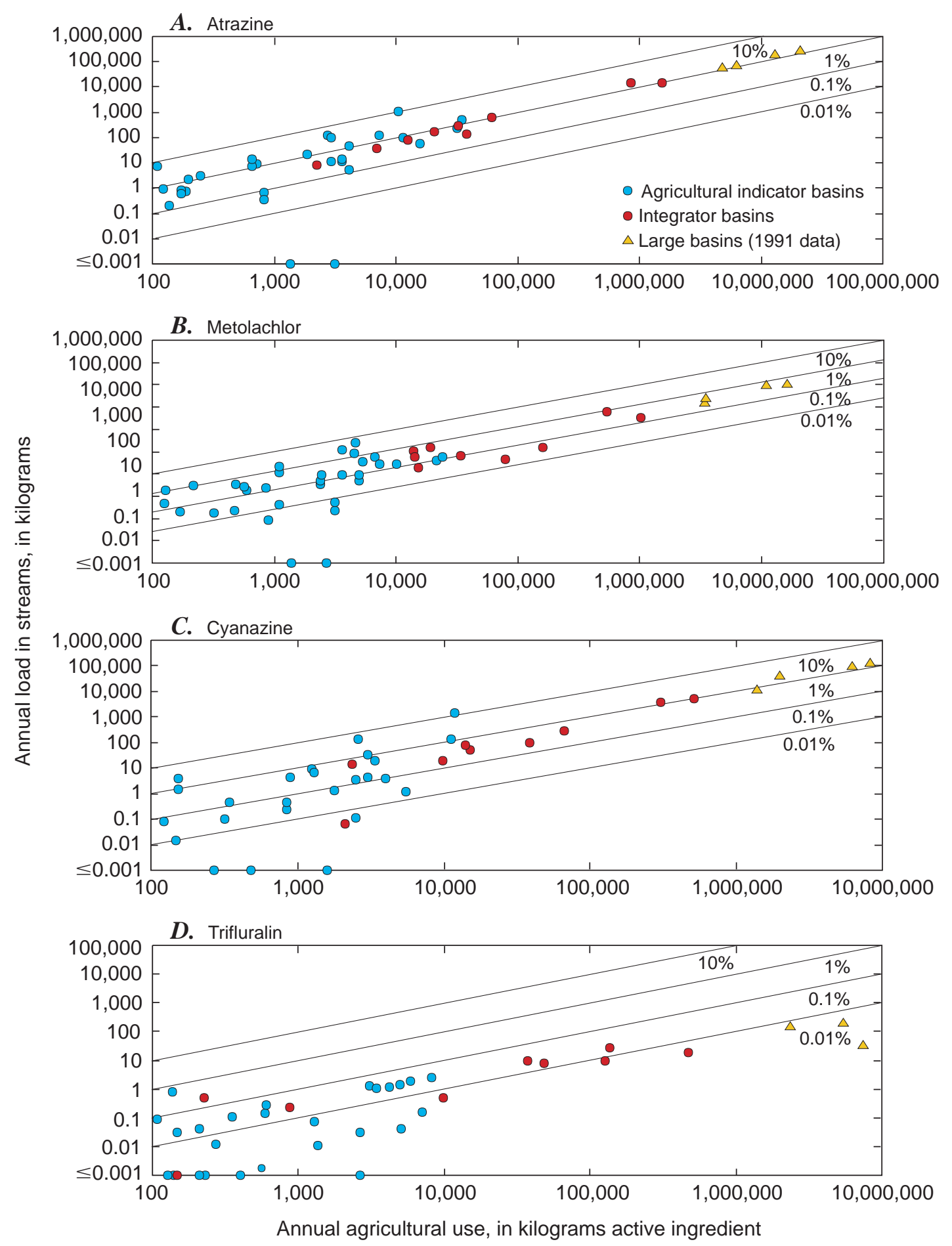

Figure 31. Annual loads of specific compounds in streams in relation to agricultural use in the drainage basin of a particular stream. Each value represents the annual load of the compound at one site. The diagonal lines represent theoretical percentages of the amount used in the basin. For example, a point on the lowest diagonal line means that the estimated load of that pesticide at a particular sampling site was 0.01 percent of the amount applied agriculturally in the basin of that site. Agricultural-use data are from Gianessi and Anderson (1996). 
estimate of load for the insecticides is more difficult than for many of the herbicides because of the generally low detection frequencies for insecticides, especially at the agricultural indicator sites and the integrator sites. In addition, values of load as a percentage of use are potentially less accurate for some insecticides because of their widespread use in nonagricultural applications. Nonagricultural use is not included in the estimates used in figure 31 .
Several sources of potential error should be noted for the estimates of annual load and for the values of load as a percentage of use:

(1) As mentioned previously, load estimates probably are biased low for small basins because of the low probability of sampling peak concentrations in small streams.

(2) For compounds with low detection frequencies, load estimates may be biased low because

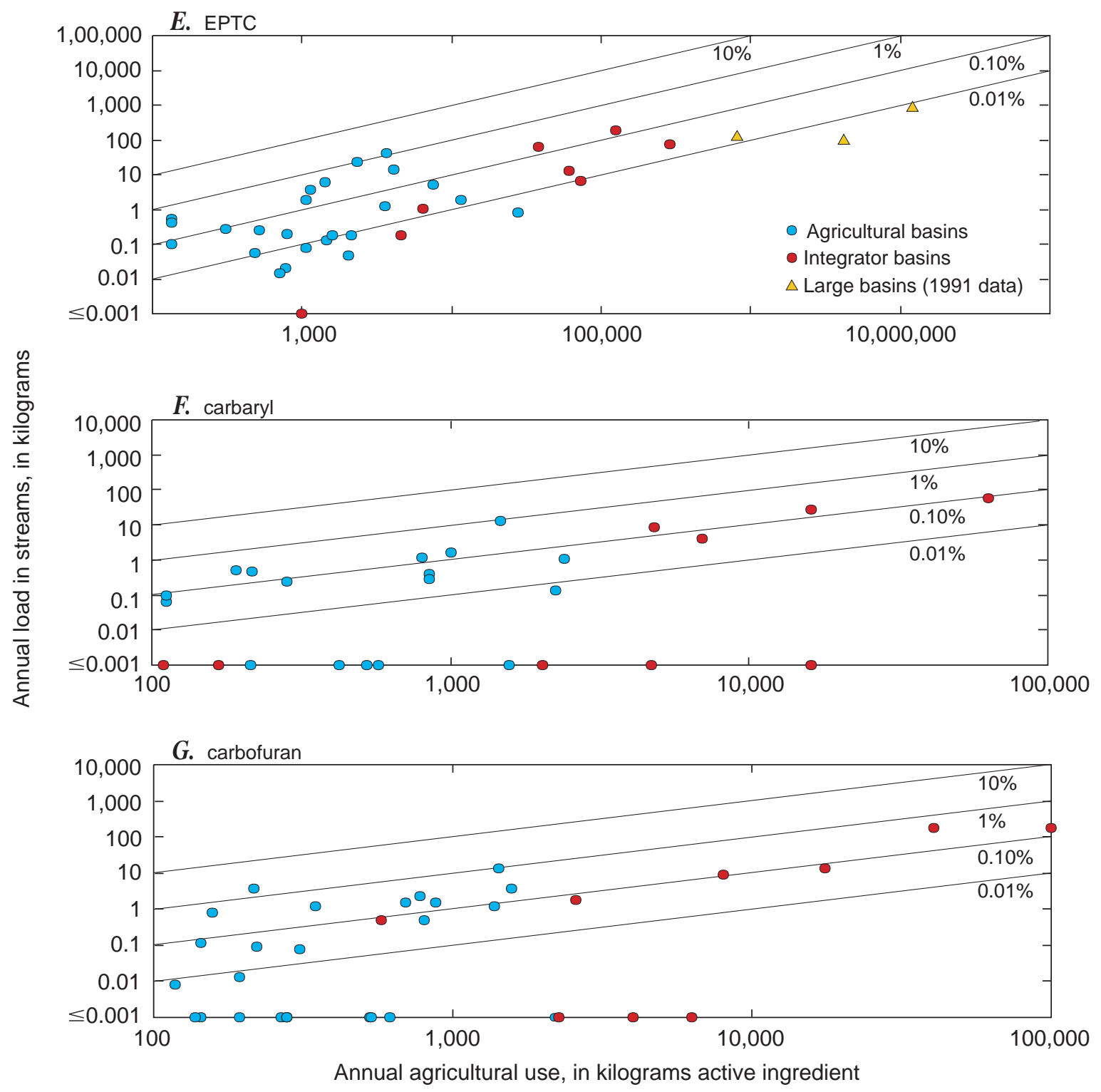

Figure 31- Continued. 
concentrations less than the detection limit were set equal to zero for the load calculations. In some cases, pesticides may have been present in the stream at concentrations high enough to affect the load total but less than the concentrations required for detection.

(3) Load estimates were made only for parent compounds and no degradation products were considered.

(4) Estimates of pesticide use were inferred from data on crop acreage and from average application rates of pesticides on specific crops. For small basins in particular, a change in either one of these can have a large effect on the accuracy of the use estimates.

(5) Nonagricultural use is not accounted for in the pesticide-use estimates. The integrator sites were selected to represent a variety of land uses, and it is very likely that significant nonagricultural use of specific pesticides occurs in each of these basins.
(6) The same estimates of pesticide use were used for the calculations of load as a percentage of use regardless of the year of sample collection. If the pesticide load varies significantly from year to year at a site, estimates of load as a percentage of use also will vary. Because the load is influenced by stream discharge, weather, agricultural practices, and other factors (Leonard, 1990), some variation in pesticide load from year to year is to be expected in a stream even if the same amounts of pesticides were applied in the basin. This variability is illustrated in figure 32 , in which total herbicide and insecticide loads are compared for 25 sites where load estimates were available for similar periods during different years. The diagonal line in these plots represents 1:1 agreement. The axes in these plots are logarithmic so a substantial deviation from the 1:1 line means that the load at a site was quite different for the 2 years. For total herbicides

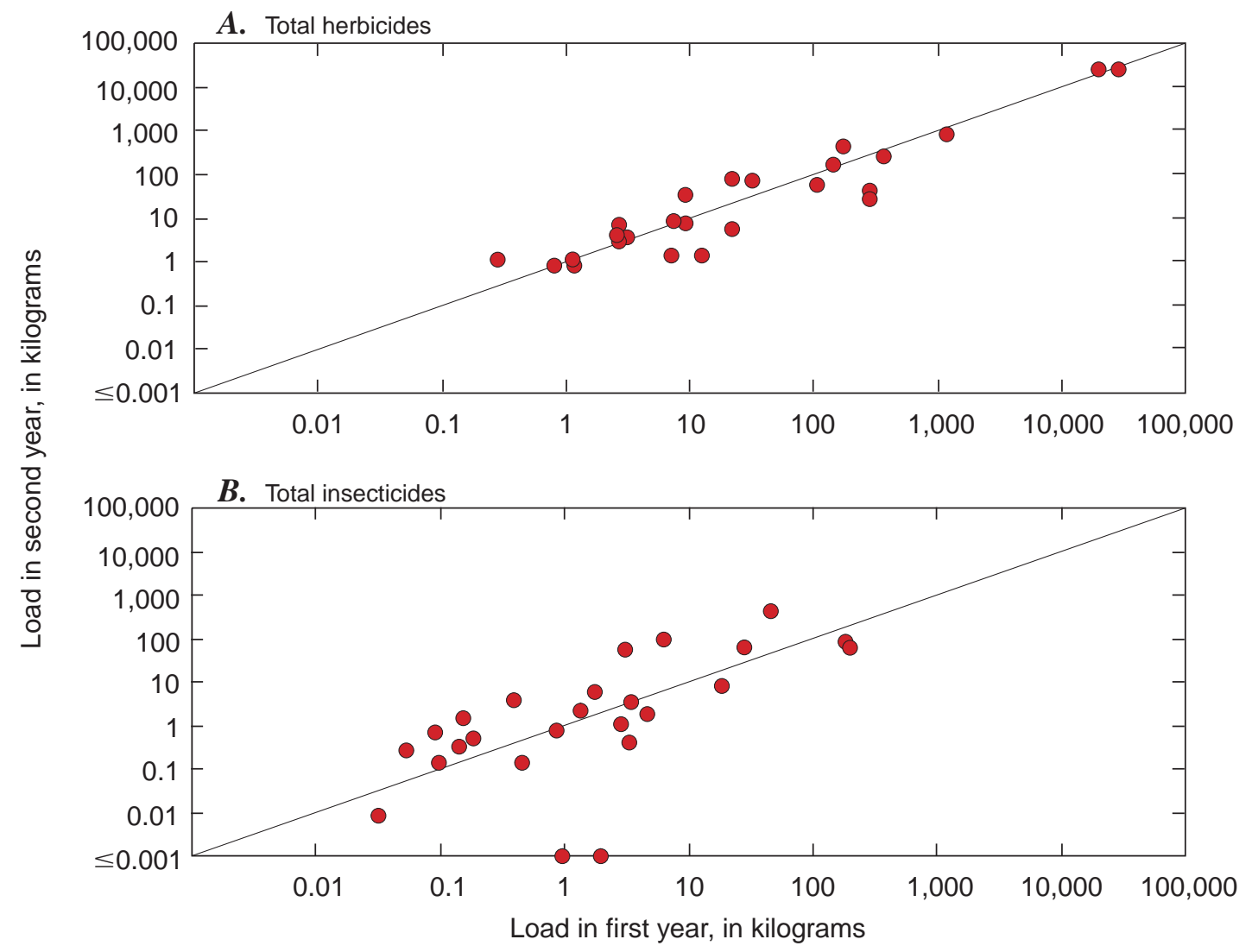

Figure 32. Comparison of estimated loads of $(\boldsymbol{A})$ total herbicides and $(\boldsymbol{B})$ insecticides for 25 sites with suffic ient data for load estimates for 2 different years. Data from 14 agricultural, 7 urban, and 4 integrator sites are included. For 23 sites, loads for 1993 are compared with loads for 1994. For tw o sites, loads for 1992 are compared with loads for 1993. For nine sites, loads are compared for 1 full year. For 16 sites, loads for a 5 to 6 month period are compared. The diagonal line shows what would be 1:1 agreement between the loads for both years for a site. 
(fig. 32A), loads were similar for the 2 years at most sites. Total herbicide loads for the 2 years were within a factor of 2 at 14 of the 25 sites and within a factor of 10 at all but 1 site. The relatively constant loads of total herbicides for these 2 years suggest that calculation of load as a percentage of use on the basis of 1 to 2 years of sampling is reasonable for many of the target herbicides, especially since values for a number of different sites are available. For total insecticides (fig. $32 B$ ), differences between the estimated loads for the 2 years generally were greater. Total insecticide loads for the 2 years were within a factor of 2 at 4 of the 25 sites and within a factor of 5 at 16 of the 25 sites. At four sites, loads during the 2 years differed by more than a factor of 10. These differences may reflect actual differences in the amounts of insecticides used in the basins during different years, as well as differences owing to the six factors mentioned above. Insecticide use is inherently more variable than herbicide use because many insecticides are used in response to specific pest problems rather than on a preset schedule. Because the same estimates of insecticide use were used for both 1993 and 1994, values of insecticide load as a percentage of use are potentially less accurate than the values calculated for herbicides.

\section{ENVIRONMENTAL SIGNIFICANCE OF PESTICIDE CONCENTRATIONS}

The question of whether the pesticide concentrations measured in samples collected during this study have a significant effect on human or environmental health is difficult to answer. Standards and guidelines have been established by various agencies for a number of the pesticides discussed in this report. Generally, these standards and guidelines are estimates of concentrations in water below which adverse effects on human health or aquatic life are not expected to occur (International Joint Commission, 1977; Canadian Council of Resource and Environment Ministers, 1991; Nowell and Resek, 1994). Regulatory standards have been established by the USEPA for the concentrations of specific compounds in drinking water (the maximum contaminant level, or MCL). Other (nonregulatory) values have been established by the USEPA, the Canadian Council of Resource and Environment Ministers (CCRM), and the International Joint Commission (IJC) for the protection of human health or aquatic life. In this report, the terms criteria and criteria values are used for both regulatory standards and nonregulatory guideline concentrations.

The criteria values selected for comparison are shown in table 8. For pesticides with a USEPAestablished criterion value, that value was used. If no USEPA-established value was available, values established by other agencies were used. Of the 46 compounds discussed in this report, 26 have a criterion established for protection of human health and 18 have a criterion established for protection of aquatic life. The criteria have several limitations (discussed below) that must be considered when they are used for comparison with pesticides concentrations measured in streams. The criteria can, however, provide an indication of the potential for adverse environmental effects of the pesticide concentrations measured during this study.

\section{Limitations of Criteria}

The criteria established for protection of both human health and aquatic life have limitations to their use in evaluating the potential effects of pesticides in streams (Nowell and Resek, 1994). The limitations discussed here do not address the validity or accuracy of these criteria, an assessment of which is beyond the scope of this report. Rather, these limitations pertain to the relevance or the usefulness, or both, of the criteria for comparisons with concentrations of pesticides measured in rivers and streams during this study.

(1) Criteria have not been established for many of the pesticides. Several of the pesticides that were frequently detected during this study, including alachlor, azinphos-methyl, carbaryl, DCPA, EPTC, prometon, and propargite, lack an established value for protection of either human health or aquatic life, or both.

(2) Criteria have been established for very few pesticide transformation products. DEA, a transformation product of atrazine, was one of the most frequently detected compounds at many of the sites in this study. Recent studies have shown that transformation products of several other commonly detected compounds, including alachlor, cyanazine, and metolachlor, can be present at higher levels and can persist much longer in surface waters than the parent compounds (Goolsby and others, 1993; Kalkhoff and others, 1998). 
Table 8. Human-health and aquatic-life criteria established for target compounds and the number of sites where the criterion value was exceeded.

[Type: H, herbicide; I, insecticide; d-H, herbicide degradation product; d-I, insecticide degradation product. Source: USEPA, U.S. Environmental Protection Agency; MCL, USEPA-established maximum contaminant level for drinking water; HAL, USEPA-established human health advisory level for drinking water; CAN, Canadian aquatic-life criterion; RSD5, risk-specific dose associated with an excess cancer risk of 1 in 100,000 for a concentration in drinking water equal to the RSD; IJC, International Joint Commission. $\mu \mathrm{g} / \mathrm{L}$, microgram per liter; —, no criterion established]

\begin{tabular}{|c|c|c|c|c|c|c|c|}
\hline \multirow[b]{2}{*}{ Compound } & \multirow[b]{2}{*}{ Type } & \multicolumn{3}{|c|}{ Human-health criteria } & \multicolumn{3}{|c|}{ Aquatic-life criteria } \\
\hline & & $\begin{array}{l}\text { Value } \\
(\mu \mathrm{g} / \mathrm{L})\end{array}$ & Source & $\begin{array}{c}\text { Number of sites } \\
\text { where value } \\
\text { was exceeded }\end{array}$ & $\begin{array}{l}\text { Value } \\
(\mu \mathrm{g} / \mathrm{L})\end{array}$ & Source & $\begin{array}{l}\text { Number of sites } \\
\text { where value } \\
\text { was exceeded }\end{array}$ \\
\hline 2,6-Diethylaniline & $\mathrm{d}-\mathrm{H}$ & - & - & - & - & - & - \\
\hline Alachlor & $\mathrm{H}$ & 2 & MCL & 10 & - & - & - \\
\hline Atrazine & $\mathrm{H}$ & 3 & MCL & 16 & 2 & CAN & 17 \\
\hline Azinphos-methyl & I & - & - & - & 0.01 & USEPA & 16 \\
\hline Benfluralin & $\mathrm{H}$ & - & - & - & - & - & - \\
\hline Butylate & $\mathrm{H}$ & 350 & HAL & 0 & - & - & - \\
\hline Carbaryl & I & 700 & HAL & 0 & - & - & - \\
\hline Carbofuran & I & 40 & MCL & 0 & 1.75 & CAN & 1 \\
\hline Chlorpyrifos & I & 20 & HAL & 0 & 0.041 & USEPA & 20 \\
\hline Cyanazine & $\mathrm{H}$ & 1 & HAL & 13 & 2 & CAN & 10 \\
\hline $\mathrm{DCPA}^{1}$ & $\mathrm{H}$ & - & - & - & - & - & - \\
\hline$p, p^{\prime}-\mathrm{DDE}$ & d-I & 0.1 & RSD5 & 0 & - & - & - \\
\hline Deethylatrazine (DEA) & $\mathrm{d}-\mathrm{H}$ & - & - & - & - & - & - \\
\hline Diazinon & I & 0.6 & HAL & 9 & 0.08 & IJC & 18 \\
\hline Dieldrin & I & 0.02 & RSD5 & 4 & 0.0625 & USEPA & 1 \\
\hline Disulfoton & I & 0.3 & HAL & 0 & - & - & - \\
\hline EPTC $^{2}$ & $\mathrm{H}$ & - & - & - & - & - & - \\
\hline Ethalfluralin & $\mathrm{H}$ & - & - & - & - & - & - \\
\hline Ethoprop & I & - & - & - & - & - & - \\
\hline Fonofos & I & 10 & HAL & 0 & - & - & - \\
\hline$\alpha-\mathrm{HCH}^{3}$ & d-I & 0.06 & RSD5 & 1 & 0.01 & CAN & 1 \\
\hline Lindane & I & 0.2 & MCL & 0 & 0.08 & USEPA & 3 \\
\hline Linuron & $\mathrm{H}$ & - & - & - & 7 & CAN & 0 \\
\hline Malathion & I & 200 & HAL & 0 & 0.1 & USEPA & 13 \\
\hline Methyl parathion & I & 2 & HAL & 0 & - & - & - \\
\hline Metolachlor & $\mathrm{H}$ & 70 & HAL & 0 & 8 & CAN & 5 \\
\hline Metribuzin & $\mathrm{H}$ & 100 & HAL & 0 & 1 & CAN & 0 \\
\hline Molinate & $\mathrm{H}$ & - & - & - & - & - & - \\
\hline Napropamide & $\mathrm{H}$ & - & - & - & - & - & - \\
\hline Parathion & I & - & - & - & 0.013 & USEPA & 3 \\
\hline Pebulate & $\mathrm{H}$ & - & - & - & - & - & - \\
\hline Pendimethalin & $\mathrm{H}$ & - & - & - & - & - & - \\
\hline Permethrin, cis & I & - & - & - & - & - & - \\
\hline Phorate & I & - & - & - & - & - & - \\
\hline Prometon & $\mathrm{H}$ & 100 & HAL & 0 & - & - & - \\
\hline Pronamide & $\mathrm{H}$ & 50 & HAL & 0 & - & - & - \\
\hline Propachlor & $\mathrm{H}$ & 90 & HAL & 0 & - & - & - \\
\hline Propanil & $\mathrm{H}$ & - & - & - & - & - & - \\
\hline Propargite & I & - & - & - & - & - & - \\
\hline Simazine & $\mathrm{H}$ & 4 & MCL & 6 & 10 & CAN & 0 \\
\hline Tebuthiuron & $\mathrm{H}$ & 500 & HAL & 0 & 1.6 & CAN & 0 \\
\hline Terbacil & $\mathrm{H}$ & 90 & HAL & 0 & - & - & - \\
\hline Terbufos & I & 0.9 & HAL & 0 & - & - & - \\
\hline Thiobencarb & $\mathrm{H}$ & - & - & - & - & - & - \\
\hline Triallate & $\mathrm{H}$ & - & - & - & 0.24 & CAN & 2 \\
\hline Trifluralin & $\mathrm{H}$ & 5 & HAL & 0 & 0.1 & CAN & 3 \\
\hline
\end{tabular}

${ }^{1}$ dimethyl 2,3,5,6-tetrachloro-1,4-benzenedicarboxylate.

${ }^{2}$ S-ethyl dipropylthiocarbamate.

${ }^{3} \alpha$-hexachlorocyclohexane. 
(3) Human-health and aquatic-life criteria generally are based on toxicity tests conducted with a single compound. The criteria do not take into account the possible additive or synergistic effects of more than one pesticide or combinations of pesticides, pesticide transformation products, or other chemicals that may be present in water. In addition, testing most often involves exposure of an organism to a single compound at a series of concentrations to determine a no-effect level. As shown in previous sections of this report, exposure in actual rivers and streams is more likely to involve a mixture of pesticides and pesticide transformation products, with frequent fluctuations in concentrations and in the types of compounds present. In many locations, seasonal pulses of relatively high concentrations of several pesticides are superimposed on a background of low-level concentrations of many other chemicals.

(4) The aquatic-life criteria do not account for the possible combined effects of pesticides and other potential stressors on aquatic biota, such as high concentrations of suspended sediment, low dissolved oxygen, fluctuations in temperature, or the presence of metals or other inorganic contaminants. It is difficult to predict the effect of individual pesticides on aquatic life in complex natural systems.

(5) Recent concerns about the possible effects of pesticides and other organic compounds on the endocrine systems of humans and aquatic organisms (Colborn and Clement, 1992) are not addressed by the criteria. In general, the criteria do not account for potential long-term effects of pesticides, particularly effects on development and on the reproductive success of future generations of relatively long-lived organisms. There is evidence, however, that some pesticides may affect the endocrine systems of fish (Goodbred and others, 1997).

(6) Most of the sampling sites discussed in this report are on streams that are not used as sources of drinking water, although in many cases the water eventually reaches rivers that are used for drinking water. Some pesticides are removed during normal treatment procedures at water-supply facilities. Studies have shown, however, that several commonly detected compounds, including atrazine, cyanazine, and metolachlor, are only partly removed from water during conventional water treatment (Baker, 1985; Wnuk and others, 1987; Miltner, 1989; Patrick, 1990; Kent and others, 1991).
(7) The human-health criteria are based on longterm (lifetime) exposure to a specific compound. Obviously, the results presented in this report cannot be used for an assessment of lifetime exposure, even if the water were being used directly for drinking water. The aquatic-life criteria established by the USEPA are based on exposure times of 24 to 96 hours. Although sampling was quite frequent at some of the sites in this study, it was not possible to determine the actual exposure times of aquatic organisms to specific compounds using the data from these samples. In addition, the USEPA criteria specify a recurrence interval of 3 years, which implies that an aquatic ecosystem can recover if the concentration of a specific compound does not exceed the criterion value more than once in 3 years (Stephan and others, 1985). For most of the streams sampled, the data were not sufficient to make such a specific determination; thus, the criteria are used in this report as indicators of the potential (or the lack thereof) for adverse effects.

The above limitations are important and should be considered whenever the criteria values are used. Despite these limitations, the criteria are the only nationally consistent, toxicologically derived values that can be used for comparison with the concentrations of many of the pesticides included in this study. In their compilation of standards for pesticides in water, Nowell and Resek (1994) state that the use of these national criteria "facilitate[s] federal and state regulation, as well as consistent comparison and evaluation of water-quality conditions among different hydrologic systems. National standards and guidelines are widely used to assess the potential water-quality significance of pesticide concentrations measured in the aquatic environment ..."

\section{Comparison of Concentrations with Human-Health Criteria Values}

All comparisons with human-health criteria values in this report refer to chronic criteria, which are based on exposure over a 70-year lifetime. Criteria values based on acute (short-term) exposure generally are much higher than chronic criteria values. An acute human-health criterion value was exceeded in only one sample during this study. Estimated concentrations of atrazine $(120 \mu \mathrm{g} / \mathrm{L})$ and cyanazine $(160 \mu \mathrm{g} / \mathrm{L})$ exceeded the 1-day health advisory level (HAL) for drinking water $(100 \mu \mathrm{g} / \mathrm{L}$ for both compounds) in one sample from Kessinger Ditch in Indiana (whit-kess) in 
May 1993 (U.S. Geological Survey, 1999); water from this stream is not used for drinking water. For most of the other compounds with acute criteria values, the acute values are 10 to several thousand times higher than the maximum concentration detected in this study.

Of the 46 compounds discussed in this report, 26 have a human-health chronic criterion (table 8). All these criteria apply to an average concentration in finished (treated) drinking water. The criteria values ranged from 1 to $100 \mu \mathrm{g} / \mathrm{L}$ for most of the target herbicides and 0.1 to $50 \mu \mathrm{g} / \mathrm{L}$ for most of the target insecticides. Five compounds - alachlor, atrazine, carbofuran, lindane, and simazine - have an MCL established by the USEPA. The MCL is an enforceable standard for the concentration of a specific compound in drinking water. The MCLs are based primarily on results of toxicity testing but also are influenced by the economic and technological feasibility of water treatment and by analytical detection capability (Nowell and Resek, 1994). Eighteen other compounds have a USEPA-established HAL, which is a nonenforceable guideline derived solely on the basis of toxicity testing. The criteria values for three compounds— $p, p^{\prime}$-DDE, dieldrin, and $\alpha-\mathrm{HCH}-$ are in terms of a risk-specific dose (RSD), which is the concentration associated with a specified cancer risk level. The RSD values given for these compounds (table 8) are for a cancer risk level of $10^{-5}$, meaning that the excess cancer risk associated with drinking water containing a compound at a concentration of the RSD is estimated to be 1 in 100,000 persons. It also should be noted that the herbicide alachlor is classified by the USEPA as a probable human carcinogen (Nowell and Resek, 1994). The MCL for alachlor is $2 \mu \mathrm{g} / \mathrm{L}$, but the maximum contaminant level goal (MCLG) is a concentration of zero, as for all compounds classified as known or probable human carcinogens. For a thorough discussion of human-health criteria values for pesticides and for a compilation of these values, see Nowell and Resek (1994).

Of the 26 compounds with human-health criteria, 7 compounds were detected at concentrations greater than their criterion value in one or more samples (table 8). These include the herbicides alachlor, atrazine, cyanazine, and simazine and the insecticides diazinon, dieldrin, and $\alpha-\mathrm{HCH}$. These four herbicides and the insecticide diazinon were detected at concentrations greater than their criteria values at six or more sites. These five compounds will be discussed in more detail below. Dieldrin concentrations exceeded the criterion value of $0.02 \mu \mathrm{g} / \mathrm{L}$ at four sites, but in only
1 to 3 samples at each site. $\alpha-\mathrm{HCH}$ was detected in one sample at a concentration slightly higher than the criterion value of $0.06 \mu \mathrm{g} / \mathrm{L}$. Of the remaining 19 compounds with human-health criteria, 8 compounds were detected at concentrations greater than one-tenth of the criterion value at one or more sites and 11 were not detected at concentrations greater than one-tenth of the criterion value at any site.

In previous sections of this report, concentrations of specific pesticides were described primarily by using aggregated data from groups of sites, often in terms of monthly median concentrations. The human-health criteria, however, are based on longterm exposure to specific chemicals; compliance with regulatory standards for drinking water is based on the annual mean concentration of a specific compound in drinking water. For comparisons with human-health criteria, the most appropriate measure of concentration is the long-term mean concentration of a specific compound at a site. The time-weighted mean (TWM) concentration provides a relatively unbiased estimate of the mean concentration for a period during which sampling frequency varied. At a number of sites in this study, sampling was not sufficient during some parts of the year to determine a reliable TWM concentration for a 1-year period. TWM concentrations were determined, however, for all the target compounds for a 5-month critical period, during which sample collection was most intense at each site. These values were combined with monthly median concentrations for the remaining 7 months to obtain an estimate of the annual mean concentration of each target compound at each site. Specifically, the estimated annual mean concentration was calculated as

where:

$$
\text { Annual mean }=\left[\left(t w_{-} \text {mean }\right)^{*} 155+\sum_{i=1}^{7}\left(\text { mon_med }_{i}^{*} 30\right)\right] \div 365
$$

$t w \_$mean $=$the time-weighted mean concentration for the 5-month critical period, which is approximated as a 155 days.

mon_med ${ }_{i}=$ the monthly median concentration for 1 of the 7 remaining months, all of which are approximated as 30 days.

Five compounds (alachlor, atrazine, cyanazine, diazinon, and simazine) were detected at concentrations higher than the human-health criteria values at numerous sites (table 8). Estimates of annual 
mean concentrations for these five compounds are given in table 9 and figure 33 for all 58 sites. In figure 33, the top of each bar represents the TMW during the 5-month critical period for the compound at a specific site, and the shaded part of the bar represents the estimated annual mean concentration. Annual mean concentrations exceeded criteria values for cyanazine at two sites [Maple Creek in Nebraska (cnbr-maple) and Kessinger Ditch in Indiana (whit-kess)] and for atrazine at one site [Kessinger Ditch (whit-kess)]; concentrations did not exceed criteria values for alachlor, diazinon, and simazine at any site. TWM concentrations during the 5-month critical period exceeded criteria values for atrazine at two sites [Prairie Creek in Nebraska (cnbr-prairie) and Kessinger Ditch (whit-kess)] and for cyanazine at three sites [Maple and Shell Creeks in Nebraska (cnbr-maple and cnbr-shell) and Kessinger Ditch (whit-kess)] all of which are in corn-growing areas. The TWM concentration for diazinon exceeded the criterion value at one urban site [Rush Creek, near Arlington, Texas (trin-rush)]. No human-health criteria values were exceeded at any of the integrator sites. These results show that the long-term mean concentrations of these pesticides rarely exceed human-health criteria even though concentrations in individual samples often exceed the criteria values during seasonal pulses.

\section{Comparison of Concentrations with Aquatic-Life Criteria Values}

The aquatic-life criteria values that were selected for comparison with concentrations measured during this study are shown in table 8 . The USEPA has established aquatic-life criteria for six of the target compounds (U.S. Environmental Protection Agency, 1991). For 11 compounds with no USEPA-established values, Canadian criteria values were selected (Canadian Council of Resource and Environment Ministers, 1991). The selected aquatic-life criterion value for diazinon is the Great Lakes Water-Quality Objective established by the IJC (International Joint Commission, 1977). No aquatic-life criteria have been established by the United States or Canadian governments for the remaining 28 target compounds.

The aquatic-life criteria values range from 0.1 to $10 \mu \mathrm{g} / \mathrm{L}$ for the target herbicides and from 0.01 to 0.1 $\mu \mathrm{g} / \mathrm{L}$ for most of the target insecticides. The criteria values generally are based on the highest concentration at which no adverse effects are observed for the most sensitive aquatic organism tested (plant or animal), multiplied by an appropriate safety factor. The safety factor can range from 0.01 to 0.1 , depending on the persistence of the chemical and on the availability and the quality of the toxicity data for the chemical.

Information on the derivation of the criteria values can be found in the Canadian water-quality guidelines document (Canadian Council of Resource and Environment Ministers, 1991) for Canadian values, the USEPA water-quality criteria summary (U.S. Environmental Protection Agency, 1991) for criteria established by the USEPA, and the IJC document (International Joint Commission, 1977) for diazinon. In general, the Canadian criteria are somewhat more stringent than the USEPA values. The Canadian criteria "....are set at such levels as to protect all forms of aquatic life and all aspects of the aquatic life cycles. The clear intention is to protect all life stages during indefinite exposure to the water" (Canadian Council of Resource and Environment Ministers, 1991). The USEPA values are based on an average concentration for either a 24-hour or 96-hour period, depending on when the criterion was established, and are set at levels that will protect 95 percent of the organisms for which acceptable chronic-toxicity data are available (Nowell and Resek, 1994). In addition, the USEPA criteria contain a recurrence interval provision which states that if the criterion value is not exceeded more than once in 3 years, aquatic ecosystems are expected to recover (Stephan and others, 1985). The Canadian and IJC criteria do not contain this provision. It should be noted that all the aquatic-life criteria are guidelines - they are not enforceable standards.

Concentrations of one or more compounds exceeded an aquatic-life criterion value in at least one sample from 25 of the 37 agricultural sites, 10 of the 11 urban sites, and 4 of the 10 integrator sites (table 10). No aquatic-life criteria values were exceeded in any sample from the remaining 19 sites throughout the entire sampling period. At most sites, fewer than 5 compounds exceeded aquatic-life criteria values, but at four sites, 6 to 8 compounds were detected at concentrations greater than their aquatic-life criterion value.

Only 9 of the 27 target herbicides have an aquatic-life criterion, all of which are Canadian values (table 8). Concentrations of four of these herbicides-linuron, metribuzin, simazine, and 
Table 9. Estimated mean concentrations of selected compounds for a 1-year period.

[Mean values exceeding human-health criteria are shaded in gray. Crop group codes are defined in table 4. MCL, U.S. Environmental Protection Agency established maximum contaminant level for drinking water; HAL, U.S. Environmental Protection Agency established health advisory level for drinking water; $\mu \mathrm{g} / \mathrm{L}$, micrograms per liter; - , no crop group classification assigned]

\begin{tabular}{|c|c|c|c|c|c|c|c|}
\hline \multirow[b]{2}{*}{ Site code } & \multirow[b]{2}{*}{ Crop group code } & \multirow[b]{2}{*}{ Year } & \multicolumn{5}{|c|}{ Estimated mean concentration for a 1-year period } \\
\hline & & & $\begin{array}{c}\text { Alachlor } \\
\text { (MCL, } \\
2 \mu \mathrm{g} / \mathrm{L})\end{array}$ & $\begin{array}{l}\text { Atrazine (MCL, } \\
3 \mu \mathrm{g} / \mathrm{L})\end{array}$ & $\begin{array}{c}\text { Cyanazine } \\
\text { (HAL, } \\
1 \mu \mathrm{g} / \mathrm{L})\end{array}$ & $\begin{array}{c}\text { Diazinon } \\
\text { (HAL, } \\
0.6 \mu \mathrm{g} / \mathrm{L})\end{array}$ & $\begin{array}{c}\text { Simazine } \\
\text { (MCL, } \\
4 \mu \mathrm{g} / \mathrm{L})\end{array}$ \\
\hline \multicolumn{8}{|c|}{ AGRICULTURAL INDICATOR SITES } \\
\hline lsus-mill & $\mathrm{C}$ & 1993 & 0.01 & 0.13 & 0.00 & 0.00 & 0.20 \\
\hline cnbr-prairie & $\mathrm{C}$ & 1993 & 0.25 & 2.33 & 0.06 & 0.00 & 0.08 \\
\hline wmic-duck & $\mathrm{C}$ & 1993 & 0.07 & 0.39 & 0.16 & 0.00 & 0.03 \\
\hline hdsn-canaj & $\mathrm{CA}$ & 1994 & 0.00 & 0.17 & 0.02 & 0.00 & 0.00 \\
\hline poto-muddy & $\mathrm{CA}$ & 1993 & 0.01 & 0.32 & 0.02 & 0.00 & 0.08 \\
\hline wmic-nbmilw & CAv & 1993 & 0.01 & 0.05 & 0.04 & 0.00 & 0.07 \\
\hline cnbr-maple & $\mathrm{CS}$ & 1993 & 0.19 & 1.12 & 3.04 & 0.00 & 0.01 \\
\hline cnbr-shell & $\mathrm{CS}$ & 1993 & 0.26 & 1.31 & 0.89 & 0.00 & 0.01 \\
\hline whit-kess & CS & 1993 & 0.23 & 3.83 & 4.13 & 0.00 & 0.05 \\
\hline whit-sugar & $\mathrm{CS}$ & 1993 & 0.07 & 0.72 & 0.04 & 0.01 & 0.03 \\
\hline albe-pete & CScot & 1993 & 0.07 & 0.05 & 0.00 & 0.00 & 0.00 \\
\hline albe-albe & CSW & 1993 & 0.07 & 0.07 & 0.00 & 0.00 & 0.00 \\
\hline 1sus-eastm & $\mathrm{CW}$ & 1993 & 0.02 & 0.15 & 0.10 & 0.00 & 0.04 \\
\hline poto-mono & $\mathrm{CW}$ & 1994 & 0.05 & 0.59 & 0.07 & 0.00 & 0.19 \\
\hline splt-lone & $\mathrm{CW}$ & 1993 & 0.18 & 0.22 & 0.33 & 0.01 & 0.01 \\
\hline acfb-lime & CWp & 1993 & 0.00 & 0.01 & 0.01 & 0.00 & 0.01 \\
\hline trin-chamb & CWsor & 1994 & 0.02 & 1.48 & 0.00 & 0.01 & 0.03 \\
\hline ccpt-crab.rl & WA & 1993 & 0.00 & 0.02 & 0.00 & 0.00 & 0.01 \\
\hline usnk-rock & WAb & 1993 & 0.00 & 0.01 & 0.00 & 0.00 & 0.00 \\
\hline ccpt-palouse & $\mathrm{Wb}$ & 1993 & 0.00 & 0.03 & 0.00 & 0.00 & 0.01 \\
\hline redn-turtle & $\mathrm{Wb}$ & 1993 & 0.00 & 0.01 & 0.00 & 0.00 & 0.00 \\
\hline usnk-teton & Wpot & 1993 & 0.00 & 0.00 & 0.00 & 0.00 & 0.00 \\
\hline gafl-tucsa & WScot & 1993 & 0.00 & 0.00 & 0.00 & 0.00 & 0.00 \\
\hline albe-devils & WStob & 1993 & 0.02 & 0.02 & 0.00 & 0.00 & 0.01 \\
\hline ccpt-crab.m & W & 1993 & 0.00 & 0.01 & 0.00 & 0.00 & 0.01 \\
\hline ccpt-el68 & W & 1993 & 0.03 & 0.01 & 0.00 & 0.00 & 0.00 \\
\hline redn-snake & $\mathrm{W}$ & 1993 & 0.00 & 0.01 & 0.00 & 0.00 & 0.00 \\
\hline redn-wildr & W & 1993 & 0.00 & 0.03 & 0.01 & 0.00 & 0.00 \\
\hline gafl-little & $\mathrm{P}$ & 1993 & 0.02 & 0.01 & 0.00 & 0.00 & 0.00 \\
\hline acfb-aycocks & $\mathrm{P}$ & 1993 & 0.00 & 0.01 & 0.00 & 0.00 & 0.00 \\
\hline sanj-salt & COTv & 1993 & 0.00 & 0.01 & 0.13 & 0.05 & 0.03 \\
\hline will-pudding & FGv & 1994 & 0.01 & 0.11 & 0.00 & 0.00 & 0.06 \\
\hline will-zollner & $\mathrm{FGv}$ & 1993 & 0.01 & 0.64 & 0.00 & 0.07 & 0.37 \\
\hline sanj-merced & $\mathrm{O}$ & 1993 & 0.00 & 0.00 & 0.00 & 0.04 & 0.07 \\
\hline sanj-orest & $\mathrm{O}$ & 1993 & 0.02 & 0.01 & 0.00 & 0.05 & 0.04 \\
\hline ozrk-dous & $X X$ & 1994 & 0.00 & 0.00 & 0.00 & 0.00 & 0.00 \\
\hline ozrk-yocum & $X X$ & 1994 & 0.00 & 0.01 & 0.00 & 0.00 & 0.00 \\
\hline
\end{tabular}


Table 9. Estimated mean concentgrations of selected compounds for a one year period-Continued

\begin{tabular}{|c|c|c|c|c|c|c|c|}
\hline \multirow[b]{2}{*}{ Site code } & \multirow[b]{2}{*}{ Crop group code } & \multirow[b]{2}{*}{ Year } & \multicolumn{5}{|c|}{ Estimated mean concentration over a one-year period } \\
\hline & & & $\begin{array}{c}\text { Alachlor } \\
\text { (MCL, } \\
2 \mu \mathrm{g} / \mathrm{L})\end{array}$ & $\begin{array}{l}\text { Atrazine (M CL, } \\
\quad 3 \mu \mathrm{g} / \mathrm{L})\end{array}$ & $\begin{array}{c}\text { Cyanazine } \\
\text { (HAL, } \\
1 \mu \mathrm{g} / \mathrm{L})\end{array}$ & $\begin{array}{c}\text { Diazinon } \\
\text { (HAL, } \\
0.6 \mu \mathrm{g} / \mathrm{L})\end{array}$ & $\begin{array}{c}\text { Simazine } \\
\text { (MCL, } \\
4 \mu \mathrm{g} / \mathrm{L} \text { ) }\end{array}$ \\
\hline \multicolumn{8}{|c|}{ URBAN INDICATOR SITES } \\
\hline conn-norwalk & - & 1993 & 0.00 & 0.01 & 0.00 & 0.00 & 0.01 \\
\hline hdsn-lisha & - & 1994 & 0.00 & 0.00 & 0.00 & 0.02 & 0.00 \\
\hline lsus-cedar & - & 1993 & 0.01 & 0.14 & 0.01 & 0.00 & 0.03 \\
\hline poto-acco & - & 1994 & 0.00 & 0.01 & 0.00 & 0.15 & 0.31 \\
\hline gafl-lafayette & - & 1993 & 0.00 & 0.06 & 0.00 & 0.05 & 0.03 \\
\hline acfb-sope & - & 1994 & 0.00 & 0.04 & 0.00 & 0.03 & 0.32 \\
\hline whit-little & - & 1993 & 0.10 & 0.43 & 0.02 & 0.06 & 0.04 \\
\hline splt-cherry & - & 1993 & 0.00 & 0.03 & 0.00 & 0.04 & 0.03 \\
\hline trin-rush & - & 1993 & 0.00 & 0.18 & 0.00 & 0.58 & 0.17 \\
\hline nvbr-lasvegas & - & 1994 & 0.00 & 0.01 & 0.00 & 0.08 & 0.18 \\
\hline will-fanno & - & 1993 & 0.00 & 0.02 & 0.00 & 0.03 & 0.06 \\
\hline \multicolumn{8}{|c|}{ INTEGRATOR SITES } \\
\hline hdsn-moh & $\mathrm{CA}$ & 1994 & 0.00 & 0.05 & 0.01 & 0.00 & 0.00 \\
\hline poto-shenan & $\mathrm{CA}$ & 1993 & 0.00 & 0.12 & 0.01 & 0.00 & 0.05 \\
\hline albe-tar & CScot & 1993 & 0.01 & 0.03 & 0.00 & 0.01 & 0.04 \\
\hline gafl-withla & $\mathrm{P}$ & 1993 & 0.00 & 0.03 & 0.00 & 0.00 & 0.01 \\
\hline whit-white & $\mathrm{CS}$ & 1993 & 0.14 & 1.29 & 0.37 & 0.01 & 0.09 \\
\hline wmic-milw & CAv & 1993 & 0.03 & 0.10 & 0.08 & 0.00 & 0.04 \\
\hline redn-rr.fargo & CSW & 1994 & 0.00 & 0.09 & 0.06 & 0.00 & 0.01 \\
\hline redn-rr.em & $\mathrm{W}$ & 1993 & 0.01 & 0.07 & 0.03 & 0.00 & 0.00 \\
\hline cnbr-platte & $\mathrm{CW}$ & 1993 & 0.09 & 0.93 & 0.29 & 0.00 & 0.01 \\
\hline sanj-sanj & $\mathrm{O}$ & 1993 & 0.00 & 0.00 & 0.02 & 0.06 & 0.08 \\
\hline
\end{tabular}

tebuthiuron-did not exceed criteria values in any sample (U.S. Geological Survey, 1999). Triallate concentrations exceeded the criterion value of 0.24 $\mu \mathrm{g} / \mathrm{L}$ in six samples from two sites in the Central Columbia Plateau study unit in Washington (ccptcrab.m and ccpt-palouse). Trifluralin concentrations exceeded the criterion value of $0.1 \mu \mathrm{g} / \mathrm{L}$ in 6 samples, 5 of which were from two agricultural sites in the San Joaquin River Basin in California (sanj-orest and sanjsalt). Metolachlor concentrations exceeded the relatively high criterion value of $8 \mu \mathrm{g} / \mathrm{L}$ in 11 samples from five sites. All samples in which metolachlor exceeded its aquatic-life criterion value were collected during seasonal peaks in herbicide concentrations in corn-growing areas. The criteria values for atrazine and cyanazine were exceeded much more frequently; these compounds are discussed in more detail below.
Aquatic-life criteria are established for 9 of the 19 target insecticides, and all of these criteria values were exceeded in at least one sample from one or more sites (table 8). Concentrations of five compounds - carbofuran, dieldrin, $\alpha-\mathrm{HCH}$, lindane, and parathion-exceeded criteria values in fewer than five samples at 1 to 3 sites (U.S. Geological Survey, 1999). Carbofuran concentrations exceeded its relatively high criterion value of $1.75 \mu \mathrm{g} / \mathrm{L}$ only in Zollner Creek in Oregon (will-zollner); the criterion value was exceeded in 2 samples in 1993 and in 1 sample in 1994. Criteria values for four insecticides-azinphos-methyl, chlorpyrifos, diazinon, and malathion-were exceeded much more frequently; these compounds are discussed in more detail below.

Six compounds_-atrazine, azinphos-methyl, chlorpyrifos, cyanazine, diazinon, and 

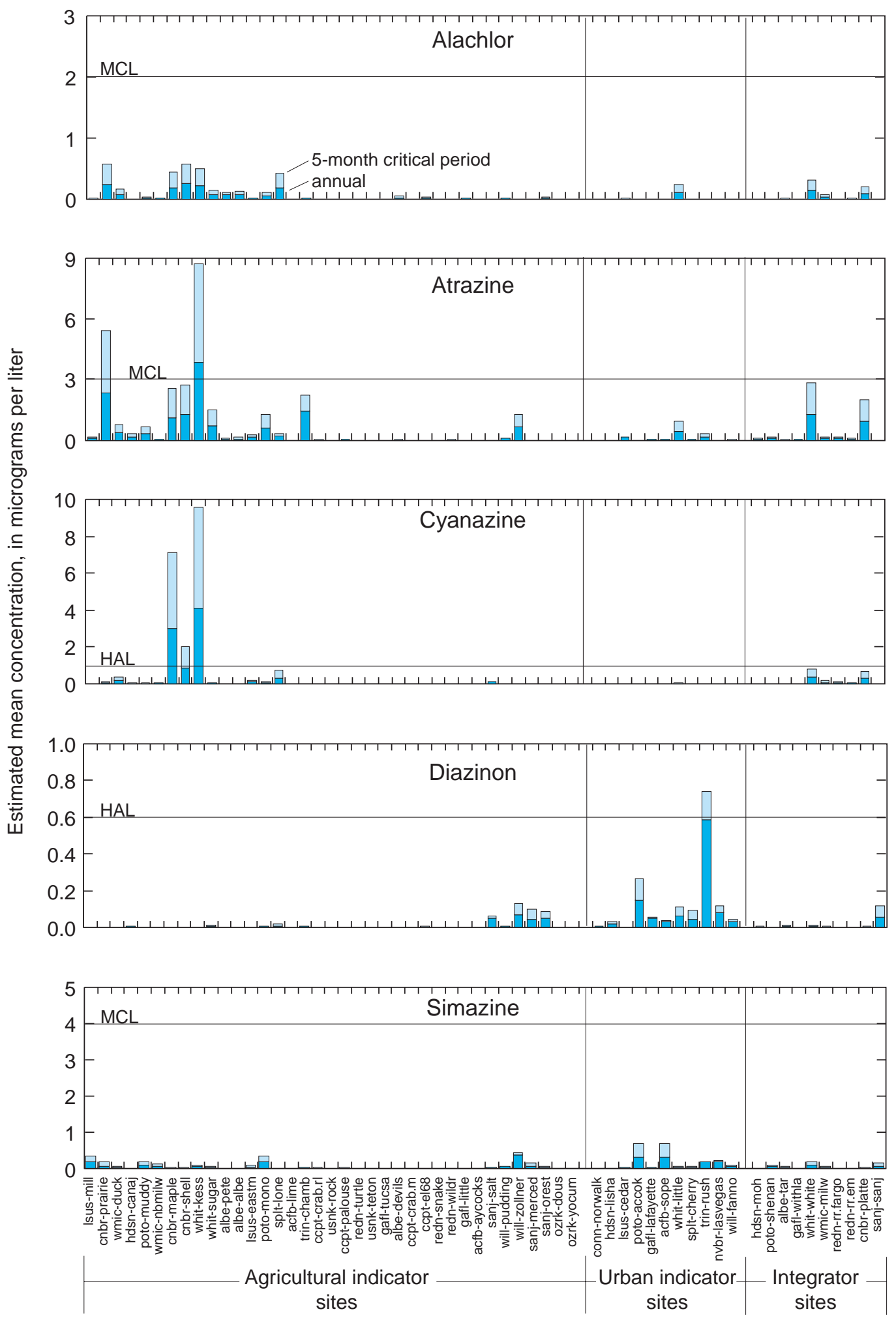

Figure 33. Estimated annual mean concentrations and 5-month time-w eighted mean (TW M ) concentrations of selected compounds at all 58 sites. The drinking-water criterion value for each compound is show $n$ as a horizontal line. Criteria values for alachlor, atrazine, and simazine are U.S. Environmental Protection Agency's established maximum contaminant levels (MCL). Criteria values for cyanazine and diazinon are USEPA-established health advisory levels (HAL). 
Table 10. Compounds with concentrations greater than the aquatic-life criterion in at least one sample, by type of site.

\begin{tabular}{l}
\hline Number of \\
compounds \\
exceeding an \\
$\begin{array}{l}\text { aquatic-life } \\
\text { criteria }\end{array}$
\end{tabular}

AGRICULTURAL INDICATOR SITES

will-zollner atrazine, azinphos-methyl, carbofuran, chlorpyrifos, diazinon, lindane, malathion

poto-mono atrazine, azinphos-methyl, cyanazine, diazinon, malathion, metolachlor

splt-lone atrazine, azinphos-methyl, chlorpyrifos, cyanazine, diazinon, dieldrin

whit-kess atrazine, chlorpyrifos, cyanazine, malathion, metolachlor

cnbr-shell atrazine, chlorpyrifos, cyanazine, trifluralin

sanj-orest azinphos-methyl, chlorpyrifos, diazinon, trifluralin

sanj-salt chlorpyrifos, diazinon, malathion, trifluralin

trin-chamb atrazine, azinphos-methyl, diazinon, $\alpha-\mathrm{HCH}$

whit-sugar atrazine, cyanazine, diazinon, malathion

cnbr-maple atrazine, chlorpyrifos, cyanazine

cnbr-prairie atrazine, chlorpyrifos, parathion

sanj-merced azinphos-methyl, chlorpyrifos, diazinon

wmic-duck atrazine, cyanazine, metolachlor

ccpt-crab.m azinphos-methyl, triallate

ccpt-crab.rl azinphos-methyl, chlorpyrifos

ccpt-el68 azinphos-methyl, chlorpyrifos

ccpt-palouse lindane, triallate

lsus-eastm atrazine, azinphos-methyl

poto-muddy atrazine, metolachlor

acfb-aycocks chlorpyrifos

albe-albe azinphos-methyl

albe-pete diazinon

hdsn-canaj atrazine

redn-turtle atrazine

will-pudding azinphos-methyl

acfb-lime, albe-devils, gafl-little, gafl-tucsa, lsus-mill, ozrk-dous, ozrk-yocum,

redn-snake, redn-wildr, usnk-rock, usnk-teton, wmic-nbmilw

\section{URBAN INDICATOR SITES}

$8 \quad$ whit-little

5 splt-cherry

4 trin-rush

3 nvbr-lasvegas

3 will-fanno

2 acfb-sope

2 gafl-lafayette

2 poto-acco

1 conn-norwalk

1 lsus-cedar

0 hdsn-lisha

3 cnbr-platte

whit-white

sanj-sanj

gafl-withla atrazine, azinphos-methyl, chlorpyrifos, diazinon, malathion, metolachlor, parathion, cyanazine diazinon, lindane, malathion, parathion, chlorpyrifos

azinphosmethyl, diazinon, malathion, chlorpyrifos

diazinon, malathion, chlorpyrifos

azinphos-methyl, diazinon, chlorpyrifos

diazinon, chlorpyrifos

diazinon, malathion

diazinon, malathion

malathion

azinphos-methyl

\section{INTEGRATOR SITES}

atrazine, chlorpyrifos, cyanazine

atrazine, chlorpyrifos, cyanazine

azinphos-methyl, diazinon

malathion

0 albe-tar, hdsn-moh, poto-shenan, redn-rr.fargo, redn-rr.em, wmic-milw 
Table 11. Estimated number of days per year that selected compounds exceeded an aquatic-life criterion value, by type of site.

[For some sites, estimates are shown for more than 1 year. Estimates are for compounds th;at exceeded an aquatic-life criterion at 10 or more sites. Crop group codes are defined in table 4. Values shown as a range indicate that there was uncertainty about whether the concentration remained above the criteria value between successive samples. nsd, not sufficient data-sampling was not frequent enough to provide a reliable estimate. Value shown has greater uncertainty than other values in table. - , no crop group classifiction assigned]

\begin{tabular}{|c|c|c|c|c|c|c|c|c|}
\hline \multirow[b]{2}{*}{ Site code } & \multirow[b]{2}{*}{$\begin{array}{l}\text { Crop group } \\
\text { code }\end{array}$} & \multirow[b]{2}{*}{ Year } & \multicolumn{6}{|c|}{ Estimated number of days per year concentration exceeded an aquatic-life criterion } \\
\hline & & & Atrazine & Cyanazine & $\begin{array}{c}\text { Azinphos- } \\
\text { methyl }\end{array}$ & Chlorpyrifos & Diazinon & Malathion \\
\hline \multicolumn{9}{|c|}{ AGRICULTURAL INDICATOR SITES } \\
\hline lsus-mill & $\mathrm{C}$ & 1993 & 0 & 0 & 0 & 0 & 0 & 0 \\
\hline lsus-mill & $\mathrm{C}$ & 1994 & 0 & 0 & 0 & 0 & 0 & 0 \\
\hline cnbr-prairie & $\mathrm{C}$ & 1993 & 42 to 91 & 0 & 0 & 1 & 0 & 0 \\
\hline wmic-duck & $\mathrm{C}$ & 1993 & 14 & 3 & 0 & 0 & 0 & 0 \\
\hline wmic-duck & $\mathrm{C}$ & 1994 & 10 & 0 & 0 & 0 & 0 & 0 \\
\hline hdsn-canaj & $\mathrm{CA}$ & 1994 & 8 & 0 & 0 & 0 & 0 & 0 \\
\hline poto-muddy & $\mathrm{CA}$ & 1993 & 7 & 0 & 0 & 0 & 0 & 0 \\
\hline wmic-nbmilw & CAv & 1993 & 0 & 0 & 0 & 0 & 0 & 0 \\
\hline wmic-nbmilw & CAv & 1994 & 0 & 0 & 0 & 0 & 0 & 0 \\
\hline cnbr-maple & $\mathrm{CS}$ & 1992 & 42 & 30 & 0 & 1 & 0 & 0 \\
\hline cnbr-maple & $\mathrm{CS}$ & 1993 & 70 & 3 to 56 & 0 & 1 & 0 & 0 \\
\hline cnbr-shell & $\mathrm{CS}$ & 1993 & 35 to 77 & 15 to 56 & 0 & 2 & 0 & 0 \\
\hline whit-kess & $\mathrm{CS}$ & 1993 & 72 & 32 & 0 & 3 & 0 & 0 \\
\hline whit-kess & $\mathrm{CS}$ & 1994 & 70 & 1 to 28 & 0 & 2 & 0 & 1 \\
\hline whit-sugar & $\mathrm{CS}$ & 1992 & 42 & 1 & 0 & 0 & 1 & 0 \\
\hline whit-sugar & $\mathrm{CS}$ & 1993 & 28 & 0 & 0 & 0 & 1 & 0 \\
\hline albe-pete & $\mathrm{CScot}$ & 1993 & 0 & 0 & 0 & 0 & 1 & 0 \\
\hline albe-albe & CSW & 1993 & 0 & 0 & 1 & 0 & 0 & 0 \\
\hline lsus-eastm & $\mathrm{CW}$ & 1993 & 0 & 0 & 0 & 0 & 0 & 0 \\
\hline lsus-eastm & $\mathrm{CW}$ & 1994 & 15 & 0 & 0 & 0 & 0 & 0 \\
\hline poto-mono & $\mathrm{CW}$ & 1994 & 20 & 1 & 1 & 0 & 1 & 1 \\
\hline splt-lone & $\mathrm{CW}$ & 1993 & 7 & 2 & 1 & 1 & 1 & 0 \\
\hline splt-lone & $\mathrm{CW}$ & 1994 & 0 & 0 & 0 & 0 & 1 & 0 \\
\hline acfb-lime & CWp & 1993 & 0 & 0 & 0 & 0 & 0 & 0 \\
\hline trin-chamb & CWsor & 1994 & 84 & 0 & 1 & 0 & 0 & 0 \\
\hline ccpt-crab.rl & WA & 1993 & 0 & 0 & 70 & 8 & 0 & 0 \\
\hline usnk-rock & WAb & 1993 & 0 & 0 & 0 & 0 & 0 & 0 \\
\hline usnk-rock & WAb & 1994 & 0 & 0 & 0 & 0 & 0 & 0 \\
\hline ccpt-palouse & $\mathrm{Wb}$ & 1993 & 0 & 0 & 0 & 0 & 0 & 0 \\
\hline redn-turtle & $\mathrm{Wb}$ & 1993 & 0 & 0 & 0 & 0 & 0 & 0 \\
\hline usnk-teton & Wpot & 1993 & 0 & 0 & 0 & 0 & 0 & 0 \\
\hline gafl-tucsa & WScot & 1993 & 0 & 0 & 0 & 0 & 0 & 0 \\
\hline albe-devils & WStob & 1993 & 0 & 0 & 0 & 0 & 0 & 0 \\
\hline ccpt-crab.m & W & 1993 & 0 & 0 & 1 & 0 & 0 & 0 \\
\hline ccpt-el68 & W & 1993 & 0 & 0 & 16 & 2 & 0 & 0 \\
\hline redn-snake & W & 1993 & 0 & 0 & 0 & 0 & 0 & 0 \\
\hline redn-wildr & W & 1993 & 0 & 0 & 0 & 0 & 0 & 0 \\
\hline gafl-little & $\mathrm{P}$ & 1993 & 0 & 0 & 0 & 0 & 0 & 0 \\
\hline
\end{tabular}


Table 11. Estimated number of days per year that selected compounds exceeded an aquatic-life criteria value, by type of site-Continued

\begin{tabular}{|c|c|c|c|c|c|c|c|c|}
\hline \multirow[b]{2}{*}{ Site code } & \multirow{2}{*}{$\begin{array}{l}\text { Crop group } \\
\text { code }\end{array}$} & \multirow[b]{2}{*}{ Year } & \multicolumn{6}{|c|}{ Estimated number of days per year concentration exc eeded an aquatic-life criterion } \\
\hline & & & Atrazine & Cyanazine & $\begin{array}{c}\text { Azinphos- } \\
\text { methyl }\end{array}$ & Chlorpyrifos & Diazinon & Malathion \\
\hline \multicolumn{9}{|c|}{ AGRICULTURAL INDICATOR SITES - CONTINUED } \\
\hline acfb-aycocks & $P$ & 1993 & 0 & 0 & 0 & 0 & 0 & 0 \\
\hline acfb-aycocks & $\mathrm{P}$ & 1994 & 0 & 0 & 0 & 1 & 0 & 0 \\
\hline sanj-salt & COTv & 1993 & 0 & 0 & 0 & 1 & 49 & 1 \\
\hline will-pudding & FGv & 1993 & 0 & 0 & 1 & 0 & 0 & 0 \\
\hline will-zollner & FGv & 1993 & 49 & 0 & 1 & 0 & 35 & 1 \\
\hline will-zollner & FGv & 1994 & 14 & 0 & 0 & 1 & 21 & 0 \\
\hline sanj-merced & $\mathrm{O}$ & 1993 & 0 & 0 & 1 & 10 & 14 & 0 \\
\hline sanj-merced & $\mathrm{O}$ & 1994 & 0 (nsd) & 0 (nsd) & 0 & 10 & 14 & 0 \\
\hline sanj-orest & $\mathrm{O}$ & 1992 & 0 & 0 & 77 (nsd) & 49 & 40 & 0 \\
\hline sanj-orest & $\mathrm{O}$ & 1993 & 0 & 0 & 130 (nsd) & 17 to 25 & 23 & 0 \\
\hline ozrk-dous & $\mathrm{XX}$ & 1994 & 0 & 0 & 0 & 0 & 0 & 0 \\
\hline ozrk-yocum & $\mathrm{XX}$ & 1994 & 0 & 0 & 0 & 0 & 0 & 0 \\
\hline \multicolumn{9}{|c|}{ URBAN INDICATOR SITES } \\
\hline conn-norwalk & - & 1993 & 0 & 0 & 0 & 0 & 0 & 0 \\
\hline conn-norwalk & - & 1994 & 0 & 0 & 0 & 0 & 0 & 1 \\
\hline hdsn-lisha & - & 1994 & 0 & 0 & 0 & 0 & 0 & 0 \\
\hline 1sus-cedar & - & 1993 & 0 & 0 & 0 & 0 & 0 & 0 \\
\hline lsus-cedar & - & 1994 & 0 & 0 & 0 & 0 & 0 & 0 \\
\hline poto-acco & - & 1994 & 0 & 0 & 0 & 0 & 77 & 2 \\
\hline gafl-lafayette & - & 1993 & 0 & 0 & 0 & 0 & 14 to 28 & 0 \\
\hline gafl-lafayette & - & 1994 & 0 (nsd) & 0 (nsd) & 0 (nsd) & 0 (nsd) & 8 (nsd) & 1 (nsd) \\
\hline acfb-sope & - & 1993 & 0 & 0 & 0 & 2 & 17 & 0 \\
\hline whit-little & - & 1992 & 14 & 1 & 1 & 1 & 38 & 2 \\
\hline whit-little & - & 1993 & 17 & 0 & 0 & 2 & 24 & 1 \\
\hline whit-little & - & 1994 & 0 & 0 & 0 & 0 & 1 & 0 \\
\hline splt-cherry & - & 1993 & 0 & 0 & 0 & 2 & 30 & 2 \\
\hline splt-cherry & - & 1994 & 0 & 0 & 0 & 4 & 9 & 0 \\
\hline trin-rush & - & 1993 & 0 & 0 & 1 & 13 to 38 & 180 to 250 & 3 \\
\hline nvbr-lasvegas & - & 1993 & 0 & 0 & 0 & 0 & 11 & 4 \\
\hline nvbr-lasvegas & - & 1994 & 0 & 0 & 0 & 4 to 20 & 30 & 0 \\
\hline will-fanno & - & 1993 & 0 & 0 & 1 & 1 & 1 & 0 \\
\hline will-fanno & - & 1994 & 0 & 0 & 0 & 0 & 1 & 0 \\
\hline \multicolumn{9}{|c|}{ INTEGRATOR SITES } \\
\hline hdsn-moh & CA & 1994 & 0 & 0 & 0 & 0 & 0 & 0 \\
\hline poto-shenan & CA & 1993 & 0 & 0 & 0 & 0 & 0 & 0 \\
\hline albe-tar & CScot & 1993 & 0 & 0 & 0 & 0 & 0 & 0 \\
\hline gafl-withla & $\mathrm{P}$ & 1993 & 0 & 0 & 0 & 0 & 0 & 0 \\
\hline whit-white & CS & 1992 & 38 & 1 & 0 & 0 & 0 & 0 \\
\hline whit-white & CS & 1993 & 63 & 14 & 0 & 1 & 0 & 0 \\
\hline whit-white & CS & 1994 & 77 & 0 & 0 & 0 & 0 & 0 \\
\hline wmic-milw & $\mathrm{CAv}$ & 1993 & 0 & 0 & 0 & 0 & 0 & 0 \\
\hline wmic-milw & $\mathrm{CAv}$ & 1994 & 0 & 0 & 0 & 0 & 0 & 0 \\
\hline redn-rr.fargo & CSW & 1994 & 0 (nsd) & 0 (nsd) & 0 (nsd) & 0 (nsd) & 0 (nsd) & 0 (nsd) \\
\hline redn-rr.em & W & 1993 & 0 & 0 & 0 & 0 & 0 & 0 \\
\hline cnbr-platte & $\mathrm{CW}$ & 1992 & 49 & 28 & 0 & 2 & 0 & 0 \\
\hline cnbr-platte & $\mathrm{CW}$ & 1993 & 49 & 1 (nsd) & 0 & 1 to 10 & 0 & 0 \\
\hline sanj-sanj & $\mathrm{O}$ & 1993 & 0 & 0 & 35 & 0 & 35 & 0 \\
\hline sanj-sanj & $\mathrm{O}$ & 1994 & 0 (nsd) & 0 (nsd) & 0 (nsd) & 0 (nsd) & 24 (nsd) & 0 (nsd) \\
\hline
\end{tabular}


malathion-exceeded aquatic-life criteria values at 10 or more sites (table 8 ). To more closely examine the potential effects of these compounds in the sampled streams, it is important to determine whether the concentrations that exceeded the criteria values were isolated cases or whether the concentrations remained higher than these levels for significant periods of time. Because the aquatic-life criteria are based on either a one-time exposure (Canadian values) or an exposure to a 24-hour or a 96-hour average concentration (USEPA values), the monthly median concentrations and 5month TWM concentrations are not appropriate measures of concentration for comparison with these criteria values. A more useful measure is the number of days the concentration of a specific compound exceeds its criterion value at a site each year. The number of days a compound exceeded its criterion value during a year was estimated by linear interpolation between concentrations in successive samples from a given site. These estimates are given in table 11 for the six compounds that exceeded criteria values at 10 or more sites. The reliability of the estimates varies, depending on the sampling frequency at a particular site. In some cases, a somewhat arbitrary judgement was made as to whether the concentration of a compound remained higher than the criterion value between adjacent samples. For samples in which a concentration exceeded a criterion value but concentrations in adjacent samples were less than the criterion value, only the concentration for that day was counted as greater than the criterion value. For a few sites, data from 1992 also are included in table 11 and in figures 34-40. Sampling at these sites was very intensive during 1992, allowing more reliable estimates of the length of time concentrations exceeded criteria values. Observations for the six compounds that exceed aquatic-life criteria values at 10 or more sites are discussed in the following sections.

\section{Malathion}

Concentrations of malathion exceeded its USEPA aquatic-life criterion value of $0.1 \mu \mathrm{g} / \mathrm{L}$ at 13 sites (table 8). Concentrations of malathion greater than this value, however, were rare (table 11). Concentrations greater than $0.1 \mu \mathrm{g} / \mathrm{L}$ were primarily in isolated samples. An example of this is shown in figure 34 for Las Vegas Wash in Nevada (nvbr-lasvegas), which had the highest estimate for days on which malathion exceeded the criterion. Between each instance of a concentration greater than the criterion value, a concentration less than the criterion value was measured in one or more samples. A similar pattern was observed for the other sites at which malathion concentrations exceeded the criterion value.

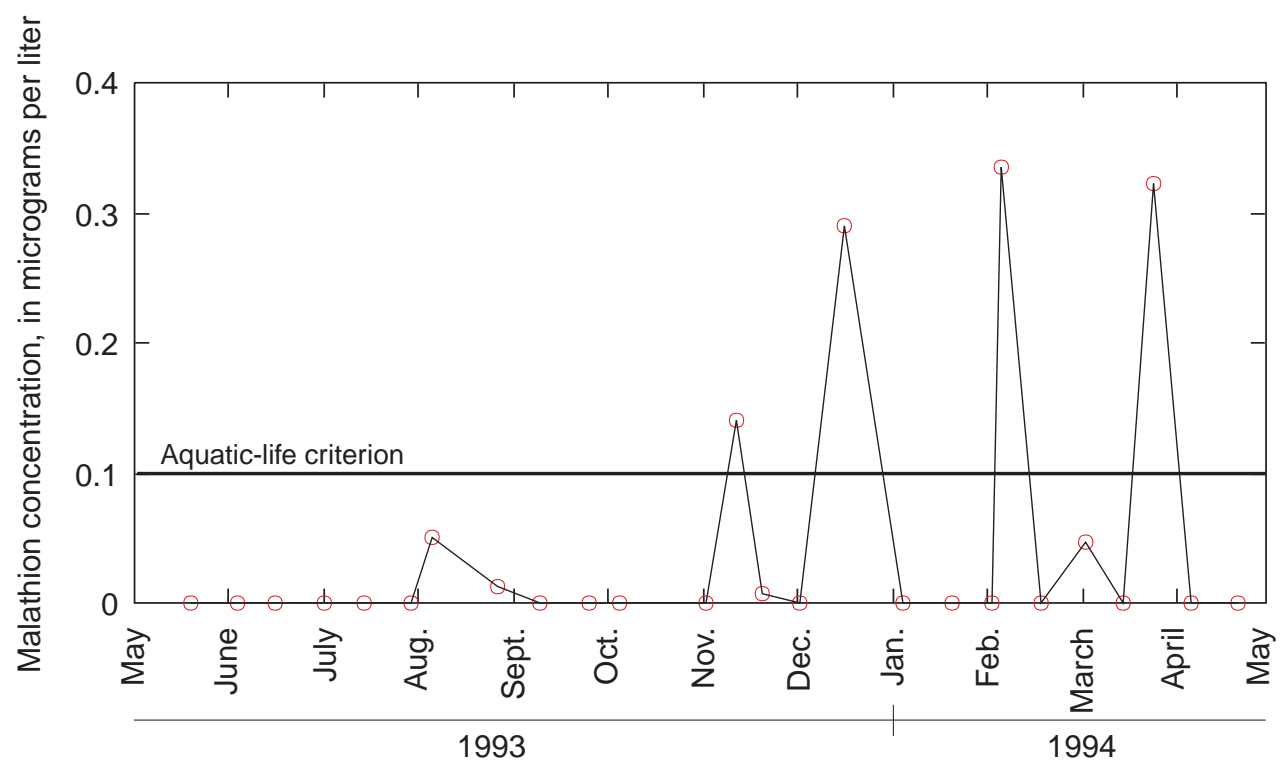

Figure 34. Concentrations of malathion in Las Vegas Wash, Nevada (nvbr-lasvegas). The U.S. Environmental Protection Agency aquatic-life criterion value of 0.1 mic rogram per liter is shown as a horizontal line. Concentrations reported as not detected were assigned a value of zero. 


\section{Azinphos-Methyl}

Concentrations of azinphos-methyl exceeded its USEPA aquatic-life criterion value of $0.01 \mu \mathrm{g} / \mathrm{L}$ at 16 sites (table 8 ). At 11 of these sites, concentrations exceeded the criterion value only 1 day in a given year (table 11), similar to malathion. Concentrations were greater than $0.01 \mu \mathrm{g} / \mathrm{L}$ for many more days at four sites-Crab Creek Lateral (ccpt-crab.rl) and El68 Wasteway (ccpt-el68) in Washington and Orestimba Creek (sanj-orest) and the San Joaquin River (sanjsanj) in California. Concentrations at Orestimba Creek in 1992 and 1993 and at Crab Creek Lateral in 1993 are shown in figure 35. Concentrations at Orestimba Creek were much higher than the criterion value during the summers of 1992 and 1993. Concentrations at Crab Creek Lateral ranged from 0.05 to 0.2 from mid-May through July 1993. A similar pattern was observed at the ccpt-e168 and sanj-sanj sites, with concentrations exceeding the criterion value primarily during early to midsummer. It should be noted that the analytical recovery of azinphos-methyl was low (table 2); therefore, the concentrations reported for samples in which azinphos-methyl was detected probably are low estimates.

\section{Chlorpyrifos}

Concentrations of chlorpyrifos exceeded its USEPA aquatic-life criterion value of $0.041 \mu \mathrm{g} / \mathrm{L}$ at 20 sites (table 8); 6 sites were urban indicator sites (table 11). At most sites, concentrations greater than the criterion value occurred only in isolated samples (table 11). Concentrations were greater than $0.041 \mu \mathrm{g} / \mathrm{L}$ for longer periods at several sites, including Crab Creek

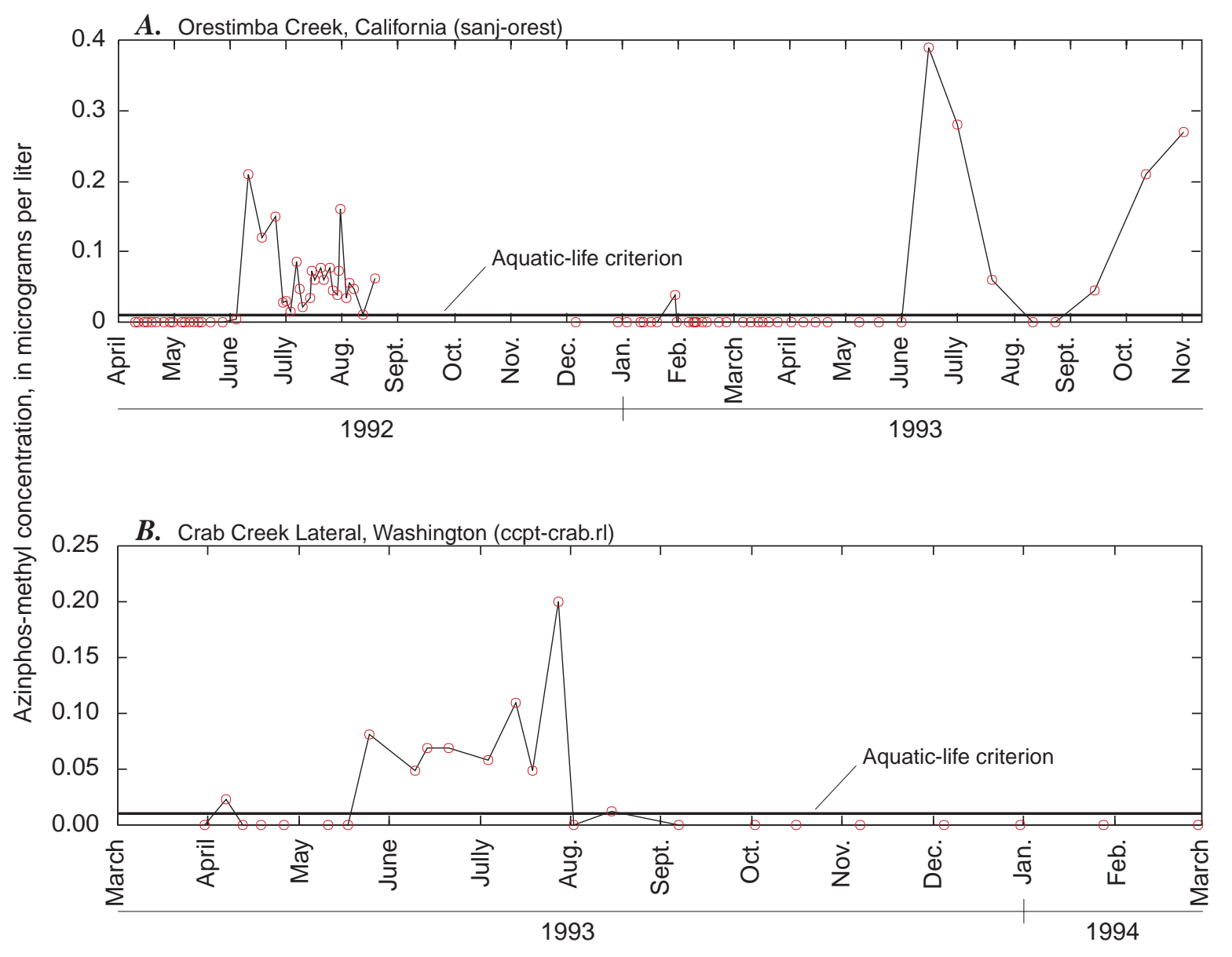

Figure 35. Concentrations of azinphos-methyl at tw o sites. The U.S. Environmental Protection Agency aquatic-life criterion value of 0.01 mic rogram per liter is show $n$ as a horizontal line. Concentrations reported as not detected w ere assigned a value of zero. 
Lateral (ccpt-crab.rl) in Washington, the Merced River (sanj-merced) and Orestimba Creek (sanj-orest) in California, and Rush Creek (trin-rush), an urban site in Texas. Concentrations of chlorpyrifos in Orestimba Creek in 1992 and 1993 and in Rush Creek in 1993 are shown in figure 36. In Orestimba Creek, chlorpyrifos was detected in most samples from early spring through the summer during both years, with concentrations in some samples much higher than the criterion value. In Rush Creek, chlorpyrifos was detected in samples for much of the year, with concentrations exceeding $0.041 \mu \mathrm{g} / \mathrm{L}$ in 5 of 16 samples collected during the summer of 1993.

\section{Diazinon}

Concentrations of diazinon exceeded the IJC aquatic-life criterion value of $0.08 \mu \mathrm{g} / \mathrm{L}$ at 18 sites (table 8). Concentrations exceeded the aquatic-life criterion value for extended periods at 12 sites, including 4 agricultural sites, 1 integrator site, and 7 urban sites (table 11). Concentration patterns for several of the agricultural indicator sites and the integrator site are shown in figure 37. These five sites are in areas where diazinon is used extensively for agriculture - the San Joaquin Valley in California (sanj-sanj) and the Willamette River Basin in Oregon. Figure 37 shows distinct peaks in concentrations for the Merced (sanj-merced), San Joaquin (sanj-sanj), and the Orestimba (sanj-orest) sites during the months of January or February, or both; these peaks are the result of the application of diazinon to orchards during the dormant season. Concentrations of diazinon in Orestimba Creek were much higher than the criterion value in many of the samples collected during the summer of 1992 and in several samples collected during the summer of 1993. Concentrations exceeded the criterion value in Salt Slough (sanj-salt) and Zollner Creek (will-zollner) mainly during the summer. Concentrations for three urban sites-Rush Creek near

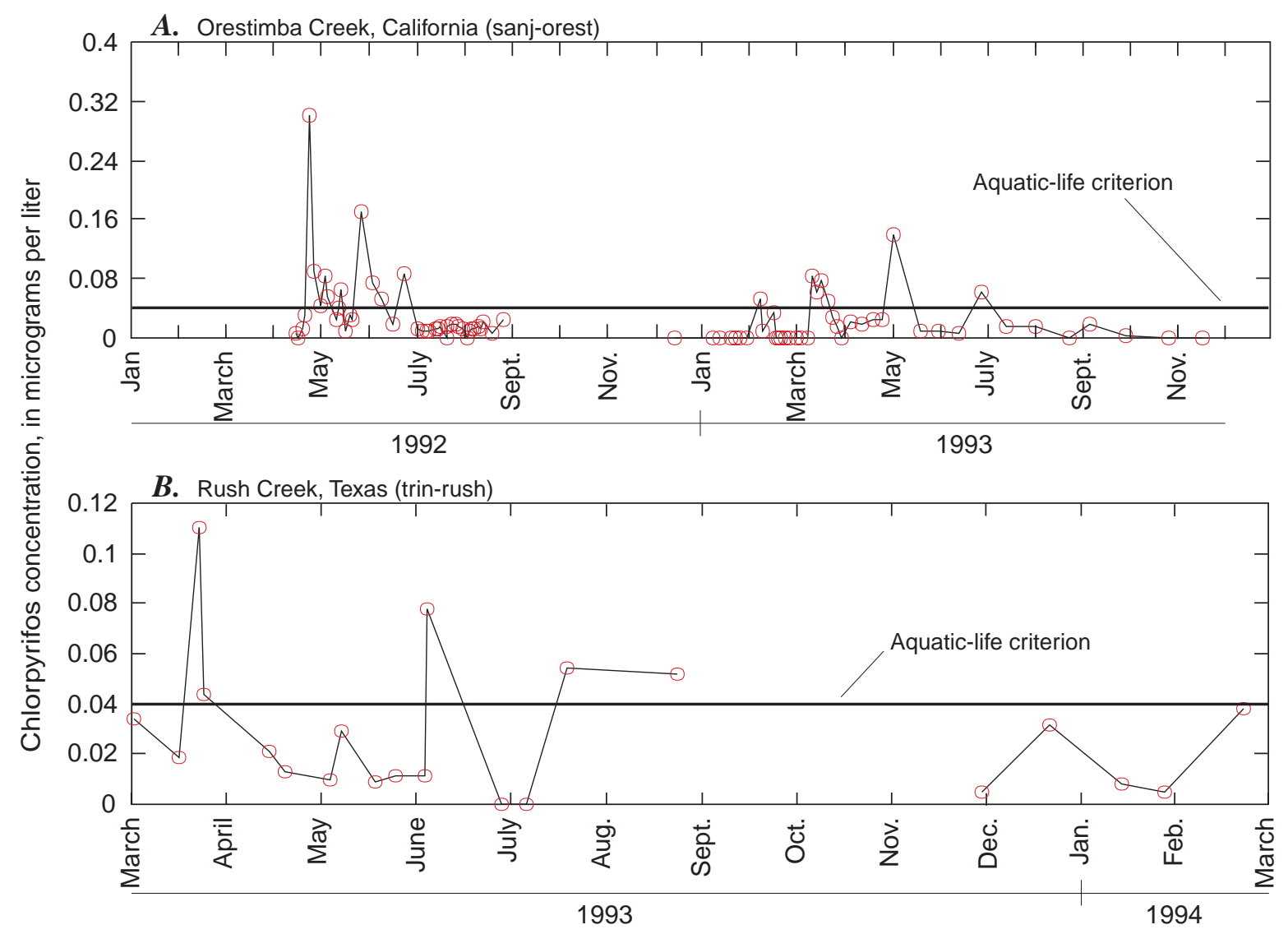

Figure 36. Concentrations of chlorpyrifos at two sites. The U.S. Environmental Protection Agency aquatic-life criterion value of 0.041 microgram per liter is shown as a horizontal line. Concentrations reported as not detected were assigned a value of zero. 

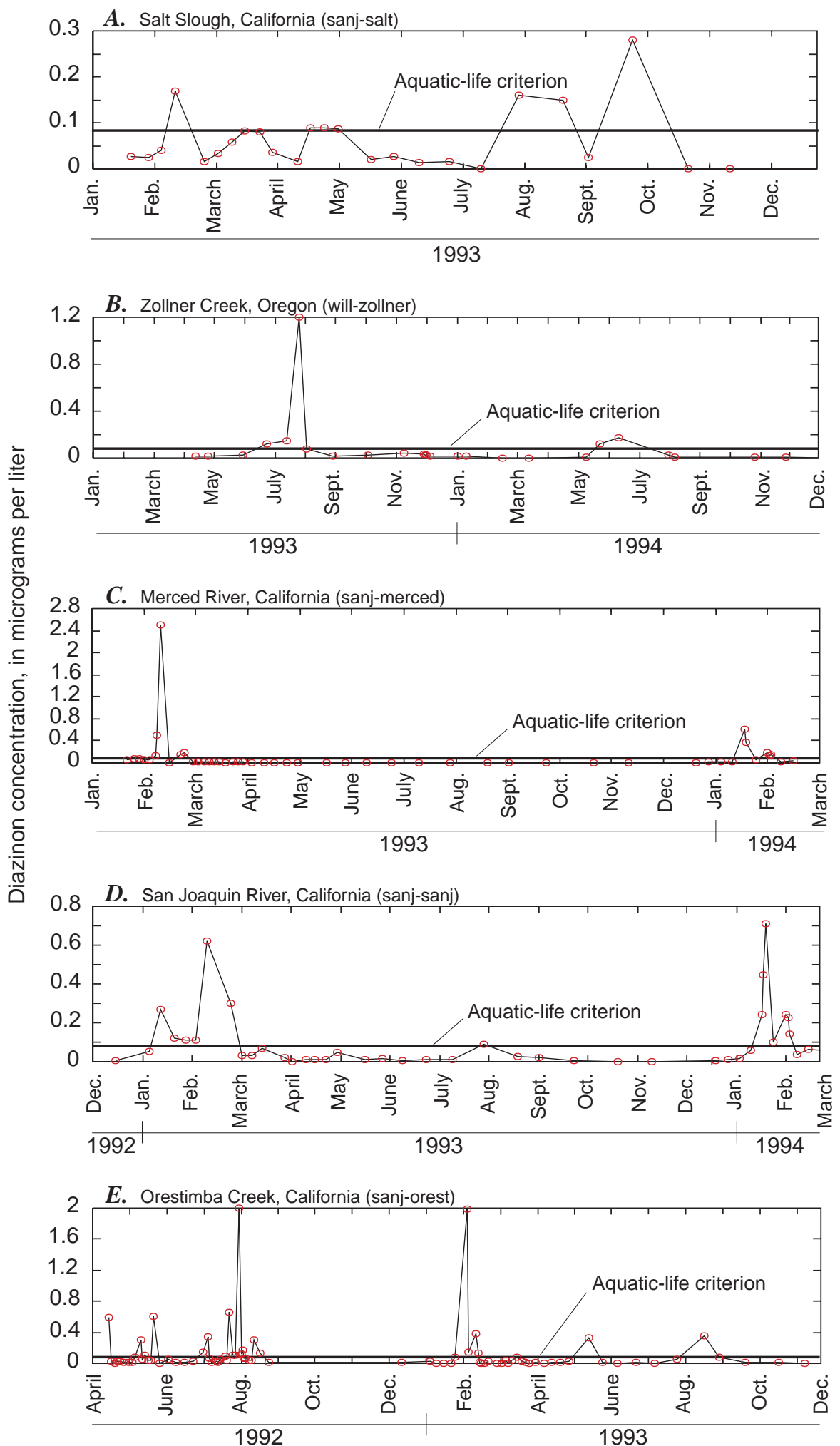

Figure 37. Concentrations of diazinon at five sites. The aquatic-life criterion value of 0.08 mic rogram per liter established by the International J oint Commission is show $\mathrm{n}$ as a horizontal line. Concentrations reported as not detected were assigned a value of zero. 
Dallas, Texas (trin-rush), Accotink Creek near Washington, D.C. (poto-acco), and Cherry Creek in Denver, Colorado (splt-cherry) — are shown in figure 38. In Rush Creek, concentrations were much higher than the criterion value in nearly every sample from March through September of 1993. In Accotink and Cherry Creeks, concentrations also were greater than the criterion value for much of the summer.

\section{Atrazine}

Concentrations of atrazine exceeded the Canadian aquatic-life criterion value of $2 \mu \mathrm{g} / \mathrm{L}$ at 17 sites (table 8 ). Nearly all of these sites are agricultural indicator sites and integrator sites in corn-growing areas. The criterion value also was frequently exceeded in Little Buck Creek (whit-little), an urban stream in Indiana with a substantial amount of cropland planted
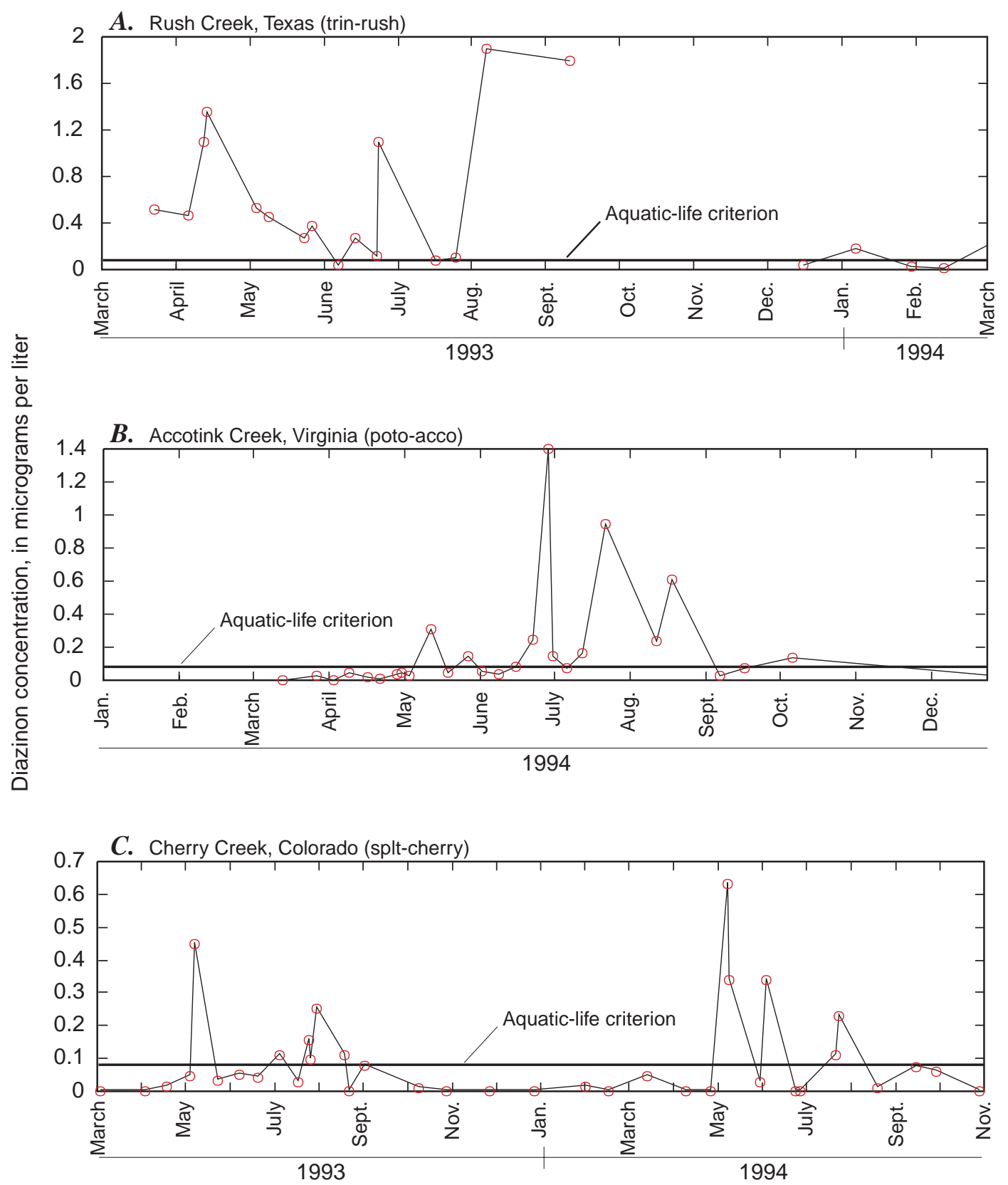

Figure 38. Concentrations of diazinon at three urban sites. The aquatic-life criterion value of 0.08 microgram per liter established by the International J oint Commission is shown as a horizontal line. Concentrations reported as not detected were assigned a value of zero. 
in corn in its drainage basin. At sites where the atrazine criterion value was exceeded, concentrations often remained higher than this value for extended periods (table 11). Temporal patterns of herbicide concentrations at these sites were discussed previously. Concentrations of atrazine at integrator sites on the White River in Indiana (whit-white) and the Platte River in Nebraska (cnbr-platte) and at the agricultural site on Chambers Creek in Texas (trin-chamb) are shown in figure 39. At all three sites, concentrations were much higher than the criterion value of $2 \mu \mathrm{g} / \mathrm{L}$ after application in the spring, remained elevated for a period of several weeks or more, and then declined to lower levels for the remainder of the year. The plots for the White and Platte rivers show that this pattern is repeated annually.

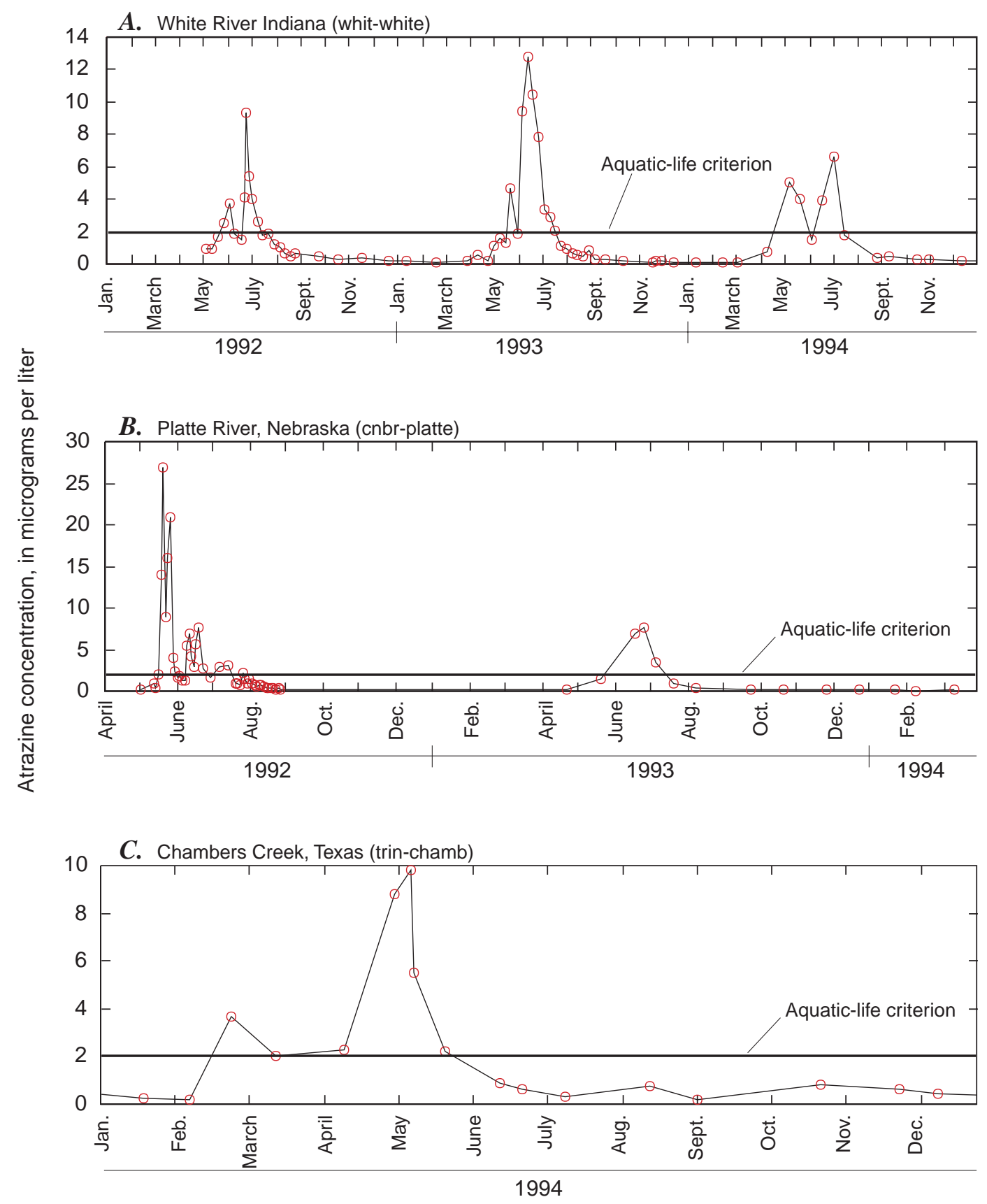

Figure 39. Concentrations of atrazine at three sites. The Canadian aquatic-life criterion value of 2 micrograms per liter is shown as a horizontal line. Concentrations reported as not detected were assigned a value of zero. 


\section{Cyanazine}

Concentrations of cyanazine exceeded the Canadian aquatic-life criterion value of $2 \mu \mathrm{g} / \mathrm{L}$ at 10 sites (table 8 ). The aquatic-life criterion value for atrazine also was exceeded at these 10 sites (table 11). The estimated period of time that concentrations of cyanazine were greater than the criterion value, however, was shorter than the period for atrazine at all sites. Concentrations of cyanazine at the integrator sites on the White (whit-white) and the Platte (cnbr-platte) rivers and at the agricultural site on Maple Creek in Nebraska (cnbr-maple) are shown in figure 40. The temporal pattern of concentrations at these three sites was very similar to the patterns observed for atrazine.

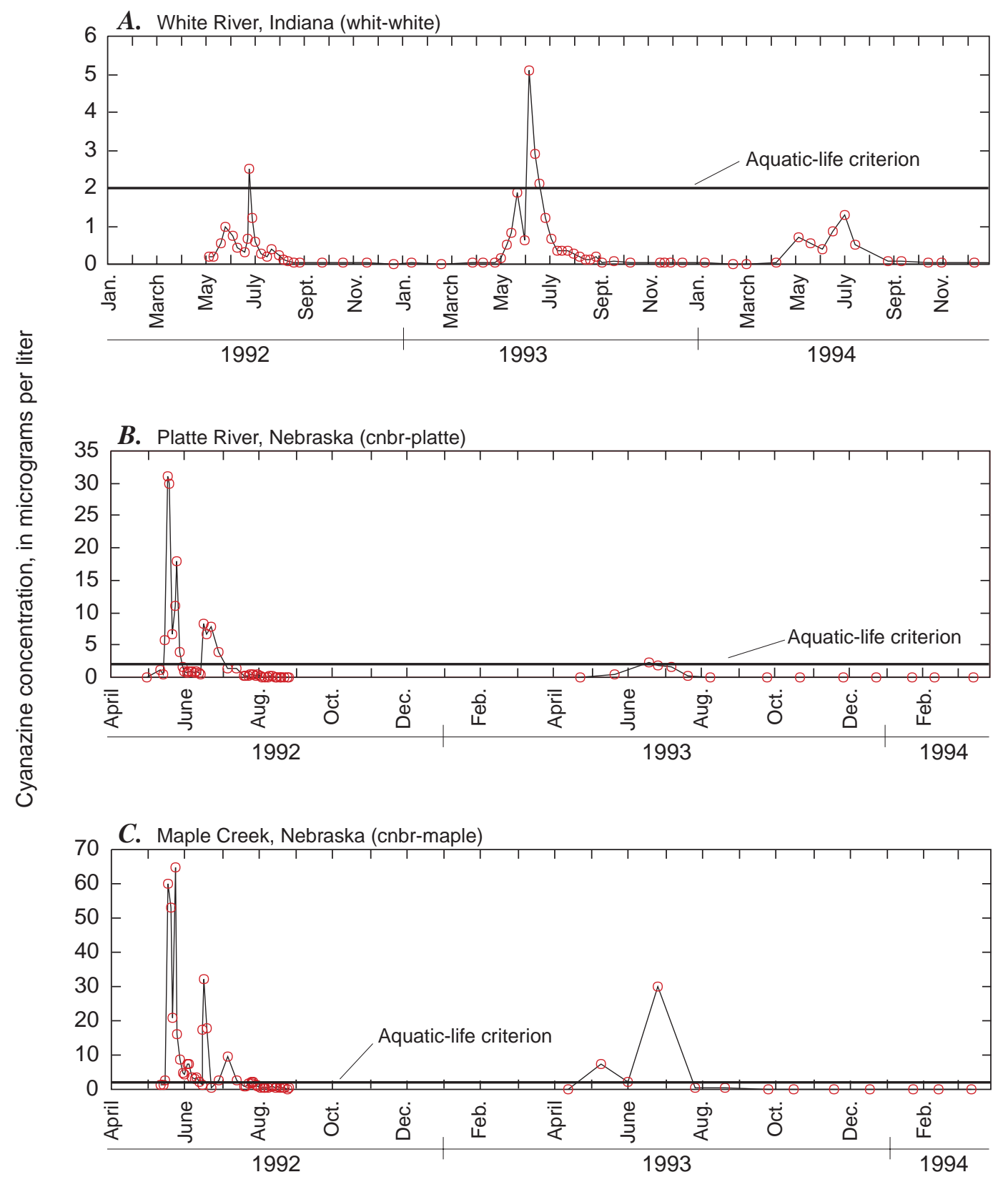

Figure 40. Concentrations of cyanazine at three sites. The Canadian aquatic-life criterion value of 2 micrograms per liter is show $n$ as a horizontal line. Concentrations reported as not detected were assigned a value of zero. 


\section{Co-Occurrence of Pesticides at Concentrations Exceeding Criteria Values}

At many sites, concentrations of more than one compound exceeded an aquatic-life criterion value (table 10). In some cases, this occurred in the same sample or during the same period. For example, the concentrations of atrazine and cyanazine in the White River in Indiana [whit-white (figs. 39 and 40)] were much higher than their respective aquatic-life criteria values during the same period in both 1992 and 1993. Using the data from all 58 sites for the entire sampling period, one or more aquatic-life criteria values were exceeded in 410 samples: 131 samples had 2 compounds with concentrations greater than their criteria values, 17 samples had 3 compounds with concentrations greater than their criteria values, and 7 samples had 4 compounds with concentrations greater than their criteria values. The presence of multiple compounds with concentrations greater than their aquatic-life criteria values was widespread, occurring at 29 sites, including 8 of the 11 urban sites, in 12 of the 19 study units.

At some sites, the occurrence of two or more compounds with concentrations greater than the criteria values was particularly evident. Figure 41 shows a variety of situations where concentrations of two or more compounds exceeded aquatic-life criteria values at some of these sites. In these plots, concentrations of each compound have been normalized by dividing the concentrations by the aquatic-life criterion value for that compound.

Normalizing the concentrations accounts for differences among the criteria values for the various compounds. In the plots, a normalized concentration greater than 1 indicates a concentration greater than the criterion value. Note that the concentration scales in these plots are logarithmic; thus, a normalized concentration of 10 indicates that the concentration in that sample was 10 times higher than the criterion value for that compound.

At several the agricultural sites, criteria values for atrazine and cyanazine, and occasionally metolachlor, were exceeded in the same sample or during the same period (fig. $41 A, B$ ). This also was true at the Platte and White river sites (cnbr-platte and whitwhite), the two integrator sites where corn is the major crop grown in the basin (figs. 39, 40, 41C).

Occasionally, concentrations of the insecticide chlorpyrifos also exceeded its criterion value in the same samples from these sites.
At agricultural sites in the San Joaquin River (sanj-salt, sanj-merced, and sanj-orest) and the Willamette River (will-pudding and will-zollner) basins, concentrations of two or more insecticides often exceeded criteria values in the same samples or during the same period. Concentrations of diazinon, chlorpyrifos, and azinphos-methyl were higher than their criteria values in many of the samples from Orestimba Creek in California [sanj-orest (fig. 41D)]. To a lesser extent, diazinon and chlorpyrifos concentrations exceeded criteria values in samples from the Merced River in California [sanj-merced (fig. $41 E)$ ]. In Zollner Creek in Oregon [will-zollner (fig. $41 F)$ ], concentrations of several insecticides, including azinphos-methyl, carbofuran, chlorpyrifos, diazinon, and malathion, as well as the herbicide atrazine, were higher than or near criteria values at various times throughout 1993 and 1994, often in the same samples.

Example plots for four of the urban sites are shown in figure 41G-J. In Rush Creek, Cherry Creek, and Las Vegas Wash (trin-rush, splt-cherry, and nvbrlasvegas), diazinon concentrations greater than the criterion value often coincided with concentrations of other insecticides greater than or near their criteria values, including the insecticides azinphos-methyl, chlorpyrifos, and malathion. Concentrations of several insecticides were greater than the criteria values for much of the year in Rush Creek (fig. 41G) and Las Vegas Wash (fig. 41H). Finally, Little Buck Creek in Indiana [whit-little (fig. 41J)] shows characteristics of both agricultural and urban basins. Atrazine concentrations in samples from this site exceeded the criterion value in spring and early summer similar to concentrations in samples from agricultural sites in corn-growing areas, whereas diazinon and malathion concentrations were greater than or near their criteria values for much of the summer and autumn, which is typical of many of the urban sites.

The plots in figure 41 and the data in table 11 illustrate another important point concerning the concentrations measured during this study. Throughout this report, it has been stated that herbicide concentrations generally were greater than insecticide concentrations at most sites, often by a factor of 10 or more. The aquatic-life criteria values for herbicides, however, often are substantially greater than the values for insecticides. When concentrations of compounds are normalized to their criteria values (fig. 41), it is apparent that at most sites insecticides may be more important than herbicides in terms of potential effects 
A. Maple Creek, Nebraska (cnbr-maple)
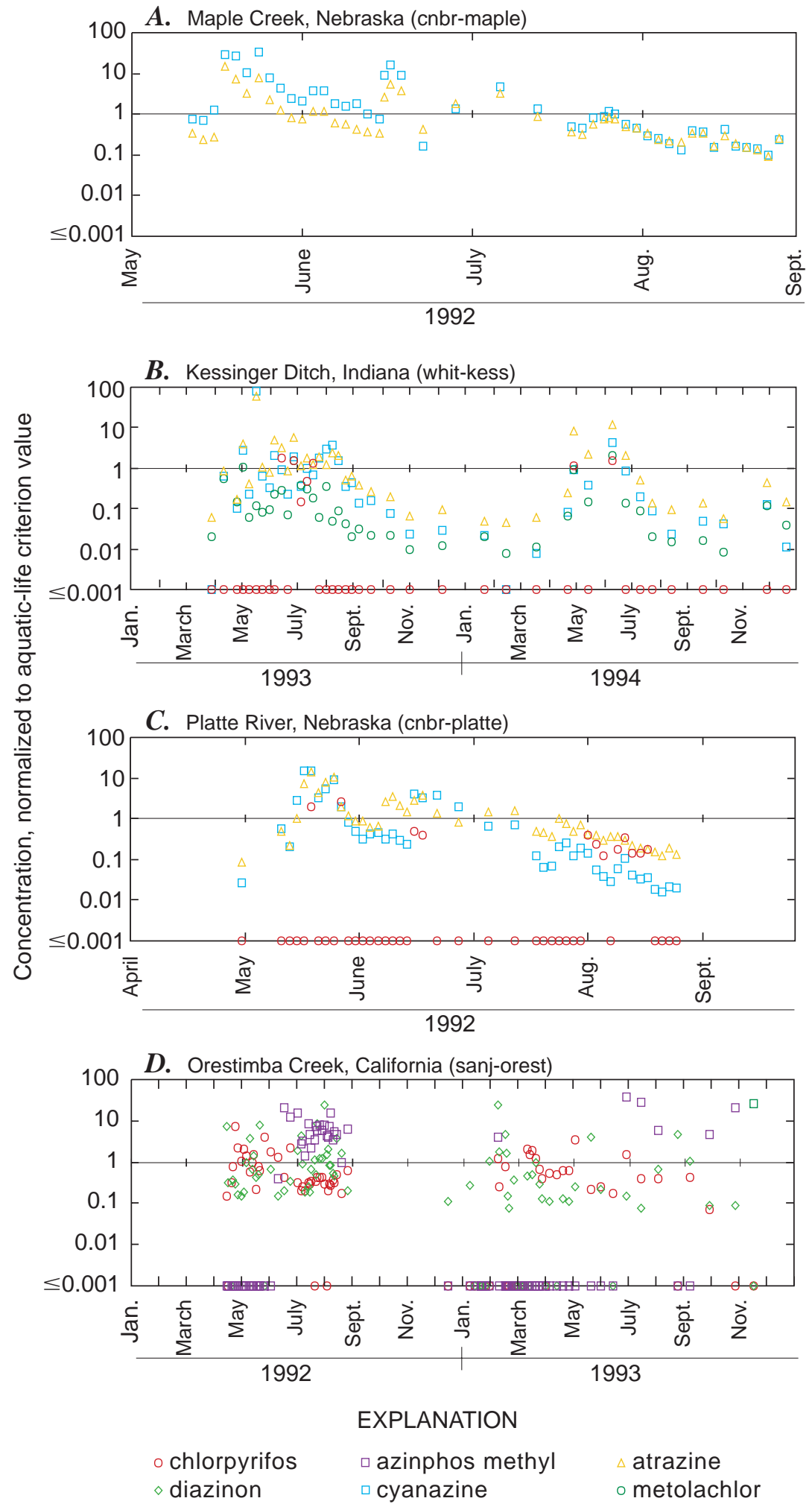

Figure 41. Concentrations of co-occurring compounds at various sites. Concentrations of each compound have been normalized by dividing by the aquatic-life criterion value for that compound. Thus, a normalized concentration greater than 1 (shown as a horizontal line) indicates a concentration greater than the aquatic-life criterion value. The $y$-axis is logarithmic, so that a normalized concentration of 10 means that the concentration is 10 times the aquatic-life criterion value. Concentrations reported as not detected are plotted on the $x$-axis. 
on aquatic life. This is evident in agricultural areas with high use of insecticides, such as the Orestimba (sanjorest), Merced (sanj-merced), and Zollner (willzollner) sites, and at most urban sites, where insecticides commonly are detected at concentrations greater than their criteria values. In addition, two of the agricultural sites in the Central Columbia Plateau (ccpt-crab.m and ccpt-el68) study unit had concentrations of azinphos-methyl greater than the criterion value for extended periods (table 11, figure 35). Even where insecticide levels are much lower than herbicide levels, insecticides may be more important in

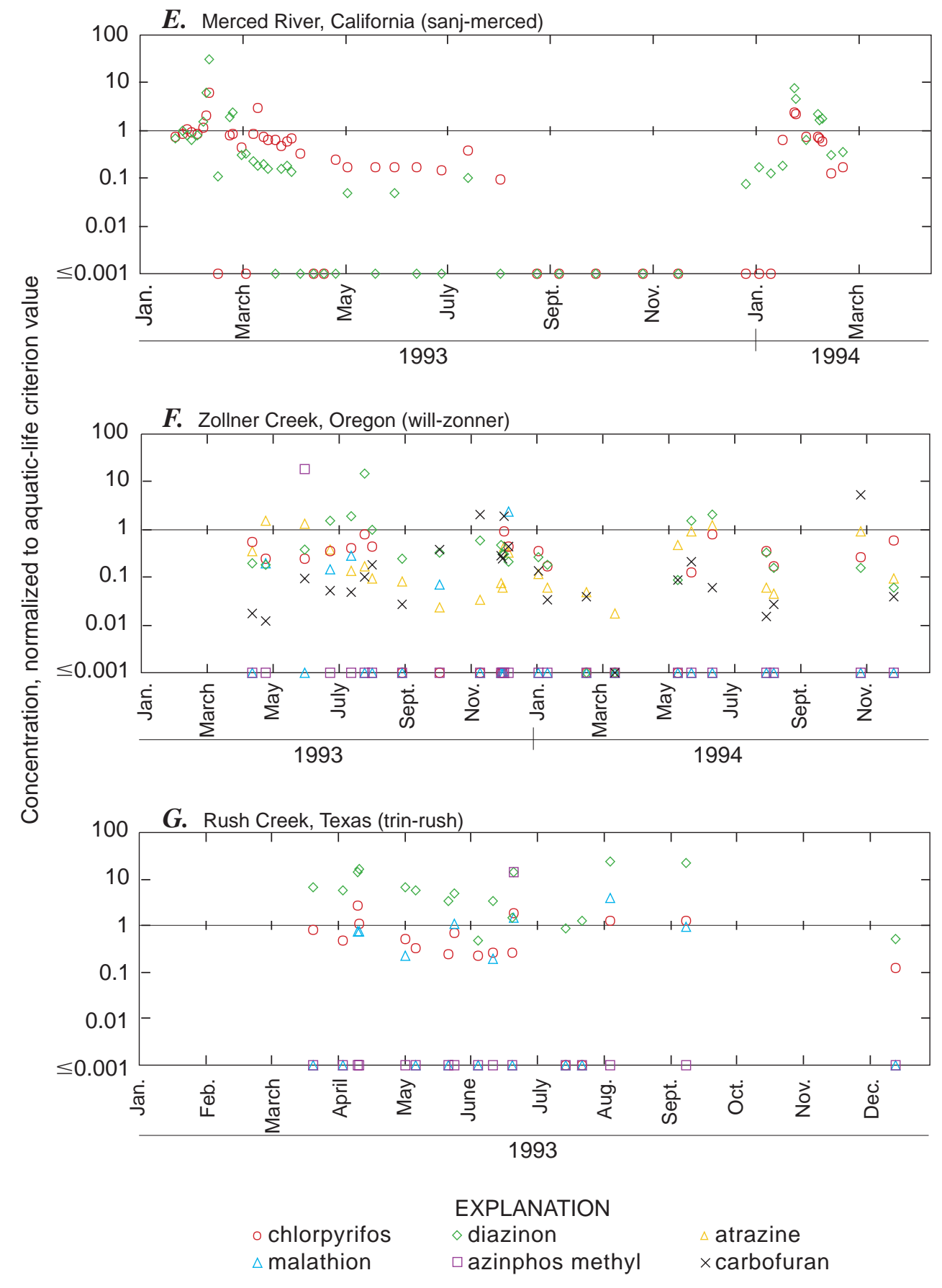

Figure 41-- Continued. 
terms of potential effects on aquatic life. At many of the agricultural sites usually associated with high levels of herbicides (for example, sites in corn-growing areas) concentrations of azinphos-methyl, chlorpyrifos, diazinon, and malathion were occasionally greater than the criteria values, often during the same period when herbicide levels were high. Whether this combination of herbicides and insecticides has an effect on the

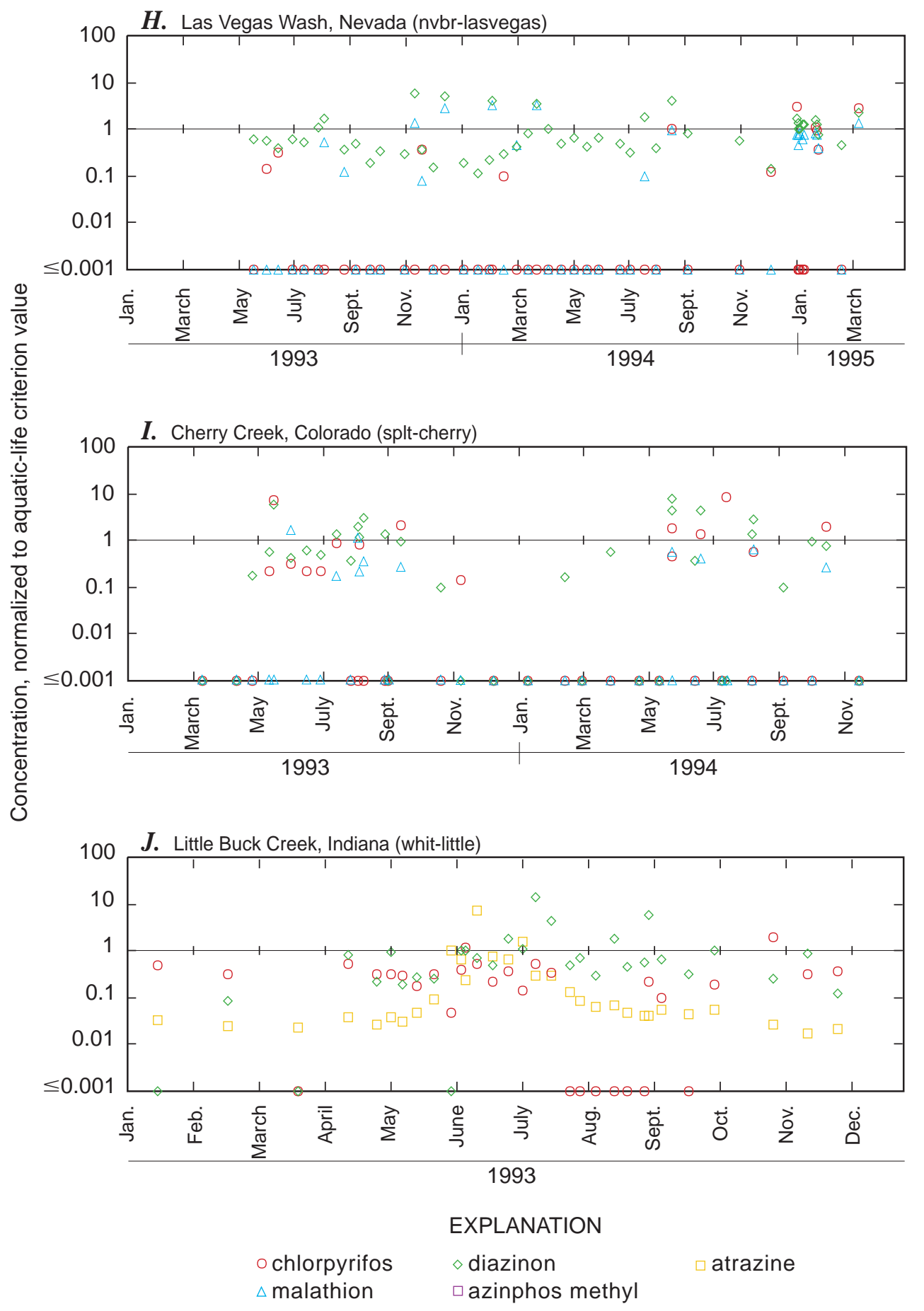

Figure 41- Continued. 
toxicity to aquatic organisms is unknown, but it is not accounted for in the derivation of the criteria values for either group of compounds.

\section{SUMMARY AND CONCLUSIONS}

Pesticides were commonly detected in streams draining small agricultural and urban basins (agricultural and urban indicator sites) and in large streams and rivers draining major basins with mixed land uses (integrator sites). Of the 46 targeted pesticides and pesticide degradation products, all were detected in at least 1 of the approximately 2,200 samples analyzed. On average, about 20 of the target compounds were detected at each site regardless of land-use setting and basin size, and an average of 6 to 7 of the target compounds were detected in each individual sample.

The pesticides that were detected most frequently were among the pesticides with highest national agricultural use, including the herbicides atrazine, metolachlor, alachlor, and cyanazine. Several other pesticides with high national use, however, such as the herbicides trifluralin, pendimethalin, and butylate, and the insecticides methyl parathion, phorate, and terbufos, were detected in less than 5 percent of samples. In general, the relation between the frequency of detection of pesticides in streams and the amount used in the basin was significant, but variability in pesticide use accounted for only about 25 percent of the observed variability in detection frequencies of the target compounds as a group. Herbicides generally were detected more frequently than insecticides, particularly in streams draining agricultural basins. Some compounds, including several insecticides, were detected more frequently in streams draining urban areas than in streams draining primarily agricultural areas. Concentrations in streams generally were less than $1 \mu \mathrm{g} / \mathrm{L}$ for all compounds, although concentrations greater than $1 \mu \mathrm{g} / \mathrm{L}$ were frequently measured for several herbicides during seasonal peaks. Herbicide concentrations were higher than insecticide concentrations at most agricultural and integrator sites. In areas where a large variety of crops are grown, especially vegetables and orchard and vineyard crops, insecticide concentrations often were higher than herbicide concentrations. Concentrations of several insecticides consistently were higher at urban sites than at most of the agricultural indicator sites and the integrator sites.
Seasonal patterns in pesticide occurrence were observed at most agricultural and integrator sites. At many of these sites, elevated concentrations of several compounds, particularly herbicides, occurred during the early part of the growing season. At other sites, the seasonal patterns were determined by local pesticide application and irrigation practices. Seasonal patterns were less evident in most of the urban streams where low levels of several compounds persisted for much of the year.

Annual stream loads of pesticide parent compounds (not including degradation products) generally accounted for less than 2 percent of the amounts applied agriculturally in the drainage basins. For several herbicides, including atrazine, cyanazine, and metolachlor, the amount transported in the streams consistently represented about 1 percent of the amount applied in most of the agricultural and integrator basins. For other herbicides and all insecticides, the amount transported in the streams represented a much smaller (10 to 100 times lower) portion of the amount applied in the basins. Transport of pesticides in urban streams could not be compared to the amount applied in the urban basins because of the lack of information on nonagricultural pesticide use. The annual total insecticide yields for many of the urban basins, however, were as high or higher than the annual total insecticide yields for most of the agricultural or integrator basins.

Concentrations of several compounds frequently were higher than water-quality standards and criteria established for these compounds in drinking water. When expressed as a long-term mean concentration, however, the concentrations measured at these 58 sites rarely exceeded USEPA-established standards and criteria for drinking water. It should be noted that human-health criteria have not been established for 20 of the target compounds.

Criteria values established for the protection of aquatic life, which generally are lower than the humanhealth criteria values, were frequently exceeded. One or more aquatic-life criteria values were exceeded at 39 of the 58 sampling sites. For some compounds, particularly herbicides, this occurred primarily during relatively short seasonal pulses of elevated concentrations that followed periods of pesticide application. For some insecticides, concentrations were higher than the aquatic-life criteria values for longer periods, particularly at some of the urban sites and at agricultural sites in California and Oregon. At a 
number of sites, concentrations of several compounds were higher than their aquatic-life criteria values in the same samples or during the same period. The established criteria do not account for the presence of mixtures of pesticides or pesticide degradation

products. In addition, aquatic-life criteria have not been established for 28 of the target compounds. These and other limitations hinder the assessment of the environmental significance of the pesticide concentrations measured in this study.

\section{REFERENCES CITED}

Anderson, J.R., Hardy, E.E., Roach, J.T., and Witmer, R.E., 1976, A land use and land cover classification system for use with remote sensor data: U.S. Geological Survey Professional Paper 964, 28 p.

Baker, D.B., 1985, Regional water quality impacts of intensive row-crop agriculture: A Lake Erie basin case study: Journal of Soil and Water Conservation, v. 40, no. 1, p. 125-132.

Barbash, J.E., and Resek, E.A., 1996, Pesticides in ground water: Distribution, trends, and governing factors: Chelsea, Mich., Ann Arbor Press, Pesticides in the Hydrologic System series, v. 2, 588 p.

Canadian Council of Resource and Environment Ministers, 1991, Canadian water quality guidelines: Ottawa, Ontario, Environment Canada, Inland Waters Directorate, Water Quality Branch, variously paged.

Capel, P.D., 1991, Wet atmospheric deposition of herbicides in Minnesota, in Mallard, G.E. and Aronson, D.A., eds., U.S. Geological Survey Toxic Substances Hydrology Program-Proceedings of the technical meeting, Monterey, California, March 11-15, 1991: U.S. Geological Survey Water-Resources Investigations Report 91-4034, p. 334-337.

Capel, P.D., Spexet, A.H., and Larson, S.J., 1999, The occurrence and behavior of the herbicide prometon in the hydrologic system: Environmental Science and Technology, in press.

Colborn, Theo, and Clement, C.R., eds., 1992, Chemicallyinduced alterations in sexual and functional development: The wildlife/human connection: Princeton, N.J., Princeton Scientific Publishing Co., Advances in Modern Environmental Toxicology series, v. 21, 403 p.

del Rosario, Aurora, Remoy, John, Soliman, Violeta, Dhaliwal, Joginder, Dhoot, Jagdev, Perera, Kusum, 1994, Monitoring for selected degradation products following a spill of VAPAM into the Sacramento River: Journal of Environmental Quality, v. 23, no. 2, p. 279-286.
Draper, W.M., and Wakeham, D.E., 1993, Rate constants for metam-sodium cleavage and photodecomposition in water: Journal of Agricultural and Food Chemistry, v. 41, no. 7, p. 1129-1133.

E\&S Environmental Chemistry, Inc., and Tetra Tech, Inc., 1995, Willamette River Basin Water Quality Study, Phase II-Non-point Source Pollution in the Pudding River Sub-Basin of the Willamette River: Corvallis, Oregon, and Redmond, Washington, prepared for Oregon Department of Environmental Quality, Portland, variously paged.

Gentile, I.A., Ferraris, L., and Crespi, S., 1989, The degradation of methyl bromide in some natural fresh waters. The influence of temperature, $\mathrm{pH}$, and light: Pesticide Science, v. 25, p. 261-272.

Gentile, I.A., Ferraris, L., Sanguinetti, M., Tiprigan, M., and Fisichella, G., 1992, Methyl bromide in natural fresh waters: hydrolysis and volatilization: Pesticide Science, v. 34, no. 3, p. 297-301.

Gianessi, L.P., and Anderson, J.E., 1996, Pesticide use in U.S. crop production: National data report: Washington, D.C., National Center for Food and Agricultural Policy, unpaged.

Gilliom, R.J., Alley, W.M., and Gurtz, M.E., 1995, Design of the National Water-Quality Assessment Program: Occurrence and distribution of water-quality conditions: U.S. Geological Survey Circular 1112, 33 p.

Gilliom, R.J., and Thelin, G.P., 1997, Classification and mapping of agricultural land for national water-quality assessment: U.S. Geological Survey Circular 1131, 70 p.

Goodbred, S.L., Gilliom, R.J., Gross, T.S., Denslow, N.P., Bryant, W.L., and Schoeb, T.R., 1997, Reconnaissance of $17 ß$-estradiol, 11-ketotestosterone, vitellogenin, and gonad histopathology in common carp of United States streams: Potential for contaminant-induced endocrine disruption: U.S. Geological Survey Open-File Report 96-627, $47 \mathrm{p}$.

Goolsby, D.A., and Battaglin, W.A., 1993, Occurrence, distribution, and transport of agricultural chemicals in surface waters of the midwestern United States, in Goolsby, D.A., Boyer, L.L., and Mallard, G.E., compilers, Selected papers on agricultural chemicals in water resources of the Midcontinental United States: U.S. Geological Survey Open-File Report 93-418, p. 1-25.

Goolsby, D.A., Battaglin, W.A., Fallon, J.D., Aga, D.S., Kolpin, D.W., and Thurman, E.M., 1993, Persistence of herbicides in selected reservoirs in the midwestern United States: Some preliminary results, in Goolsby, D.A., Boyer, L.L., and Mallard, G.E., compilers, Selected papers on agricultural chemicals in water resources of the Midcontinental United States: U.S. Geological Survey Open-File Report 93-418, p. 51-63. 
Goolsby, D.A., Thurman, E.M., Pomes, M.L., Meyer, M., and Battaglin, W.A., 1997, Herbicides and their metabolites in rainfall: Origin, transport, and deposition patterns across the midwestern and northeastern United States, 1990-1991: Environmental Science and Technology, v. 31, no. 5, p. 1325-1333.

Goss, D.W., and Wauchope, R.D., 1990, The SCS/ARS/CES pesticide properties database: II Using it with soils data in a screening procedure, in Weigman, D.L., ed., Pesticides in the next decade. The challenges ahead: Blacksburg, Va., Virginia Water Resources Research Center, p. 471-493.

Hirsch, R.M., Alley, W.M., and Wilber, W.G., 1988, Concepts for a national water-quality assessment program: U.S. Geological Survey Circular 1021, 42 p.

Hitt, K. J., 1994, Refining 1970's land-use data with 1990 population data to indicate new residential development: U.S. Geological Survey Water-Resources Investigations Report 94-4250, 15 p.

International Joint Commission, 1977, New and revised Great Lakes water quality objectives, International Joint Commission Canada and United States, 155 p.

Kalkhoff, S.J., Kolpin, D.W., Thurman, E.M., Ferrer, I., and Barcelo, D., 1998, Degradation of chloroacetanilide herbicides: the prevalence of sulfonic and oxanilic acid metabolites in Iowa ground and surface waters: Environmental Science and Technology, v. 32, no. 11, p. 1738-1740.

Kent, R.A., Pauli, B.D., Trotter, D.M., and Gareau, J., 1991, Canadian water quality guidelines for metolachlor: Environment Canada, Inland Waters Directorate, Water Quality Branch, Scientific Series No. 184, 34 p.

Kimbrough, R.A., and Litke, D.W., 1996, Pesticides in streams draining agricultural and urban areas in Colorado: Environmental Science and Technology, v. 30, no. 3, p. 908-916.

Kolpin, D.W., Barbash, J.E., and Gilliom, R.J., 1998, Occurrence of pesticides in shallow groundwater of the United States: Initial results from the National WaterQuality Assessment Program: Environmental Science and Technology, v. 32, no. 5, p. 558-566.

Larson, S.J., Capel, P.D., Goolsby, D.A., Zaugg, S.D., and Sandstrom, M.W., 1995, Relations between pesticide use and riverine flux in the Mississippi River Basin: Chemosphere, v. 31, no. 5, p. 3305-3321.

Larson, S.J., Capel, P.D., and Majewski, M.S., 1997, Pesticides in surface waters: Distribution, trends, and governing factors: Chelsea, Mich., Ann Arbor Press, Pesticides in the Hydrologic System series, v. 3, 373 p.

Leahy, P.P., Rosenshein, J.S., and Knopman, D.S., 1990, Implementation plan for the National Water-Quality Assessment Program: U.S. Geological Survey OpenFile Report 90-174, 10 p.
Leonard, R.A., 1990, Movement of pesticide into surface waters, in Cheng, H.H., ed., Pesticides in the soil environment: Processes, impacts, and modeling: Madison, Wis., Soil Science Society of America, p. 303-349.

Majewski, M.S., and Capel, P.D., 1995, Pesticides in the atmosphere: Distribution, trends, and governing factors: Chelsea, Mich., Ann Arbor Press, Pesticides in the Hydrologic System series, v. 1, 214 p.

Meister, R.T., ed, 1996, Farm Chemicals Handbook '96: Willoughby, Ohio, Meister Publishing Company, variously paged.

Miltner, R.J., Baker, D.B., Speth, T.F., and Fronk, C.A., 1989, Treatment of seasonal pesticides in surface waters: Journal of the American Water Works Association, v. 81, no. 1, p. 43-52.

Mitchell, W.B., Guptill, S.C., Anderson, K.E., Fegeas, R.G., and Hallam, C.A., 1977, GIRAS: A geographic information retrieval and analysis system for handling land use and land cover data: U.S. Geological Survey Professional Paper 1059, 16 p.

Nowell, L.H., and Resek, E.A., 1994, National standards and guidelines for pesticides in water, sediment, and aquatic organisms: Application to water-quality assessments: Reviews for Environmental Contamination and Toxicology, v. 140, p. 1-164.

Panshin, S.Y., Dubrovsky, N.M., Gronberg, J.M., and Domagalski, J.L., in press, Occurrence and Distribution of Dissolved Pesticides in the San Joaquin River Basin, California: U.S. Geological Survey Water-Resources Investigations Report 98-4032.

Patrick, J.E., 1990, Pesticides in Ontario municipal drinking water from surface sources, 1987: Ontario Ministry of the Environment, Water Resources Branch, Drinking Water Section, 35 p.

Rathbun, R.E., 1998, Transport, behavior, and fate of volatile organic compounds in streams: U.S. Geological Survey Professional Paper 1589, $151 \mathrm{p}$.

Richard, R.P., and Baker, D.B., 1993, Pesticide concentration patterns in agricultural drainage networks in the Lake Erie Basin: Environmental Toxicology and Chemistry, v. 12, no. 1, p. 13-26.

Schottler, S.P., Eisenreich, S.J., and Capel, P.D., 1994, Atrazine, alachlor, and cyanazine in a large agricultural river system: Environmental Science and Technology, v. 28, no. 6, p. 1079-1089.

Shelton, L.R., 1994, Field guide for collecting and processing stream-water samples for the National Water-Quality Assessment Program: U.S. Geological Survey Open-File Report 94-455, 42 p.

Stephan, C.R., Mount, D.I., Hansen, D.J., Gentile, J.H., Chapman, G.A., and Brungs, W.A., 1985, Guidelines for deriving numerical national water quality criteria for the protection of aquatic organisms and their uses: U.S. Environmental Protection Agency, PB 85-227049. 
Thurman, E.M., Goolsby, D.A., Meyer, M.T., and Kolpin, D.W., 1991, Herbicides in surface waters of the midwestern United States: The effect of spring flush: Environmental Science and Technology, v. 25, no. 10, p. 1794-1796.

U.S. Department of Commerce, 1995, 1992 Census of Agriculture: Washington, D.C. [CD-ROM, dBase format].

U.S. Environmental Protection Agency, 1991, Water-quality criteria summary: U.S. Environmental Protection Agency, Office of Water, Office of Science and Technology, Health and Ecological Effects Division, wall poster.

1994, Guidelines establishing test procedures for the analysis of pollutants (App. B, Part 136, Definition and procedures for the determination of the method detection limit): U.S. Code of Federal Regulations, Title 40, revised July 1, 1994, p. 635-637.

U.S. Geological Survey, 1990, Land use and land cover digital data from 1:250,000- and 1:100,000-scale maps: U.S. Geological Survey Data User Guide, no. 4, 25 p. (Accessed January 1998 on the World Wide Web at URL ftp://www-nmd.usgs.gov/pub/ti/LULC/ lulcguide)

-1998, NAWQA analytical methods, MDLs, and performance characteristics for pesticides in water, Table 2: U.S. Geological Survey data, accessed July 1, 1998, on the World Wide Web, at URL http:// water.wr.usgs.gov/pnsp/anstrat/\#t2
U.S. Geological Survey, 1999, Data on pesticides in surface and ground water of the United States: Results of the National Water Quality Assessment Program (NAWQA): U.S. Geological Survey data available on the World Wide Web, accessed January 28, 1999, at URL http://wa.water.usgs.gov/ccpt/pns_data/data.html

Whitmore, R.W., Kelly, J.E., and Reading, P.L., 1992, Executive summary, results, and recommendations, v. 1 of National home and garden pesticide use survey:

Research Triangle Park, North Carolina, Research Triangle Institute, RTI/5100/17-01F68-WD-0032, 140 p.

Wnuk, M., Kelley, R., Breuer G., and Johnson, L., 1987, Pesticides in water supplies using surface water sources: Des Moines, Iowa, Iowa Department of Natural Resources, 33 p.

Wotzka, P.J., Lee, J., Capel, P.D., Ma, L., 1994, Pesticide concentrations and fluxes in an urban watershed, in Peterson, G.L., ed., Proceedings of the American Water Resources Association National Symposium on Water Quality: American Water Resources Association technical publication series, no. TSP 94-4, p. 135-145.

Zaugg, S.D., Sandstrom, M.W., Smith, S.G., and Fehlberg, K.M., 1995, Methods of analysis by the U.S. Geological Survey National Water-Quality Laboratory: Determination of pesticides in water by $\mathrm{C}-18$ solid-phase extraction and capillary-column gas chromatography/ mass spectrometry with selected-ion monitoring: U.S. Geological Survey Open-File Report 95-181, 49 p. 